Rogério Michelan

\title{
INFLUÊNCIA DO TIPO DE IMPELIDOR SOBRE O DESEMPENHO DO REATOR ANAERÓBIO EM BATELADA SEQÜENCIAL COM BIOMASSA GRANULADA TRATANDO ESGOTO SINTÉTICO
}

Dissertação apresentada à Escola de Engenharia de São Carlos da Universidade de São Paulo, como parte dos requisitos para a obtenção do Titulo de Mestre em Hidráulica e Saneamento.

Orientador: Prof. Dr. José Alberto Domingues Rodrigues Co-orientadora: Prof. Dra.Suzana Maria Ratusznei

São Carlos 
Ficha catalográfica preparada pela Seção de Tratamento da Informação do Serviço de Biblioteca - EESC/USP

Michelan, Rogério

Influência do tipo de impelidor sobre o desempenho do reator anaeróbio em batelada seqüencial com biomassa granulada tratando esgoto sintético / Rogério Michelan. - São Carlos, 2005.

Dissertação (Mestrado) -- Escola de Engenharia de São Carlos-Universidade de São Paulo, 2005. Área: Hidráulica e Saneamento.

Orientador: Prof. Dr. José Alberto Domingues Rodrigues.

Co-orientadora : Profa ${ }^{a}{ }^{a}$ Suzana Maria Ratusznei.

1. Tratamento anaeróbio. 2. Impelidor. 3. Esgoto sintético. 4. Baixa carga orgânica. 5. Batelada seqüencial. 6. Biomassa granulada. 7. Tubo interno. I. Título. 


\section{FOLHA DE JULGAMENTO}

\section{Candidato: Engenheiro ROGÉRIO MICHELAN}

Dissertação defendida e julgada em 10-02-2006 perante a Comissão Julgadora:

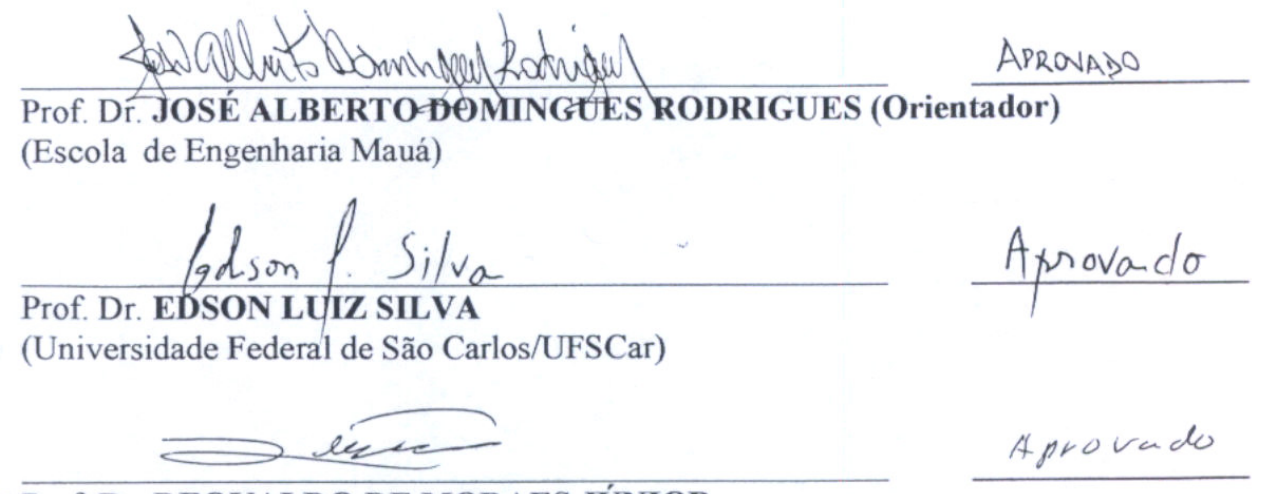

Prof. Dr. DEOVALDO DE MORAES JÚNIOR

(Universidade Santa Cecília/ UNISANTA)

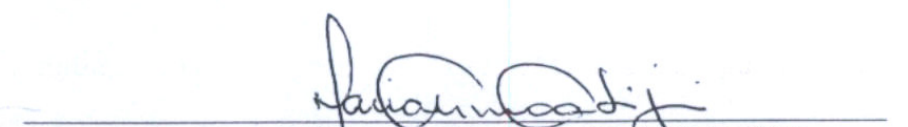

Profa. Titular MARIA DO CARMO CALIJURI

Coordenadora do Programa de Pós-Graduação em

Engenharia (Hidráulica e Saneamento) e

Presidente da Comissão de Pós-Graduação 

Dedico este trabalho aos meus pais, Vicente Michelan e Dalva Agostini Michelan, que me forneceram os subsídios para poder trilhar pelos caminhos da vida. 



\section{Agradecimentos}

Agradeço inicialmente a Deus por me mostrar, a cada dia, que apesar de eu gozar de meu livre arbítrio seus planos são infinitamente melhores e por me fazer entender que o meu trabalho pode não gerar frutos imediatamente, mas que é recompensado no momento adequado.

Dona Dalva e Seu Vicente, meus pais, que durante toda a minha vida me foram ótimos exemplos de boa conduta moral e ética. Além de, desde sempre, terem lutado contra tantas adversidades para que hoje eu pudesse estar aqui. E que espero um dia poder retribuir todo o amor e carinho.

Ao meu irmão Renato Michelan pelas várias brigas da infância e pelos papos profundos regados a cerveja na praça de Palmares Paulista ou no "bar do Tião".

A Dorival Gilberto Michelan, o Tio Val, que nos momentos mais difíceis aparecia como Anjo Salvador para fornecer apoio em gestos e palavras.

A Denise Conceição de Góis Santos que com sua companhia e palavras tornaram inesquecíveis momentos simples dia a dia participando de minha vida como mais do que uma amiga.

Aos professores da Universidade Federal de São Carlos, em especial a Prof. Dra. Teresa Cristina Zangirolami que sempre se esforçaram para que eu desse o melhor de $\operatorname{mim}$.

Aos professores, funcionários e colegas da Escola de Engenharia de São Carlos - Universidade de São Paulo me ajudaram a galgar mais este degrau de minha vida profissional.

A Dra. Catarina Simone de Andrade Canto, Thiago Ruiz Zimmer, Roberto Antônio Bezerra Júnior que tornaram extremamente agradável e divertida a convivência no laboratório durante o ano de 2005 em São Caetano.

A Roberta Albanez por operar o reator nas semanas em que viajei Brasil afora.

A Kelly de Araújo Rodrigues que com muito carinho me acolheu em minhas idas a São Carlos.

A Romina Beatriz de Silva Moura uma grande amiga com quem tive o prazer de conviver durante a primeira etapa deste trabalho e que tenho a honra de conservar a amizade. 
A Leonardo Henrique Soares Damasceno com suas piadas no laboratório de informática do SHS e pelo convívio durante este período.

A Iolanda Cristina Silveira Duarte pela ajuda com as análises microbianas.

Ao Prof. Dr. José Alberto Domingues Rodrigues pela sua amizade, competência e profissionalismo com que me orientou durante este projeto.

A Prof. Dra. Susana Maria Ratusznei que pela amizade e ajuda na realização deste trabalho.

Ao Prof. Dr. Deovaldo de Moraes Junior pela ajuda com os ensaios de consumo de potência e pelas sugestões durante as qualificações.

Ao Pessoal do Bloco 27 do alojamento da Universidade Federal de São Carlos que me possibilitaram entender melhor a Humanidade em sua variedade de personalidades.

A Escola de Engenharia Mauá, do Instituto Mauá de Tecnologia, na pessoa do Ilmo. Reitor Prof. Dr. Otávio de Mattos Silvares, pela cessão das instalações e apoio para a realização da etapa experimental.

À FAPESP pela concessão de bolsa de estudos (Processo $n^{\circ} 04 / 03,216-5$ ) e pelo financiamento do projeto (Processo n²001/05.489-0)

Ao CNPQ pela concessão de bolsa de estudos (Processo nº130521/2004-3).

Não posso deixar de agradecer a todas as pedras que estiveram em meu caminho e que me possibilitaram vislumbrar, a cada pedra, um horizonte mais distante. 


\section{RESUMO}

Em um reator de fundo redondo e volume útil de $5 l$ tratando esgoto sintético com carga orgânica de $800 \mathrm{mgDQO} . l^{-1}$ com biomassa granulada a influência do tipo de escoamento e velocidade rotacional foi investigada com o uso de cinco impelidores sendo eles turbina e pá de seis pás planas verticais, turbina e pá de seis pás planas inclinadas $45^{\circ}$ e hélice, comumente aplicados em processos biológicos. Foi também investigada a viabilidade de implementação de tubo de tiragem ao reator em conjunto com os impelidores tipo hélice e tipo pá de pás planas inclinadas alternadamente, com vistas a melhorar a mistura e conseqüente transferência de massa no meio reacional. Os resultados mostram que a alteração do tipo de impelidor e as variações da velocidade rotacional não exerceram influência significativa sobre a estabilidade e desempenho dos sistemas estudados. Entretanto a análise das constantes do modelo cinético de primeira ordem mostrou que a alteração na velocidade rotacional exerceu influência de aumento dos valores das constantes, demonstrando com isto que o aumento da velocidade rotacional melhora a transferência de massa sólido-líquido no meio reacional. A análise das constantes cinéticas também demonstrou que a promoção de escoamento axial em reatores agitados mecanicamente é preferível ao escoamento radial quando comparados os impelidores tipo pá de pás planas verticais e de pás planas inclinadas. A presença do tubo de tiragem demonstrou incrementar significativamente a transferência de massa, através do aumento dos valores numéricos das constantes utilizadas no ajuste do modelo cinético de primeira ordem aos valores experimentais. A potência consumida foi inferior

a $1,6.10^{-3} \mathrm{HP} / \mathrm{m}^{3}$ com rotações abaixo de $200 \mathrm{rpm}$ e os impelidores axiais consumiram $75 \%$ a menos de potência do que os radiais.

Palavras chaves: tratamento anaeróbio; impelidor; esgoto sintético, baixa carga orgânica, batelada seqüencial; biomassa granulada, tubo de tiragem. 


\begin{abstract}
The effect of flow type and rotor speed were investigated in a round-bottom reactor with 51 useful volume containing granular biomass and treating synthetic wastewater with organic load of $800 \mathrm{mgCOD}$.1-1. Five impellers have been used to this end, namely: turbine and paddle with six-vertical-flat blade, turbine and paddle with six$45^{\circ}$-inclined-flat-blade and helix, commonly used in biological processes. Utilization of a draft tube together with the helix and six-alternately-inclined-flat-blade impellers was also assessed as a means to improve mixing and consequently mass transfer in the reaction medium. Results showed that altering impeller type and variation in rotor speed did not exert significant effect on the stability and performance of the investigated systems. However, analysis of the first order kinetic model constants showed that alteration in rotor speed resulted in increase in the values of the constants, demonstrating that increase in rotor speed improves solid-liquid mass transfer in the reaction medium. Analysis of the kinetic constants also showed that axial flow in mechanically stirred reactors is preferable over radial flow when the vertical flat blade impeller is compared to the inclined flat blade impeller. The presence of the draft tube showed significant improvement in mass transfer, which could be seen by the increase in the values of the constants used in the fit of the first order kinetic model to the experimental values. The power consumed was less than $1.6 .10-3 \mathrm{HP} / \mathrm{m} 3$ at rotor frequency below $200 \mathrm{rpm}$ and the axial impellers consumed $75 \%$ less power than the radial ones.
\end{abstract}

Key words: anaerobic treatment; impeller; synthetic wastewater; low organic load; sequencing batch; granular biomass; draft tube. 


\section{LISTA DE FIGURAS}

Figura 2.1. Representação de escoamentos em reator para escoamentos do tipo axial (a) e radial (b)

Figura 3.1. Esquema do reator anaeróbio com agitação operado em batelada seqüencial [1 - Biorreator com capacidade de $6 \mathrm{~L}(\mathrm{a}=20 \mathrm{~cm} ; \mathrm{b}=$ $17 \mathrm{~cm} ; \mathrm{c}=3 \mathrm{~cm} ; \mathrm{d}=17 \mathrm{~cm}, \mathrm{e}=6 \mathrm{~cm}$ ) e um impelidor contendo biomassa granulada; 2 - Afluente; 3 - Bomba de alimentação; 4 Bomba de descarga; 5 - Sistema de agitação; 6 - Sistema de automação; 7 - Efluente].

Figura 3.2. Fotografia do aparato experimental.

Figura 3.3. Parâmetros de projeto para construção dos impelidores e disposição destes no reator.

Figura 3.4. Disposição do tubo de tiragem no reator e fotografia do mesmo.

Figura 3.5. Aparato utilizado para medida do consumo de potência ( $\mathrm{a}$ - motor, $\mathrm{b}$ impelidor, $\mathrm{c}$ - reator, $\mathrm{d}$ - tacômetro digital, e - suporte para reator e $\mathrm{f}$ - dinamômetro).

Figura 4.1. Concentração de matéria orgânica efluente e eficiência de remoção na condição Tu50. 35

Figura 4.2. Alcalinidade a bicarbonato e ácidos voláteis totais na condição Tu50........ 35

Figura 4.3. Sólidos totais (ST), sólidos voláteis totais (SVT), sólidos suspensos totais (SST) e sólidos suspensos voláteis (SSV) na condição Tu50..... 36

Figura 4.4. Perfis da concentração de matéria orgânica na forma de DQO e da eficiência de conversão ao longo de dois ciclos de operação na condição Tu50. 
Figura 4.5. Perfis da alcalinidade na forma de bicarbonato de cálcio e da concentração de ácidos voláteis totais na forma de ácido acético ao longo de dois ciclos de operação na condição Tu50.

Figura 4.6. Perfis do volume acumulado e da produção de metano no reator ao longo de dois ciclos de operação na condição Tu50

Figura 4.7. Perfis da fração molar e da concentração de metano no "head-space"ao longo de dois ciclos de operação na condição Tu50

Figura 4.8. Perfis de concentração de ácido propiônico por cromatografia durante dois ciclos de operação na condição de Tu50.

Figura 4.9. Concentração de matéria orgânica efluente e eficiência de remoção utilizando impelidor tipo pá de pás planas inclinadas nas condições Ti50 e Ti75.

Figura 4.10. Alcalinidade a bicarbonato e Ácidos voláteis totais utilizando impelidor tipo pá de pás planas inclinadas nas condições Ti50 e Ti75...... 40

Figura 4.11. Sólidos totais (ST), sólidos voláteis totais (SVT), sólidos suspensos totais (SST) e sólidos suspensos voláteis (SSV), utilizando impelidor tipo pá de pás planas inclinadas nas condições Ti50 e Ti75.

Figura 4.12. Impelidor tipo turbina de seis pás planas inclinadas após a realização do ensaio

Figura 4.13. Perfis da concentração de matéria orgânica na forma de DQO e da eficiência de conversão ao longo de dois ciclos de operação na condição Ti50.

Figura 4.14. Perfis da alcalinidade na forma de bicarbonato de cálcio e da concentração de ácidos voláteis totais na forma de ácido acético ao longo de dois ciclos de operação na condição Ti50.

Figura 4.15. Perfis do volume acumulado e da produção de metano no reator ao longo de dois ciclos de operação na condição Ti50.

Figura 4.16. Perfis da fração molar e da concentração de metano no "head-space" ao longo de dois ciclos de operação na condição Ti50. 
Figura 4.17. Perfis da concentração de ácidos voláteis por cromatografia durante dois ciclos de operação na condição Ti50 (valores médios). 44

Figura 4.18. Perfis da concentração de matéria orgânica na forma de DQO e da eficiência de conversão ao longo de dois ciclos de operação na condição Ti75

Figura 4.19. Perfis da alcalinidade na forma de bicarbonato de cálcio e da concentração de ácidos voláteis totais na forma de ácido acético ao longo de dois ciclos de operação na condição Ti75.

Figura 4.20. Perfis do volume acumulado e da produção de metano no reator ao longo de dois ciclos de operação na condição Ti75.

Figura 4.21. Perfis da fração molar e da concentração de metano no "head-space" ao longo de dois ciclos de operação na condição Ti75.

Figura 4.22. Perfis da concentração de ácidos voláteis por cromatografia durante dois ciclos de operação na condição Ti75. 47

Figura 4.23. Concentração de matéria orgânica efluente e eficiência de remoção utilizando impelidor tipo pá de pás planas inclinadas nas condições $\mathrm{Pa} 50$ e $\mathrm{Pa} 75$. 50

Figura 4.24. Alcalinidade a bicarbonato e Ácidos voláteis totais utilizando impelidor tipo pá de pás planas inclinadas nas condições Pa50 e Pa75...... 50

Figura 4.25. Sólidos totais (ST), sólidos voláteis totais (SVT), sólidos suspensos totais (SST) e sólidos suspensos voláteis (SSV), utilizando impelidor tipo pá de pás planas inclinadas nas condições Pa50 e Pa75.

Figura 4.26. Perfis da concentração de matéria orgânica na forma de DQO e da eficiência de conversão ao longo de dois ciclos de operação na condição Pa50 52

Figura 4.27. Perfis da alcalinidade na forma de bicarbonato de cálcio e da concentração de ácidos voláteis totais na forma de ácido acético ao longo de dois ciclos de operação na condição Pa50.

Figura 4.28. Perfis do volume acumulado e da produção de metano no reator ao longo de dois ciclos de operação na condição Pa50. 
Figura 4.29. Perfis da fração molar e da concentração de metano no "head-space" ao longo de dois ciclos de operação na condição Pa50.

Figura 4.30. Perfis da concentração de ácidos voláteis por cromatografia durante dois ciclos de operação na condição Pa50 (valores médios).

Figura 4.31. Perfis da concentração de matéria orgânica na forma de DQO e da eficiência de conversão ao longo de dois ciclos de operação na condição Pa75

Figura 4.32. Perfis da alcalinidade na forma de bicarbonato de cálcio e da concentração de ácidos voláteis totais na forma de ácido acético ao longo de dois ciclos de operação na condição Pa75.

Figura 4.33. Perfis do volume acumulado e da produção de metano no reator ao longo de dois ciclos de operação na condição Pa75. 56

Figura 4.34. Perfis da fração molar e da concentração de metano no "head-space" ao longo de dois ciclos de operação na condição Pa75. 56

Figura 4.35. Perfis da concentração de ácidos voláteis por cromatografia durante dois ciclos de operação na condição Pa75 (valores médios). 56

Figura 4.36. Concentração de matéria orgânica efluente e eficiência de remoção utilizando impelidor tipo pá de pás planas inclinadas nas condições Pi50 e Pi75.

Figura 4.37. Alcalinidade a bicarbonato e Ácidos voláteis totais utilizando impelidor tipo pá de pás planas inclinadas nas condições Pi50 e Pi75.......59

Figura 4.38. Sólidos totais (ST), sólidos voláteis totais (SVT), sólidos suspensos totais (SST) e sólidos suspensos voláteis (SSV) utilizando impelidor tipo pá de pás planas inclinadas nas condições Pi50 e Pi75.

Figura 4.39.Impelidor tipo pá de pás planas inclinadas antes e após o ensaio. 61

Figura 4.40. Perfis da concentração de matéria orgânica na forma de DQO e da eficiência de conversão ao longo de dois ciclos de operação na condição Pi50. 
Figura 4.41. Perfis da alcalinidade na forma de bicarbonato de cálcio e da concentração de ácidos voláteis totais na forma de ácido acético ao longo de dois ciclos de operação na condição Pi50.

Figura 4.42. Perfis do volume acumulado e da produção de metano no reator ao longo de dois ciclos de operação na condição Pi50.

Figura 4.43. Perfis da fração molar e da concentração de metano no "head-space" ao longo de dois ciclos de operação na condição Pi50.

Figura 4.44. Perfis da concentração de ácidos voláteis por cromatografia durante dois ciclos de operação na condição Pi50 (valores médios).

Figura 4.45. Perfis da concentração de matéria orgânica na forma de DQO e da eficiência de conversão ao longo de dois ciclos de operação na condição Pi75.

Figura 4.46. Perfis da alcalinidade na forma de bicarbonato de cálcio e da concentração de ácidos voláteis totais na forma de ácido acético ao longo de dois ciclos de operação na condição Pi75.

Figura 4.47. Perfis do volume acumulado e da produção de metano no reator ao longo de dois ciclos de operação na condição Pi75.

Figura 4.48. Perfis da fração molar e da concentração de metano no "head-space" ao longo de dois ciclos de operação na condição Pi75.

Figura 4.49. Perfis da concentração de ácidos voláteis por cromatografia durante dois ciclos de operação na condição Pi75.

Figura 4.50. Concentração de matéria orgânica efluente e eficiência de remoção utilizando impelidor tipo pá de pás planas inclinadas e reator com tubo de tiragem nas condições Pd100 e Pd120.

Figura 4.51. Alcalinidade a bicarbonato e Ácidos voláteis totais utilizando impelidor tipo pá de pás planas inclinadas e reator com tubo de tiragem nas condições Pd100 e Pd120.

Figura 4.52. Sólidos totais (ST), sólidos voláteis totais (SVT), sólidos suspensos totais (SST) e sólidos suspensos voláteis (SSV) utilizando impelidor 
tipo pá de pás planas inclinadas e reator com tubo de tiragem nas condições Pd100 e Pd120.

Figura 4.53. Perfis da concentração de matéria orgânica na forma de DQO e da eficiência de conversão ao longo de dois ciclos de operação na condição Pd100.

Figura 4.54. Perfis da alcalinidade na forma de bicarbonato de cálcio e da concentração de ácidos voláteis totais na forma de ácido acético ao longo de dois ciclos de operação na condição Pd100.

Figura 4.55. Perfis do volume acumulado e da produção de metano no reator ao longo de dois ciclos de operação na condição Pd100.

Figura 4.56. Perfis da fração molar e da concentração de metano no "head-space" ao longo de dois ciclos de operação na condição Pd100.

Figura 4.57. Perfis da concentração de ácidos voláteis por cromatografia durante dois ciclos de operação na condição pá Pd100. 73

Figura 4.58. Perfis da concentração de matéria orgânica na forma de DQO e da eficiência de conversão ao longo de dois ciclos de operação na condição $\operatorname{Pd} 120$.

Figura 4.59. Perfis da alcalinidade na forma de bicarbonato de cálcio e da concentração de ácidos voláteis totais na forma de ácido acético ao longo de dois ciclos de operação na condição Pd120.

Figura 4.60. Perfis do volume acumulado e da produção de metano no reator ao longo de dois ciclos de operação na condição Pd120............................... 76

Figura 4.61. Perfis da fração molar e da concentração de metano no "head-space" ao longo de dois ciclos de operação na condição Pd120.

Figura 4.62. Perfis da concentração de ácidos voláteis por cromatografia durante dois ciclos de operação na condição Pd120. 76

Figura 4.63. Concentração de matéria orgânica efluente e eficiência de remoção nas condições He70 e He100. 78

Figura 4.64. Alcalinidade a bicarbonato e Ácidos voláteis totais nas condições $\mathrm{He} 70$ e He100. 
Figura 4.65. Sólidos totais (ST), sólidos voláteis totais (SVT), sólidos suspensos totais (SST) e sólidos suspensos voláteis (SSV) nas condições He70 e He100.

Figura 4.66. Perfis da concentração de matéria orgânica na forma de DQO e da eficiência de conversão ao longo de dois ciclos de operação na condição He70.

Figura 4.67. Perfis da alcalinidade na forma de carbonato de cálcio e da concentração de ácidos voláteis totais na forma de ácido acético ao longo de dois ciclos de operação na condição He70.

Figura 4.68. Perfis do volume acumulado e da produção de metano no reator ao longo de dois ciclos de operação na condição He70. 82

Figura 4.69. Perfis da fração molar e da concentração de metano no "head-space" ao longo de dois ciclos de operação na condição He70. 82

Figura 4.70. Perfis da concentração de ácidos voláteis por cromatografia durante dois ciclos de operação na condição He70.

Figura 4.71. Perfis da concentração de matéria orgânica na forma de DQO e da eficiência de conversão ao longo de dois ciclos de operação na condição He100.

Figura 4.72. Perfis da alcalinidade na forma de bicarbonato de cálcio e da concentração de ácidos voláteis totais na forma de ácido acético ao longo de dois ciclos de operação na condição He100.

Figura 4.73. Perfis do volume acumulado e da produção de metano no reator ao longo de dois ciclos de operação na condição He100.

Figura 4.74. Perfis da fração molar e da concentração de metano no "head-space" ao longo de dois ciclos de operação na condição He100. 85

Figura 4.75. Perfis da concentração de ácidos voláteis por cromatografia durante dois ciclos de operação na condição He100. 85

Figura 4.76. Concentração de matéria orgânica efluente e eficiência de remoção utilizando impelidor tipo hélice e reator com tubo de tiragem nas condições Hd100 e Hd120. 
Figura 4.77. Alcalinidade a bicarbonato e Ácidos voláteis totais utilizando impelidor tipo hélice e reator com tubo de tiragem nas condições Hd100 e Hd120.

Figura 4.78. Sólidos totais (ST), sólidos voláteis totais (SVT), sólidos suspensos totais (SST) e sólidos suspensos voláteis (SSV) utilizando impelidor tipo hélice e reator com tubo de tiragem nas condições Hd100 e Hd120

Figura 4.79. Perfis da concentração de matéria orgânica na forma de DQO e da eficiência de conversão ao longo de dois ciclos de operação na condição Hd100

Figura 4.80. Perfis da alcalinidade na forma de bicarbonato de cálcio e da concentração de ácidos voláteis totais na forma de ácido acético ao longo de dois ciclos de operação na condição Hd100.

Figura 4.81. Perfis do volume acumulado e da produção de metano no reator ao longo de dois ciclos de operação na condição Hd100.

Figura 4.82. Perfis da fração molar e da concentração de metano no "head-space" ao longo de dois ciclos de operação na condição Hd100.

Figura 4.83. Média dos perfis da concentração de ácidos voláteis por cromatografia durante dois ciclos de operação na condição Hd100.

Figura 4.84. Perfis da concentração de matéria orgânica na forma de DQO e da eficiência de conversão ao longo de dois ciclos de operação na condição Hd120

Figura 4.85. Perfis da alcalinidade na forma de bicarbonato de cálcio e da concentração de ácidos voláteis totais na forma de ácido acético ao longo de dois ciclos de operação na condição Hd120.

Figura 4.86. Perfis do volume acumulado e da produção de metano no reator ao longo de um ciclo de operação na condição hélice com tubo de tiragem a $120 \mathrm{rpm}$.

Figura 4.87. Perfis da fração molar e da concentração de metano no "head-space" ao longo de um ciclo de operação na condição Hd120. 
Figura 4.88. Média dos perfis da concentração de ácidos voláteis por cromatografia durante dois ciclos de operação na condição Hd120. ......... 95

Figura 4.89. Imagens obtidas do inóculo utilizado no reator..................................... 96

Figura 4.90. Imagens obtidas do lodo proveniente do reator ao final dos experimentos.

Figura 4.91. Imagens obtidas do material gelatinoso coletado ao final do experimento.

Figura 4.92. Comparação entre o lodo do inoculo (direita) e o lodo do reator após os ensaios (esquerda)

Figura 4.93. Material esbranquiçado gelatinoso coletado da biomassa do reator.

Figura 4.94. Variação de $N_{P}$ em função de $N_{R e}$ para os ensaios realizados neste trabalho. (a) condições sem tubo de tiragem e (b) condições com tubo de tiragem. 100

Figura 4.95. Valores experimentais e ajuste do modelo cinético na condição Tu50. .. 109

Figura 4.96. Valores experimentais e ajuste do modelo cinético na condição Pa50... 110

Figura 4.97. Valores experimentais e ajuste do modelo cinético na condição Pa75... 110

Figura 4.98. Valores experimentais e ajuste do modelo cinético na condição Ti50.... 111

Figura 4.99. Valores experimentais e ajuste do modelo cinético na condição Ti75. ... 111

Figura 4.100. Valores experimentais e ajuste do modelo cinético na condição Pi50.

Figura 4.101. Valores experimentais e ajuste do modelo cinético na condição Pi75.

Figura 4.102. Valores experimentais e ajuste do modelo cinético na condição Pd100.

Figura 4.103. Valores experimentais e ajuste do modelo cinético na condição Pd120.

Figura 4.104. Valores experimentais e ajuste do modelo cinético na condição $\mathrm{He} 70$. 
Figura 4.105. Valores experimentais e ajuste do modelo cinético na condição

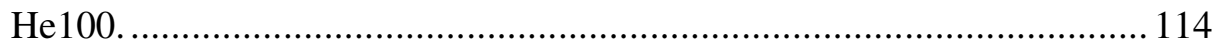

Figura 4.106. Valores experimentais e ajuste do modelo cinético na condição

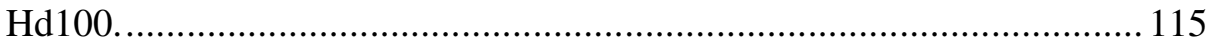

Figura 4.107. Valores experimentais e ajuste do modelo cinético na condição

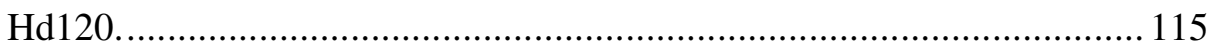




\section{LISTA DE TABELAS}

Tabela 3.1. Parâmetros de construção dos impelidores ........................................... 19

Tabela 3.2. Composição geral da água residuária sintética. ................................... 23

Tabela 3.3. Composição da água residuária sintética utilizada nos experimentos......... 23

Tabela 3.4. Estratégia de operação do sistema em batelada seqüencial a ser implementada. ........................................................................... 25

Tabela 3.5. Resumo dos ensaios realizados nesse projeto. ................................... 26

Tabela 4.1. Valores médios das variáveis monitoradas durante o ensaio Tu50............ 34

Tabela 4.2. Valores médios das variáveis monitoradas na operação com impelidor tipo turbina de pás planas inclinadas nas condições de operação Ti50 e Ti75

Tabela 4.3. Valores médios das variáveis monitoradas no ensaio com impelidor tipo pá de pás planas verticais nas condições de operação Pa50 e Pa75. .... 49

Tabela 4.4. Valores médios das variáveis monitoradas na operação com impelidor tipo pá de pás planas inclinadas nas condições de operação Pi50 e Pi75.

Tabela 4.5. Valores médios das variáveis monitoradas na operação com impelidor tipo pá de pás planas inclinadas $45^{\circ}$ e tubo de tiragem nas condições Pd100 e Pd120.

Tabela 4.6. Valores médios das variáveis monitoradas na operação com impelidor tipo hélice nas condições He70 e He100.

Tabela 4.7. Valores médios das variáveis monitoradas na operação com impelidor tipo hélice com tubo de tiragem nas condições de operação Hd100 e Hd120.

Tabela 4.8. Valores médios do número de potência e da potência consumida nas treze condições operacionais deste trabalho. 
Tabela 4.9. Valores médios das variáveis monitoradas nas condições sem uso de

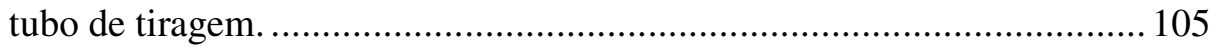

Tabela 4.10. Valores médios das variáveis monitoradas nas condições com uso de tubo de tiragem.

Tabela 4.11. Parâmetro $\mathrm{k}_{1}$ estimado através ajustes da equação 4.1 aos perfis temporais coletados em cada condição operacional.

Tabela 4.12. Parâmetros $\mathrm{k}_{1}$ e $\mathrm{k}_{2}$ estimados através ajustes da equação 4.2 aos perfis temporais coletados em cada condição operacional.

Tabela 4.13. Parâmetros $k_{1}$ e $k_{2}$ estimados através ajustes da equação 4.3 aos perfis temporais coletados em cada condição operacional. 


\section{LISTA DE ABREVIATURAS E SIGLAS}

$\mathrm{AB}$

ASBR

AT

AVT

AVTc

DQO

EESC/USP

Hd100

Hd120

$\mathrm{He} 70$

He100

IMT

Pa50

Pa75

$\operatorname{Pd} 100$

Pd120

Pi50
Alcalinidade a Bicarbonato $\left(\mathrm{gNaHCH}_{3} \cdot l^{-1}\right)$.

Reator anaeróbio operado em bateladas seqüenciais (Anaerobic Sequencing Batch Reactor).

Alcalinidade Total $\left(\mathrm{gNaHCO}_{3} \cdot l^{-1}\right)$.

Ácidos Voláteis Totais (gHAc. $l^{-1}$ ).

Ácidos Voláteis Totais por cromatografia $\left(\mathrm{g} \cdot l^{-1}\right)$.

Demanda Química de Oxigênio (gDQO. $l^{-1}$ ).

Escola de Engenharia de São Carlos da Universidade de São Paulo.

Reator com tubo de tiragem e impelidor tipo hélice operado em rotação de $100 \mathrm{rpm}$.

Reator com tubo de tiragem e impelidor tipo hélice operado em rotação de $120 \mathrm{rpm}$.

Reator operado com impelidor tipo hélice em rotação de 70 rpm.

Reator operado com impelidor tipo hélice em rotação de 100 rpm. Instituto Mauá de Tecnologia.

Reator operado com impelidor tipo pá de seis pás planas verticais e rotação de $50 \mathrm{rpm}$.

Reator operado com impelidor tipo pá de seis pás planas verticais e rotação de $75 \mathrm{rpm}$.

Reator operado com tubo de tiragem e impelidor tipo pá de seis pás planas inclinadas $45^{\circ}$ e rotação de $100 \mathrm{rpm}$.

Reator operado com tubo de tiragem e impelidor tipo pá de seis pás planas inclinadas $45^{\circ}$ e rotação de $120 \mathrm{rpm}$.

Reator operado com impelidor tipo pá de seis pás planas inclinadas $45^{\circ}$ e rotação de $50 \mathrm{rpm}$ 
Pi75 Reator operado com impelidor tipo pá de seis pás planas inclinadas $45^{\circ}$ e rotação de $75 \mathrm{rpm}$

Rpm Rotações por minuto.

Ti50 Reator operado com impelidor tipo turbina de seis pás planas inclinadas $45^{\circ}$ e rotação de $50 \mathrm{rpm}$

Ti75 Reator operado com impelidor tipo turbina de seis pás planas inclinadas $45^{\circ}$ e rotação de $50 \mathrm{rpm}$

Tu50 Reator operado com impelidor tipo turbina de seis pás planas verticais em rotação de $50 \mathrm{rpm}$.

UASB Reator anaeróbio de manta de lodo e escoamento ascendente (Upflow Anaerobic Sludge Blanket). 


\section{LISTA DE SÍMBOLOS}

\begin{tabular}{|c|c|}
\hline$\theta_{\mathrm{h}}$ & Tempo de detenção hidráulica (h). \\
\hline $\mathrm{C}_{\mathrm{AF}}$ & Concentração afluente (gDQO. $\left.l^{-1}\right)$. \\
\hline $\mathrm{CH}_{4}$ & Metano. \\
\hline $\mathrm{CO}_{2}$ & Dióxido de carbono. \\
\hline $\mathrm{C}_{\mathrm{SF}}$ & $\begin{array}{l}\text { Concentração de matéria orgânica, em termos de DQO, em } \\
\left.\text { amostras filtradas (gDQO. } l^{-1}\right) \text {. }\end{array}$ \\
\hline $\mathrm{C}_{\mathrm{ST}}$ & $\begin{array}{l}\text { Concentração de matéria orgânica, em termos de DQO, em } \\
\left.\text { amostras não filtradas (gDQO. } l^{-1}\right) \text {. }\end{array}$ \\
\hline $\mathrm{E}$ & Eficiência de conversão de matéria orgânica (\%). \\
\hline $\mathrm{E}_{\mathrm{F}}$ & Eficiência de conversão de matéria orgânica filtrada (\%). \\
\hline $\mathrm{E}_{\mathrm{T}}$ & Eficiência de conversão de matéria orgânica não filtrada (\%). \\
\hline $\mathrm{F} / \mathrm{M}$ & Razão substrato/microrganismos. \\
\hline $\mathrm{H}_{2} \mathrm{SO}_{4}$ & Ácido sulfúrico. \\
\hline $\mathrm{NaCl}$ & Cloreto de sódio. \\
\hline $\mathrm{NaHCO}_{3}$ & Bicarbonato de Sódio. \\
\hline $\mathrm{NC}$ & Número de ciclos ao dia. \\
\hline $\mathrm{N}_{\text {CLS }}$ & Rotação para suspensão completa dos sólidos. \\
\hline $\mathrm{pH}$ & Potencial hidrogeniônico. \\
\hline SFT & Sólidos fixos totais (gSFT. $l^{-1}$ ). \\
\hline SST & Sólidos suspensos totais (gSST. $\left.l^{-1}\right)$. \\
\hline SSV & Sólidos suspensos voláteis (gSSV. $l^{-1}$ ). \\
\hline ST & Sólidos Totais (gST.l-1). \\
\hline SVT & Sólidos voláteis totais (gSVT. $l^{-1}$ ). \\
\hline $\mathrm{T}$ & Temperatura $\left({ }^{\circ} \mathrm{C}\right)$. \\
\hline$t_{C}$ & Tempo de ciclo (horas). \\
\hline V & Volume descarregado em um ciclo $(l)$ \\
\hline VR & Volume do reator $(l)$ \\
\hline
\end{tabular}


xxvi 


\section{SUMÁRIO}

RESUMO IX IX IX

ABSTRACT $\quad X$

LISTA DE FIGURAS $\quad$ XI

LISTA DE TABELAS $\quad$ XXI

LISTA DE ABREVIATURAS E SIGLAS XXIII

LISTA DE SÍMBOLOS XXV

SUMÁRIO

1 INTRODUÇÃO 1

1.1 Motivação ao estudo 1

1.2 Objetivos 1

2 REVISÃO BIBLIOGRÁFICA

2.1 O reator anaeróbio operado em batelada seqüencial (ASBR) 3

2.2 Mecanismos de promoção de mistura e agitação 4

2.2.1 Mistura promovida recirculação de biogás

2.2.2 Mistura promovida por recirculação de líquido

2.2.3 Fundamentos sobre agitação mecânica 10

2.2.3.1 Agitadores mecânicos $\quad 10$

2.2.3.2 Suspensão de sólidos

2.2.3.3 Tubo de tiragem ("draft tube") 12

2.2.4 Mistura promovida por agitação mecânica

$\begin{array}{llr}2.3 & \text { Considerações finais } & 16\end{array}$

$3 \quad$ MATERIAIS E MÉTODOS 17

$\begin{array}{lll}3.1 & \text { Materiais } & 17\end{array}$

3.1.1 Configuração do reator operado em batelada seqüencial 17

$\begin{array}{ll}3.1 .2 & \text { Impelidores }\end{array}$

$\begin{array}{ll}3.1 .3 & \text { Tubo de tiragem }\end{array}$

$\begin{array}{ll}3.1 .4 & \text { Sistema para medida do consumo de potência }\end{array}$ 
3.1.5 Inóculo 22

3.1.6 Água residuária - esgoto sintético 22

3.2 Métodos $\quad 23$

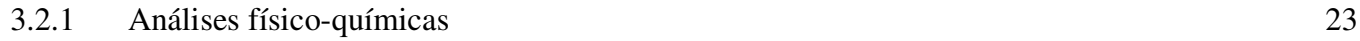

$\begin{array}{ll}3.2 .2 & \text { Análises microbianas }\end{array}$

$\begin{array}{ll}3.2 .3 & \text { Composição e produção do biogás }\end{array}$

3.3 Procedimento experimental $r$

$\begin{array}{lll}\text { 3.3.1 Operação do reator em batelada seqüencial } & 25\end{array}$

$\begin{array}{ll}3.3 .2 & \text { Monitoramento do reator }\end{array}$

$\begin{array}{ll}\text { 3.3.3 Perfil ao longo do ciclo de operação } & 26\end{array}$

$\begin{array}{ll}\text { 3.3.4 } & \text { Ensaio sobre consumo de potência }\end{array}$

3.4 Formulação matemática e modelagem cinética $\quad 27$

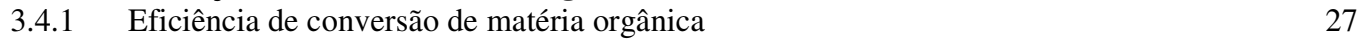

$\begin{array}{ll}3.4 .2 & \text { Número de potência e Número de Reynolds } \\ 3.4 .3 & 28\end{array}$

$\begin{array}{lr}3.4 .3 & \text { Modelagem cinética }\end{array}$

$4 \quad$ RESULTADOS E DISCUSSÃO 33

4.1 Apresentação dos dados experimentais 33

4.1.1 Impelidor tipo turbina de seis pás planas verticais 33

$\begin{array}{ll}\text { 4.1.2 Impelidor tipo turbina de seis pás planas inclinadas } & 39\end{array}$

4.1.2.1 Condição de operação Ti50

4.1.2.2 Condição de operação Ti75 46

4.1.3 Impelidor tipo pá de seis pás planas verticais $\quad 49$

4.1.3.1 Condição de operação Pa50

4.1.3.2 Condição de operação Pa75

4.1.4 Impelidor tipo pá de seis pás planas inclinadas $\quad 58$

4.1.4.1 Condição de operação Pi50

4.1.4.2 Condição de operação Pi75

4.1.5 Impelidor tipo pá de seis pás planas inclinadas e tubo de tiragem 68

4.1.5.1 Condição de operação Pd100

4.1.5.2 Condição de operação Pd120

$\begin{array}{lll}\text { 4.1.6 Impelidor tipo hélice } & 77\end{array}$

4.1.6.1 Condição de operação He70

4.1.6.2 Condição de operação He100

$\begin{array}{lll}4.1 .7 & \text { Impelidor tipo hélice e tubo de tiragem } & 87\end{array}$

4.1.7.1 Condição de operação Hd100

4.1.7.2 Condição de operação Hd120

4.1.8 Análise microbiana 96

$\begin{array}{lll}4.2 & \text { Viabilidade econômica } & 100\end{array}$

4.3 Visão holística sobre as condições estudadas 102

$\begin{array}{lll}\text { 4.3.1 Monitoramento dos sistemas } & 102\end{array}$

$\begin{array}{lll}\text { 4.3.1.1 Sistemas convencionais } & 102\end{array}$

$\begin{array}{ll}\text { 4.3.1.2 Sistemas com uso de tubo de tiragem } & 107\end{array}$

$\begin{array}{lll}\text { 4.3.2 } & \text { Perfis temporais } & 108\end{array}$

5 CONCLUSÕES E SUGESTÕES 123

$\begin{array}{lll}5.1 & \text { Considerações gerais } & 123\end{array}$

$\begin{array}{lll}5.2 & \text { Considerações sobre tubo de tiragem } & 124\end{array}$

$\begin{array}{lll}\text { 5.3 Propostas para trabalhos futuros } & 125\end{array}$ 
APÊNDICE A. Dedução do modelo cinético

APÊNDICE B. Ensaio com impelidor tipo turbina de pás planas verticais - valores experimentais

APÊNDICE C. Ensaio com impelidor tipo turbina de pás planas inclinadas - valores experimentais

APÊNDICE D. Ensaio com impelidor tipo pá de pás planas verticais - valores experimentais

APÊNDICE E. Ensaio com impelidor tipo pá de pás planas inclinadas - valores experimentais

APÊNDICE F. Ensaio com impelidor tipo pá de pás planas inclinadas e tubo de tiragem valores experimentais

APÊNDICE G. Ensaio com impelidor tipo hélice - valores experimentais

APÊNDICE H. Ensaio com impelidor tipo hélice e tubo de tiragem - valores experimentais. 


\section{INTRODUÇÃO}

\subsection{Motivação ao estudo}

A tecnologia de tratamento anaeróbio surgiu sem a utilização de equipamentos ou procedimentos que fornecessem mistura no meio reacional. Entretanto, as condições em que eram operados estes sistemas possibilitavam a movimentação necessária ao meio, produzida pela própria formação e eliminação de biogás, os quais podem ser gerados em função de altas cargas orgânicas do afluente a ser tratado.

Com a utilização de processos anaeróbios para o tratamento de efluentes de baixa carga orgânica, constatou-se que a movimentação do fluido passa a ser um parâmetro importante no projeto e operação destes sistemas. Dentre as formas de provocar movimentação no fluido em tratamento estão: a) a recirculação de biogás, que não pode ser aplicada a processos de baixas cargas orgânicas por causa da baixa produção de biogás; b) a recirculação de líquido e c) a agitação mecânica, esta que é utilizada em diversos processos químicos e bioquímicos.

O reator aqui utilizado foi o reator anaeróbio operado em batelada seqüencial tratando esgoto sintético com biomassa granular e mistura promovida através de agitação mecânica através da aplicação de impelidores.

No mercado podem ser encontrados os mais variados tipos de impelidores para as mais diversas aplicações em misturas. Como o estudo da agitação mecânica em tratamento de efluentes de baixa carga é ainda insipiente, neste trabalho optou-se por pesquisar os impelidores mais conhecidos e utilizados em aplicações químicas e bioquímicas.

\subsection{Objetivos}

O objetivo principal desse projeto de pesquisa é a investigação da influência do tipo de impelidor sobre a estabilidade e eficiência de um reator anaeróbio com agitação 
mecânica, operado em batelada seqüencial e contendo biomassa granulada, aplicado ao tratamento de esgoto sintético de baixa carga com fonte de carbono e energia, constando de sacarose, amido e celulose, além de extrato de carne e sais.

Os objetivos específicos deste trabalho foram:

1. Estudar a influência dos tipos de escoamento (axial, radial ou misto) produzidos por agitação mecânica em duas freqüências rotacionais com cinco tipos de impelidores, sendo que em dois destes implementando tubo de tiragem no reator ("draft-tube"), sobre o desempenho de sistema ASBR operando com biomassa granulada tratando esgoto sintético de baixa carga orgânica;

2. Estudar as configurações propostas visando encontrar um sistema ótimo pelo ajuste de modelos cinéticos e caracterização microbiana;

3. Estudar o consumo de potência destas configurações aplicadas ao tratamento de esgoto sintético de baixa carga orgânica em reatores ASBR. 


\section{REVISÃO BIBLIOGRÁFICA}

\subsection{O reator anaeróbio operado em batelada seqüencial (ASBR)}

Um ciclo típico do reator anaeróbio operado em batelada compreende quatro etapas: (i) alimentação; (ii) tratamento propriamente dito, por meio das reações ou biotransformações dos constituintes do esgoto por microrganismos; (iii) sedimentação; e (iv) descarga, com retirada do líquido tratado e clarificado. Durante a alimentação, a matéria orgânica a ser tratada é inserida no reator em um curto espaço de tempo, prédeterminado. Desta forma ocorre variação das concentrações dos componentes com picos de concentração de compostos intermediários e alta produção de biogás. Esta etapa é a mais importante do processo e pode durar $80 \%$ ou mais do tempo total de ciclo. O tempo necessário para a etapa de reação depende da qualidade requerida de efluente e de outros fatores como concentração de biomassa, temperatura, características do substrato e tipo de biomassa. Em função da escassez de matéria orgânica aos microorganismos, que proporciona baixa razão $\mathrm{F} / \mathrm{M}$ (substrato/microorganismo) as condições de sedimentação são excelentes ao final da etapa de reação. (DAGUE et al., 1992; ANGENENT \& DAGUE, 1995; NDON \& DAGUE, 1997; ZAIAT et al.,2001).

A desvantagem do ASBR provocada pelo maior volume de reator pode ser compensada com a vantagem de não necessitar de mecanismos de sedimentação e recirculação de biomassa (SPEECE, 1996).

Um objeto de comparação entre reatores ASBR e UASB é com relação ao fato de possibilitarem o desenvolvimento de biomassa granular que permite ótimas condições de sedimentação. Contudo, há a necessidade de baixas concentrações de sólidos suspensos no afluente de um UASB enquanto que esta limitação não se verifica no ASBR (ANGENENT \& DAGUE, 1995).

Diversas vantagens podem ser atribuídas aos sistemas anaeróbios operados em batelada para tratamento de águas residuárias, como melhor controle da qualidade do efluente, alta eficiência de remoção da matéria orgânica e operação simples e estável do 
sistema. Apesar de apresentar muitas vantagens, este tipo de biorreator é deficiente em métodos estabelecidos e técnicas de operação bem definidas (Zaiat et al., 2001). Ocorrência de zonas mortas, alto tempo de sedimentação, arraste de sólidos e inibições devido a sobrecargas orgânicas são alguns dos problemas que afetam o desempenho do tratamento.

Segundo Zaiat et al. (2001), o tratamento promovido em ASBR é particularmente apropriado para os casos de indústrias que geram efluentes de maneira intermitente ou somente em algumas épocas do ano; indústrias que trabalham com padrões de lançamento muito restritivo ou de difícil degradação onde o tempo de ciclo é o parâmetro a ser ajustado para se garantir a degradação do composto presente ou para se atingir a remoção e do ponto de vista operacional para sistemas que tenham a finalidade de reutilizar a água residuária tratada por permitir um maior controle operacional e em estudos que visam o entendimento de fenômenos relacionados com a digestão anaeróbia por permitirem maior instrumentação e controle. Ainda pelo mesmo autor, os fatores que geralmente afetam o rendimento de um ASBR são a agitação, a razão entre a concentração de substrato e a concentração de biomassa (F/M), a configuração geométrica do reator e a estratégia de alimentação.

\subsection{Mecanismos de promoção de mistura e agitação}

A agitação proporciona maior eficiência de contato entre matéria orgânica e os microrganismos durante a fase de reação, para isto podem ser utilizados agitação mecânica que pode ser aplicada de forma intermitente ou contínua ou recirculação de gás ou de líquido (ANGENENT \& DAGUE, 1995; NDON \& DAGUE, 1997; ZAIAT et al., 2001). A intensidade de agitação é um importante fator a ser observado, pois esta pode prejudicar o sistema causando danos aos grânulos presentes na biomassa ou até mesmo destruí-los.

A resistência à transferência de massa da fase líquida para a biomassa pode reduzir a velocidade global de reação, diminuindo o desempenho do reator. Dessa forma, a agitação do meio torna-se importante por aumentar o contato entre a matéria orgânica e a biomassa, reduzindo a resistência à transferência de massa e aumentando a velocidade global de reação e, portanto, o desempenho do reator.

A mistura no ASBR é realizada normalmente por agitação mecânica ou por reciclo do biogás gerado no processo. No entanto, Brito et al. (1997) afirmam que para o 
tratamento de águas residuárias de baixa carga, a produção de biogás é insuficiente para promover a turbulência necessária para minimizar a ocorrência de possíveis zonas de estagnação e resistência à transferência de massa. Atentados para este fato, os pesquisadores desenvolveram um ASBR para o tratamento de águas residuárias de baixa concentração (1.000 mgDQO. $l^{-1}$ ) na qual a agitação era promovida pela recirculação do efluente por uma bomba tipo diafragma, obtendo eficiências de remoção de DQO de 60 a $70 \%$ e qualificando a possibilidade do uso da recirculação do efluente para agitação do reator.

Cubas et al, (2001) estudando o efeito do tamanho de partículas de poliuretano na transferência de massa e conseqüentemente no desempenho global do sistema. Trabalharam com partículas variando de 0,5 a $3 \mathrm{~cm}$ de lado. $\mathrm{O}$ reator foi alimentado com água residuária sintética operando em ciclos de $8 \mathrm{~h}$ a $30^{\circ} \mathrm{C}$. A concentração de efluente residual aumentou com o aumento do tamanho da biopartícula. O tempo de ciclo não foi afetado com o aumento do tamanho da biopartícula quando esta variou de 0,5 a $2 \mathrm{~cm}$, mas foi observado que para partículas de $3 \mathrm{~cm}$ o tempo de ciclo teria que se maior para atingir a eficiência alcançada quando utilizadas partículas menores. Foi estimado uma constante cinética de primeira ordem próximo a $0,59 \mathrm{~h}^{-1}$ para partículas entre 0,5 e $2 \mathrm{~cm}$ e de $0,48 \mathrm{~h}^{-1}$ para partículas de $3 \mathrm{~cm}$.

Sung \& Dague (1995) mostraram que o uso de agitação contínua ou intermitente não influenciou no desempenho do reator em termos de remoção de DQO e produção de metano. Apesar de a agitação contínua aparentar resultar em uma mais rápida remoção de DQO durante as três primeiras horas de ciclo.

Liu \& Tay (2002) atentam para a influência da tensão de cisalhamento na granulação em reatores tipo UASB e outras configurações confirmando que o padrão de escoamento ascendente não é primordial para a garantia da granulação apesar de que quase $100 \%$ dos eventos de granulação em grande escala se confirmarem em reatores tipo coluna. Ainda reforçam a idéia de que a o cisalhamento favorece a formação de grânulos porém pode ocorrer a destruição deles com altas tenções.

Monteith \& Stephenson (1981) estudaram a hidrodinâmica de duas plantas de digestão de lodo utilizando fluoreto como traçador. Neste estudo observaram desvios significativos da mistura ideal nos digestores, diferenças causadas por curto circuito ou presença de zonas mortas ou uma combinação de ambos. No digestor primário de uma das plantas observaram que zonas mortas correspondiam a mais de $77 \%$ do volume do digestor, reduzindo seriamente o tempo de detenção hidráulica, em outro caso 
observaram que $61 \%$ do escoamento passavam por um curto circuito fazendo com que este material não recebesse tratamento.

Karim et al (2005b) estudaram o efeito do tipo de agitação utilizando recirculação de biogás, agitação mecânica e recirculação de lodo em conjunto com o efeito da carga orgânica na performance de oito digestores, sendo quatro alimentados com $5 \%$ de esterco e os outros quatro com $10 \%$. O suprimento de energia foi fixado em $8 \mathrm{~W} \cdot \mathrm{m}^{-3}$ para todos os digestores. Os estudos foram conduzidos em oito reatores de volume útil de $3,73 \mathrm{l}$ em temperatura de $35 \pm 2{ }^{\circ} \mathrm{C}$. O tempo de detenção hidráulica foi mantido em 16,2 dias resultando em cargas orgânicas de 3,08 e 6,2 g. $l^{-1} . \mathrm{d}^{-}$ ${ }^{1}$,respectivamente. Os resultados mostraram que para alimentação de $5 \%$ não houve variação nos valores de produção $\left(0,84-0,94 l \cdot l^{-1} \cdot \mathrm{d}^{-1}\right)$ e de produtividade de metano. Esta constatação pode ser explicada pela baixa concentração de sólidos por ser suficientemente movimentada pelo biogás produzido. Já para concentração de $10 \%$ o tipo de agitação demonstrou ser importante e necessária. Os reatores agitados com recirculação de lodo, mecânica e recirculação de biogás apresentaram 29 \%, 22 \% e $15 \%$ mais biogás do que o reator operado sem agitação, respectivamente. A agitação tornou-se necessária devido à deposição de sólidos observados nos reatores operados a $10 \%$, fato não observado em carga de $5 \%$.

Bagley \& Brodkorb (1999) desenvolveram um modelo cinético baseado nas diferentes populações microbianas em uma comunidade anaeróbia, prevendo a formação e o consumo de produtos intermediários como função da pressão parcial de hidrogênio prevendo efeitos de inibição causados por esta e pelo pH. Para validar o modelo os pesquisadores simularam com resultados experimentais obtidos em um ASBR de $12 l$ de volume total, sendo alimentados $6 l$ por ciclo e a recirculação era feita pela recirculação de líquido a uma taxa de $6 l \cdot \mathrm{h}^{-1}$.

Moreno et al (1998) estudaram o efeito da relação substrato/microrganismo durante um teste de biodegradabilidade. Os ensaios foram realizados em frascos de soro com duas fontes de carbono (acetato e corante azo) a $35^{\circ} \mathrm{C}$ com agitação de $150 \mathrm{rpm}$ e sem agitação. A concentração de substrato variou entre 625 e $12500 \mathrm{mgAcetato} . l^{-1} \mathrm{e}$ de biomassa entre 2500 e $12500 \mathrm{mg} . l^{-1} \mathrm{O}$ uso de agitação aumentou significativamente os valores das constantes cinéticas utilizadas para representar o experimento. $\mathrm{O}$ efeito da concentração de biomassa foi negativo, isto é, baixas concentrações de biomassa apresentaram altos valores de velocidade de reação quando comparados com ensaios em altas concentrações de biomassa. Já a concentração de substrato apresentou efeito 
positivo na velocidade de reação, onde altas concentrações de substrato apresentaram altas velocidades reacionais.

\subsubsection{Mistura promovida recirculação de biogás}

São agora apresentados alguns estudos sobre a influência do desempenho de sistemas de tratamento cuja mistura foi promovida por recirculação de biogás gerado no processo. No qual um problema observado foi a inviabilidade de utilização de mistura por recirculação de biogás em processos de tratamento de efluentes de baixa carga orgânica.

Karim et al, (2005a) trabalharam com seis digestores de volume útil de 3,73 $l$ agitados com recirculação de biogás. Estudaram o efeito da velocidade de recirculação de biogás e altura de tubo de tiragem na performance do sistema. Os reatores tiveram produção de metano de 0,40 a $0,45 l \cdot l^{-1} \mathrm{~d}^{-1}$ sendo a maior produção de metano no reator não agitado enquanto que um aumento na recirculação de biogás provocou uma redução na produção deste, sendo uma possível explicação para este fenômeno o fato de ocorrer baixa concentração de sólidos no reator $\left(50 \mathrm{gST} . l^{-1}\right)$ tornando suficiente a agitação provocada pela produção de biogás. Enquanto que diferentes alturas do tubo de tiragem em relação ao fundo do reator não provocaram alteração significativa na produção de metano.

Muroyama et al, (2001) operaram um reator de $1 l$ com tubo de tiragem em regime de batelada alimentada com recirculação de biogás promovendo a agitação. A agitação ocorria durante uma hora por ciclo sendo o ciclo de $24 \mathrm{~h}$. Observou-se que ocorre um aumento gradual da concentração de metano com o aumento da carga orgânica até atingir um valor de pico a partir do qual ocorre uma queda da concentração com o aumento da carga orgânica. A concentração máxima de metano foi de 53,7 \%, muito próximo do valor teórico de $55 \%$.

Massé \& Masse (2000) utilizando agitação intermitente (um minuto de agitação a cada cinco minutos) por recirculação de biogás gerado em ASBR de 42 L, tratando água residuária de matadouro suíno, obtiveram eficiências de remoção de DQO total entre 90 e 96\%, para cargas orgânicas volumétricas variando de 2,07 a $4,93 \mathrm{gDQO} \cdot l^{-1} \cdot \mathrm{d}^{-1}$.

Ndon \& Dague (1997), operaram um ASBR com agitação por recirculação de biogás, nas concentrações de $0,4,0,6,0,8$ e 1 gDQO. $l^{-1}$ de água residuária produzida 
com leite em pó desnatado com $\theta_{\mathrm{h}}$ de 12, 16, 24 e 48 horas. Atingiram eficiência de conversão de 80 a $90 \%$ para todos os tempos testados, com exceção do $\theta_{\mathrm{h}}$ de 12 nas concentrações de 0,8 e 1 gDQO. $l^{-1}$ e do $\theta_{\mathrm{h}}$ de 16 horas na concentração de 1 gDQO. $l^{-1}$ nos quais foi observada queda de eficiência e perda de sólidos.

Schmit \& Dague (1993) tratando resíduos suínos em ASBR com recirculação de biogás concluíram que para cargas orgânicas variando entre 0,9 a $5 \mathrm{gSV} \cdot l^{-1} \cdot \mathrm{d}^{-1}$ é possível promover remoção entre 40 e $60 \%$ a uma temperatura de $20^{\circ} \mathrm{C}$, confirmando que o ASBR é capaz de se adaptar a baixas temperaturas através de adaptação da biomassa por um longo período de tempo a baixas temperaturas. Observaram também que para baixas cargas o reator funcionou bem, porém com o aumento da carga ocorreram problemas de estabilidade sugerindo tratamento adicional para altas cargas.

Wirtz \& Dague (1997) utilizando agitação intermitente por recirculação de biogás estudaram a redução do tempo de granulação em ASBR pela adição de polímero catiônico comparada com a granulação sem a adição de polímero. Estes pesquisadores obtiveram redução de $75 \%$ no tempo de granulação quando comparado com o tempo necessário para o caso sem a adição do agente de granulação.

\subsubsection{Mistura promovida por recirculação de líquido}

A recirculação de líquido como apresenta como fator importante a velocidade superficial aplicada em cada sistema e são aqui apresentados, de forma não exaustiva, estudos da influência deste fator sobre o desempenho de sistemas de tratamento anaeróbio.

Angenent et al, (2002), avaliando o efeito da duração e da intensidade de agitação sobre o desempenho de ASBR de $5 l$ de volume útil tratando resíduo suíno, verificaram que o uso de agitação suave e intermitente permitiu um maior desempenho do reator quando comparada à agitação suave e contínua, resultando em maiores eficiências de remoção de sólidos voláteis e maior produção de metano. Segundo os autores, a agitação contínua resulta no desenvolvimento de biomassa com más características de sedimentação, a qual é lavada mais facilmente com o efluente durante a descarga. Diminuindo, assim, o desempenho do reator. Os pesquisadores observaram também que o aumento da intensidade de agitação diminuiu severamente o desempenho do reator e a quantidade total de biomassa metanogênica. 
Camargo et al, (2002), utilizando um ASBR com biomassa imobilizada para o tratamento de água residuária sintética a base de glicose (500 mgDQO. $l^{-1}$ ), estudaram a influência da velocidade de recirculação da fase líquida sobre o desempenho do reator e verificaram que a eficiência de remoção de matéria orgânica não filtrada (em termos de DQO) aumentou de $83 \%$ (sem recirculação) para $95 \%$ quando a recirculação foi implementada, indicando uma melhora no contato substrato/biomassa com o uso da recirculação, ou seja, o uso da recirculação resultou em diminuição da resistência à transferência de massa, com aumento da velocidade global da reação e possibilidade de redução do tempo de ciclo.

Ramos et al, (2003), tratando água residuária sintética com concentração de 500 mgDQO. $l^{-1}$, obtiveram um incremento do desempenho de um ASBR com biomassa imobilizada por implantação de recirculação da fase líquida. A eficiência de remoção de matéria orgânica não filtrada, em termos de DQO aumentou de 72 para $87 \%$ depois da implantação da recirculação. Estudos cinéticos indicaram que a constante de primeira ordem da reação aumentou de 1,19 a $2,00 \mathrm{~h}^{-1}$ com o aumento da velocidade superficial que passou de 0,032 para $0,191 \mathrm{~cm} \cdot \mathrm{s}^{-1}$, respectivamente. Um valor estável de $1,90 \mathrm{~h}^{-1}$ foi obtido para velocidades superficiais entre $0,191 \mathrm{e} 0,467 \mathrm{~cm} \cdot \mathrm{s}^{-1}$. Além disso, utilizando velocidade de recirculação de $0,191 \mathrm{~cm} \cdot \mathrm{s}^{-1}$, verificaram aumento da velocidade global da reação com possibilidade de redução do tempo de ciclo.

Angenent et al, (2001), estudaram o efeito do aumento na duração e intensidade de agitação em ASBRs alimentados com resíduo suíno (20 gSV. $\left.l^{-1}\right)$ e concluíram que agitação contínua não é necessária para a digestão de resíduo suíno e que além disto o aumento da agitação pela implementação de bomba peristáltica deteriorou a performance do sistema severamente diminuindo a quantidade de microrganismos metanogênicos que utilizam acetato.

Kennedy et al, (1991) utilizando recirculação da fase líquida estudaram em um reator de manta de lodo operado em bateladas seqüenciais trataram resíduo biodegradável solúvel com carga orgânica variando entre 2,5 e 18,5 gDQO. $l^{-1} \cdot \mathrm{d}^{-1}$. Para cada carga orgânica variando o tempo de alimentação obtiveram remoção de DQO variando entre 35 e 97 \% dependendo da carga orgânica e do tempo de alimentação. 


\subsubsection{Fundamentos sobre agitação mecânica}

Impelidores de vários tipos têm sido utilizados para produzir agitação e mistura na fase líquida. Para produzir mistura é necessário suprimento de energia e isto normalmente é produzido através da rotação de um impelidor. A potência fornecida não depende unicamente do tipo de impelidor e da velocidade de rotação, mas também das propriedades físicas do fluido e da forma do reator, além da disposição dos componentes do sistema como chicanas, serpentinas e suportes. Portanto, para caracterizar o comportamento de um impelidor é necessário levar em consideração todo o ambiente em que opera o sistema.

\subsubsection{Agitadores mecânicos}

Quando um impelidor é inserido em um reator contendo um fluido, movimentação do fluido e redemoinhos são produzidos. Com isto um padrão de escoamento é estabelecido. Desta forma ficam estabelecidos impelidores, fluido e reator e a única forma de mudança nas condições de fornecimento de potência é a mudança na velocidade de rotação do impelidor. Por esta razão a demanda de potência é controlada pela rotação do impelidor. Assim sendo, o consumo de potência é usado para caracterizar vários impelidores em relação ao ambiente em que estes estão inseridos.

\section{Reator com chicanas e impelidor tipo hélice}

Quando chicanas são usadas em reator com impelidor tipo hélice o conjunto causa correntes verticais e laterais de fluido eliminando a presença de vórtices em torno do eixo do impelidor e redemoinhos. Este tipo de movimento do fluido é classificado como axial desta forma hélices são classificadas como impelidores do tipo axial, como pode ser observado na Figura 2.1(a). Este tipo de movimentação também pode ser observado para reatores operando com impelidor tipo pá inclinada.

\section{Reator com chicanas e turbina}

O impelidor tipo turbina possui a característica de produzir escoamento radial. Quando utilizado junto com chicanas estas evitam formação de vórtices em torno do 
eixo e o sistema produz escoamento com linhas de corrente laterais e verticais aumentando a transferência de potência e a misturas dos fluidos e eventuais sólidos em suspensão. O escoamento gerado pode ser visualizado na Figura 2.1 (b).

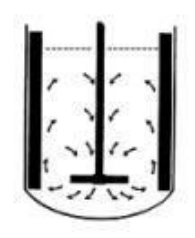

a

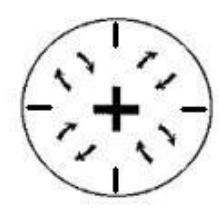

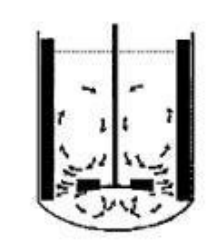

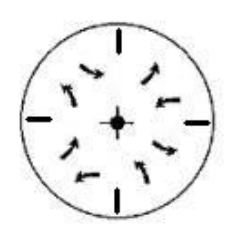

b

Figura 2.1. Representação de escoamentos em reator para escoamentos do tipo axial (a) e radial (b).

\section{Outros impelidores}

O parâmetro básico de relação entre impelidores é o diâmetro, outros impelidores podem ser construídos mudando-se algum parâmetro de construção como, por exemplo, largura ou comprimento das pás. Com estas mudanças o resultado observado para um determinado impelidor seria uma curva como as da Figura 2.1 deslocada verticalmente.

\subsubsection{Suspensão de sólidos}

A suspensão de sólidos por agitação é necessária para vários tipos de operações industriais como, por exemplo, dissolução de sólidos em líquidos, controle de crescimento de cristais, redução de tamanho de partículas, floculação de precipitados, lixiviação e reação química. Nestes casos podem ser definidos dois tipos de suspensões: a suspensão completa que ocorre quando qualquer partícula da suspensão não permanece depositada no fundo do tanque mais do que um segundo e a suspensão homogênea caracterizada pela concentração de sólidos ser a mesma em qualquer ponto da suspensão. Vários autores sugerem que a suspensão completa já é um estado satisfatório para atingir os objetivos desejados como transporte de massa, por exemplo. E este estado pode ser alcançado quando a velocidade do rotor é igual a um certo valor crítico $\mathrm{N}_{\text {CLS }}$ (TERRON, 1986).

Os impelidores mais empregados para a suspensão de sólidos são os do tipo turbina dispostos coincidentemente com o eixo central do vaso e com uma distância com relação ao fundo em torno de 1/3 do diâmetro do impelidor. É interessante que esta 
altura nunca seja menor do que a altura dos sólidos depositados no fundo do vaso, pois quando o sistema está em repouso para evitar que o impelidor fique soterrado quando a movimentação cessa.

De acordo com Baldi (1980), para $\mathrm{N}<\mathrm{N}_{\mathrm{CLS}}$ existem muitas partículas depositadas no fundo do reator e a área efetiva da interface sólido-líquido, para o transporte de massa, diminui grandemente do observado quando $\mathrm{N}=\mathrm{N}_{\mathrm{CLS}}$. $\mathrm{O}$ que causa um acentuado decréscimo no transporte de massa. Por outro lado, quando $\mathrm{N}>\mathrm{N}_{\mathrm{CLS}}$ o aumento na potência dissipada na agitação não é balanceado pelo aumento no transporte de massa.

Segundo Terron (1986), dois modelos são comumente aplicados na análise do transporte de massa, o primeiro é o modelo de velocidade de escorregamento que está baseado nas equações propostas para transporte de massa em convecção forçada que ocorre em esferas isoladas imersas em fluidos escoando em regime turbulento. Porém este modelo esbarra na dificuldade em se obter a velocidade relativa entre a partícula e o fluido além do fato de que equações do modelo são válidas para escoamento no estado estacionário o que não ocorre no caso de suspensões agitadas. O segundo modelo é o da energia dissipada e propõe que idênticos coeficientes de transporte de massa sólidolíquido em partículas suspensas livremente em fluidos agitados ocorram a iguais potências dissipadas, na agitação, por unidade de massa da suspensão.

\subsubsection{Tubo de tiragem ("draft tube")}

Na maioria dos casos os agitadores com tubo de tiragem consistem de um tanque com fundo chato contendo um tubo de tiragem que na prática varia entre 20 e $40 \%$ do diâmetro do tanque. Onde no topo do tubo existe um impelidor promotor de escoamento axial movimentando o fluido para baixo produzindo um retorno do fluido para cima na região anular.

O tubo de tiragem é mais recomendado para suspensão de lodo, em situações onde é essencial a minimização da energia gasta com agitação e aplicações que requerem controle do cisalhamento e de gradientes de velocidade. As condições a serem observadas para a implementação do tubo de tiragem são: utilização em reatores onde não ocorra a variação do nível de fluido ao longo da operação e sua aplicação em reatores que apresentam altos valores para a relação altura/diâmetro. Sendo desta forma desaconselhado para os casos onde ocorre variação do nível do líquido e onde a relação altura/diâmetro esteja próxima a unidade. 
Existem dois critérios distintos para a escolha da velocidade de rotação. O primeiro é baseado na velocidade na base do tubo de tiragem, na qual a velocidade mínima deve promover a suspensão do lodo do fundo do tanque. Normalmente esta velocidade é obtida experimentalmente e é função do tamanho da partícula, porcentagem de sólidos, reologia do fluido e forma do fundo do tanque. O segundo critério é obtido pela velocidade do fluido na região anular, que para o caso da indústria da alumina, deve ser múltipla da velocidade de sedimentação para garantir que a maior partícula irá circular. E este múltiplo dever ser suficiente para garantir que não haja acúmulo das partículas grandes na região anular. Foi provado que quando estes dois pontos são satisfeitos ocorre uma minimização da necessidade de energia, o que resulta em uma redução de $35 \%$ da potência requerida para promover a mesma agitação.

A partida do sistema e re-suspensão dos sólidos é um fator de importância na definição da potência do motor e rotação do impelidor por ser maior o gasto energético para promover a suspensão do lodo quando comparado com a energia gasta para manter a suspensão (SHAW, 1982).

Jiricková \& Rieger (1995) estudando a suspensão de sólidos em vasos altos, agitados e com tubo de tiragem, desenvolveram fórmulas para descrever o consumo de potência e velocidade de suspensão. Concluíram que o baixo consumo de potência em reatores com tubo de tiragem, comparado com vasos padrão $(\mathrm{D}=\mathrm{H})$ é causado pelo fato de que somente uma parte do volume do vaso é usada para que o impelidor promova suspensão, enquanto que a outra parte funciona como uma região de sedimentação pela gravidade.

\subsubsection{Mistura promovida por agitação mecânica}

Estudos sobre o desempenho de sistemas anaeróbios de tratamento de efluentes mostram que ocorre aumento da eficiência de remoção destes com o aumento da rotação dos impelidores. E neste item são apresentados alguns estudos de relevância sobre o assunto.

Droste \& Massé (1995) tratando resíduos suínos com carga orgânica volumétrica de 1,6 gDQO.$l^{-1} \cdot \mathrm{d}^{-1}$ conseguiram $80 \%$ de remoção carga orgânica em amostras filtradas na forma de DQO e $75 \%$ de remoção de sólidos voláteis. Obtiveram estes resultados sem a utilização de agitação, porém com tempos de alimentação e reação durando entre 14 e 28 dias. 
Angenent \& Dague (1995) confirmando os dados de Brito et al, (1997) afirmam que a produção de gás em reatores anaeróbios operados em batelada seqüencial (ASBR), tratando águas residuárias de baixa concentração, é insuficiente para realizar agitação no reator, sendo necessário um sistema de agitação para distribuir uniformemente o substrato durante a fase de reação. Entretanto, se a agitação for muito intensa, pode causar a destruição de grânulos, resultando em baixa eficiência de separação de sólidos. Utilizaram agitação mecânica seguindo um programa de agitação intermitente de dois minutos a cada meia hora sem, contudo informar tipo de impelidor e velocidade de rotação. Obtiveram eficiências de remoção de aproximadamente $90 \%$ e $80 \%$ para $\mathrm{C}_{\mathrm{SS}}$ e $\mathrm{C}_{\mathrm{ST}}$, respectivamente. Afirmam também que a agitação mecânica pode ser responsável pela maior densidade e menor tamanho dos grânulos.

Deveci (2004) estudou o efeito da velocidade de agitação, o tamanho das partículas e a forma dos sólidos na viabilidade de uma cultura mesofílica de bactérias acidofílicas em reator agitado operado com impelidotes tipo turbina Rushton e pá. Na ausência de sólidos, para velocidades de rotação entre 1,0 e 3,35 m.s ${ }^{-1}$, a queda na viabilidade não foi significativa, ficando abaixo de $16 \%$ para um período de agitação de 4 h. Já na presença de sólidos $\left(20 \% \mathrm{w} \cdot \mathrm{w}^{-1}\right)$ e com velocidade de agitação de $3,35 \mathrm{~m} . \mathrm{s}^{-1}$ ocorreu uma intensa queda de viabilidade aparentemente devido a ação dos sólidos. O impelidor tipo turbina provocou maiores danos às células do que o impelidor tipo pá sob as mesmas condições experimentais.

No trabalho desenvolvido por Rodrigues et al (2004) um ASBR operando com agitação contínua e impelidor tipo turbina com seis pás planas verticais trabalhou sob duas estratégias de agitação. Na primeira utilizaram rotação constante e igual a 50rpm, já na segunda condição utilizaram agitação variável com uma hora a $75 \mathrm{rpm}$, duas horas a $50 \mathrm{rpm}$ e meia hora a $25 \mathrm{rpm}$, para um ciclo de quatro horas.Eles obtiveram eficiência de remoção de $87 \%$ e $88 \%$ para DQO em amostras filtradas nas condições de velocidade constante e variável, respectivamente. Diferenças significativas foram observadas quando avaliaram a cinética de degradação da matéria orgânica sendo preferível a condição de velocidade variável.

Rodrigues et al (2003) estudaram a influência da velocidade de rotação em um ASBR operado com impelidor tipo turbina com seis pás planas verticais nas velocidades de rotação de $0,25,50$ e 75 rpm tratando $2 l$ de esgoto sintético com concentração de aproximadamente $500 \mathrm{mgDQO} . l^{-1}$. Para rotação de $50 \mathrm{rpm}$ o sistema obteve eficiência de remoção de 80 e 88 \% para amostras não filtradas e filtradas, respectivamente. Nesta 
condição o sistema também apresentou boa retenção de sólidos evitando a quebra de grânulos.

Ratusznei et al (2001) pesquisando a influência da intensidade de agitação em reator anaeróbio tratando esgoto sintético com biomassa imobilizada em espumas de poliuretano observaram que a velocidade de agitação afeta o tempo necessário para o sistema atingir a eficiência máxima em um ciclo de agitação. Indicando que um tempo de ciclo de três horas seria suficiente para atingir remoção desejada, aumentando o número de ciclos diários e com isto otimizando o processo. Trabalhando com um modelo cinético de primeira ordem observaram também que a intensidade de agitação modifica o valor da constante utilizada no modelo, aumentando seu valor com o aumento da agitação.

Cubas et al (2004), trabalhando em um ASBR com biomassa imobilizada em espumas de poliuretano de $5 \mathrm{~mm}$ de lado, em velocidades de agitação de 300 a 1100 rpm, confirmaram que a intensidade de agitação modifica a eficiência do sistema podendo diminuir o tempo de batelada de um ciclo além de diminuir a concentração residual de matéria orgânica para rotações superiores a 800 rpm. Foi observado que para a variação na velocidade de rotação de 300 para $900 \mathrm{rpm}$ a constante cinética de primeira ordem aumenta em aproximadamente três vezes, partindo de 0,54 para 1,5 $\mathrm{h}^{-1}$. A concentração residual de matéria orgânica cai significativamente para velocidades de rotação acima de $800 \mathrm{rpm}$.

Timur \& Özturk (1999), utilizando agitação intermitente de um minuto por hora tendo como impelidor uma barra magnética, avaliaram a tratabilidade de chorume de aterro sanitário em um ASBR de 2 litros a $35 \mathrm{C}$. Foram realizados estudos de cargas orgânicas volumétricas de 0,4 a 9,4 gDQO $l^{-1} \cdot \mathrm{d}^{-1}$ e cargas orgânicas específicas de 0,2 a 1,9 gDQO.gSSV ${ }^{-1} \cdot \mathrm{d}^{-1}$, variando-se os $\theta_{\mathrm{h}}$ de 1,5 a 10 dias, para concentrações afluentes de 3,8 a 15,9 gDQO. $l^{-1}$. A eficiência de conversão de DQO variou entre 64 e $85 \%$ em função da carga orgânica aplicada. A DQO convertida em metano foi $83 \%$ da DQO removida.

Pinho et al.(2004) estudaram a influência da intensidade de agitação promovida por três impelidores tipo pá com velocidade entre 500 e 1100 rpm na degradação de matéria orgânica em reator ASBR contendo biomassa imobilizada em partículas cúbicas de poliuretano de $3 \mathrm{~cm}$, agitado mecanicamente e alimentado com leite de soja parcialmente solúvel de DQO de $974 \mathrm{mg} . l^{-1}$. Como resultado observaram que um modelo de primeira ordem modificado representou bem os dados no intervalo de 
agitação pesquisado e que ocorreu um aumento de $360 \%$ na constante cinética aparente quando a velocidade de agitação foi aumentada de 500 para $900 \mathrm{rpm}$, acima do qual a constante cinética não variou significativamente.

Pinho et al, (2005), tratando água residuária de abatedouro de suínos, demonstraram que a agitação melhora a velocidade global de degradação de matéria orgânica particulada, visto que a agitação mecânica ajuda a aumentar a velocidade de redução dos tamanhos de partículas da fração de matéria orgânica particulada.

\subsection{Considerações finais}

Historicamente a agitação em sistemas a anaeróbios não era considerada como fator de importância sobre a estabilidade e eficiência destes. Porém, com o aprofundamento dos estudos observou-se que pode existir um valor ótimo de agitação, abaixo da qual pode ocorrer uma queda na eficiência devido a limitação por de transferência de massa, e acima da qual pode haver uma redução da eficiência pela formação excessiva de biomassa dispersa seguida por perda da mesma. Isto posto, o tipo de impelidor pode apresentar influência significativa no desempenho do sistema pois conforme suas características de agitação (axial, radial ou mista), promove um modo de escoamento e mistura no meio líquido contido no reator, impondo tanto um estado de agitação, que define os aspectos de transferência de massa, quando as características de sedimentabilidade do lodo envolvido. Assim sendo, o estudo de cinco tipos de impelidores em duas freqüências rotacionais visa contribuir para o melhor entendimento da influência de aspectos como modo de escoamento e, conseqüentemente, consumo de potência sobre a estabilidade e eficiência de sistemas agitados mecanicamente.

A aplicação de reator com tubo de tiragem para tratamento de efluentes por via anaeróbia é interessante por promover suspensão de sólidos com baixo consumo e potência e mantendo baixos níveis de tensão de cisalhamento, combinação esta que pode vir a promover redução dos efeitos de transferência de massa externa à biopartícula sem contudo degradar a biomassa. Desta forma a implementação de tubo de tiragem ao reator anaeróbio pode vir a ser boa opção de configuração para o tratamento de esgoto sintético de baixa carga orgânica. 


\section{MATERIAIS E MÉTODOS}

\subsection{Materiais}

\subsubsection{Configuração do reator operado em batelada seqüencial}

A Figura 3.1 e Figura 3.2 mostram o esquema do reator com agitação mecânica operado em batelada seqüencial contendo lodo granulado. O reator é o modelo BIOFLO III da New Brunswick Scientific Co.

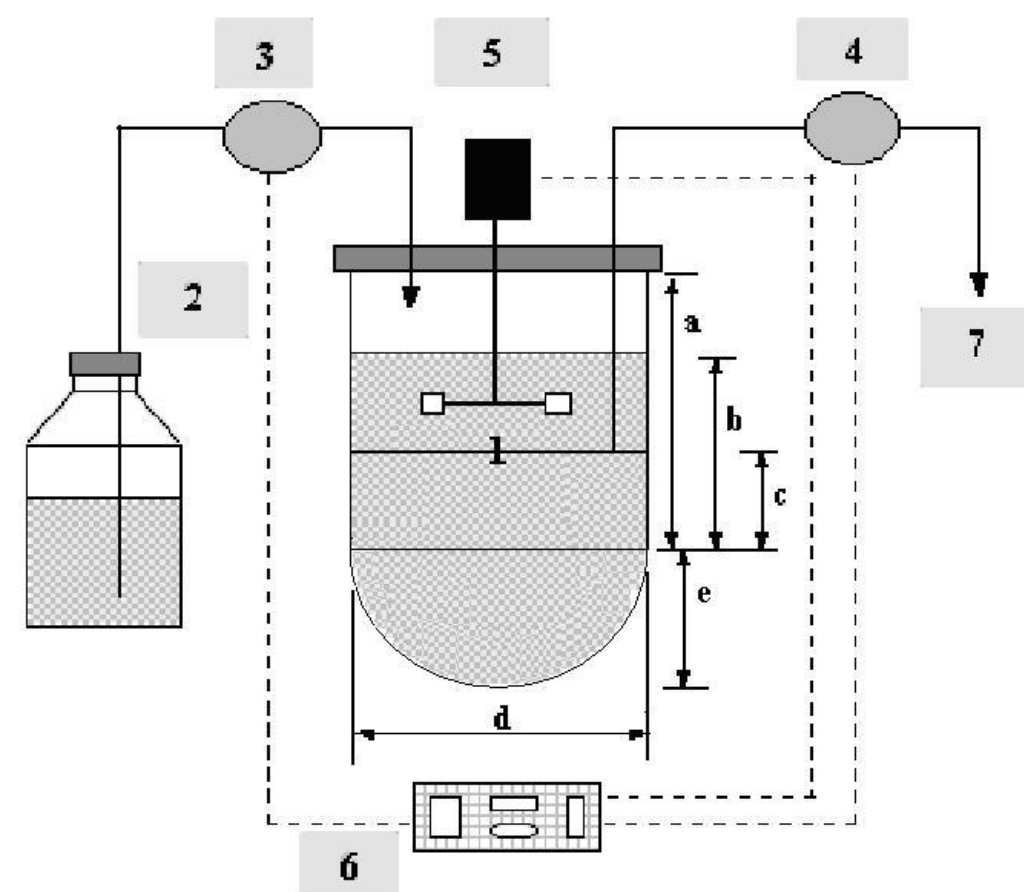

Figura 3.1. Esquema do reator anaeróbio com agitação operado em batelada seqüencial [1 - Biorreator com capacidade de $6 \mathrm{~L}(\mathrm{a}=20 \mathrm{~cm} ; \mathrm{b}=17 \mathrm{~cm} ; \mathrm{c}=3 \mathrm{~cm} ; \mathrm{d}=17 \mathrm{~cm}, \mathrm{e}=$

$6 \mathrm{~cm}$ ) e um impelidor contendo biomassa granulada; 2 - Afluente; 3 - Bomba de alimentação; 4 - Bomba de descarga; 5 - Sistema de agitação; 6 - Sistema de automação; 7 - Efluente]. 
A alimentação e descarga foram realizadas por bombas tipo diafragma, marca Prominente, modelos $\beta$ e Concept, respectivamente. Um sistema de automação, composto por temporizadores, foi o responsável pelo acionamento/parada das bombas e do agitador, de modo a implementar as etapas da operação em batelada seqüencial: alimentação, reação, sedimentação e descarga.

A temperatura foi controlada por uma jaqueta de aquecimento na parte inferior do reator ligada a um banho ultratermostatizado na qual a manutenção da temperatura foi feita através do sensor do reator e do controlador do banho de aquecimento.

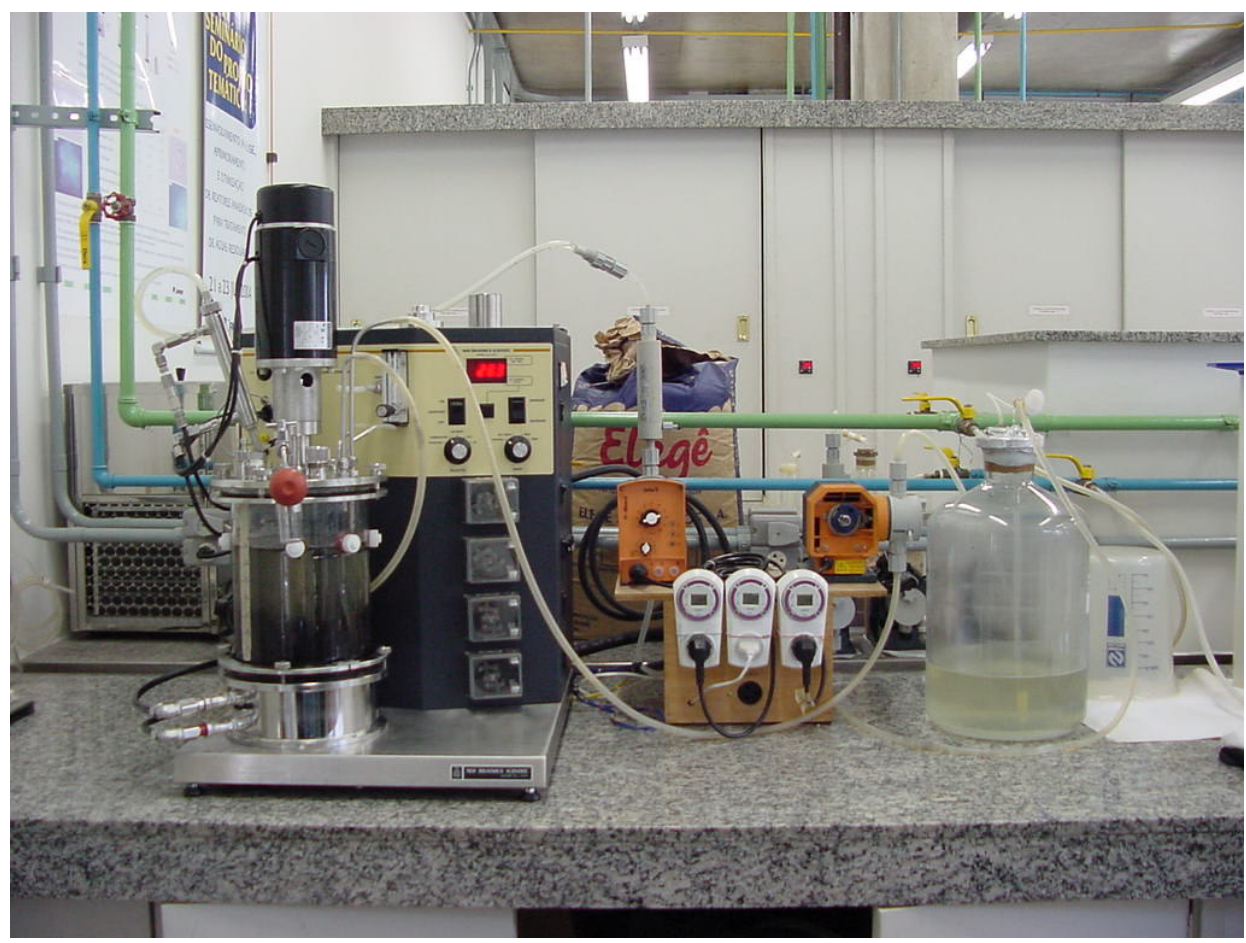

Figura 3.2. Fotografia do aparato experimental.

\subsubsection{Impelidores}

A agitação foi implementada por diferentes tipos de impelidores ao longo da etapa experimental no intuito de analisar a influência das características de mistura e escoamento radiais, axiais ou mistas:

a. Tipo turbina constituído por seis pás planas verticais;

b. Tipo turbina de constituído por seis pás planas inclinadas em $45^{\circ}$;

c. Tipo pá constituído por seis pás planas verticais; 
d. Tipo pá constituído por seis pás planas inclinadas em $45^{\circ}$;

e. Tipo hélice constituído por três lâminas.

São apresentados na Tabela 3.1 os parâmetros de construção dos impelidores utilizados neste trabalho.

Tabela 3.1. Parâmetros de construção dos impelidores

\begin{tabular}{ccccccc}
\hline Tipo de Impelidor & $\mathrm{D}_{\mathrm{t}} / \mathrm{D}_{\mathrm{i}}$ & $\mathrm{H}_{\mathrm{L}} / \mathrm{D}_{\mathrm{i}}$ & $\mathrm{H}_{\mathrm{i}} / \mathrm{D}_{\mathrm{i}}$ & Inclinação & $\begin{array}{c}\mathrm{n}^{\mathrm{o}} \\
\text { pás/lâminas }\end{array}$ & $\begin{array}{c}\text { Diâmetro } \\
(\mathrm{cm})\end{array}$ \\
\hline $\begin{array}{c}\text { Turbina plana } \\
\mathrm{L}_{\mathrm{i}} / \mathrm{D}_{\mathrm{i}}=0,25 ; \mathrm{W}_{\mathrm{i}} / \mathrm{D}_{\mathrm{i}}=0,2 \\
\text { Turbina inclinada }\end{array}$ & 3 & 3 & 1 & $0^{\circ}$ & 6 & 6,2 \\
$\begin{array}{c}\text { L } / \mathrm{D}_{\mathrm{i}}=0,25 ; \mathrm{W}_{\mathrm{i}} / \mathrm{D}_{\mathrm{i}}=0,2 \\
\quad \text { Pá plana }\end{array}$ & 3 & 3 & 1 & $45^{\circ}$ & 6 & 5,7 \\
$\begin{array}{c}\mathrm{W}_{\mathrm{i}} / \mathrm{D}_{\mathrm{i}}=0,25 \\
\text { Pá Inclinada } \\
\mathrm{W}_{\mathrm{i}} / \mathrm{D}_{\mathrm{i}}=0,25 \\
\text { Hélice }\end{array}$ & 3 & 3 & 1 & $0^{\circ}$ & 6 & 5,7 \\
Passo $=1$ & 3 & 3 & 1 & $45^{\circ}$ & 6 & 5,7 \\
& 3 & 3 & 1 & - & 3 & 5,7 \\
\hline
\end{tabular}

Na Figura 3.1 são visualizadas as razões geométricas dos impelidores utilizados neste trabalho. 

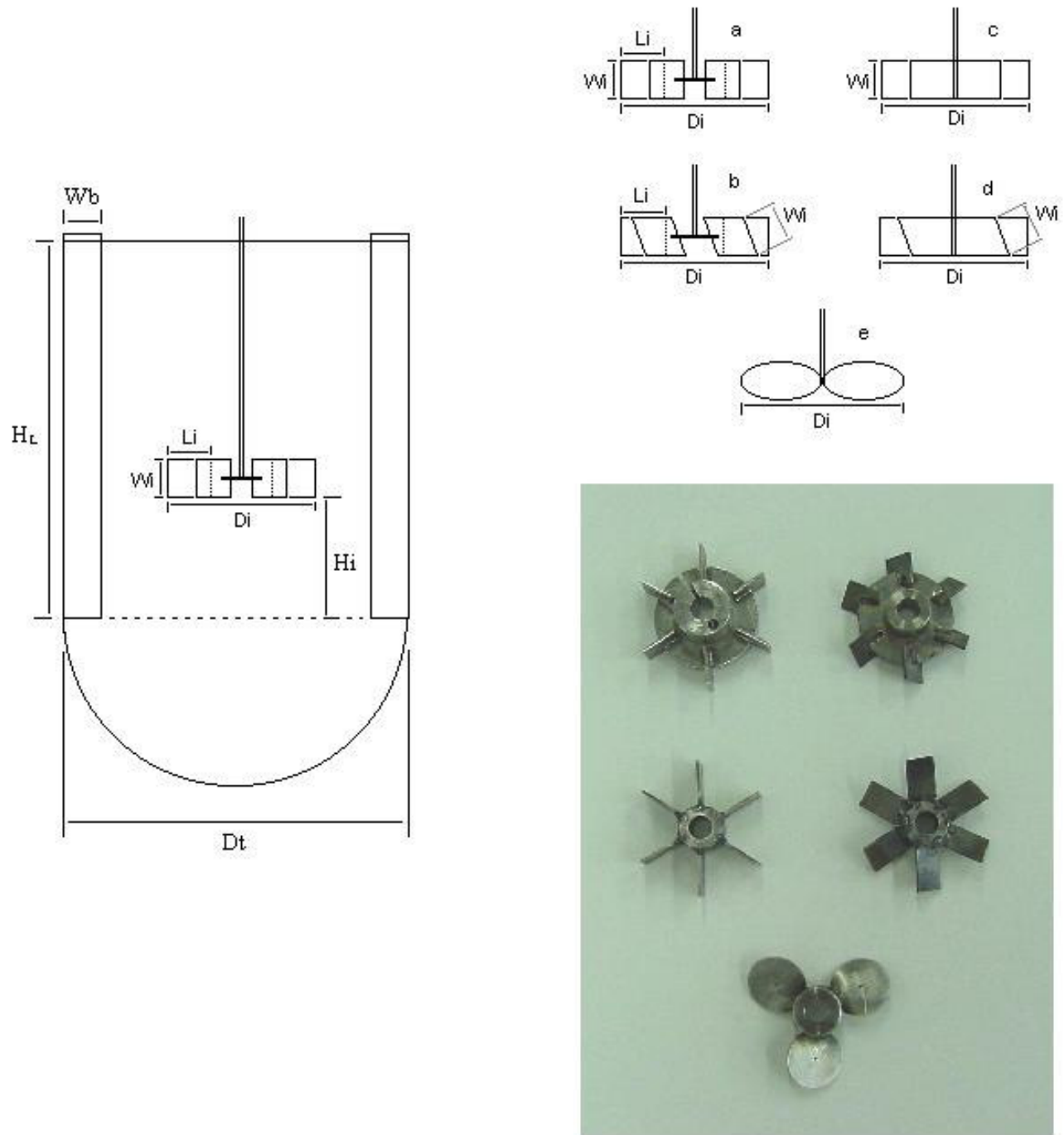

Figura 3.3. Parâmetros de projeto para construção dos impelidores e disposição destes no reator.

$\mathrm{Na}$ configuração proposta estão presentes quatro chicanas de largura $\mathrm{W}_{\mathrm{i}}$, que corresponde a $10 \%$ do diâmetro do reator e foram mantidas em todos os ensaios.

\subsubsection{Tubo de tiragem}

Seguindo proposta do Professor Deovaldo de Moraes Junior, durante $1^{\circ}$ Exame de Qualificação, sobre utilização de tubo de tiragem ("draft tube") que obriga o fluido a desenvolver escoamento axial no reator, e para sua confecção utilizou-se de um tubo de 
PVC de 3" de diâmetro nominal o que corresponde a 7,62 cm e a uma relação $\mathrm{Dt} / \mathrm{D}=0,42$ sendo seu comprimento de $15 \mathrm{~cm}$ cuja disposição no reator é apresentada na Figura 3.4.
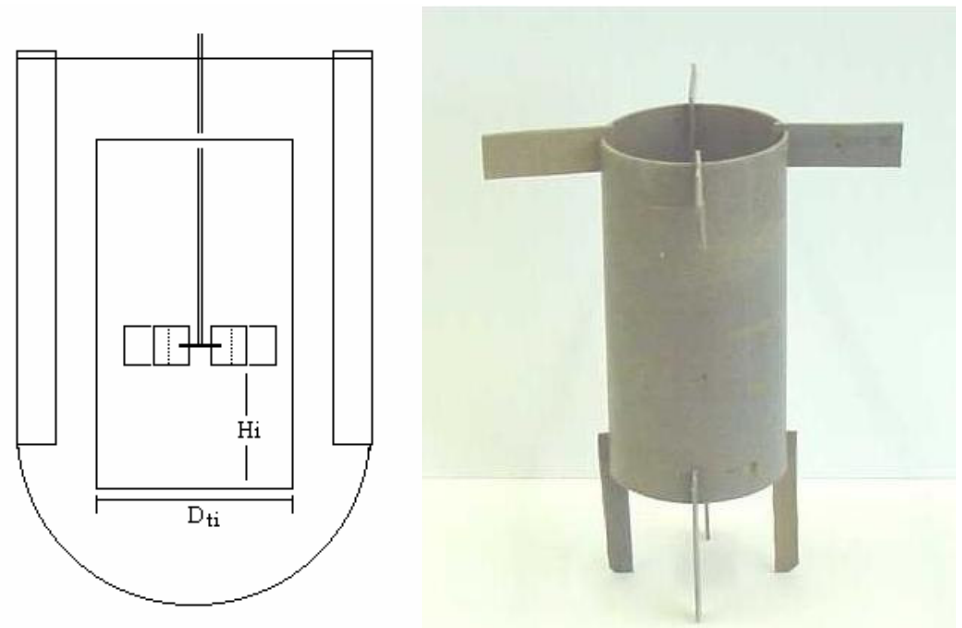

Figura 3.4. Disposição do tubo de tiragem no reator e fotografia do mesmo.

\subsubsection{Sistema para medida do consumo de potência}

O sistema utilizado para estudo do consumo de potência é apresentado na Figura 3.5. Constituído por um motor de 1/7 HP da DIACTI de corrente contínua de 20 Volts, o biorreator utilizado nos experimentos em conjunto com os impelidores acima descritos, tacômetro digital LUTRON bt-2236 utilizado para aferir a rotação dos impelidores, suporte para reator composto por duas bases unidas por rolamento para diminuir atrito e dinamômetro KRATOOS DDK2.

Este sistema possibilita medir a potência transferida do impelidor para o líquido. Para isto o reator em questão é colocado sobre um suporte móvel que está conectado a um dinamômetro a uma distância d conhecida. Ao se aplicar rotação ao impelidor este transfere potência ao sistema que por sua vez produz torque sobre o reator, que por estar sobre um suporte móvel, possibilita a leitura da força recebida através do dinamômetro. Conhecendo a distância do dinamômetro ao centro de rotação do sistema, a força medida por este e a rotação do impelidor, pode-se com o auxílio da equação 3.5 calcular a potência transferida do impelidor ao sistema para a velocidade rotacional estabelecida. 


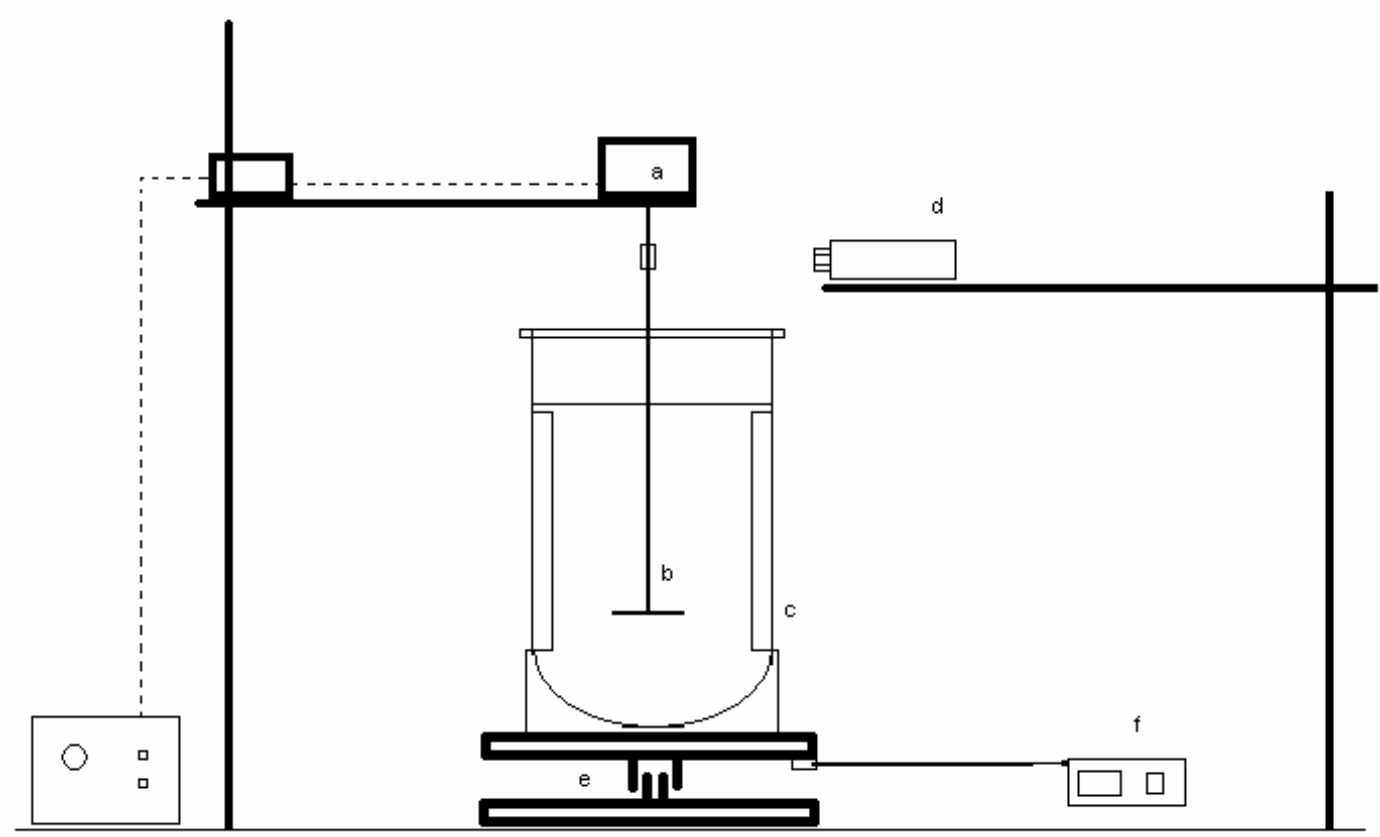

Figura 3.5. Aparato utilizado para medida do consumo de potência $(\mathrm{a}-$ motor, $\mathrm{b}-$ impelidor, c - reator, $\mathrm{d}$ - tacômetro digital, e - suporte para reator e f - dinamômetro).

\subsubsection{Inóculo}

O inóculo utilizado em todos os experimentos foi proveniente de reator anaeróbio de manta de lodo com escoamento ascendente (UASB), tratando água residuária de abatedouro de aves (Dacar Industrial S.A.), sediada em Tietê, SP.

\subsection{6 Água residuária - esgoto sintético}

O esgoto sintético utilizado apresentou aproximadamente $800 \mathrm{mgDQO} . \mathrm{l}^{-1} \mathrm{e}$ foi composto por proteínas (na forma de extrato de carne), carboidratos de fácil e de difícil degradação (nas formas de sacarose, amido e celulose) e lipídeos (na forma de óleo de soja) contendo traços de metais e bicarbonato de sódio para tamponamento, preparado de acordo com Torres (1992) e esterilizado $\left(121^{\circ} \mathrm{C}\right.$ por $\left.15 \mathrm{~min}\right)$ para manutenção das características ao longo da operação. As características da água residuária sintética estão apresentadas nas Tabela 3.2 e Tabela 3.3. 
Tabela 3.2. Composição geral da água residuária sintética.

\begin{tabular}{lll}
\hline Composto orgânico & DQO $(\%)$ & Constituinte \\
\hline Proteínas & 50 & Extrato de carne \\
Carboidratos & 40 & Sacarose, Amido, Celulose \\
Lipídeos & 10 & Óleo de soja \\
\hline
\end{tabular}

Tabela 3.3. Composição da água residuária sintética utilizada nos experimentos.

\begin{tabular}{|c|c|}
\hline Composto & Concentração $\left(\mathrm{mg} \cdot \mathrm{l}^{-1}\right)$ \\
\hline \multicolumn{2}{|l|}{ Carboidratos } \\
\hline Sacarose & 56 \\
\hline Amido & 182,4 \\
\hline Celulose & 54,4 \\
\hline \multicolumn{2}{|l|}{ Proteínas } \\
\hline Extrato de carne & 332,8 \\
\hline \multicolumn{2}{|l|}{ Lipídeos } \\
\hline Óleo de soja ${ }^{(*)}$ & 81,6 \\
\hline \multicolumn{2}{|l|}{ Sais } \\
\hline $\mathrm{NaCl}$ & 250 \\
\hline $\mathrm{MgCl}_{2} \cdot 6 \mathrm{H}_{2} \mathrm{O}$ & 7,0 \\
\hline $\mathrm{CaCl}_{2} \cdot 2 \mathrm{H}_{2} \mathrm{O}$ & 4,5 \\
\hline \multicolumn{2}{|l|}{ Tampão } \\
\hline $\mathrm{NaHCO}_{3}$ & 320 \\
\hline
\end{tabular}

\subsection{Métodos}

\subsubsection{Análises físico-químicas}

As medidas de concentrações de matéria orgânica na forma de DQO, nas formas não filtrada e filtrada, de sólidos totais (ST), sólidos voláteis totais (SVT), sólidos suspensos totais (SST), sólidos suspensos voláteis (SSV) de ácidos voláteis totais, de alcalinidade (total, parcial, intermediária e a bicarbonato) foram realizadas segundo o Standard Methods for the Examination of Water and Wastewater (1995).

A determinação de ácidos voláteis intermediários foi feita por cromatografia em fase gasosa, utilizando Cromatógrafo $H P^{\circledR} 6890$ Series com detector de ionização de chama, coluna $\mathrm{HP}^{\circledR}$,Innowax $30 \mathrm{~m} \times 0,25 \mathrm{~mm} \times 0,25 \mu \mathrm{m}$ de espessura do filme. $\mathrm{O}$ gás de arraste foi o hidrogênio (escoamento de 2,0 ml. $\mathrm{min}^{-1}$ ), temperatura do injetor igual a $250^{\circ} \mathrm{C}$, razão de "splif" de 20, volume de injeção de $1,0 \mu \mathrm{l}$. A temperatura do forno foi de $100^{\circ} \mathrm{C}$ durante 3 minutos, rampa de aquecimento de $5^{\circ} \mathrm{C} \cdot \mathrm{min}^{-1}$ até $180^{\circ} \mathrm{C}$, 
permanecendo por 5 minutos. "Postrun"de $200{ }^{\circ} \mathrm{C}$ durante 3 minutos. A temperatura do detector foi de $300{ }^{\circ} \mathrm{C}$, com escoamento de ar sintético $\left(300 \mathrm{ml} \cdot \mathrm{min}^{-1}\right)$ e hidrogênio $\left(30 \mathrm{ml} \cdot \mathrm{min}^{-1}\right)$ e vazão de "make up" de nitrogênio $\left(35 \mathrm{ml} \cdot \mathrm{min}^{-1}\right)$.

Seguindo esta análise foram verificadas, as presenças e quantidades de ácido acético, ácido propiônico, ácido butírico, ácido valérico, ácido iso-butírico e isovalérico, tendo como ácido padrão para calibração o ácido crotônico. Desta forma quando são apresentados gráficos de ácidos voláteis totais por cromatografia mas aparecem somente um dois ou três destes ácidos significa que os outros ácidos orgânicos não estiveram presentes na amostra ou ensaio em questão.

\subsubsection{Análises microbianas}

A análise microbiana do lodo anaeróbio foi realizada por: (a) microscopia óptica comum, por contraste de fases e por fluorescência, utilizando microscópio Olympus modelo $\mathrm{BH} 2$.

\subsubsection{Composição e produção do biogás}

A determinação da composição de biogás gerado pela digestão anaeróbia foi feita através de cromatografia em fase gasosa utilizando-se o cromatógrafo $\mathrm{HP}^{\circledR} 6890$ Series equipado com detector de condutividade térmica e coluna Porapak $Q^{\circledR}(2 \times 1 / 4$ " 80 a 100 mesh). O gás de arraste foi o hidrogênio a $50 \mathrm{~m} l \cdot \mathrm{min}^{-1}$, a temperatura do injetor igual a $150{ }^{\circ} \mathrm{C}$ e volume de amostra de $1,0 \mathrm{ml}$. A temperatura do forno foi de $50^{\circ} \mathrm{C}$. o detector operou a $200{ }^{\circ} \mathrm{C}$, com escoamento de hidrogênio a $50 \mathrm{ml} \cdot \mathrm{min}^{-1}$ e vazão de "make up" de nitrogênio $\left(2,5 \mathrm{ml}, \mathrm{min}^{-1}\right)$. Cabe destacar que esta análise foi capaz de identificar e quantificar a presença de $\mathrm{CH}_{4}$ e $\mathrm{CO}_{2}$, sendo os componentes utilizados no cálculo da fração molar de metano no "head-space". A produção de biogás foi acompanhada com a utilização de um gasômetro de deslocamento de hidróxido de sódio. 


\subsection{Procedimento experimental}

\subsubsection{Operação do reator em batelada seqüencial}

A operação do biorreator em batelada seqüencial foi realizada a temperatura constante de $30 \pm 1{ }^{\circ} \mathrm{C}$ e um ciclo de operação de 8 horas (ou $480 \mathrm{~min}$ ), ou seja, três ciclos por dia. As etapas de alimentação e descarga tiveram a duração de 10 min cada, a etapa de sedimentação teve a duração de $30 \mathrm{~min}$, restando, portanto, 429 min para a etapa de reação, pois 1 min foi dado como intervalo entre as etapas de alimentação e descarga como fator de segurança no sincronismo das bombas. A Tabela 3.4 resume a estratégia de operação do sistema em batelada seqüencial.

Tabela 3.4. Estratégia de operação do sistema em batelada seqüencial a ser implementada.

\begin{tabular}{|c|c|c|c|c|}
\hline Estratégia & $\begin{array}{c}\text { Alimentação } \\
(\min )\end{array}$ & $\begin{array}{c}\text { Reação } \\
\text { (min) }\end{array}$ & $\begin{array}{l}\text { Sedimentação } \\
(\min )\end{array}$ & $\begin{array}{l}\text { Descarga } \\
(\mathrm{min})\end{array}$ \\
\hline Tempo & $0-10$ & $11-437$ & $438-468$ & $469-479$ \\
\hline Bomba de alimentação & Ligada & Desligada & Desligada & Desligada \\
\hline Bomba de descarga & Desligada & Desligada & Desligada & Ligada \\
\hline Motor de agitação & Ligado & Ligado & Desligado & Desligado \\
\hline
\end{tabular}

A concentração do afluente foi de, aproximadamente, $800 \mathrm{mgDQO} . l^{-1}$, sendo realizados os ensaios conforme descrito na Tabela 3.5. O tempo de duração do ensaio em cada condição de agitação para cada tipo de impelidor foi de, aproximadamente, 15 dias, ou seja, no total um período de 30 dias. Desta forma, foi gasto um período da parte experimental de, aproximadamente, 8 meses para avaliar o comportamento do sistema em função do tipo de impelidor e da velocidade de agitação. 
Tabela 3.5. Resumo dos ensaios realizados nesse projeto.

\begin{tabular}{lcccc}
\hline \multirow{2}{*}{ Tipo de impelidor } & \multicolumn{3}{c}{ Agitação $^{(2)}$} & Tubo de \\
\cline { 2 - 4 } & E.P. ${ }^{(1)}$ & Inferior & Superior & tiragem \\
\hline Turbina de pás planas verticais & 15 dias & - & - & Não \\
Turbina de pás planas inclinadas $45^{\circ}$ & - & 15 dias & 15 dias & Não \\
Pá de pás planas verticais & - & 15 dias & 15 dias & Não \\
Pá de pás planas inclinadas 45 & - & 15 dias & 15 dias & Não \\
Pá de pás planas inclinadas $45^{\circ}$ & - & 15 dias & 15 dias & Sim \\
Hélice & - & 15 dias & 15 dias & Não \\
Hélice & - & 15 dias & 15 dias & Sim \\
\hline
\end{tabular}

Obs.: (1) $\quad$ Ensaio preliminar com agitação de 50 rpm considerado como padrão para fins de comparação, pois já foram realizados experimentos com esse tipo de impelidor e com esse valor de agitação.

(2) Os valores foram definidos ao longo dos ensaios, tendo-se como uma estimativa o intervalo de 25 a $200 \mathrm{rpm}$.

Ao final dos experimentos foi realizada uma etapa de estimativa experimental da transferência de potência dos diferentes tipos de impelidores na condição de freqüiência de agitador ótima. Essa etapa teve por objetivo avaliar os aspectos econômicos da implementação da agitação no processo.

\subsubsection{Monitoramento do reator}

O monitoramento do reator foi feito por amostras do afluente e do efluente, medindo-se as concentrações de matéria orgânica (medida como demanda química de oxigênio - DQO), de alcalinidade parcial (AP), de alcalinidade total (AT), de alcalinidade a bicarbonato ( $\mathrm{AB}$ ), de ácidos voláteis (AV), de sólidos totais (ST), de sólidos voláteis totais (SVT), de sólidos suspensos totais (SST) e de sólidos suspensos voláteis (SSV), além da medida de $\mathrm{pH}$ e do volume descarregado. Estes parâmetros foram monitorados com uma freqüência de, pelo menos, duas ou três vezes por semana.

\subsubsection{Perfil ao longo do ciclo de operação}

Uma vez atingida a estabilidade nas diferentes condições experimentais foi medido o perfil ao longo do ciclo de operação de algumas das variáveis monitoradas. Estes perfis foram obtidos pela retirada de amostras ao longo das 8 horas de operação de um ciclo. As variáveis de interesse foram: concentrações de matéria orgânica na forma filtrada, de metano, de alcalinidade a bicarbonato e de ácidos voláteis totais e intermediários, além do $\mathrm{pH}$ e velocidade de produção de metano. Desta forma, foi 
possível obter uma melhor compreensão das rotas de degradação ao longo de um ciclo, além da estimativa dos parâmetros cinéticos de degradação da matéria orgânica com a utilização do modelo cinético proposto ajustado aos valores experimentais de concentração de matéria orgânica, concentração de ácidos voláteis totais na forma de ácido acético e concentração de metano.

As amostras retiradas para obtenção do perfil anteriormente citado foram colhidas em intervalos de tempo, de 15 a $60 \mathrm{mim}$, ao longo do ciclo, conforme o tipo de variável medida. $\mathrm{O}$ volume total retirado nas amostragens foi, no máximo, de $500 \mathrm{~mL}$, ou seja, $10 \%$ do volume de meio contido no reator. Após cada operação, amostras do lodo foram retiradas do reator para análise gravimétrica dos sólidos do reator. Uma vez obtidos esses perfis, o tipo de impelidor e/ou a intensidade de agitação foram mudadas iniciando-se uma nova fase de operação.

A velocidade de produção de metano foi medida fazendo-se a razão, ponto a ponto, do volume de metano produzido pelo tempo gasto para a coleta da amostra.

\subsubsection{Ensaio sobre consumo de potência}

Ao final dos ensaios sobre estabilidade e eficiência dos sistemas foi realizado um ensaio sobre consumo de potência para os impelidores estudados neste trabalho. As velocidades para cada ensaio estão contidas dentro do intervalo de 300 a $1700 \mathrm{rpm}$. A execução da medida da potência consumida nas velocidades rotacionais estudadas não foi possível em virtude destas estarem abaixo do limite de sensibilidade tanto do tacômetro digital quanto do dinamômetro utilizados para este fim.

\subsection{Formulação matemática e modelagem cinética}

\subsubsection{Eficiência de conversão de matéria orgânica}

Dentre os parâmetros para a verificação do desempenho do sistema estão as eficiências de conversão da matéria orgânica. Foram calculadas para amostras na forma filtrada $\left(\mathrm{E}_{\mathrm{F}}\right)$, não-filtrada $\left(\mathrm{E}_{\mathrm{T}}\right)$ e eficiência de remoção no reator $(\mathrm{E})$, foram calculadas através das equações $3.1,3.2$ e 3.3, respectivamente, sendo $C_{I}$ a concentração não filtrada de matéria orgânica no afluente, $\mathrm{C}_{\mathrm{ST}}$ a concentração de matéria orgânica na 
forma não filtrada no efluente, $\mathrm{C}_{\mathrm{SF}}$ a concentração de matéria orgânica na forma filtrada no efluente, $\mathrm{C}_{S}$ a concentração de matéria orgânica no reator e $\mathrm{C}_{\mathrm{So}}$ a concentração inicial de matéria orgânica no reator.

$$
\begin{aligned}
& E_{T}=\frac{\left(C_{I}-C_{S T}\right)}{C_{I}} .100 \\
& E_{F}=\frac{\left(C_{I}-C_{S F}\right)}{C_{i}} \cdot 100 \\
& E=\frac{\left(C_{S o}-C_{S}\right)}{C_{S o}} .100
\end{aligned}
$$

\subsubsection{Número de potência e Número de Reynolds}

Quando um impelidor é inserido em um reator contendo um fluido, movimentação do fluido e redemoinhos são produzidos. Com isto um padrão de escoamento é estabelecido. Desta forma ficam estabelecidos impelidores, fluido e reator e a única forma de mudança nas condições de fornecimento de potência é a mudança na velocidade de rotação do impelidor. Por esta razão a demanda de potência é controlada pela rotação do impelidor. Assim sendo, o consumo de potência é usado para caracterizar vários impelidores em relação ao ambiente em que estes estão inseridos.

Rushton et al (1950) desenvolveram o conceito de número de potência. Eles mediram a potência consumida para promover agitação no meio líquido para vários tipos de impelidores. Estabeleceram que a razão entre as forças externas e inerciais define o número de potência.

$$
N p=\frac{P}{n^{3} \cdot D i^{5} \cdot \rho}
$$

Sabendo que a potência pode ser definida como

$$
P=F . d .2 \pi \cdot n
$$

Obtém-se que o número de potência pode ser calculado por

$$
N p=\frac{F \cdot d \cdot 2 \pi .}{n^{2} \cdot D i^{5} \cdot \rho}
$$


A movimentação de líquidos em vasos agitados é descrita pela razão entre forças inerciais e viscosas por unidade de volume de líquidos, este número é chamado de número de Reynolds modificado para impelidores.

$$
N_{\mathrm{Re}} \frac{n \cdot D i^{2} \cdot \rho}{\mu}
$$

É importante notar que os adimensionais apresentados nas equações 3.4 e 3.7 são usados para o padrão, especialmente no caso da turbina plana. Também merece menção o fato de que para altos valores de $\mathrm{N}_{\mathrm{Re}}$, isto é, para a região turbulenta, o valor de $\mathrm{N}_{\mathrm{P}}$ torna-se constante para cada tipo de impelidor. As curvas são válidas para geometrias bem definidas dos impelidores e tanques.

De posse de curvas padrão que relacionam $\mathrm{N}_{P}$ com $\mathrm{N}_{\mathrm{Re}}$ pode-se calcular a potência requerida por um sistema pelo cálculo de $\mathrm{N}_{\mathrm{Re}}$, de posse deste e pela curva característica do impelidor obtém-se $\mathrm{N}_{P}$ que pode ser utilizado, junto com as características do sistema que se deseja projetar, através da equação 3.8.

$$
P=N_{P} . n^{3} . D i^{5} \rho
$$

\subsubsection{Modelagem cinética}

O modelo anaeróbio apresentado neste trabalho é baseado na aproximação apresentada por Bagley e Brodkorb (1999) e aplicado a um reator anaeróbio de batelada seqüencial por Rodrigues (2004), desta forma este modelo é uma adaptação do modelo desenvolvido para processos de tratamento aplicado em reatores de lodo ativado desenvolvido pela "International Water Association" (IWA). A análise cinética utilizada neste trabalho simplifica o processo anaeróbio em dois processos consecutivos: primeiramente a matéria orgânica em amostras filtradas, medido na forma de DQO $\left(\mathrm{C}_{\mathrm{S}}\right)$, é convertido totalmente a ácidos voláteis totais, medidos como concentração de ácido acético $\left(\mathrm{C}_{\mathrm{AVT}}\right)$, isto é, os processos de hidrólise, acidogênese e acetogênese e a conversão deste composto a metano, medido na forma de metano produzido por volume reacional $\left(\mathrm{C}_{\mathrm{M}}\right)$, isto é, o processo de metanogênese acetoclástica. Ambos os processos foram assumidos como cinéticas de primeira ordem. Além disto foi considerado neste modelo concentração final residual de matéria orgânica em amostras filtradas $\left(\mathrm{C}_{\mathrm{Sr}}\right)$ e 
ácidos voláteis totais $\left(\mathrm{C}_{\mathrm{AVTr}}\right)$, quando os valores de velocidade de reação são iguais a zero.

Da equação 3.9 à equação 3.16 está representado o modelo proposto, onde a, b e c são coeficientes estequiométricos; $\mathrm{k}_{1}$ e $\mathrm{k}_{2}$ são parâmetros cinéticos aparentes de primeira ordem; $R_{S}$. $R_{A V T}, R_{A V T}$ e $R_{M}$ são as velocidades de reação de consumo de matéria orgânica em amostras filtradas, formação e consumo de ácidos voláteis totais e produção de metano, respectivamente; $\mu_{S}, \mu_{\mathrm{AVT}}, \mu^{\prime}{ }_{\mathrm{AVT}}$ e $\mu_{\mathrm{M}}$ são as velocidades reacionais específicas de consumo de matéria orgânica em amostras filtradas, formação e consumo de ácidos voláteis totais, e produção de metano, respectivamente; $\mathrm{C}_{\mathrm{X}}$ é a concentração de biomassa; $X_{1}, I_{1} X_{2}$, e $I_{2}$ são, respectivamente, a biomassa e outros compostos intermediários formados durante o processo de degradação anaeróbia, mas não considerados no modelo cinético; e o subscrito 0 denota os valores no tempo zero. Vale mencionar que existe consumo de matéria orgânica para manutenção celular e este não é considerado neste modelo cinético.

Reação anaeróbia:

$$
a . S \stackrel{k_{1}}{\rightarrow} \text { b.AVT }+X_{1}+I_{1} \stackrel{k_{2}}{\rightarrow} \text { c.M }+X_{2}+I_{2}
$$

Modelos cinéticos:

$$
\begin{gathered}
R_{S}=\mu_{S} C_{X}=k_{1 S}\left(C_{S}-C_{S r}\right) \\
R_{A V T}=\mu_{A V T} C_{X}=k_{1 A V T}\left(C_{S}-C_{S r}\right) \\
R_{A V T}^{\prime}=\mu_{A V T}^{\prime} C_{X}=k_{2 A V T}\left(C_{A V T}-C_{A V T r}\right) \\
R_{M}=\mu_{M} C_{X}=k_{2 M}\left(C_{A V T}-C_{A V T r}\right)
\end{gathered}
$$

Equações do balanço material:

$$
\begin{gathered}
-\frac{d C_{S}}{d t}=-k_{1 S}\left(C_{S}-C_{S r}\right), \quad \mathrm{t}=0 \rightarrow \mathrm{C}_{\mathrm{s}}=\mathrm{C}_{\mathrm{S} 0} \\
-\frac{d C_{A V T}}{d t}=k_{1 A V T}\left(C_{S}-C_{S r}\right)-k_{2 A V T}\left(C_{A V T}-C_{A V T r}\right), \quad \mathrm{t}=0 \rightarrow \mathrm{C}_{\mathrm{AVT}}=\mathrm{C}_{\mathrm{AVTr}} \\
\frac{d C_{M}}{d t}=k_{2 M}\left(C_{A V T}-C_{A V T}\right), \quad \mathrm{t}=0 \rightarrow \mathrm{C}_{\mathrm{M}}=0
\end{gathered}
$$


Integrando as equações 3.14 a 3.16 levam às equações 3.17 a 3.19.

$$
\begin{gathered}
\left(C_{S}-C_{S r}\right)=\left(C_{S 0}-C_{S r}\right) \exp \left(-k_{1 S} t\right) \\
\left(C_{A V T}-C_{A V T r}\right)=\left(C_{A V T 0}-C_{A V T r}\right) \exp \left(-k_{2 A V T} t\right)+\left(C_{S 0}-C_{S r}\right) k_{1 A V T}\left[\frac{\exp \left(-k_{1 A V T} t\right)}{\left(k_{2 A V T}-k_{1 A V T}\right)}+\frac{\exp \left(-k_{2 A V T} t\right)}{\left(k_{1 A V T}-k_{2 A V T}\right)}\right] \\
C_{M}=\left(C_{A V T 0}-C_{A V T r}\right)\left[1-\exp \left(-k_{2 M} t\right)\right]+\left(C_{S 0}-C_{S r}\right)\left[1+\frac{k_{2 M} \exp \left(-k_{1 M} t\right)}{\left(k_{1 M}-k_{2 M}\right)}+\frac{k_{1 M} \exp \left(-k_{2 M} t\right)}{\left(k_{2 M}-k_{1 M}\right)}\right]
\end{gathered}
$$

Os parâmetros foram obtidos por ajuste não linear usando o método LevenbergMarquardt pelo software Microcal Origin 6.1®, onde os subscritos S, AVT e M indicam a equação usada para estimar o parâmetro, desta forma $\mathrm{k}_{1 \mathrm{~S}}, \mathrm{k}_{1 \mathrm{AVT}}$ e $\mathrm{k}_{1 \mathrm{M}}$ são os valores do parâmetro $\mathrm{k}_{1}$ estimado pelas equações 3.17, 3.18 e 3.19,respectivamente. O mesmo ocorre para o parâmetro $\mathrm{k}_{2}$.

Todos os parâmetros cinéticos estimados são aparentes por incluírem em seus valores influência de velocidades cinéticas e de transferência de massa. Além disso, o modelo cinético é uma simplificação de todo um complexo sistema metabólico.

Os valores de concentrações iniciais de matéria orgânica na forma de DQO utilizados para o ajuste das equações 3.17, 3.18 e 3.19 foram obtidos através da média dos valores iniciais experimentais coletados no tempo zero dos dois perfis realizados em cada condição operacional. Já os valores de concentrações residuais de matéria orgânica foram obtidos através dos valores médios de monitoramento, em cada condição no decorrer dos ensaios.

As concentrações iniciais de ácidos voláteis totais utilizadas nas equações $3.18 \mathrm{e}$ 3.19 foram obtidas pelo mesmo procedimento que o utilizado para as concentrações de matéria orgânica de amostras filtradas. Em contrapartida os valores de concentração residual de ácidos voláteis totais foram obtidos através da média dos dois últimos valores de concentração de ácidos voláteis totais dos dois perfis de cada condição. Tal decisão foi tomada em função de os valores médios serem baixos e pequenas diferenças provocarem alterações significativas nos resultados dos ajustes da equação 3.18 aos valores experimentais.

A dedução completa deste modelo encontra-se no APÊNDICE A. 


\section{RESULTADOS E DISCUSSÃO}

Neste capítulo, inicialmente são apresentados os valores médios das variáveis de monitoramento em conjunto com as Figuras dos perfis experimentais obtidos no decorrer dos sete ensaios nas treze condições operacionais. Em seguida é feita uma análise comparativa estudando a influência do tipo de impelidor e velocidade rotacional sobre a eficiência e estabilidade dos sistemas praticados neste estudo.

\subsection{Apresentação dos dados experimentais}

\subsubsection{Impelidor tipo turbina de seis pás planas verticais}

Este ensaio foi realizado utilizando-se impelidor tipo turbina com seis pás planas verticais, em rotação de $50 \mathrm{rpm}$ passando a ser identificado como Tu50. O volume alimentado de $2 l$ e operando em ciclos de 8 horas. Este ensaio teve duração de 21 dias, sendo os valores médios das variáveis monitoradas apresentados na Tabela 4.1, e da Figura 4.1 à Figura 4.3. Os valores das variáveis monitoradas do afluente e do efluente são apresentados no APÊNDICE B. 
Tabela 4.1. Valores médios das variáveis monitoradas durante o ensaio Tu50.

\begin{tabular}{ccc}
\hline Parâmetro & Afluente & Efluente \\
\hline Duração ciclos (dias) & - & $63(21)$ \\
$\mathrm{C}_{\mathrm{ST}}\left(\mathrm{mgDQO} . l^{-1}\right)$ & $800 \pm 86(11)$ & $125 \pm 11(12)$ \\
$\mathrm{E}_{\mathrm{T}}(\%)$ & - & $84 \pm 1(12)$ \\
$\mathrm{C}_{\mathrm{SS}}\left(\mathrm{mgDQO} . l^{-1}\right)$ & - & $102 \pm 9(13)$ \\
$\mathrm{E}_{\mathrm{SS}}(\%)$ & - & $87 \pm 1(13)$ \\
$\mathrm{AVT}\left(\mathrm{mgHAc} . l^{-1}\right)$ & $44 \pm 6(10)$ & $20 \pm 3(12)$ \\
$\mathrm{AB}\left(\mathrm{mgCaCO} \cdot . l^{-1}\right)$ & $213 \pm 11(10)$ & $389 \pm 24(12)$ \\
$\mathrm{pH}$ & $8,9 \pm 0,2(10)$ & $6,72 \pm 0,09(12)$ \\
$\mathrm{ST}\left(\mathrm{mg} . l^{-1}\right)$ & $1424 \pm 270(5)$ & $908 \pm 129(5)$ \\
$\mathrm{SVT}\left(\mathrm{mg} . l^{-1}\right)$ & $782 \pm 79(5)$ & $258 \pm 41(5)$ \\
$\mathrm{SST}\left(\mathrm{mg} . l^{-1}\right)$ & $67 \pm 44(5)$ & $62 \pm 26(5)$ \\
$\mathrm{SSV}\left(\mathrm{mg} . l^{-1}\right)$ & $63 \pm 44(5)$ & $53 \pm 30(5)$ \\
\hline
\end{tabular}

* Os valores entre parênteses representam o número de amostras

O ensaio foi precedido por um intervalo de cinco dias de partida do reator, neste período a biomassa foi alimentada com afluente em concentração de $500 \mathrm{mgDQO} . \mathrm{l}^{-1}$ para aclimatação da biomassa. Precaução tomada devido ao tempo de armazenamento da biomassa que já contava alguns meses. Após este período aumentou-se a concentração do afluente para $800 \mathrm{mgDQO} . \mathrm{l}^{-1}$. 


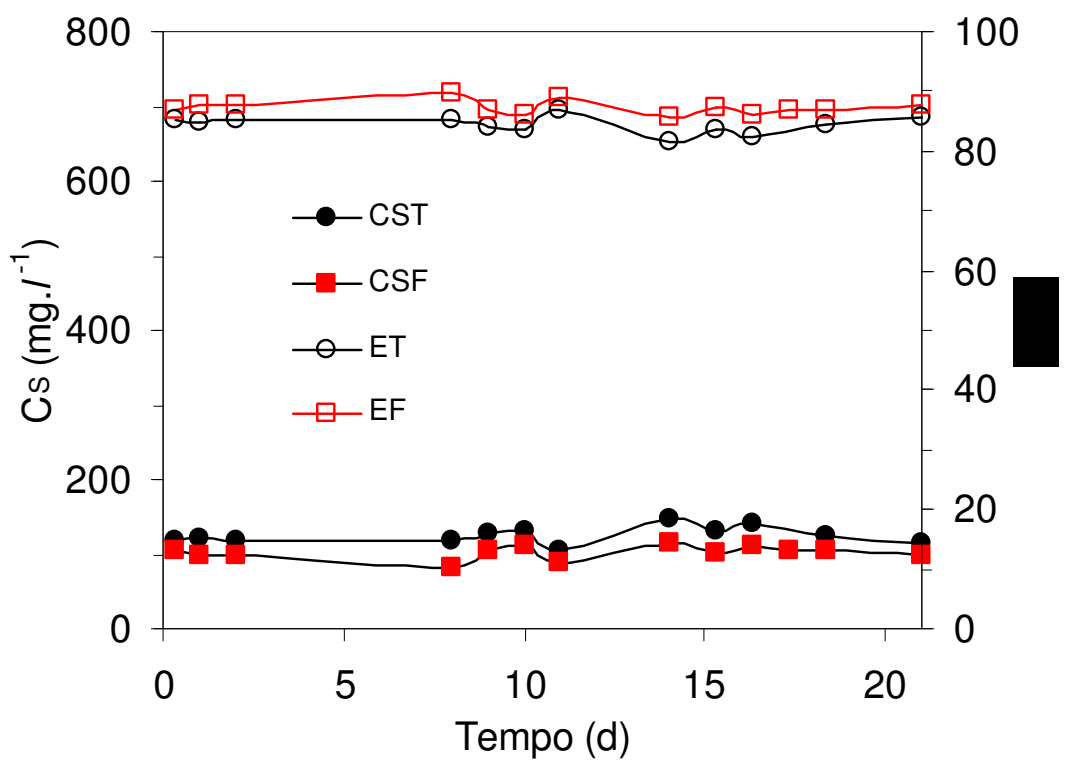

Figura 4.1. Concentração de matéria orgânica efluente e eficiência de remoção na condição Tu50.

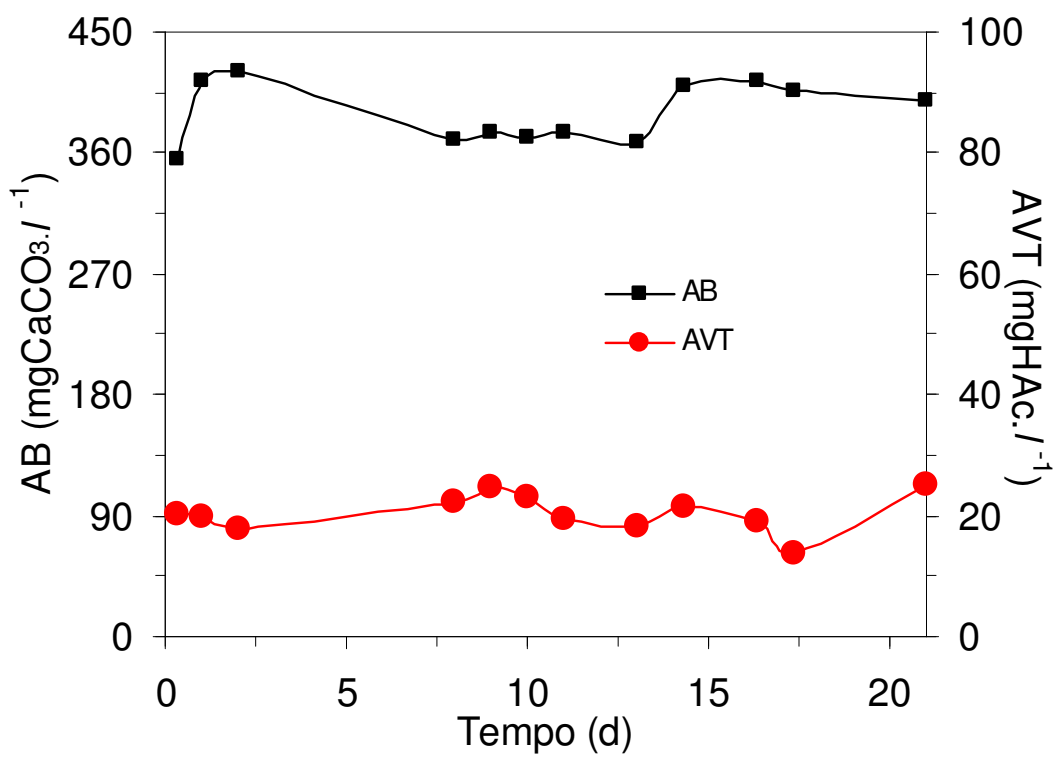

Figura 4.2. Alcalinidade a bicarbonato e ácidos voláteis totais na condição Tu50. 


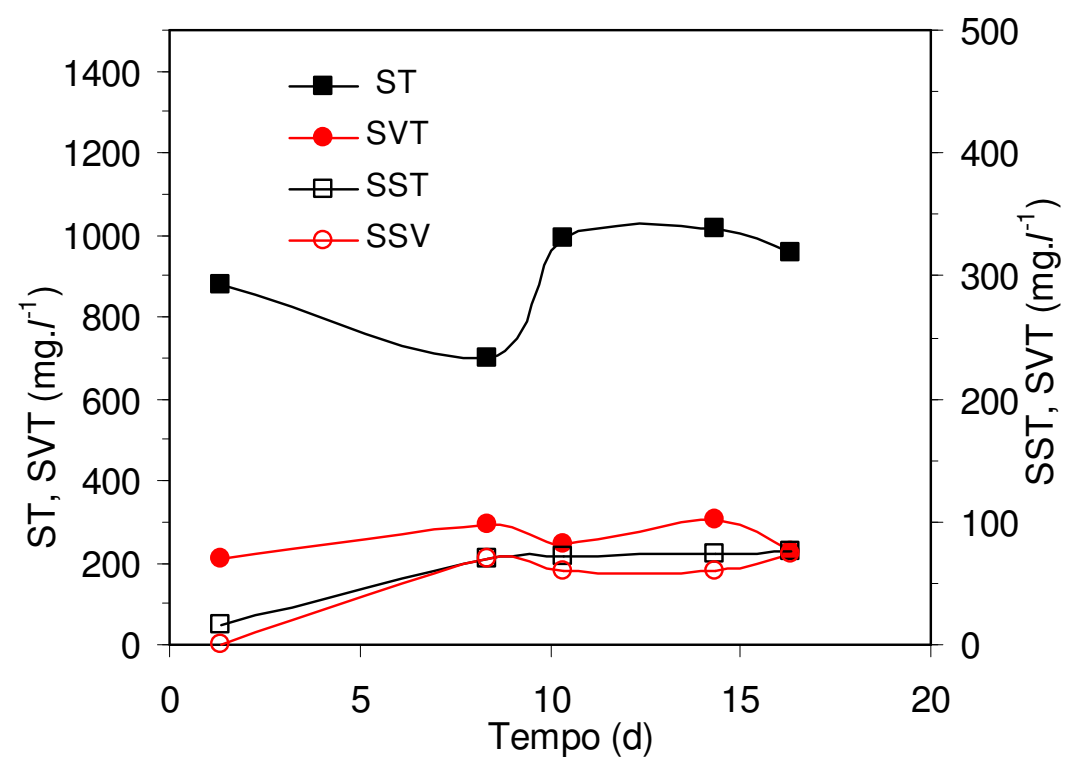

Figura 4.3. Sólidos totais (ST), sólidos voláteis totais (SVT), sólidos suspensos totais (SST) e sólidos suspensos voláteis (SSV) na condição Tu50.

O período de coleta de amostras para a elaboração da Tabela 4.1 corresponde a todo o período de ensaio, pois pelas Figura 4.1 e Figura 4.2 pode ser observado que o sistema apresentou-se estável durante toda a operação nesta condição.

Verificou-se um aumento na alcalinidade a bicarbonato efluente com relação à alcalinidade afluente, $389 \pm 24 \mathrm{mgCaCO}_{3} \cdot l^{-1}$ e $213 \pm 11 \mathrm{mgCaCO}_{3} \cdot l^{-1}$, respectivamente. Estes dados em conjunto com os baixos valores de ácidos voláteis totais no efluente $20 \pm 3$ mgHAc. $l^{-1}$ confirmam a estabilidade do sistema.

Ao final do ensaio foi observado preso às lâminas do impelidor uma camada de um material esbranquiçado e gelatinoso. Este material se encontrava preso em sua parte posterior enquanto que na parte frontal das lâminas nada foi observado. Uma possível explicação para este fato pode estar no atrito provocado pelo contado do meio reacional com as partes frontais do impelidor.

Os perfis das variáveis concentração de matéria orgânica de amostras filtradas, eficiência de remoção de matéria orgânica, alcalinidade na forma de bicarbonato, ácidos voláteis totais na forma ácido acético, volume acumulado, produção, fração molar no "head-space" e concentração de metano realizados no ensaio Tu50 são apresentados da Figura 4.4 à Figura 4.8. e APÊNDICE B. 

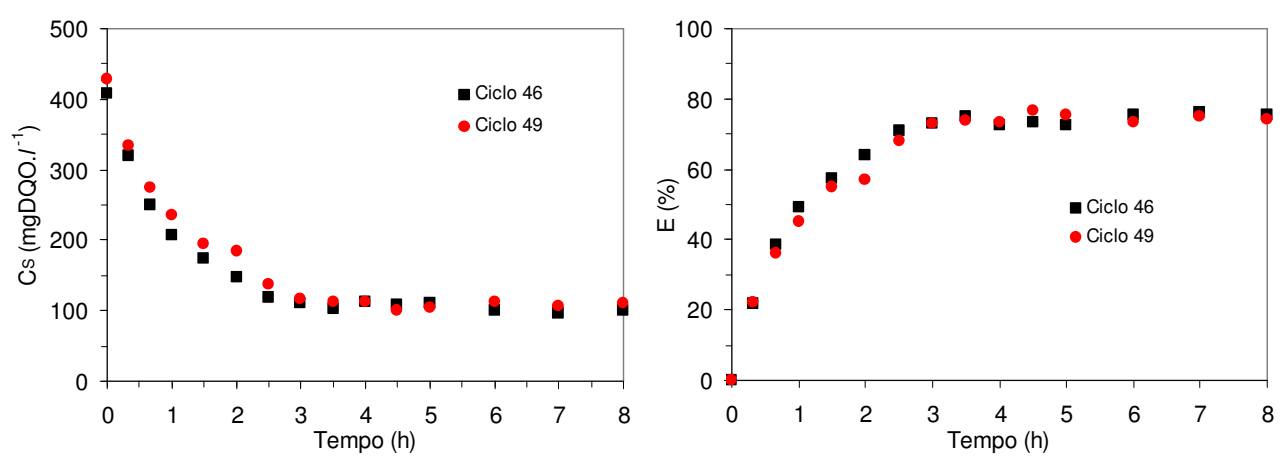

Figura 4.4. Perfis da concentração de matéria orgânica na forma de DQO e da eficiência de conversão ao longo de dois ciclos de operação na condição Tu50.
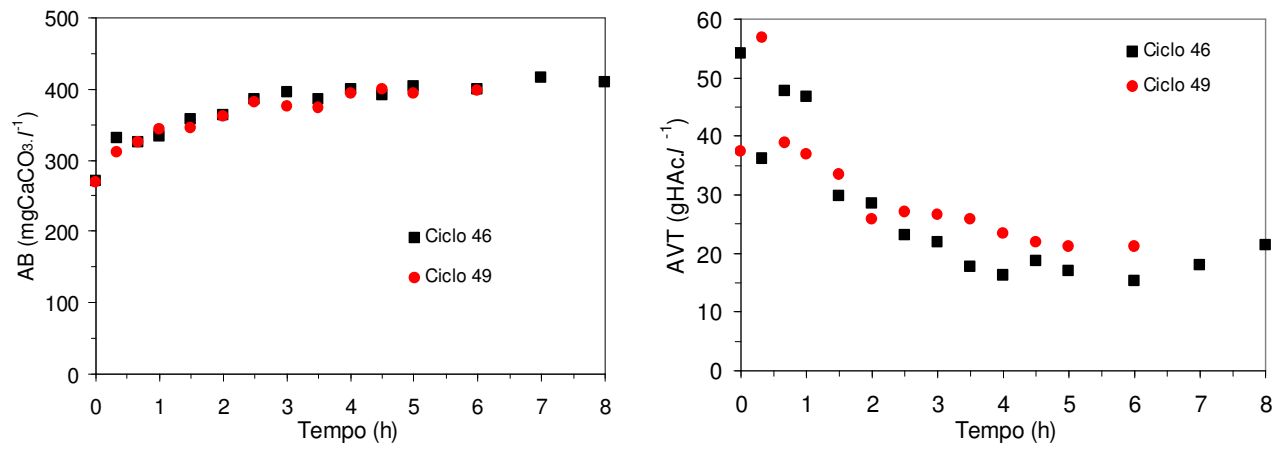

Figura 4.5. Perfis da alcalinidade na forma de bicarbonato de cálcio e da concentração de ácidos voláteis totais na forma de ácido acético ao longo de dois ciclos de operação na condição Tu50.
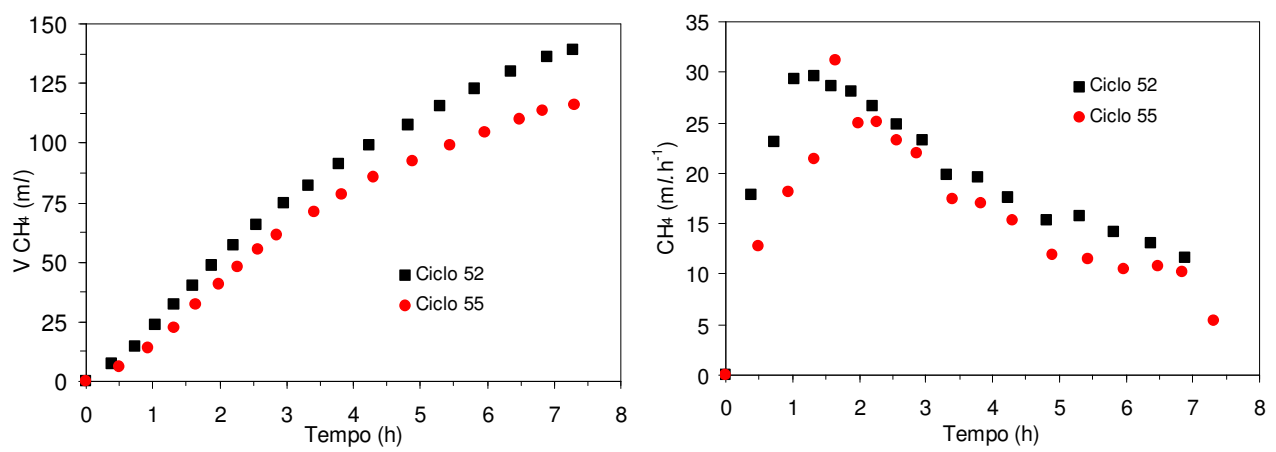

Figura 4.6. Perfis do volume acumulado e da produção de metano no reator ao longo de dois ciclos de operação na condição Tu50. 

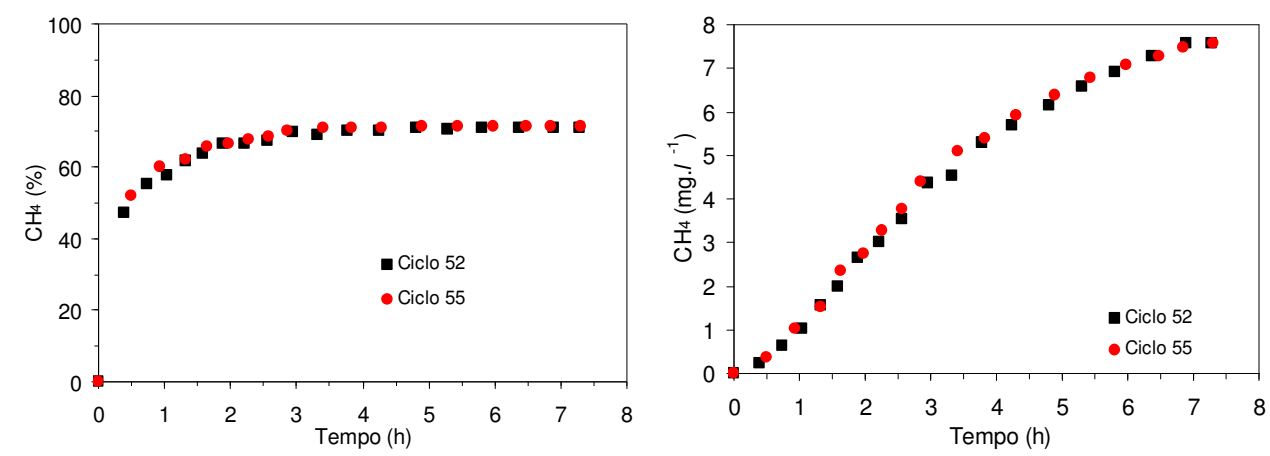

Figura 4.7. Perfis da fração molar e da concentração de metano no "head-space"ao longo de dois ciclos de operação na condição Tu50.

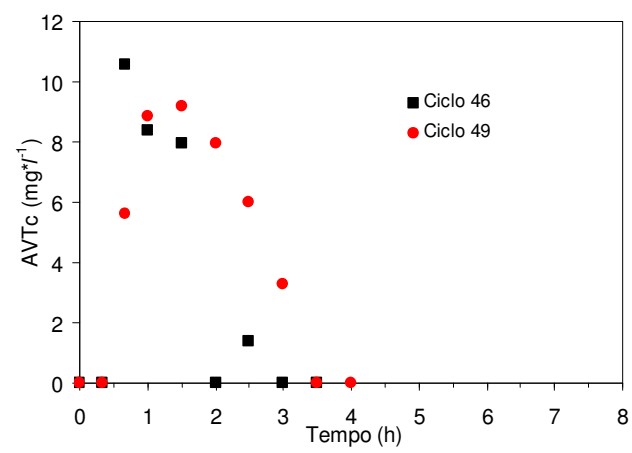

Figura 4.8. Perfis de concentração de ácido propiônico por cromatografia durante dois ciclos de operação na condição de Tu50.

O perfil de concentração de matéria orgânica na forma de DQO mostra que o sistema atinge concentração estável em 3,5 h de operação sendo o valor final próximo a $100 \mathrm{mgDQO} . l^{-1}$ e eficiência de conversão próxima a $74 \%$. Conversão esta calculada com base na concentração inicial, e por isto o valor desta, no final do perfil, é inferior ao calculado durante o monitoramento.

Os perfis de concentração de alcalinidade na forma de bicarbonato e de ácidos voláteis mostram, pela Figura 4.5, os valores destas concentrações também estabilizaram em $3,5 \mathrm{~h}$ de operação, bem como os perfis de ácidos voláteis intermediários pela Figura 4.8. O pico de ácidos voláteis totais ocorreu durante a primeira hora de ciclo e dos ácidos voláteis intermediários ocorreu de $40 \mathrm{~min}$ até $3 \mathrm{~h}$ de ciclo sendo observada somente a presença de ácido propiônico. Os ácidos voláteis presentes no meio aparentaram não influenciar no tamponamento do sistema, pois não houve queda no perfil de alcalinidade e observou-se também um acréscimo neste parâmetro, demonstrando que o próprio sistema contribui para seu tamponamento. 


\subsubsection{Impelidor tipo turbina de seis pás planas inclinadas}

Neste ensaio foi testada a viabilidade de implementação do impelidor tipo turbina de seis pás planas inclinadas $45^{\circ}$ operado em duas velocidades rotacionais sendo a primeira a $50 \mathrm{rpm}$ e a segunda a $75 \mathrm{rpm}$, aqui identificadas como Ti50 e Ti75, respectivamente.

O ensaio teve duração de 28 dias com concentração afluente de $800 \mathrm{mgDQO} \cdot l^{-1}$. $\mathrm{O}$ volume alimentado foi de $2 l$ em três ciclos diários. Na Tabela 4.2 são apresentados os valores médios dos parâmetros monitorados no decorrer do ensaio e da Figura 4.9 à Figura 4.11 é apresentada a variação destes dados ao longo do ensaio, cujos valores numéricos são apresentados no APÊNDICE C.

Tabela 4.2. Valores médios das variáveis monitoradas na operação com impelidor tipo turbina de pás planas inclinadas nas condições de operação Ti50 e Ti75.

\begin{tabular}{cccc}
\hline Parâmetro & Afluente & Ti50 & Ti75 \\
\hline Duração ciclos (dias) & - & $1-42(14)$ & $43-84(14)$ \\
$\mathrm{C}_{\mathrm{ST}}\left(\mathrm{mgDQO} . l^{-1}\right)$ & $796 \pm 53(20)$ & $131 \pm 13(9)$ & $143 \pm 13(9)$ \\
$\mathrm{E}_{\mathrm{T}}(\%)$ & - & $84 \pm 2(9)$ & $82 \pm 2(9)$ \\
$\mathrm{C}_{\mathrm{SS}}\left(\mathrm{mgDQO} . l^{-1}\right)$ & - & $106 \pm 8(9)$ & $113 \pm 7(9)$ \\
$\mathrm{E}_{\mathrm{SS}}(\%)$ & - & $87 \pm 1(9)$ & $86 \pm 1(9)$ \\
$\mathrm{V}(l)$ & - & $2,00 \pm 0,02(8)$ & $2,01 \pm 0,01(5)$ \\
$\mathrm{AVT}\left(\mathrm{mgHAc} . l^{-1}\right)$ & $40 \pm 4(18)$ & $19 \pm 1(9)$ & $19 \pm 2(9)$ \\
$\mathrm{AB}\left(\mathrm{mgCaCO} \cdot . l^{-1}\right)$ & $219 \pm 6(18)$ & $392 \pm 12(9)$ & $385 \pm 14(9)$ \\
$\mathrm{pH}$ & $9,2 \pm 0,2(18)$ & $6,82 \pm 0,05(9)$ & $6,75 \pm 0,06(9)$ \\
$\mathrm{ST}\left(\mathrm{mg} . l^{-1}\right)$ & $1622 \pm 54(8)$ & $1041 \pm 40(4)$ & $1075 \pm 37(4)$ \\
$\mathrm{SVT}\left(\mathrm{mg} . l^{-1}\right)$ & $879 \pm 37(8)$ & $336 \pm 50(4)$ & $334 \pm 38(4)$ \\
$\mathrm{SST}\left(\mathrm{mg} . l^{-1}\right)$ & $46 \pm 12(8)$ & $77 \pm 31(4)$ & $69 \pm 9(4)$ \\
SSV (mg. $\left.l^{-1}\right)$ & $34 \pm 14(8)$ & $61 \pm 12(4)$ & $55 \pm 12(4)$ \\
$\mathrm{ST}$ biomassa $\left(\mathrm{g} . l^{-1}\right)$ & - & 66,5 & 46,0 \\
$\mathrm{SFT}$ biomassa $\left(\mathrm{g} . l^{-1}\right)$ & - & 8,4 & 6,1
\end{tabular}

(*) os valores entre parênteses representam o número de amostras 


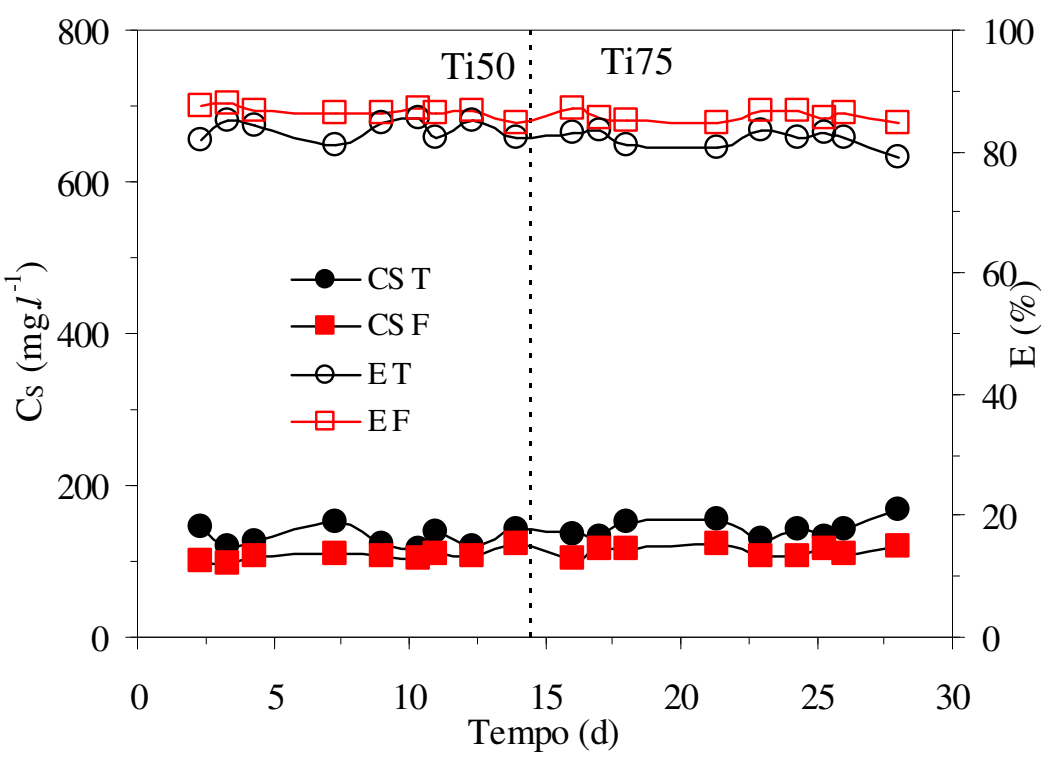

Figura 4.9. Concentração de matéria orgânica efluente e eficiência de remoção utilizando impelidor tipo pá de pás planas inclinadas nas condições Ti50 e Ti75.

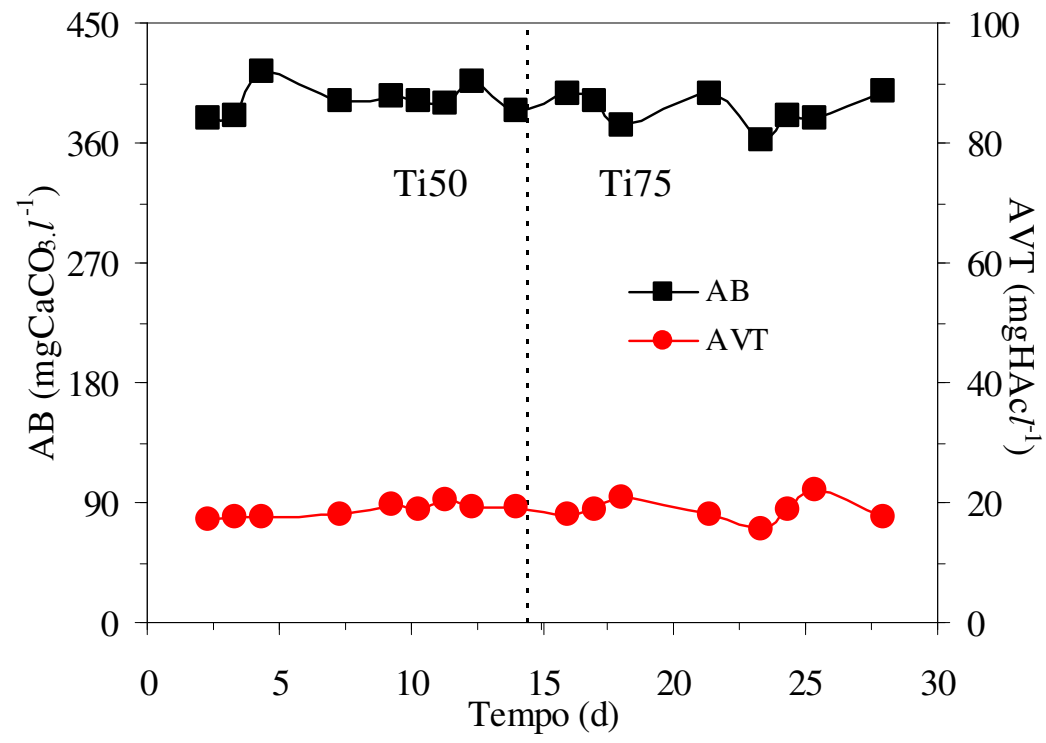

Figura 4.10. Alcalinidade a bicarbonato e Ácidos voláteis totais utilizando impelidor tipo pá de pás planas inclinadas nas condições Ti50 e Ti75. 


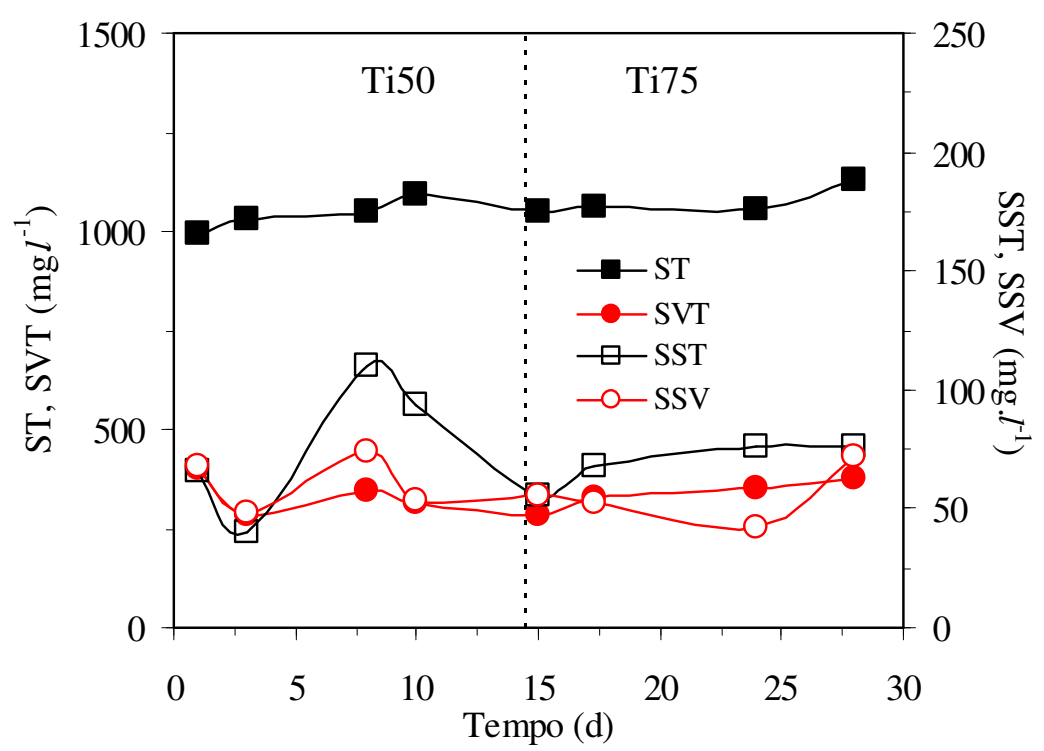

Figura 4.11. Sólidos totais (ST), sólidos voláteis totais (SVT), sólidos suspensos totais (SST) e sólidos suspensos voláteis (SSV), utilizando impelidor tipo pá de pás planas inclinadas nas condições Ti50 e Ti75.

A remoção de matéria orgânica nas duas condições apresentou similaridade, não alterando significativamente entre as condições. Os valores de alcalinidade e de ácidos voláteis confirmam a estabilidade do sistema no qual as concentrações médias de ácidos voláteis no efluente foram iguais a $19 \pm 2 \mathrm{mgHAc} . l^{-1}$ de forma que a intensidade de agitação não influenciou a concentração de ácidos voláteis totais na descarga das condições estudadas.

As eficiências de remoção de sólidos totais e sólidos voláteis totais ficaram próximas a 35 e $62 \%$, respectivamente, em ambas as condições. Já os valores de sólidos suspensos totais e sólidos suspensos voláteis tiveram acréscimo na saída do reator em relação ao afluente, porém não tiveram alterações consideráveis entre condições.

No decorrer das duas condições operacionais foi observado acúmulo de material gelatinoso no interior do reator, e ao final do ensaio o impelidor foi fotografado e apresentado na Figura 4.12. 


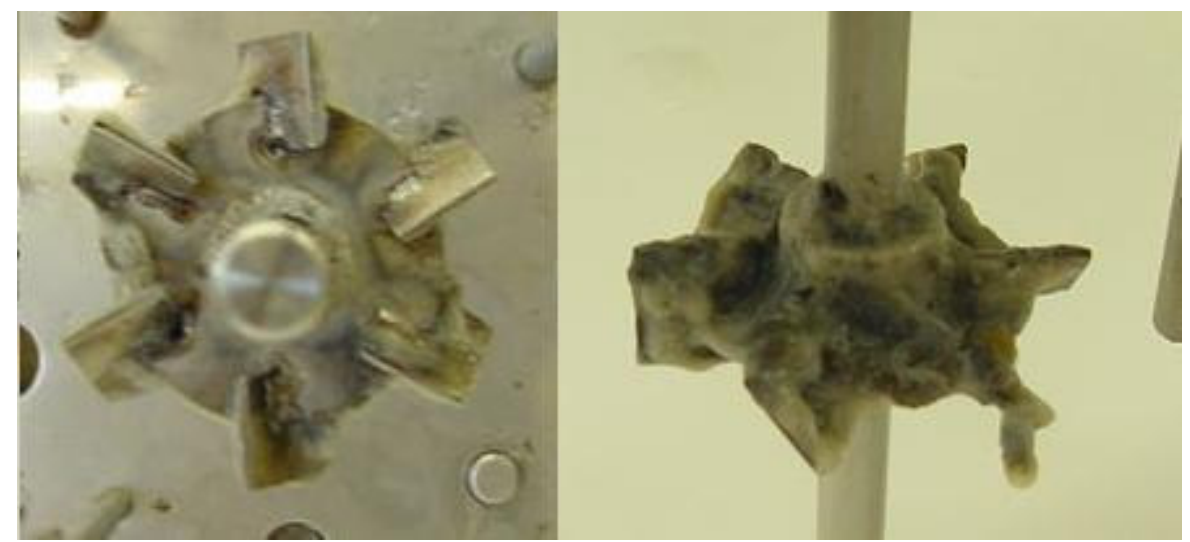

Figura 4.12. Impelidor tipo turbina de seis pás planas inclinadas após a realização do ensaio.

Como pode ser observado o maior acúmulo de material ocorreu na parte superior do impelidor. Podendo ser uma demonstração de movimentação da biomassa sem, contudo, provocar degradação desta, visto que parâmetros como concentração de matéria orgânica efluente e sólidos totais mantiveram-se relativamente estáveis ao longo do ensaio. 


\subsubsection{Condição de operação Ti50}

Os perfis de concentração de matéria orgânica de amostras filtradas, eficiência de remoção de matéria orgânica, alcalinidade na forma de bicarbonato, ácidos voláteis totais na forma ácido acético, volume acumulado, produção, fração molar no "headspace" e concentração de metano na condição Ti50 são apresentados da Figura 4.13 à Figura 4.17 e APÊNDICE C.
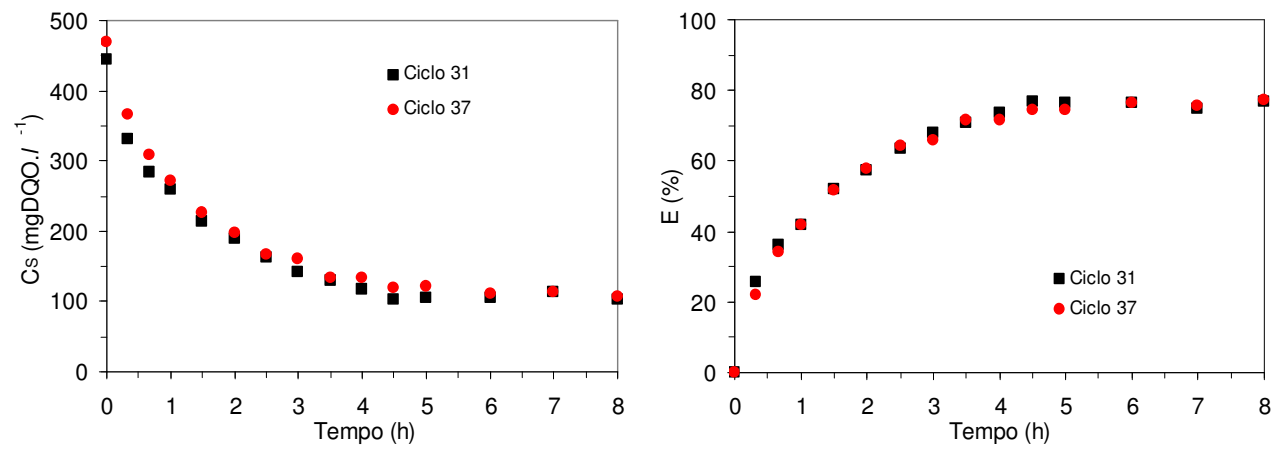

Figura 4.13. Perfis da concentração de matéria orgânica na forma de DQO e da eficiência de conversão ao longo de dois ciclos de operação na condição Ti50.
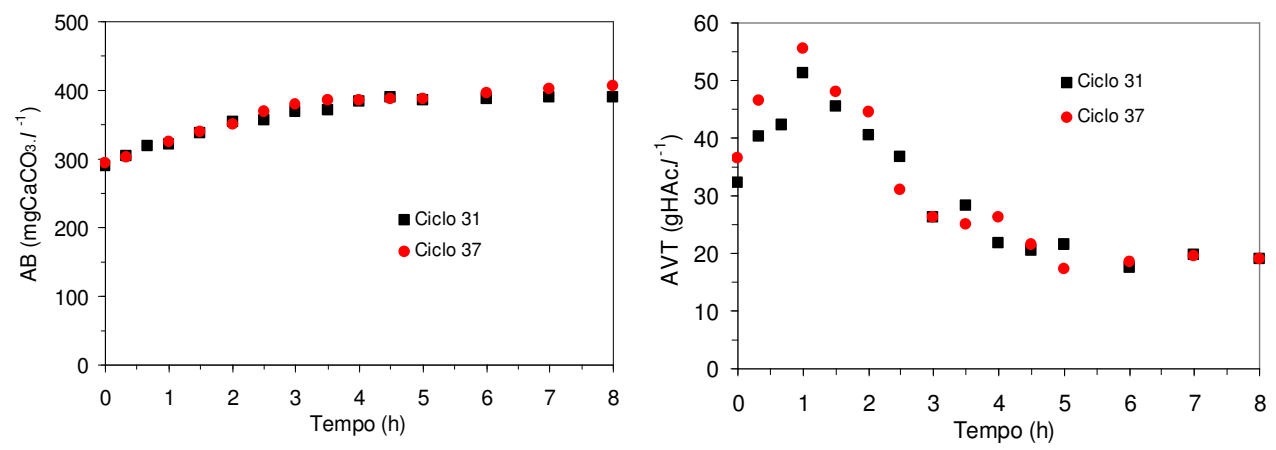

Figura 4.14. Perfis da alcalinidade na forma de bicarbonato de cálcio e da concentração de ácidos voláteis totais na forma de ácido acético ao longo de dois ciclos de operação na condição Ti50. 

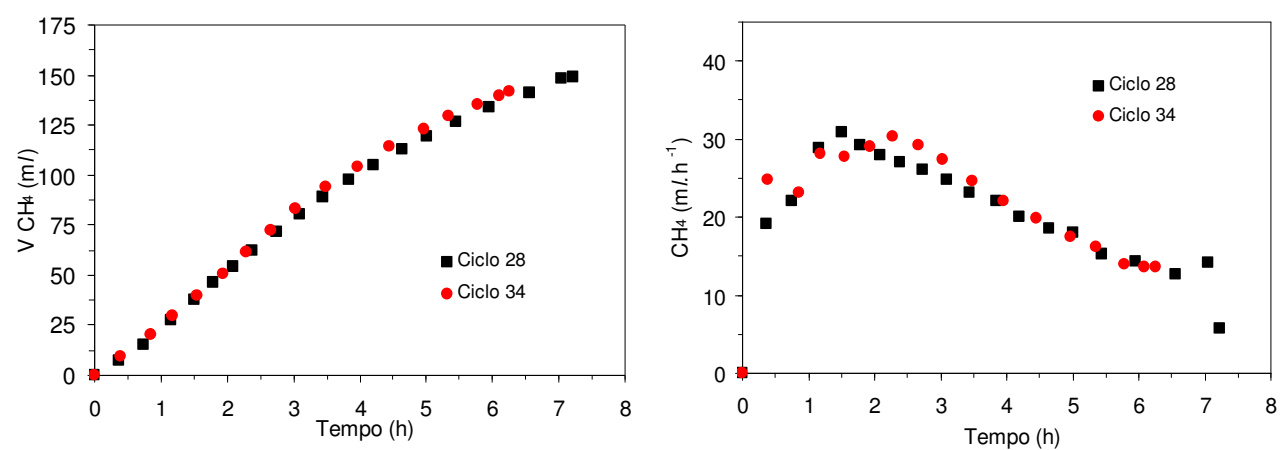

Figura 4.15. Perfis do volume acumulado e da produção de metano no reator ao longo de dois ciclos de operação na condição Ti50.
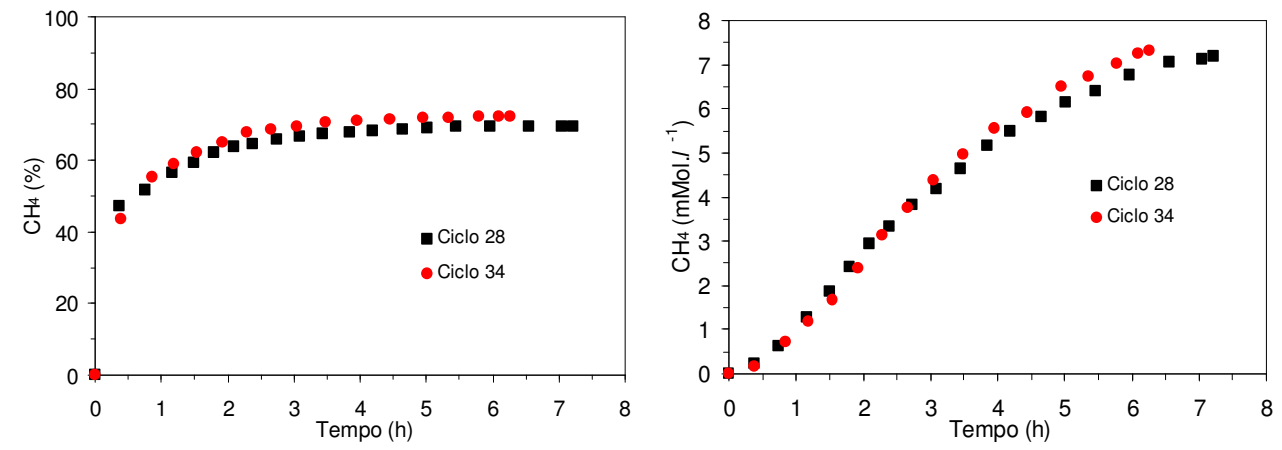

Figura 4.16. Perfis da fração molar e da concentração de metano no "head-space" ao longo de dois ciclos de operação na condição Ti50.

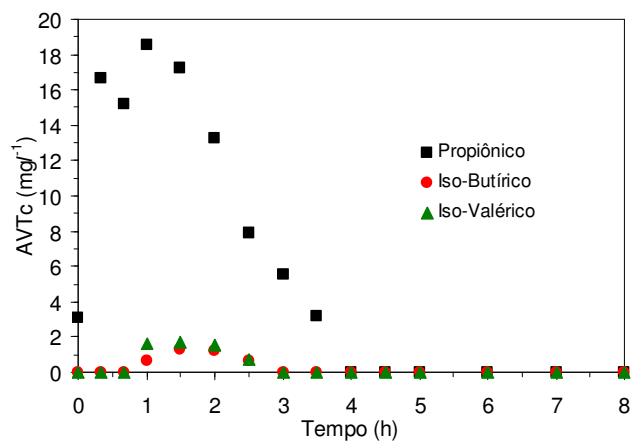

Figura 4.17. Perfis da concentração de ácidos voláteis por cromatografia durante dois ciclos de operação na condição Ti50 (valores médios).

Os perfis de consumo de matéria orgânica na forma de DQO mostram que concentração deste atinge valor de estabilidade com 4,5 h de ciclo sendo a concentração final próxima a $100 \mathrm{mgDQO} \cdot l^{-1}$.

A concentração de ácidos voláteis atingiu pico na primeira hora de perfil com valores superiores a $50 \mathrm{mgHAc} . l^{-1}$ o mesmo ocorre com ácidos voláteis intermediários que registrou a presença de ácido propiônico, iso-butírico e iso-valérico e cujos ácidos foram observados até $3,5 \mathrm{~h}$ de perfil. 
A produção de metano atingiu valores superiores a $120 \mathrm{~m} l$ sendo que a maior produção ocorreu entre 1,5 e 2,5 horas de perfil, como pode ser observado Figura 4.15. A concentração de metano no "head-space" atingiu valores superiores a $7 \mathrm{mMol} . l^{-1}$ correspondendo a $70 \%$ do biogás produzido ao final do ciclo. 


\subsubsection{Condição de operação Ti75}

Os perfis das variáveis concentração de matéria orgânica de amostras filtradas, eficiência de remoção de matéria orgânica, alcalinidade na forma de bicarbonato, ácidos voláteis totais na forma ácido acético, volume acumulado, produção, fração molar no "head-space" e concentração de metano realizados na condição Ti75 são apresentados da Figura 4.18 à Figura 4.22 e APÊNDICE C.
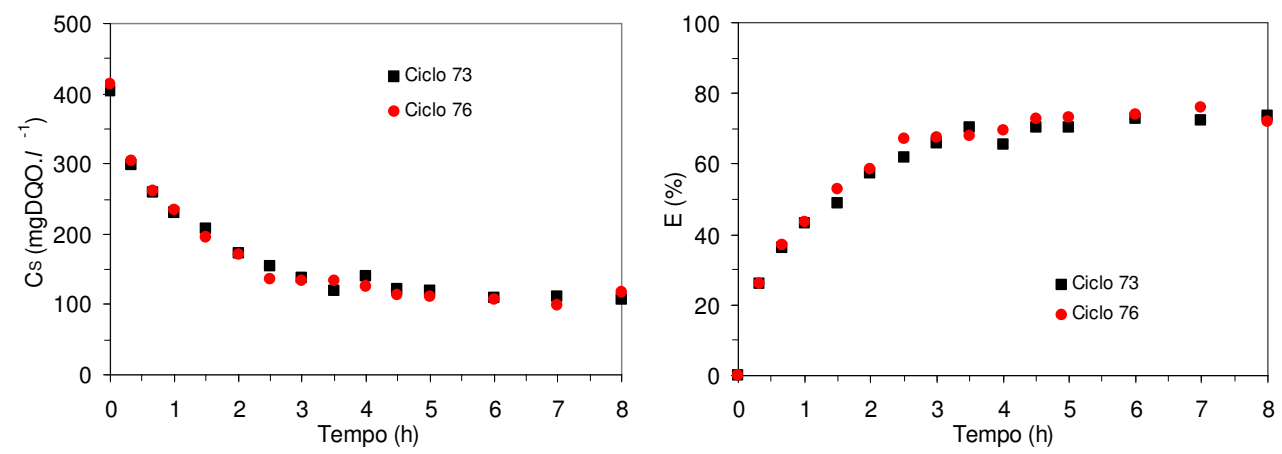

Figura 4.18. Perfis da concentração de matéria orgânica na forma de DQO e da eficiência de conversão ao longo de dois ciclos de operação na condição Ti75.
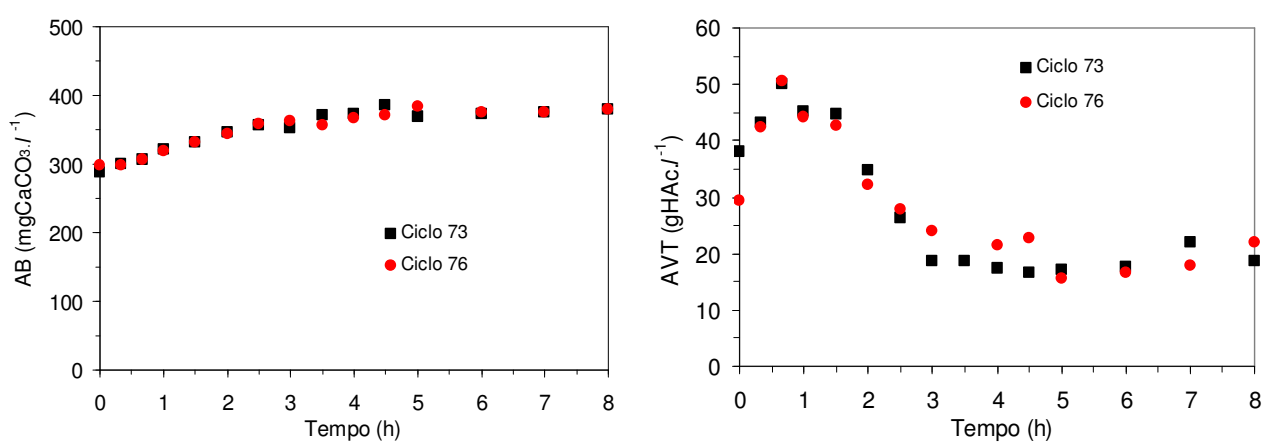

Figura 4.19. Perfis da alcalinidade na forma de bicarbonato de cálcio e da concentração de ácidos voláteis totais na forma de ácido acético ao longo de dois ciclos de operação na condição Ti75. 

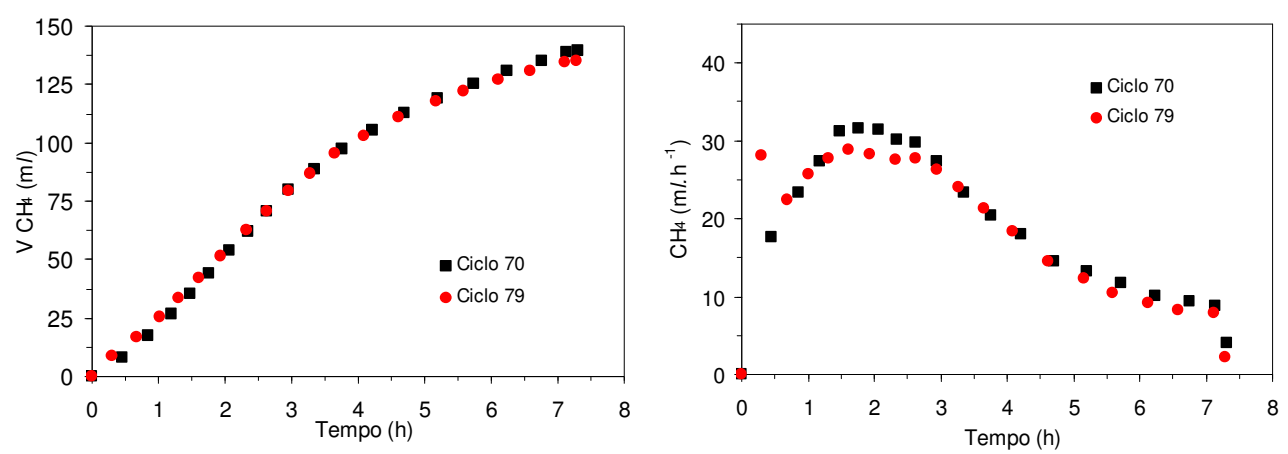

Figura 4.20. Perfis do volume acumulado e da produção de metano no reator ao longo de dois ciclos de operação na condição Ti75.
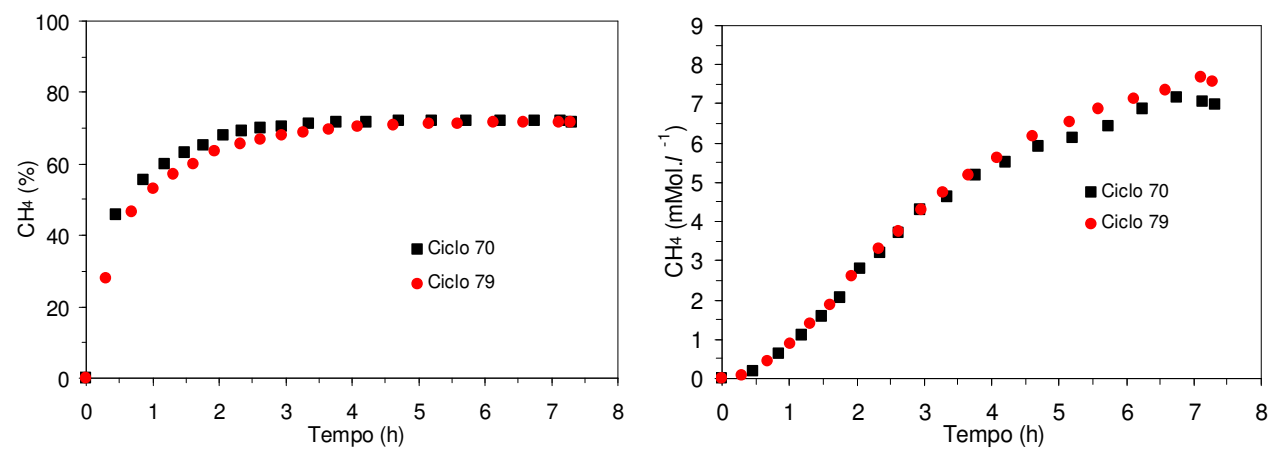

Figura 4.21. Perfis da fração molar e da concentração de metano no "head-space" ao longo de dois ciclos de operação na condição Ti75.

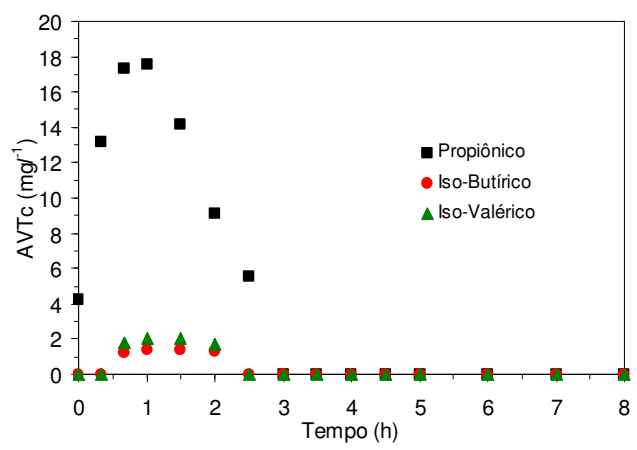

Figura 4.22. Perfis da concentração de ácidos voláteis por cromatografia durante dois ciclos de operação na condição Ti75.

Os perfis de concentração de matéria orgânica e de eficiência de conversão mostram que o equilíbrio é atingido com 4,5 h de ciclo com concentração residual e eficiência próximos a $100 \mathrm{mgDQO} . l^{-1}$ e $70 \%$ de remoção, apresentando resultados similares aos obtidos na condição Ti50.

Os perfis de alcalinidade e de ácidos voláteis totais atingiram estabilidade entre três e quatro horas de ciclo sendo que o pico de ácidos voláteis ocorreu entre vinte 
minutos e uma hora e trinta minutos. Já os perfis de ácidos intermediários mostram que o ácido propiônico foi observado do início do perfil até $2,5 \mathrm{~h}$ de ciclo, enquanto que os ácidos iso-butírico e iso-valérico foram observados entre $40 \mathrm{~min}$ e $2 \mathrm{~h}$ de ciclo.

O volume de metano produzido foi próximo a $140 \mathrm{~m} l$ sendo sua maior produção ocorrida entre a segunda e a terceira horas de ciclo com produção de $30 \mathrm{~m} l \cdot \mathrm{h}^{-1}$. Também entre a segunda e a terceira horas de ciclo houve o maior aumento da concentração de metano no "head-space" do reator, que teve concentração final próxima a $7 \mathrm{mMol} . l^{-1} \mathrm{e}$ respectiva fração molar igual a $70 \%$. 


\subsubsection{Impelidor tipo pá de seis pás planas verticais}

O impelidor tipo pá de pás planas foi testado em duas freqüências rotacionais, sendo elas 50 e 75 rpm, passando assim a serem denominadas condições Pa50 e Pa75. A concentração de matéria orgânica afluente na forma de DQO foi de $800 \mathrm{mg} . l^{-1} \mathrm{em}$ volume de $2 l$ e ciclos de $8 \mathrm{~h}$. Este ensaio teve duração de $30 \mathrm{~d}$. Os valores das variáveis monitoradas durante este ensaio são apresentados na Tabela 4.3 e da Figura 4.23 à Figura 4.25 e no APÊNDICE D.

Tabela 4.3. Valores médios das variáveis monitoradas no ensaio com impelidor tipo pá de pás planas verticais nas condições de operação Pa50 e Pa75.

\begin{tabular}{cccc}
\hline Parâmetro & Afluente & Pa50 & Pa75 \\
\hline Duração ciclos (dias) & - & $1-42(14)$ & $42-90(16)$ \\
$\mathrm{C}_{\mathrm{ST}}\left(\mathrm{mgDQO} . l^{-1}\right)$ & $807 \pm 27(21)$ & $167 \pm 19(9)$ & $185 \pm 8(12)$ \\
$\mathrm{E}_{\mathrm{T}}(\%)$ & - & $79 \pm 2(9)$ & $77 \pm 1(12)$ \\
$\mathrm{C}_{\mathrm{SS}}\left(\mathrm{mgDQO} . l^{-1}\right)$ & - & $144 \pm 17(9)$ & $139 \pm 11(12)$ \\
$\mathrm{E}_{\mathrm{SS}}(\%)$ & - & $82 \pm 2(9)$ & $83 \pm 1(12)$ \\
$\mathrm{V}(l)$ & - & $2,01 \pm 0,01(7)$ & $2,00 \pm 0,01(6)$ \\
$\mathrm{AVT}\left(\mathrm{mgHAc} . l^{-1}\right)$ & $39 \pm 3(17)$ & $22 \pm 5(8)$ & $21 \pm 3(11)$ \\
$\mathrm{AB}\left(\mathrm{mgCaCO} \cdot l^{-1}\right)$ & $223 \pm 7(17)$ & $379 \pm 10(8)$ & $375 \pm 18(11)$ \\
pH & $8,9 \pm 0,1(17)$ & $6,79 \pm 0,03(8)$ & $6,79 \pm 0,05(11)$ \\
$\mathrm{ST}\left(\mathrm{mg} . l^{-1}\right)$ & $1600 \pm 40(8)$ & $1073 \pm 53(4)$ & $1100 \pm 74(4)$ \\
$\mathrm{SVT}\left(\mathrm{mg} . l^{-1}\right)$ & $876 \pm 46(8)$ & $340 \pm 34(4)$ & $344 \pm 15(4)$ \\
SST (mg. $\left.l^{-1}\right)$ & $40 \pm 18(8)$ & $70 \pm 10(4)$ & $67 \pm 17(4)$ \\
SSV (mg. $\left.l^{-1}\right)$ & $32 \pm 19(8)$ & $60 \pm 3(4)$ & $65 \pm 16(4)$ \\
ST biomassa $\left(\mathrm{g} . l^{-1}\right)$ & - & $46,5(1)$ & $59,4(1)$ \\
SFT biomassa $\left(\mathrm{g} . l^{-1}\right)$ & - & $5,5(1)$ & $6,7(1)$ \\
\hline
\end{tabular}

(*) os valores entre parênteses representam o número de amostras 


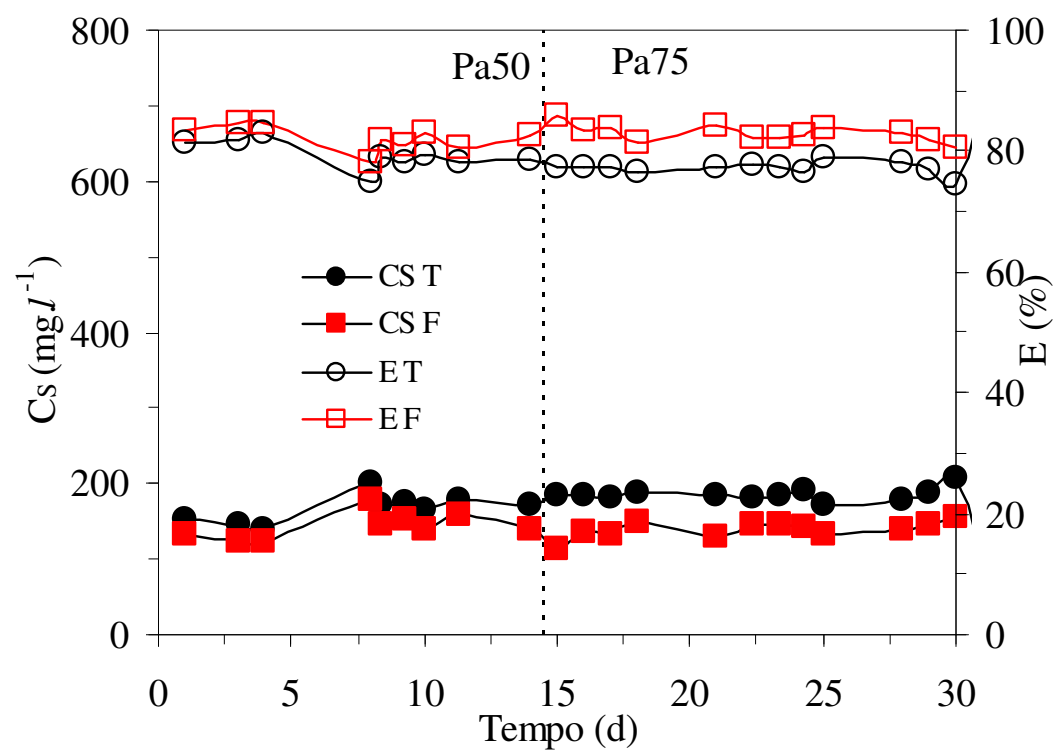

Figura 4.23. Concentração de matéria orgânica efluente e eficiência de remoção utilizando impelidor tipo pá de pás planas inclinadas nas condições Pa50 e Pa75.

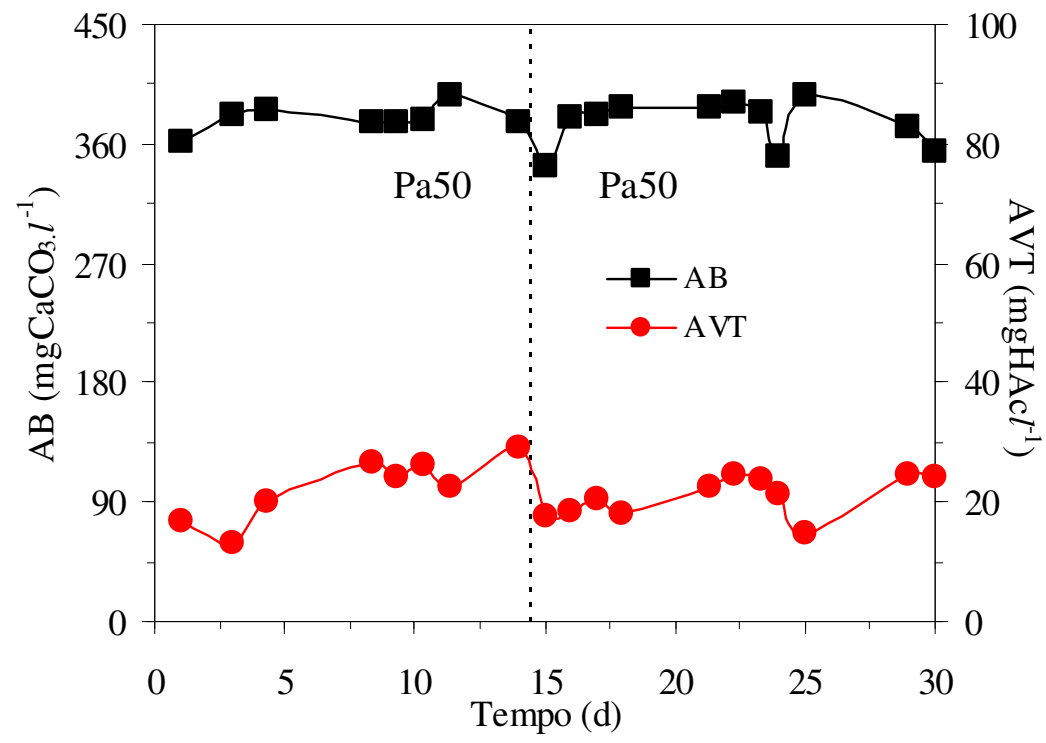

Figura 4.24. Alcalinidade a bicarbonato e Ácidos voláteis totais utilizando impelidor tipo pá de pás planas inclinadas nas condições Pa50 e Pa75. 


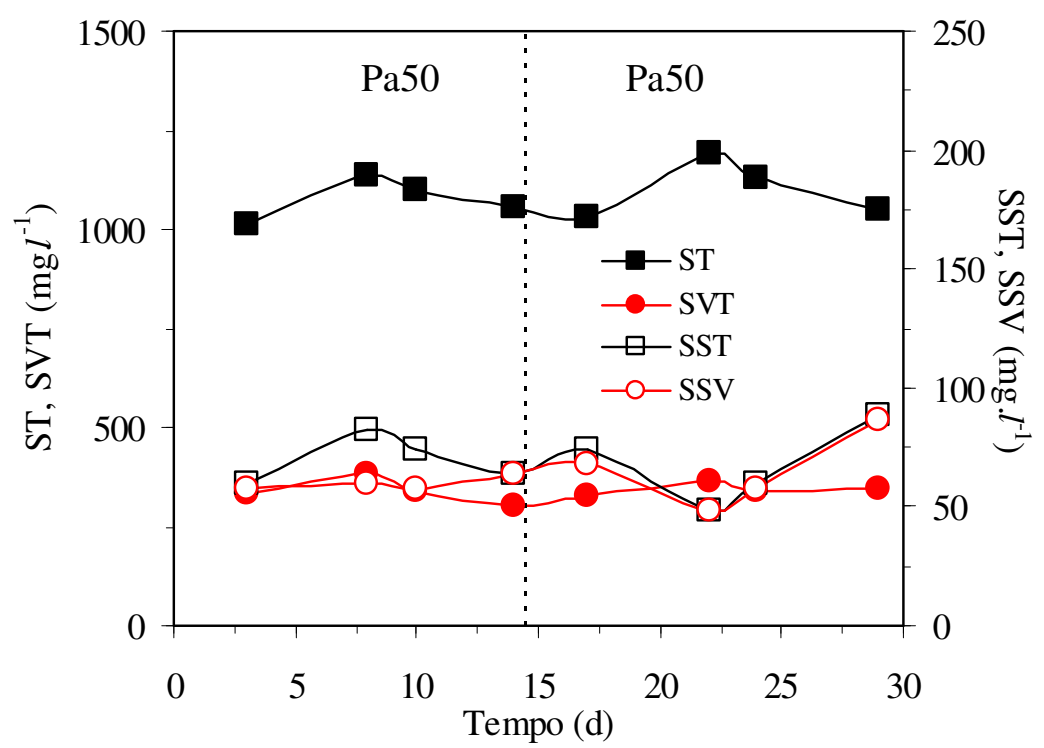

Figura 4.25. Sólidos totais (ST), sólidos voláteis totais (SVT), sólidos suspensos totais (SST) e sólidos suspensos voláteis (SSV), utilizando impelidor tipo pá de pás planas inclinadas nas condições Pa50 e Pa75.

O sistema manteve-se estável durante todo o período de sua realização, com remoção de matéria orgânica em amostras não filtradas inferior a $80 \%$ e concentração efluente de $167 \mathrm{mgDQO} . l^{-1}$ e $180 \mathrm{mgDQO} . l^{-1}$ para as condições Pa50 e Pa75, respectivamente. A diferença entre as eficiências de remoção de matéria orgânica para amostras não filtradas sofreu redução de $2 \%$ da condição Pa50 para a condição Pa75, podendo isto ser consequiência do acúmulo de material esbranquiçado no reator.

Os valores de ácidos voláteis totais e de alcalinidade na forma de bicarbonato mostram que ocorre acréscimo de alcalinidade no efluente em relação ao afluente ao mesmo tempo em que os valores de ácidos voláteis são mantidos em valores relativamente baixos, sempre inferiores a $30 \mathrm{mgHAc} . l^{-1}$ sendo os valores médios de $22 \mathrm{e}$ 21 mgHAc. $l^{-1}$ para as condições Pa50 e Pa75 respectivamente.

Não é observada variação nos parâmetros remoção de sólidos tanto sólidos totais, sólidos voláteis totais, sólidos suspensos totais e sólidos suspensos voláteis entre as duas condições de operação, visto que ambos encontram-se muito próximos. 


\subsubsection{Condição de operação Pa50}

Da Figura 4.26 à Figura 4.30 e APÊNDICE D são apresentados os perfis das variáveis concentração de matéria orgânica de amostras filtradas, eficiência de remoção de matéria orgânica, alcalinidade na forma de bicarbonato, ácidos voláteis totais na forma ácido acético, volume acumulado, produção, fração molar no "head-space" e concentração de metano realizados na condição Pa50.
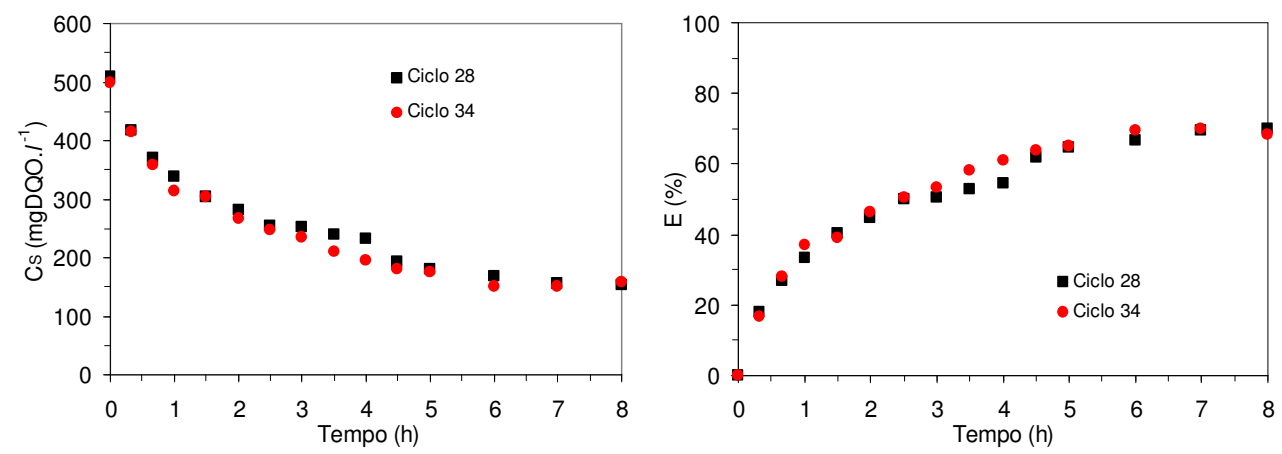

Figura 4.26. Perfis da concentração de matéria orgânica na forma de DQO e da eficiência de conversão ao longo de dois ciclos de operação na condição Pa50.
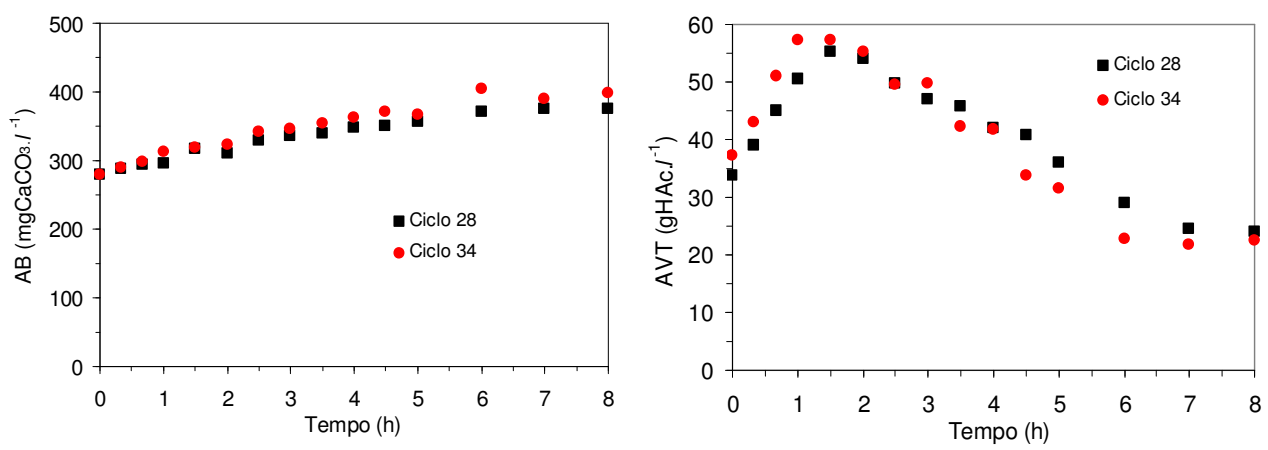

Figura 4.27. Perfis da alcalinidade na forma de bicarbonato de cálcio e da concentração de ácidos voláteis totais na forma de ácido acético ao longo de dois ciclos de operação na condição Pa50. 

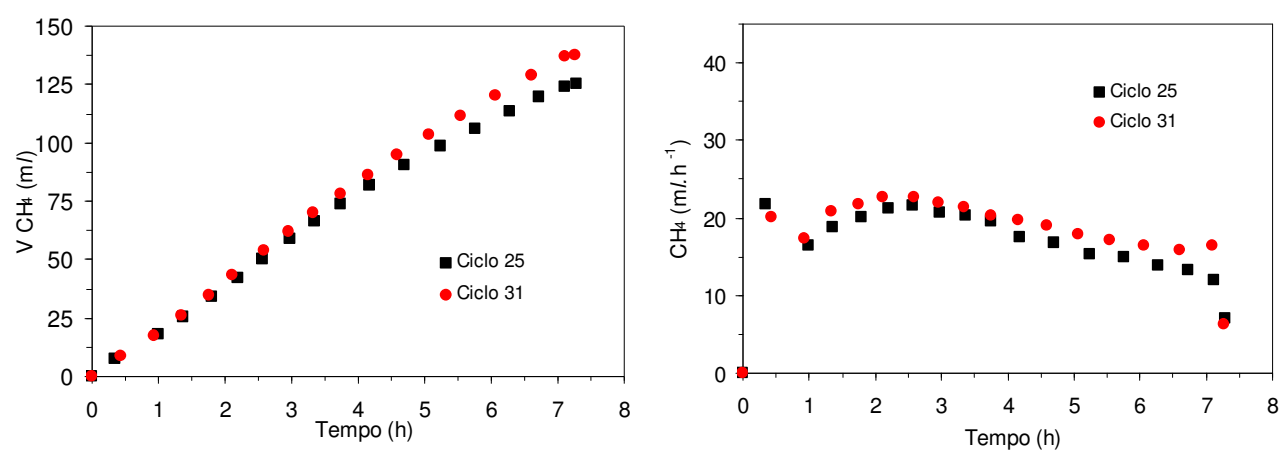

Figura 4.28. Perfis do volume acumulado e da produção de metano no reator ao longo de dois ciclos de operação na condição Pa50.
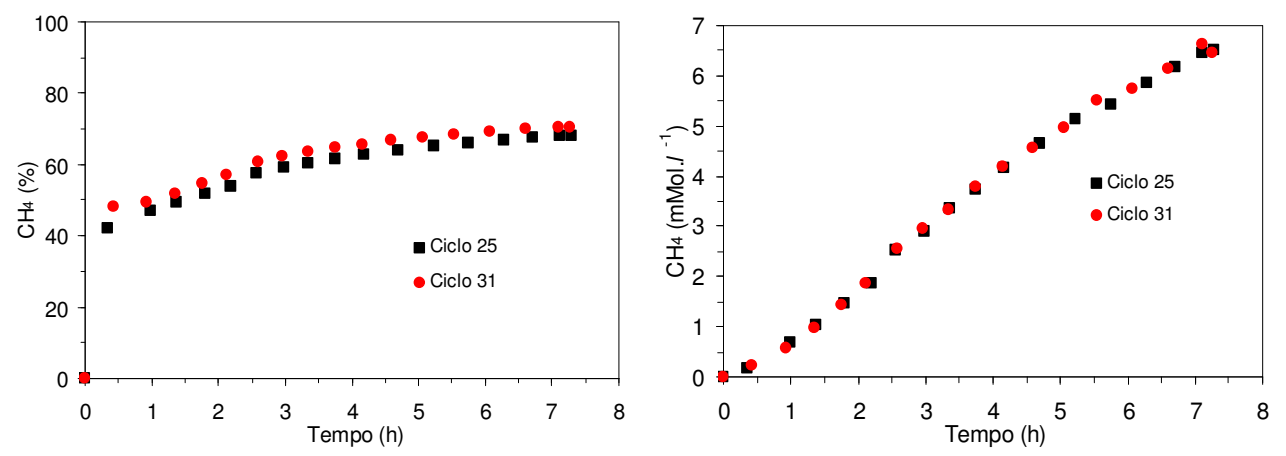

Figura 4.29. Perfis da fração molar e da concentração de metano no "head-space" ao longo de dois ciclos de operação na condição Pa50.

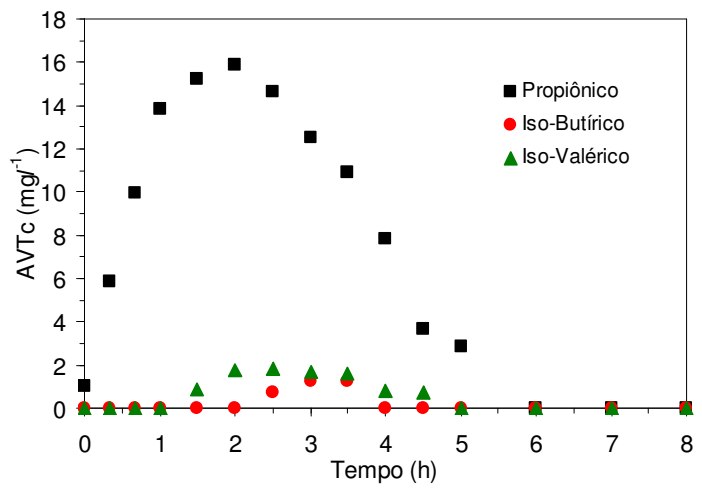

Figura 4.30. Perfis da concentração de ácidos voláteis por cromatografia durante dois ciclos de operação na condição Pa50 (valores médios).

Pode ser observado que o sistema necessita de quase a totalidade do tempo de ciclo para promover a remoção de matéria orgânica. Fato que se repete com as concentrações de ácidos voláteis totais, alcalinidade na forma de bicarbonato e concentração de metano no "head-space" do reator perfis onde a estabilidade foi atingida com sete horas de ciclo. 
A concentração de matéria orgânica no final do ciclo atingiu valor próximo a $150 \mathrm{mgDQO} . l^{-1}$ e remoção de $70 \%$. Enquanto que o pico de ácidos voláteis totais ocorreu entre 1,5 e $2,5 \mathrm{~h}$ de ciclo e a presença de ácidos voláteis intermediários foi observada do início do perfil até a quinta hora de ciclo, onde foi observada a presença de ácido propiônico que apresentou pico de $16 \mathrm{mg} . l^{-1}$ na segunda hora de ciclo e dos ácidos iso-butírico e iso-valérico que não apresentaram concentração superior a $2 \mathrm{mg} \cdot l^{-1}$.

A produção de metano variou entre 15 e $20 \mathrm{~m} l \cdot \mathrm{h}^{-1}$ durante o período reacional, não apresentando um período definido de pico de produção e a concentração de metano ao final dos ciclos ficou próximo a $6,5 \mathrm{mMol} . \mathrm{l}^{-1}$.

O potencial redox do meio reacional foi avaliado ao final da condição Pa75 e apresentou valor de $-283 \mathrm{mV}$, nesta mesma condição foi executada a leitura de oxigênio dissolvido e constatou-se ausência de oxigênio, isto é, concentração zero. 


\subsubsection{Condição de operação Pa75}

Apresenta-se da Figura 4.31 à Figura 4.35 e APÊNDICE D, os perfis das variáveis concentração de matéria orgânica de amostras filtradas, eficiência de remoção de matéria orgânica, alcalinidade na forma de bicarbonato, ácidos voláteis totais na forma ácido acético, volume acumulado, produção, fração molar no "head-space" e concentração de metano realizados na condição Pa75.
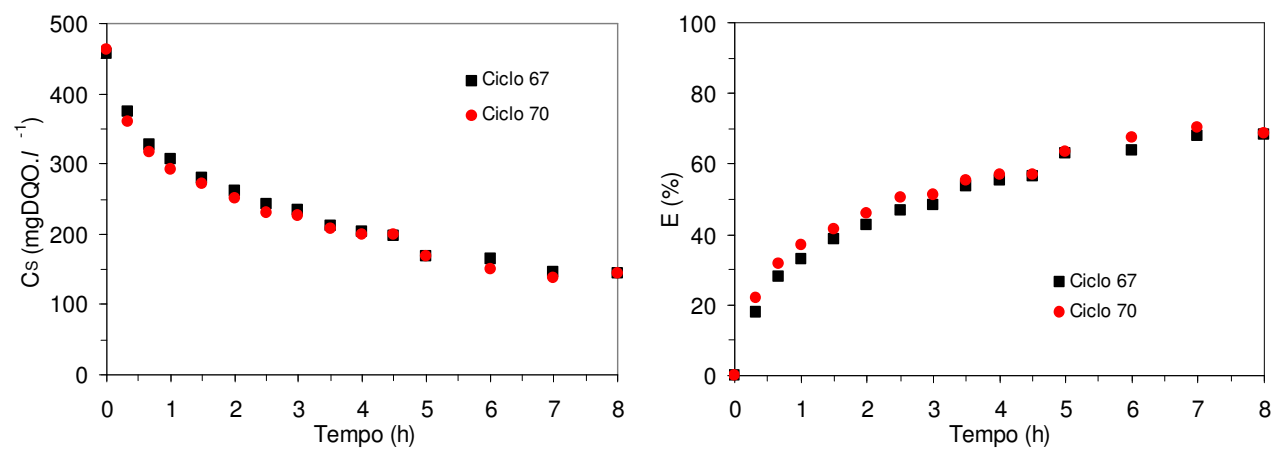

Figura 4.31. Perfis da concentração de matéria orgânica na forma de DQO e da eficiência de conversão ao longo de dois ciclos de operação na condição Pa75.
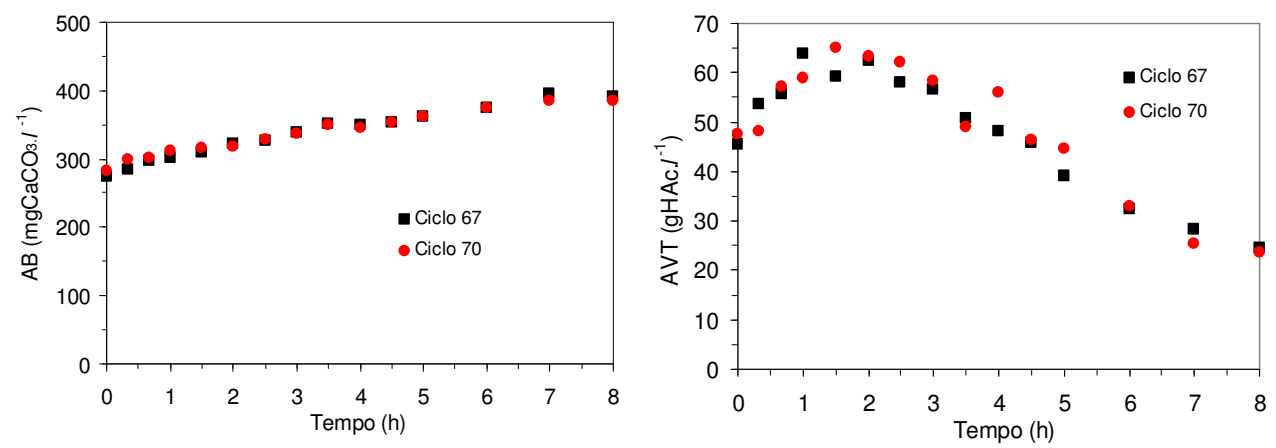

Figura 4.32. Perfis da alcalinidade na forma de bicarbonato de cálcio e da concentração de ácidos voláteis totais na forma de ácido acético ao longo de dois ciclos de operação na condição Pa75. 

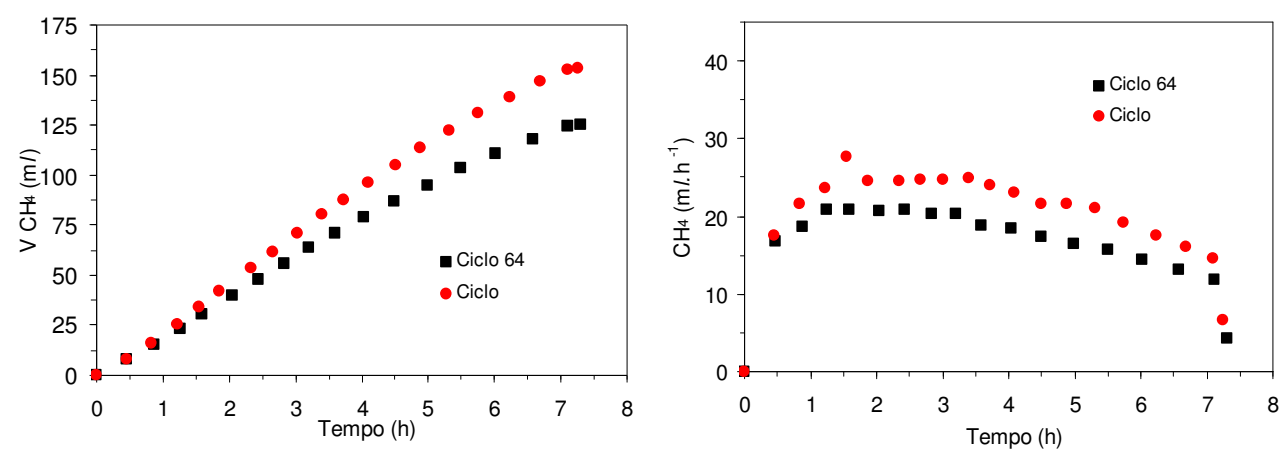

Figura 4.33. Perfis do volume acumulado e da produção de metano no reator ao longo de dois ciclos de operação na condição Pa75.
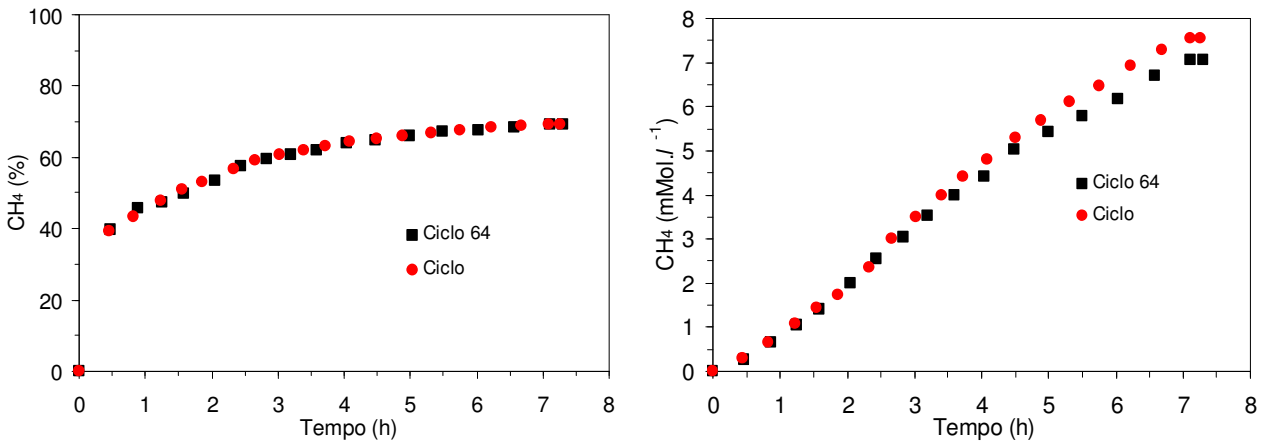

Figura 4.34. Perfis da fração molar e da concentração de metano no "head-space" ao longo de dois ciclos de operação na condição Pa75.

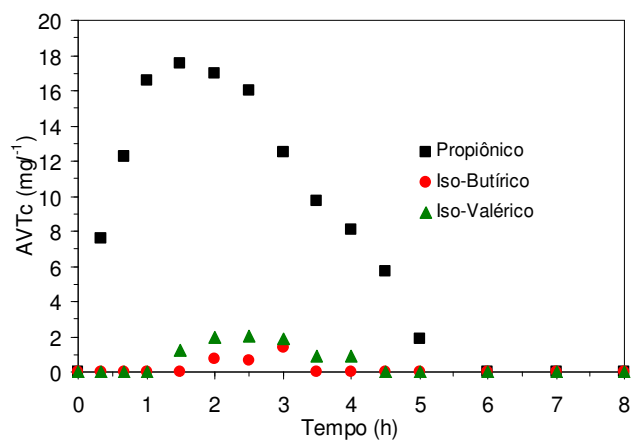

Figura 4.35. Perfis da concentração de ácidos voláteis por cromatografia durante dois ciclos de operação na condição Pa75 (valores médios).

Similar ao ocorrido na condição Pa50 nesta condição Pa75 foi necessário quase todo o tempo de ciclo para promover a degradação da matéria orgânica, que chegou a um valor de equilíbrio entre a sexta e a sétima hora de ciclo.

O consumo dos ácidos voláteis totais apresentou pico de longa duração e com valores superiores a $60 \mathrm{mgHAc} . l^{-1}$ demonstrando que esta configuração aparentou não ser capaz de promover a conversão dos ácidos voláteis a metano tão eficiente quanto o 
observado na condição Tu50, entretanto este acúmulo não chegou a influenciar o perfil de aumento da alcalinidade a bicarbonato.

Os perfis do volume acumulado e produção de metano mostram que a produção variou pouco ao longo do ciclo de operação e que o volume acumulado no final deste chegou a $125 \mathrm{~m} l$. A fração molar de metano no "head-space" atingiu valor de $70 \%$ ao final do ciclo sendo a concentração ao final do ciclo superior a $7 \mathrm{mMol} . l^{-1}$. 


\subsubsection{Impelidor tipo pá de seis pás planas inclinadas}

Neste ensaio foi testada a viabilidade de implementação de um impelidor tipo pá de pás planas inclinadas $45^{\circ}$ em sistema tratando esgoto sintético de concentração de matéria orgânica na forma de DQO próxima a $800 \mathrm{mgDQO} . l^{-1}$ sendo alimentados ao reator um volume de $2 l$ em ciclos de $8 \mathrm{~h}$. Foram utilizadas duas velocidades de rotação, de $50 \mathrm{rpm}$ e $75 \mathrm{rpm}$, que passam a ser identificadas por Pi50 e Pi75, respectivamente.

Este ensaio teve duração de 28 dias e os valores médios das variáveis monitoradas durante este ensaio são apresentados na Tabela 4.4 e da Figura 4.36 à Figura 4.38 além de os valores numéricos estarem relacionados no APÊNDICE E.

Tabela 4.4. Valores médios das variáveis monitoradas na operação com impelidor tipo pá de pás planas inclinadas nas condições de operação Pi50 e Pi75.

\begin{tabular}{cccc}
\hline Parâmetro & Afluente & Pi50 & Pi75 \\
\hline Duração ciclos (dias) & - & $42(14)$ & $42(14)$ \\
$\mathrm{C}_{\mathrm{ST}}\left(\mathrm{mgDQO} . l^{-1}\right)$ & $758 \pm 25(19)$ & $141 \pm 16(10)$ & $129 \pm 13(10)$ \\
$\mathrm{E}_{\mathrm{T}}(\%)$ & - & $81 \pm 2(10)$ & $83 \pm 2(10)$ \\
$\mathrm{C}_{\mathrm{SS}}\left(\mathrm{mgDQO} . l^{-1}\right)$ & - & $101 \pm 7(10)$ & $100 \pm 11(10)$ \\
$\mathrm{E}_{\mathrm{SS}}(\%)$ & - & $87 \pm 1(10)$ & $87 \pm 1(10)$ \\
$\mathrm{V}(l)$ & - & $2,00 \pm 0,01(6)$ & $2,00 \pm 0,02(7)$ \\
$\mathrm{AVT}\left(\mathrm{mgHAc} . l^{-1}\right)$ & $38 \pm 8(20)$ & $17 \pm 2(10)$ & $17 \pm 2(9)$ \\
$\mathrm{AB}\left(\mathrm{mgCaCO} \cdot l^{-1}\right)$ & $225 \pm 23(20)$ & $397 \pm 14(10)$ & $395 \pm 6(9)$ \\
$\mathrm{pH}$ & $8,7 \pm 0,2(20)$ & $6,77 \pm 0,05(10)$ & $6,77 \pm 0,04(9)$ \\
$\mathrm{ST}\left(\mathrm{mg} . l^{-1}\right)$ & $1596 \pm 68(8)$ & $1036 \pm 55(4)$ & $1113 \pm 61(4)$ \\
$\mathrm{SVT}\left(\mathrm{mg} . l^{-1}\right)$ & $847 \pm 26(8)$ & $327 \pm 27(4)$ & $356 \pm 63(4)$ \\
$\mathrm{SST}\left(\mathrm{mg} . l^{-1}\right)$ & $44 \pm 11(8)$ & $67 \pm 15(4)$ & $81 \pm 24(4)$ \\
$\mathrm{SSV}\left(\mathrm{mg} . l^{-1}\right)$ & $35 \pm 10(8)$ & $66 \pm 15(4)$ & $60 \pm 13(4)$ \\
$\mathrm{ST}$ biomassa $\left(\mathrm{g} . l^{-1}\right)$ & - & $57,5(1)$ & $61,6(1)$ \\
SFT biomassa $\left(\mathrm{g} . l^{-1}\right)$ & - & $8,0(1)$ & $7,1(1)$ \\
\hline
\end{tabular}

* Os valores entre parênteses representam o número de amostras 


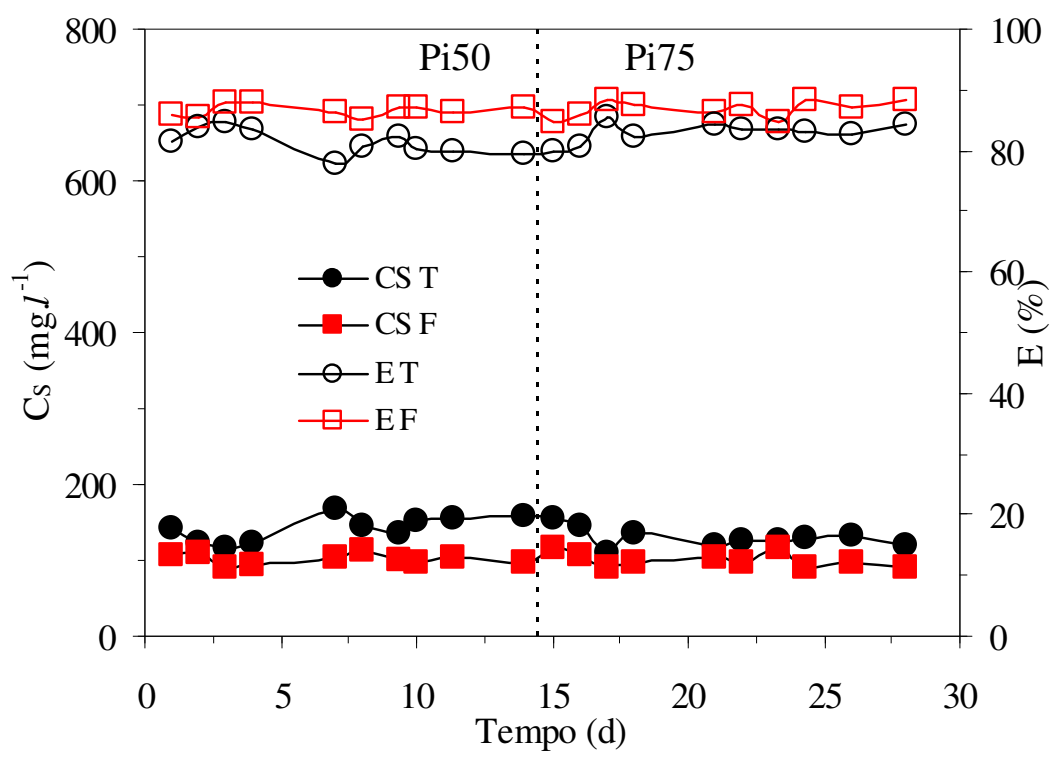

Figura 4.36. Concentração de matéria orgânica efluente e eficiência de remoção utilizando impelidor tipo pá de pás planas inclinadas nas condições Pi50 e Pi75.

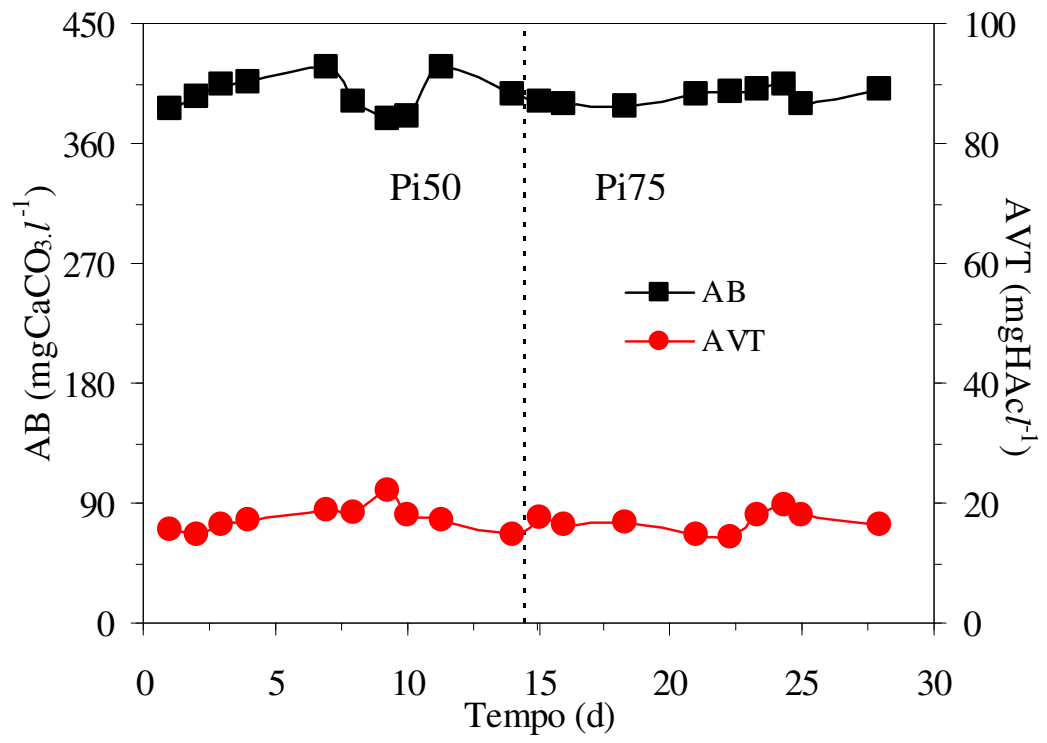

Figura 4.37. Alcalinidade a bicarbonato e Ácidos voláteis totais utilizando impelidor tipo pá de pás planas inclinadas nas condições Pi50 e Pi75. 


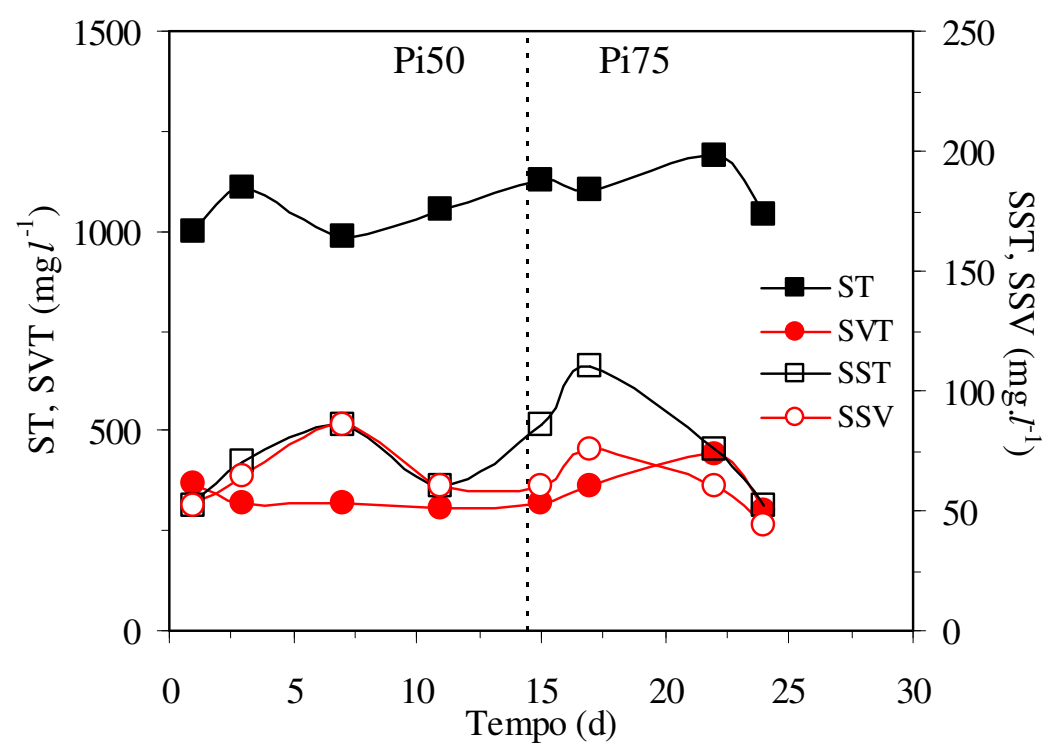

Figura 4.38. Sólidos totais (ST), sólidos voláteis totais (SVT), sólidos suspensos totais (SST) e sólidos suspensos voláteis (SSV) utilizando impelidor tipo pá de pás planas inclinadas nas condições Pi50 e Pi75.

Todos os dados coletados durante o referido ensaio foram utilizados para a montagem da Tabela 4.4, visto que o sistema operou com estabilidade. Removendo $87 \pm 1 \%$ da matéria orgânica na forma de DQO de amostras filtradas para ambas as condições, as concentrações de matéria orgânica em amostras não filtradas foram de $141 \pm 16$ e $129 \pm 13$ mgDQO. $l^{-1}$ para as condições Pi50 e Pi75, respectivamente. Para os outros parâmetros observou-se grande semelhança entre as duas condições.

A possível formação de polímero pode ser observada através da Figura 4.39 na qual o impelidor tipo pá de pás planas inclinadas é apresentado antes e após sua utilização neste ensaio. Nesta figura o impelidor aparece recoberto uma camada de um material gelatinoso ao final do ensaio. Esta pode ser uma confirmação da não ocorrência de atrito entre impelidor e biomassa. Uma vez que, em caso de atrito, este material facilmente removível do impelidor não estaria aderido ao mesmo.

Cabe registrar que foram executadas análises de nitrogênio orgânico e nitrogênio amoniacal do efluente ao final da condição Pi75, cujos valores foram $11,3 \mathrm{mg} . \mathrm{l}^{-1} \mathrm{e}$ $38,8 \mathrm{mg} . l^{-1}$, respectivamente, fornecendo assim $50,1 \mathrm{mg} . l^{-1}$ de nitrogênio total Kjeldal. 


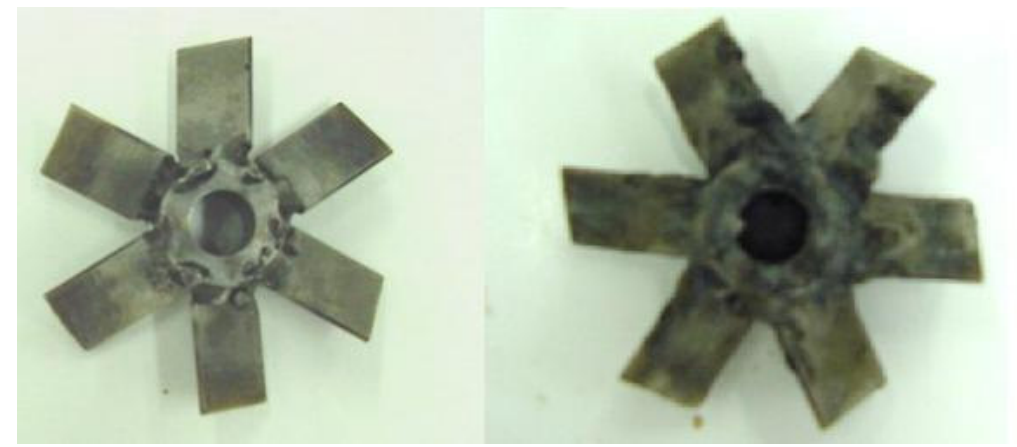

Figura 4.39.Impelidor tipo pá de pás planas inclinadas antes e após o ensaio. 


\subsubsection{Condição de operação Pi50}

Fornece-se da Figura 4.40 à Figura 4.44, cujos valores experimentais estão no APÊNDICE E, os perfis das variáveis concentração de matéria orgânica de amostras filtradas, eficiência de remoção de matéria orgânica, alcalinidade na forma de bicarbonato, ácidos voláteis totais na forma ácido acético, volume acumulado, produção, fração molar no "head-space" e concentração de metano realizados na condição Pi50.
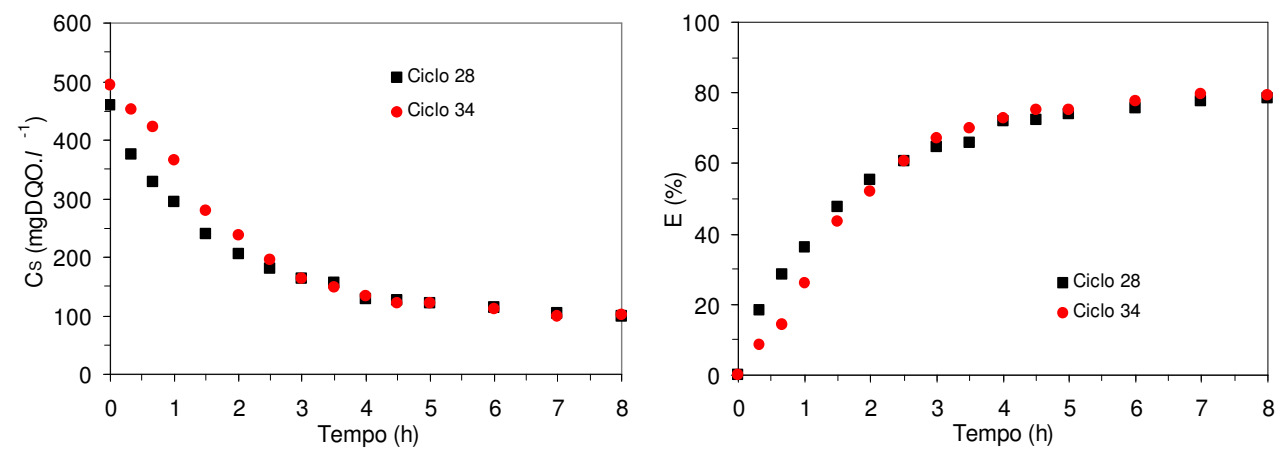

Figura 4.40. Perfis da concentração de matéria orgânica na forma de DQO e da eficiência de conversão ao longo de dois ciclos de operação na condição Pi50.
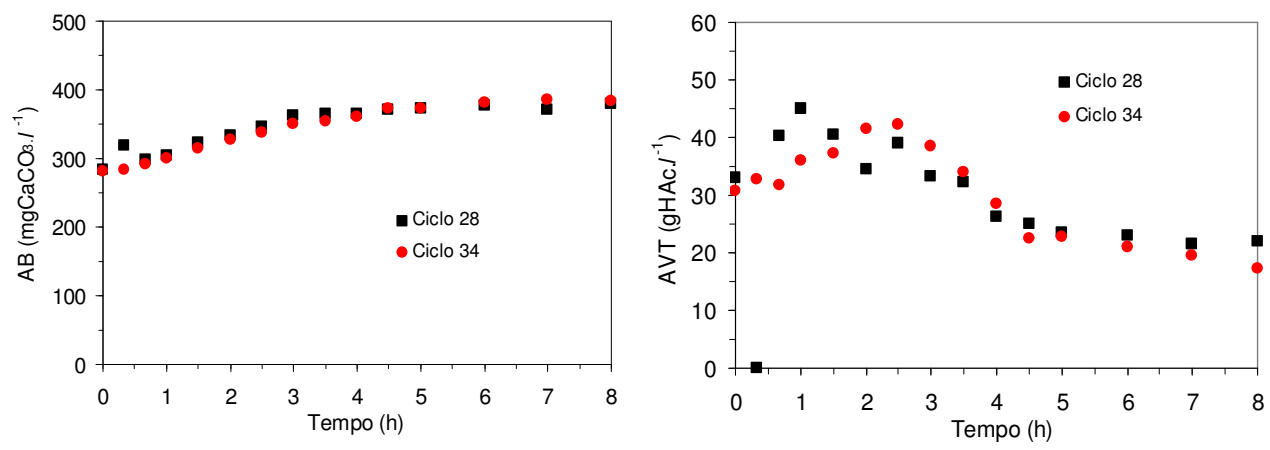

Figura 4.41. Perfis da alcalinidade na forma de bicarbonato de cálcio e da concentração de ácidos voláteis totais na forma de ácido acético ao longo de dois ciclos de operação na condição Pi50. 

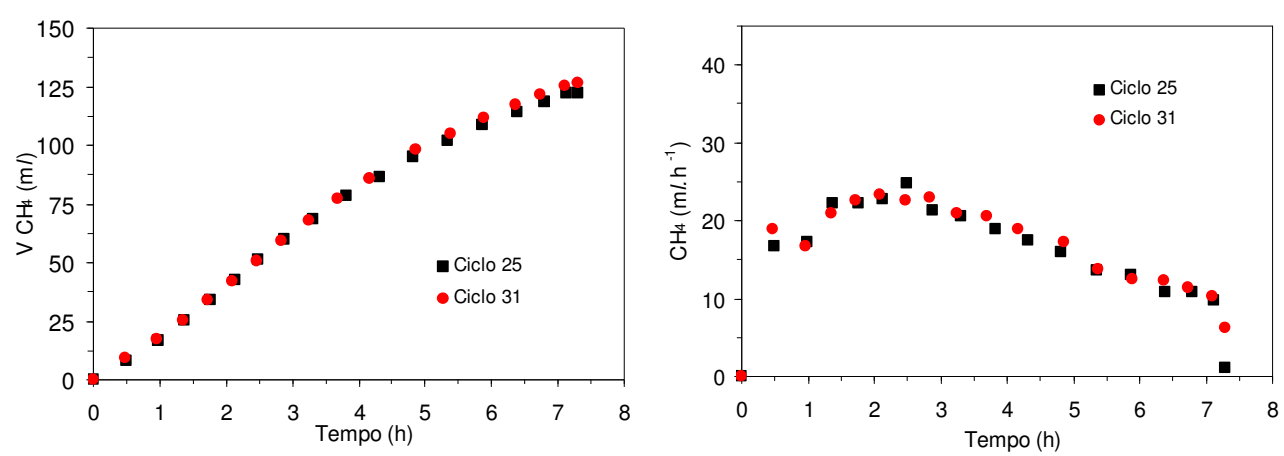

Figura 4.42. Perfis do volume acumulado e da produção de metano no reator ao longo de dois ciclos de operação na condição Pi50.
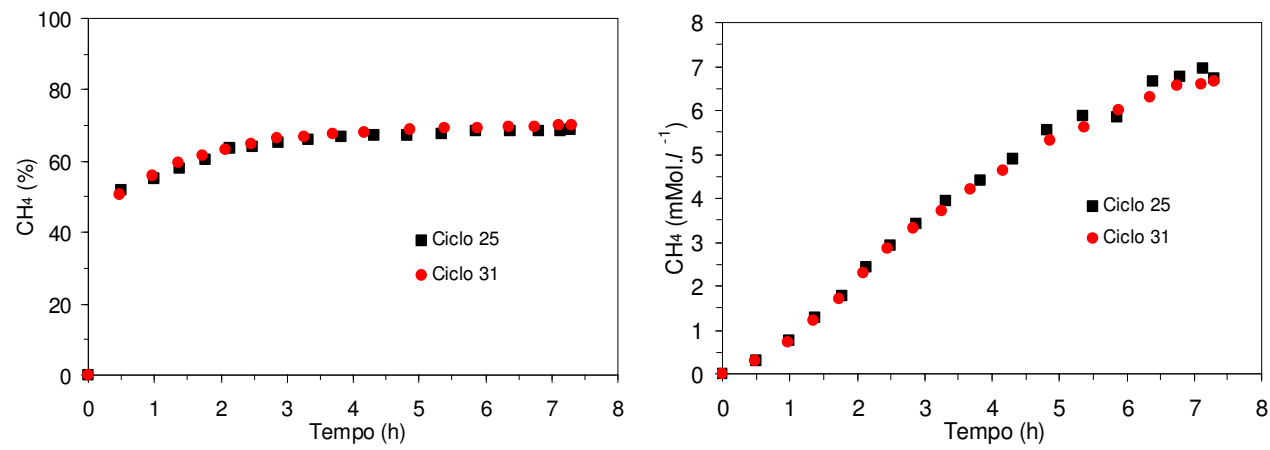

Figura 4.43. Perfis da fração molar e da concentração de metano no "head-space" ao longo de dois ciclos de operação na condição Pi50.

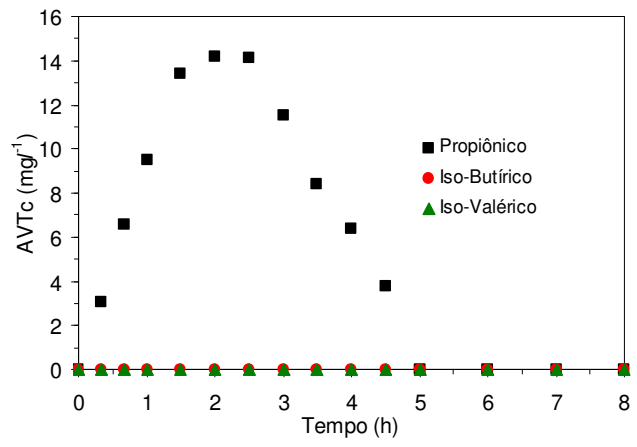

Figura 4.44. Perfis da concentração de ácidos voláteis por cromatografia durante dois ciclos de operação na condição Pi50 (valores médios).

Os perfis de concentração de matéria orgânica na forma de DQO, alcalinidade a bicarbonato e ácidos voláteis totais atingem seus valores finais entre a quinta e a sexta horas onde as concentrações finais foram próximas a $100 \mathrm{mgDQO} \cdot l^{-1}, 400 \mathrm{mgCaCO}_{3} \cdot l^{-1}$ e 20 mgHAc. $l^{-1}$, respectivamente. 
$\mathrm{O}$ volume acumulado ao final do ciclo foi de aproximadamente $125 \mathrm{ml}$, cuja produção foi próxima a $25 \mathrm{ml} \cdot \mathrm{h}^{-1}$ entre a segunda e a terceira horas de perfil. Ainda nesta condição a concentração de metano atingiu $6,5 \mathrm{mMol} . l^{-1}$ representando $70 \%$ de metano.

A partir da análise de ácidos voláteis intermediários só foi observada a presença de ácido propiônico que esteve presente do início do perfil até $4,5 \mathrm{~h}$ de ciclo, sendo o período de pico entre 1,5 e 2,5 h e concentração pouco inferior a $15 \mathrm{mg} . l^{-1}$. 


\subsubsection{Condição de operação Pi75}

Os perfis das variáveis concentração de matéria orgânica de amostras filtradas, eficiência de remoção de matéria orgânica, alcalinidade na forma de bicarbonato, ácidos voláteis totais na forma ácido acético, volume acumulado, produção, fração molar no "head-space" e concentração de metano realizados na condição Pi75 são apresentados da Figura 4.45 à Figura 4.49 e no APÊNDICE E.
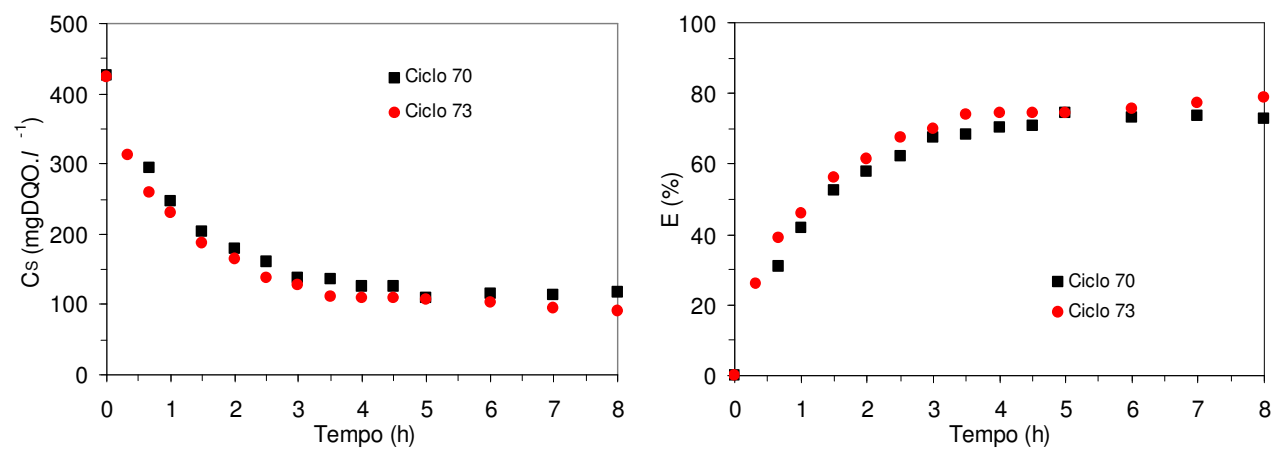

Figura 4.45. Perfis da concentração de matéria orgânica na forma de DQO e da eficiência de conversão ao longo de dois ciclos de operação na condição Pi75.
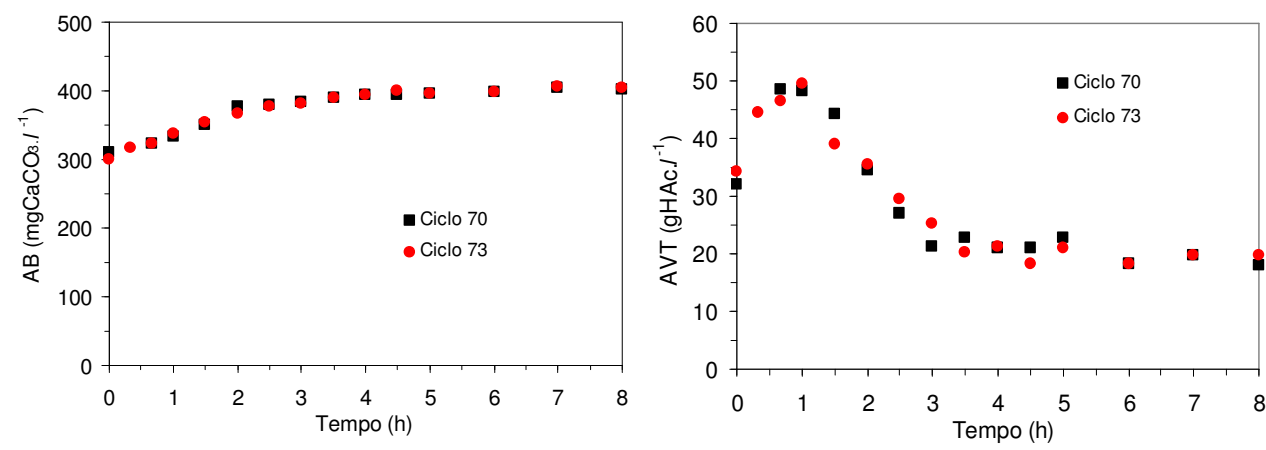

Figura 4.46. Perfis da alcalinidade na forma de bicarbonato de cálcio e da concentração de ácidos voláteis totais na forma de ácido acético ao longo de dois ciclos de operação na condição Pi75. 

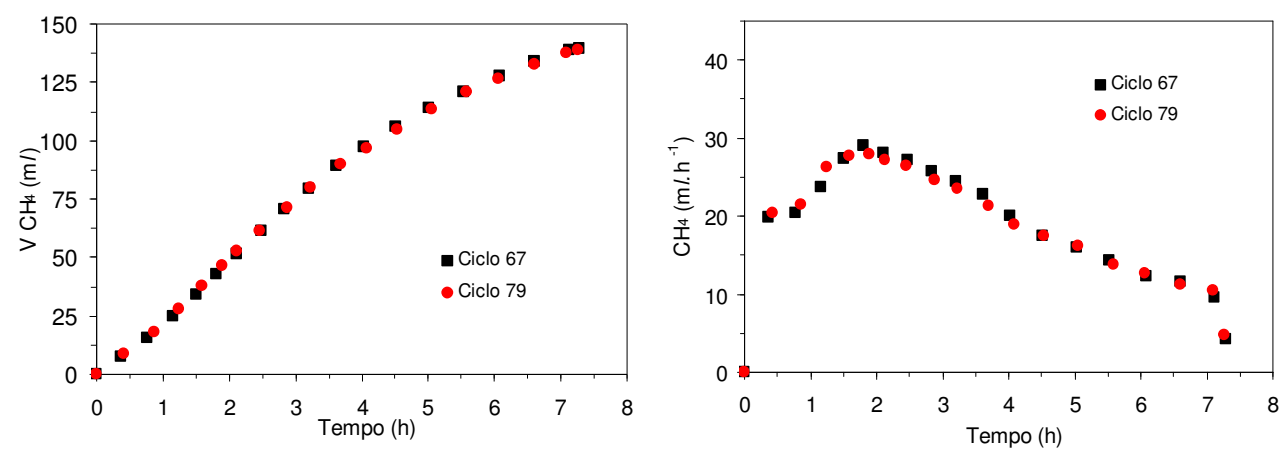

Figura 4.47. Perfis do volume acumulado e da produção de metano no reator ao longo de dois ciclos de operação na condição Pi75.
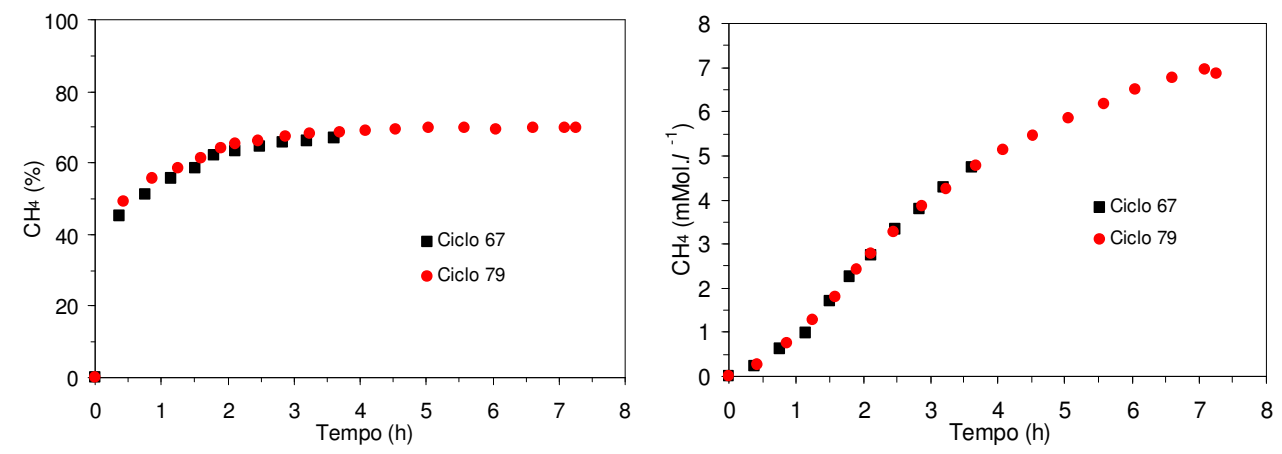

Figura 4.48. Perfis da fração molar e da concentração de metano no "head-space" ao longo de dois ciclos de operação na condição Pi75.

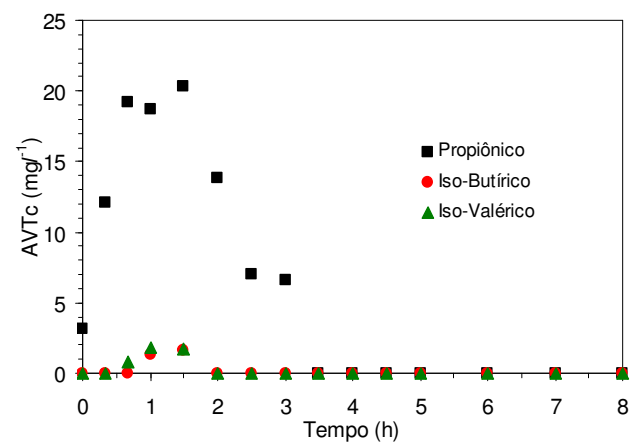

Figura 4.49. Perfis da concentração de ácidos voláteis por cromatografia durante dois ciclos de operação na condição Pi75.

O perfil de concentração de matéria orgânica teve variação significativa entre o tempo zero e a quarta horas de ciclo, sendo seu valor a partir deste momento praticamente constante e próximo a $120 \mathrm{mgDQO} . l^{-1}$. Os perfil de alcalinidade na forma de bicarbonato e de ácidos voláteis totais seguem a mesma tendência do perfil de concentração de matéria orgânica. O perfil de ácidos voláteis totais apresentou pico com uma hora de ciclo atingindo aproximadamente $50 \mathrm{mgHAc} . l^{-1}$ concentração esta que não 
chegou a influenciar significativamente a alcalinidade do meio reacional, em função de a alcalinidade na forma de bicarbonato apresentar somente tendência de aumento, conforme Figura 4.46.

O volume de metano acumulado ao final de dois perfis nesta condição foi próximo a $140 \mathrm{~m} l$ no qual o pico de produção teve início com $1,5 \mathrm{~h}$ de perfil chegando ao valor máximo na segunda hora, a partir da qual ocorre queda gradual até o final do período reacional. A fração molar de metano estabilizou próxima a $70 \%$ entre a quarta e a quinta hora de perfil no qual estes $70 \%$ equivalem a aproximadamente $7 \mathrm{mMol} . l^{-1}$.

Diferentemente da condição Pi50 onde se registrou somente a presença de ácido propiônico dentre os ácidos voláteis intermediários, nesta condição Pi75 é observada a presença dos ácidos iso-butírico e iso-valérico, cujas concentrações não ultrapassam $2 \mathrm{mg} . l^{-1}$ e do ácido propiônico com concentração próxima a $20 \mathrm{mg} \cdot l^{-1} \mathrm{em}$ uma hora de perfil. 
4.1.5 Impelidor tipo pá de seis pás planas inclinadas e tubo de tiragem

Neste ensaio foi testada a viabilidade de utilização de impelidor tipo pá de seis pás planas inclinadas $45^{\circ}$, em conjunto com tubo de tiragem. A duração deste ensaio foi de 28 dias com o estudo de duas velocidades de rotação, $100 \mathrm{rpm}$ e $120 \mathrm{rpm}$, passando assim a serem denominadas por condições Pd100 e Pd120, respectivamente. A escolha das velocidades seguiu os critérios operacionais citados no ensaio utilizando hélice com tubo de tiragem.

O reator operou com concentração inicial de esgoto sintético de $800 \mathrm{mgDQO} . l^{-1}$, operando em ciclos de $8 \mathrm{~h}$ e volume alimentado de $2 l$. Os resultados experimentais deste ensaio são apresentados na Tabela 4.5, da Figura 4.50 à Figura 4.52 e APÊNDICE F.

Tabela 4.5. Valores médios das variáveis monitoradas na operação com impelidor tipo pá de pás planas inclinadas $45^{\circ}$ e tubo de tiragem nas condições Pd100 e Pd120.

\begin{tabular}{cccc}
\hline Parâmetro & Afluente & Pd100 & Pd120 \\
\hline Duração ciclos (dias) & - & $1-41(14)$ & $44-83(14)$ \\
$\mathrm{C}_{\mathrm{ST}}\left(\mathrm{mgDQO} . l^{-1}\right)$ & $794 \pm 37(18)$ & $146 \pm 8(7)$ & $127 \pm 9(10)$ \\
$\mathrm{E}_{\mathrm{T}}(\%)$ & - & $82 \pm 1(7)$ & $84 \pm 1(10)$ \\
$\mathrm{C}_{\mathrm{SS}}\left(\mathrm{mgDQO} . l^{-1}\right)$ & - & $125 \pm 7(7)$ & $113 \pm 8(10)$ \\
$\mathrm{E}_{\mathrm{SS}}(\%)$ & - & $84 \pm 1(7)$ & $86 \pm 1(10)$ \\
V Descarregado $(l)$ & - & $2,01 \pm 0,01(7)$ & $1,98 \pm 0,02(5)$ \\
AVT (mgHAc. $\left.l^{-1}\right)$ & $36 \pm 30(16)$ & $18 \pm 3(8)$ & $14 \pm 2(9)$ \\
AB (mgCaCO.$\left.l^{-1}\right)$ & $219 \pm 9(16)$ & $374 \pm 10(8)$ & $376 \pm 5(9)$ \\
pH & $8,9 \pm 0,1(16)$ & $6,86 \pm 0,03(8)$ & $6,81 \pm 0,08(9)$ \\
ST (mg. $\left.l^{-1}\right)$ & $1576 \pm 113(8)$ & $1069 \pm 77(4)$ & $1069 \pm 47(4)$ \\
SVT (mg. $\left.l^{-1}\right)$ & $886 \pm 36(8)$ & $357 \pm 62(4)$ & $363 \pm 26(4)$ \\
SST (mg. $\left.l^{-1}\right)$ & $40 \pm 13(8)$ & $65 \pm 6(4)$ & $70 \pm 13(4)$ \\
SSV (mg. $\left.l^{-1}\right)$ & $34 \pm 15(8)$ & $46 \pm 5(4)$ & $66 \pm 11(4)$ \\
ST biomassa $\left(\mathrm{g} . l^{-1}\right)$ & - & $69,2(1)$ & $56,5(1)$ \\
SFT biomassa $\left(\mathrm{g} . l^{-1}\right)$ & - & $9,5(1)$ & $7,8(1)$
\end{tabular}

(*) Os valores entre parênteses representam o número de amostras 


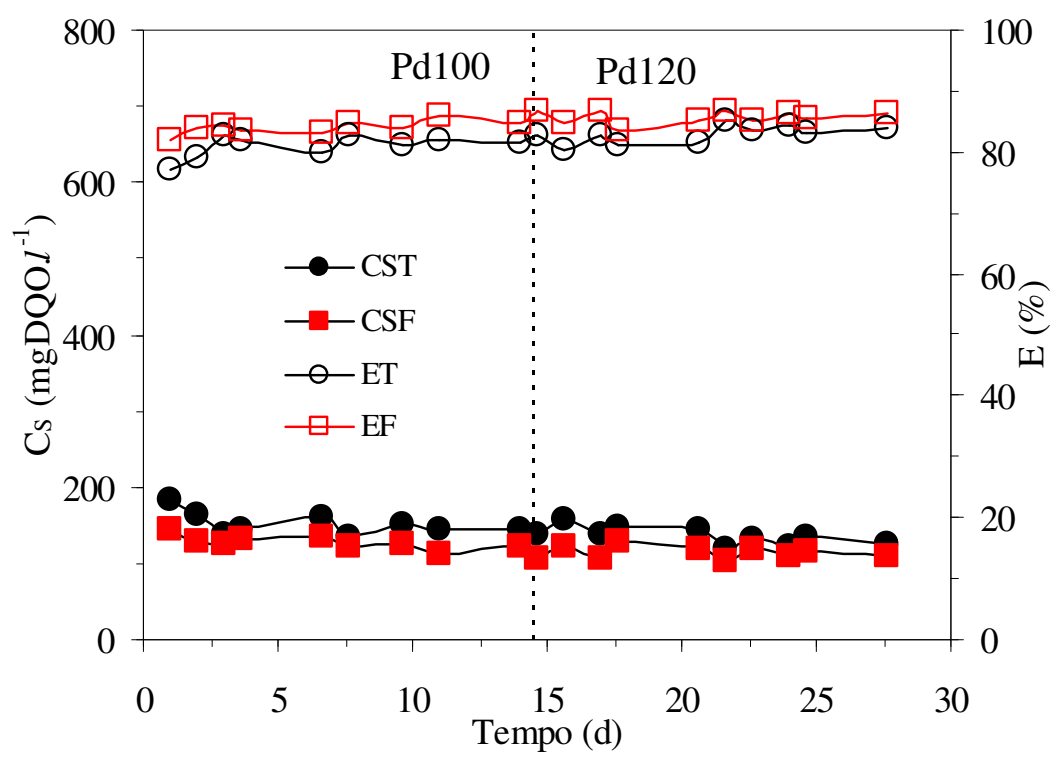

Figura 4.50. Concentração de matéria orgânica efluente e eficiência de remoção utilizando impelidor tipo pá de pás planas inclinadas e reator com tubo de tiragem nas condições Pd100 e Pd120.

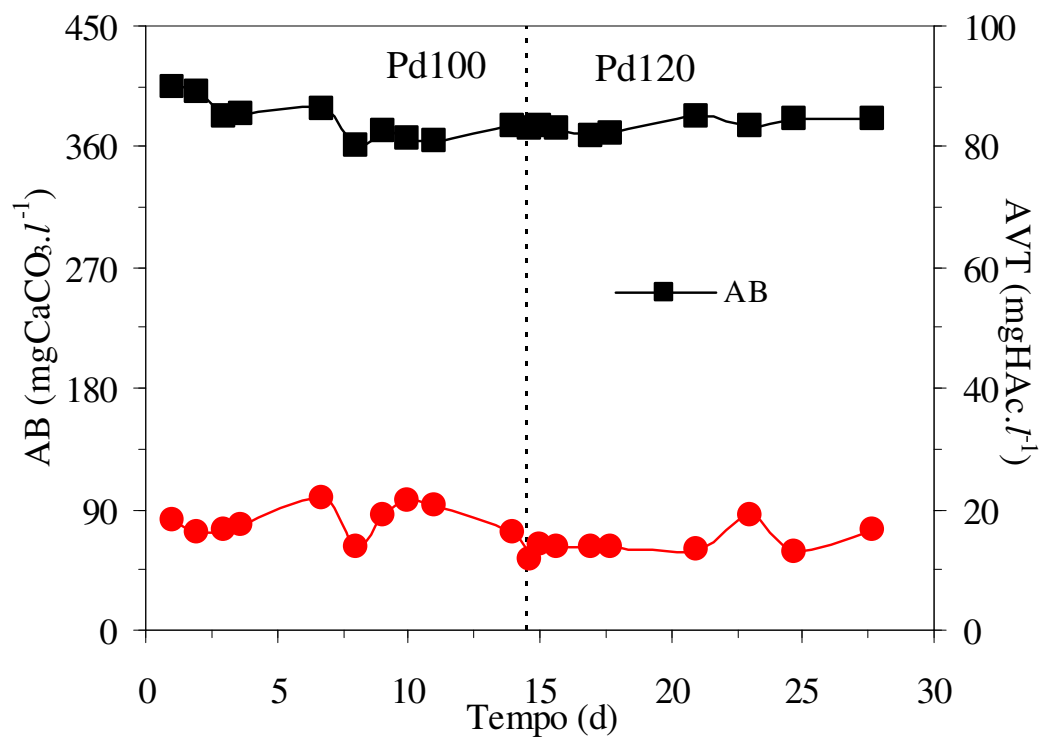

Figura 4.51. Alcalinidade a bicarbonato e Ácidos voláteis totais utilizando impelidor tipo pá de pás planas inclinadas e reator com tubo de tiragem nas condições Pd100 e Pd120. 


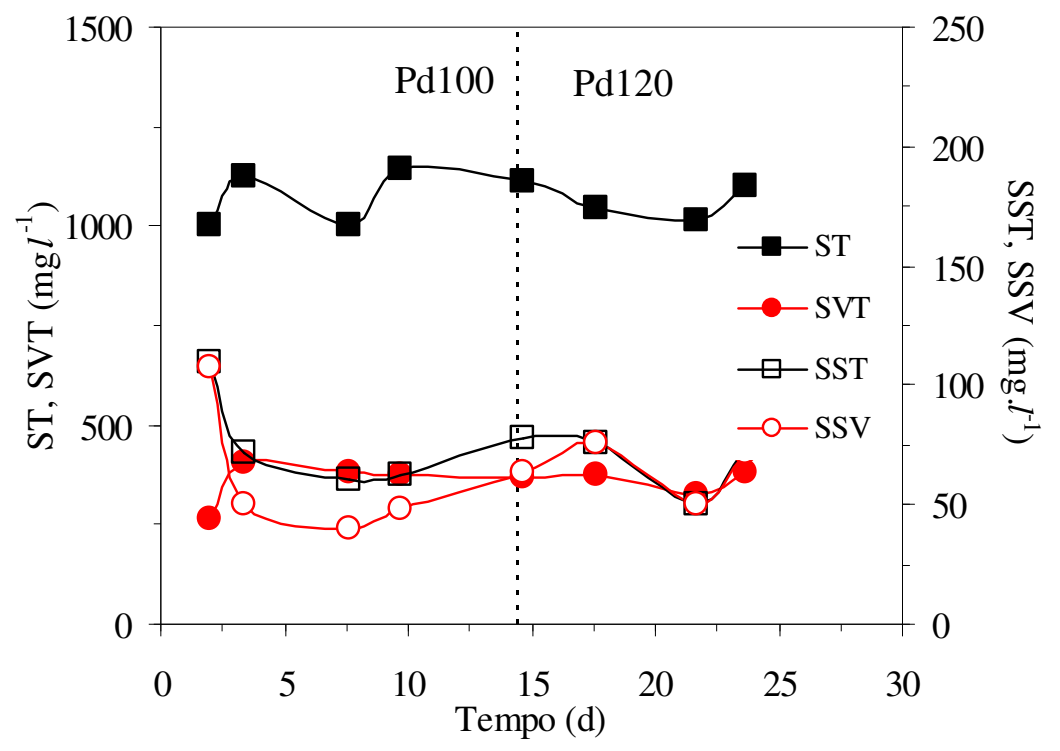

Figura 4.52. Sólidos totais (ST), sólidos voláteis totais (SVT), sólidos suspensos totais (SST) e sólidos suspensos voláteis (SSV) utilizando impelidor tipo pá de pás planas inclinadas e reator com tubo de tiragem nas condições Pd100 e Pd120.

O sistema necessitou de um curto período de adaptação de dois dias para não apresentar variação significativa nos parâmetros medidos, a partir dos quais apresentou boa estabilidade. Para a construção da Tabela 5.4 não foram utilizados os dois primeiros pontos de monitoramento do efluente na condição Pd100 dos parâmetros DQO total e filtrada, eficiência total e filtrada, alcalinidade a bicarbonato, ácidos voláteis totais e $\mathrm{pH}$. Também não foi utilizado o primeiro valor de SST e SSV da condição Pd100, em função de estes pontos representarem um período de adaptação do sistema à condição de operação, como pode ser visto nas Figura 4.50 a Figura 4.52.

Para o caso da concentração de matéria orgânica tanto filtrada quanto total, ao final do período de adaptação, notou-se uma diminuição na concentração efluente e conseqüente maior eficiência de remoção para ambos os casos, já para o caso da alcalinidade na forma de bicarbonato o efeito foi de diminuição da alcalinidade, uma vez que os dois primeiros pontos estavam próximos a $400 \mathrm{mgCaCO}_{3} l^{-1}$ e a concentração média nesta condição foi de $374 \pm 10 \mathrm{mgCaCO}_{3} \cdot l^{-1}$. A diminuição na alcalinidade do efluente pode ter sido provocada por um aumento na turbulência promovida por este sistema em relação à condição anterior e possível maior eliminação do carbonato na forma de $\mathrm{CO}_{2}$ gasoso.

Com o início da agitação espera-se que o fluido "empurre" a biomassa para através do tubo de tiragem e promova a suspensão dos grânulos na região anular (entre 
o tubo de tiragem e a parede do reator), onde os grânulos permaneceriam suspensos sem contudo chegar ao topo da coluna liquida, caracterizando escoamento axial da biomassa. A primeira condição de operação teve, durante toda sua duração, um início de ciclo diferente do esperado. Ocorreu que, com o início da agitação iniciava-se a movimentação do fluido dentro do tubo de tiragem e este expelia a biomassa para fora do tubo pela sua parte superior. Após um tempo de aproximadamente dois minutos, parte da biomassa já havia sido transferida para a região anular, diminuindo a resistência ao início da movimentação "normal" do fluido, que começa a circular gerando o escoamento axial característico, promovido pela instalação do tubo de tiragem. Este fato demonstra que para o sistema com impelidor tipo pá de pás planas inclinadas a velocidade rotacional de $100 \mathrm{rpm}$ é suficiente para manter a suspensão da biomassa na região anular durante o período reacional, porém apresenta problemas durante o início de cada ciclo por não fornecer energia suficiente para promover a adequada suspensão da biomassa.

Durante os primeiros dias de operação na segunda condição de agitação ( $\operatorname{Pd120})$ observou-se a eliminação de material celular flotado durante a descarga do reator. Este período durou cinco dias resultando ao final do ensaio em uma perda de $210 \mathrm{~m} l \mathrm{de}$ biomassa. Este fato não foi provocado por sobrecarga orgânica, visto que não foram observadas variações significativas nas concentrações de matéria orgânica, alcalinidade, concentração de ácidos voláteis totais ou $\mathrm{pH}$ do efluente. Isto posto e sabendo que no início de cada ciclo, durante estes dias, a condição Pd120 apresentou a mesma característica da condição de menor velocidade, supõe-se que uma explicação para a eliminação de biomassa seja o fato de esta encontrar-se de alguma forma excedente no sistema e com isto ser eliminada por algum mecanismo ainda não entendido.

O porquê de ter sido eliminado material celular no início da condição Pd120 mas não na condição Pd100, e o fato de a circulação de fluido começar de forma inesperada para este sistema, gerando contato direto do impelidor com a biomassa são questões que merecem um maior aprofundamento. 


\subsubsection{Condição de operação Pd100}

Da Figura 4.53 à Figura 4.57 e APÊNDICE F, pode-se observar os perfis das variáveis concentração de matéria orgânica de amostras filtradas, eficiência de remoção de matéria orgânica, alcalinidade na forma de bicarbonato, ácidos voláteis totais na forma ácido acético, volume acumulado, produção, fração molar no "head-space" e concentração de metano realizados na condição Pd100.
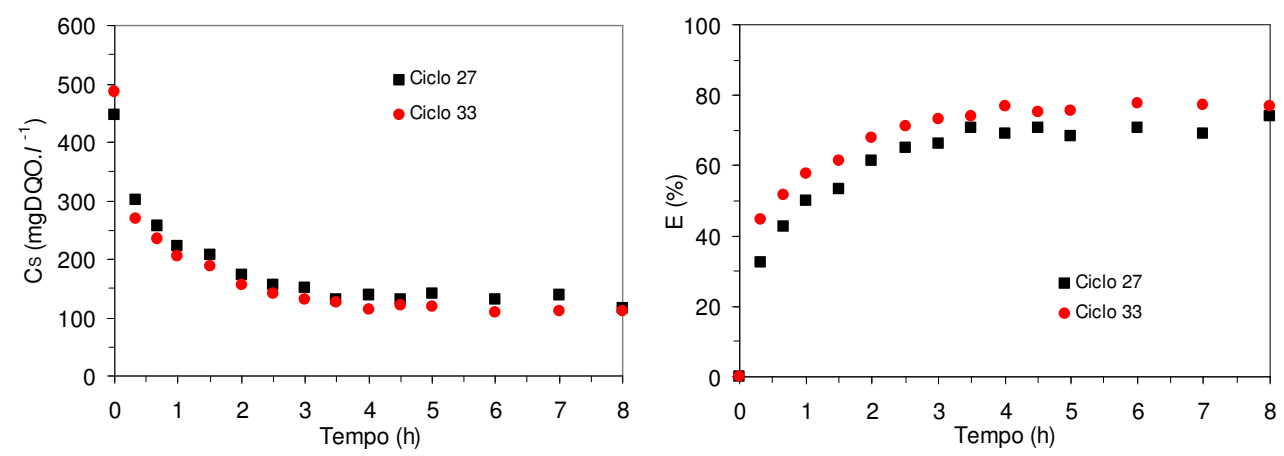

Figura 4.53. Perfis da concentração de matéria orgânica na forma de DQO e da eficiência de conversão ao longo de dois ciclos de operação na condição Pd100
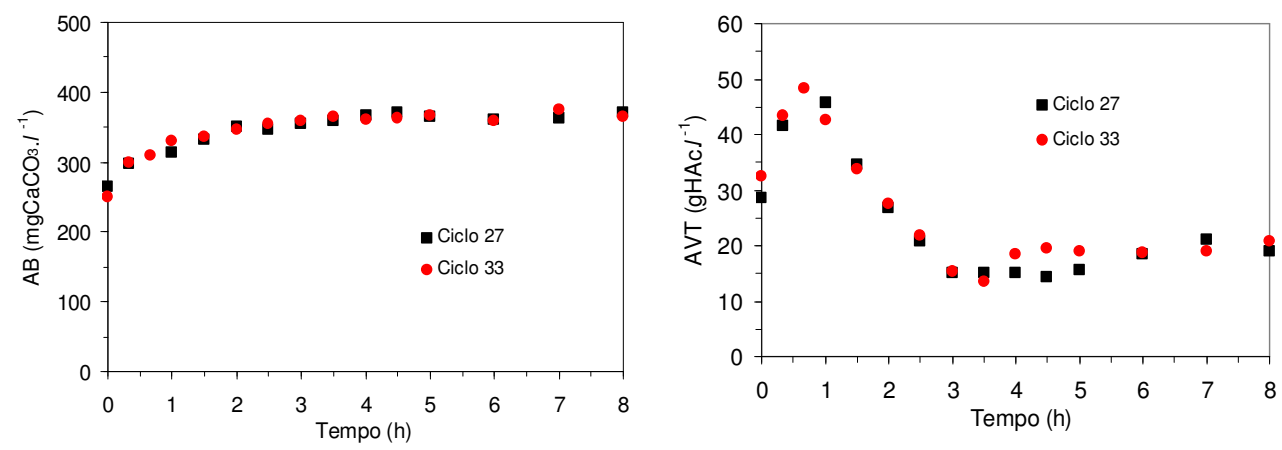

Figura 4.54. Perfis da alcalinidade na forma de bicarbonato de cálcio e da concentração de ácidos voláteis totais na forma de ácido acético ao longo de dois ciclos de operação na condição $\operatorname{Pd} 100$. 

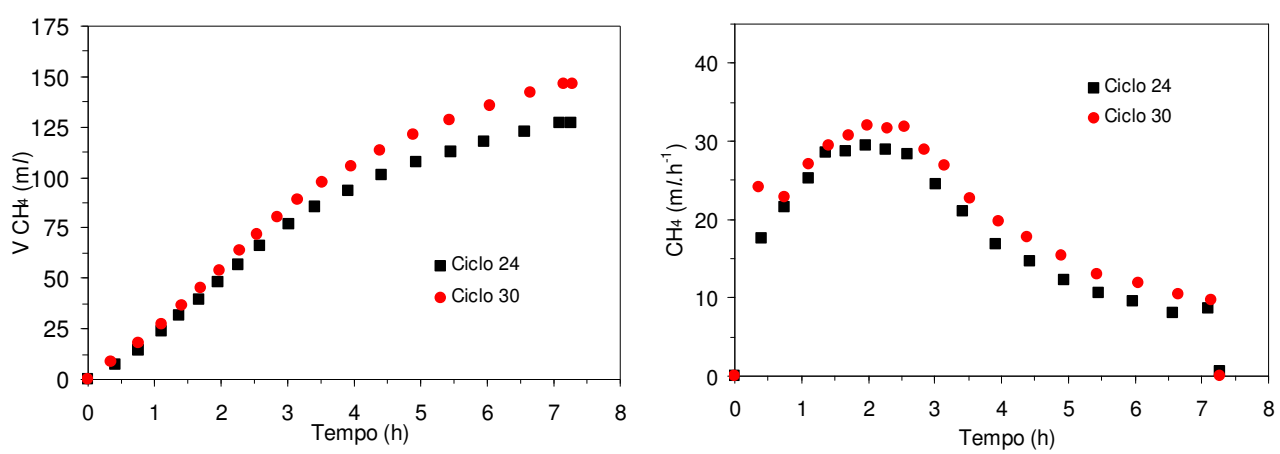

Figura 4.55. Perfis do volume acumulado e da produção de metano no reator ao longo de dois ciclos de operação na condição Pd100.
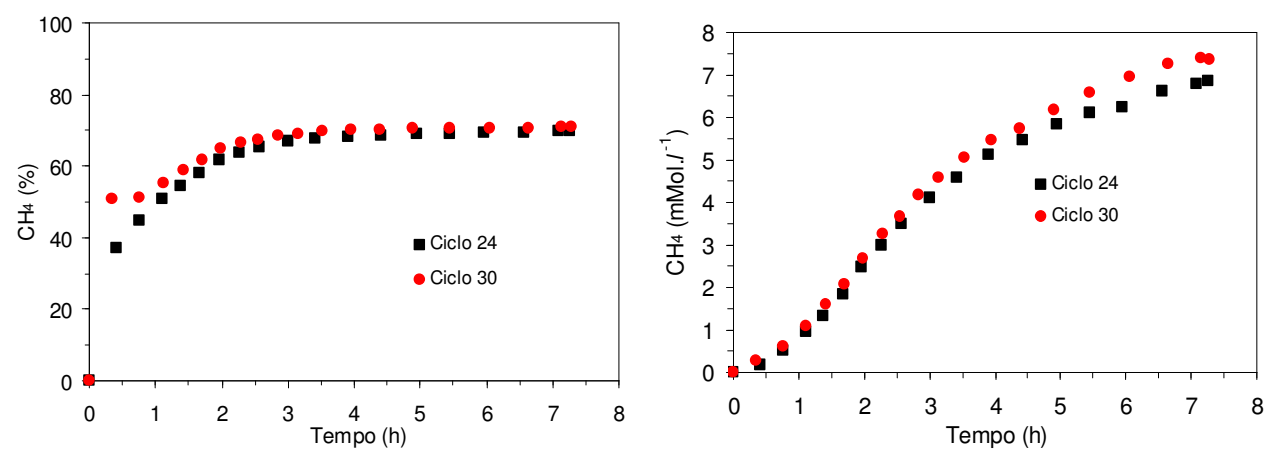

Figura 4.56. Perfis da fração molar e da concentração de metano no "head-space" ao longo de dois ciclos de operação na condição Pd100.

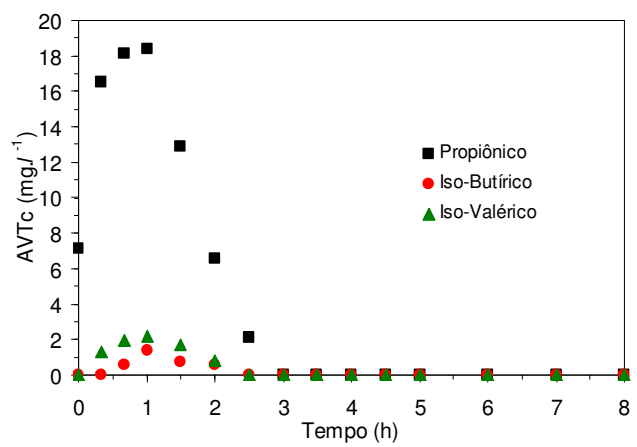

Figura 4.57. Perfis da concentração de ácidos voláteis por cromatografia durante dois ciclos de operação na condição pá Pd100.

A concentração de matéria orgânica na forma de DQO apresentou tendência de queda até a quarta hora de ciclo, a partir da qual estabilizou em valores próximos a $130 \mathrm{mgDQO} . l^{-1}$. Ao mesmo tempo a eficiência de remoção de matéria orgânica atingiu, no patamar de estabilidade, valores superiores a $70 \%$.

A alcalinidade na forma de bicarbonato apresentou sua curva característica de aumento sem demonstrar ter recebido forte influência da concentração de ácidos 
voláteis, esta que teve pico entre 20 mim e uma hora de ciclo e estabilizou em 3,5 h de ciclo. A presença de ácidos voláteis intermediários foi observada durante as três primeiras horas de ciclo, no qual foram identificados ácidos propiônico, iso-butírico e iso-valérico, sendo os dois últimos em concentrações inferiores a $2 \mathrm{mg} . l^{-1}$.

Os perfis de volume acumulado e produção de biogás mostraram que o volume acumulado variou entre 125 e $145 \mathrm{ml}$, sendo sua produção máxima próxima a $30 \mathrm{ml} \cdot \mathrm{h}^{-1}$, entre 1,5 e 2,5 h de ciclo. A fração molar de metano no biogás estabilizou em $70 \%$ perto de três horas de ciclo, enquanto que a concentração final de metano nestes perfis ficou próxima a $7 \mathrm{mMol} . l^{-1}$. 


\subsubsection{Condição de operação Pd120}

Verifica-se da Figura 4.58 à Figura 4.62 e APÊNDICE F, os perfis das variáveis concentração de matéria orgânica de amostras filtradas, eficiência de remoção de matéria orgânica, alcalinidade na forma de bicarbonato, ácidos voláteis totais na forma ácido acético, volume acumulado, produção, fração molar no "head-space" e concentração de metano realizados na condição Pd120.
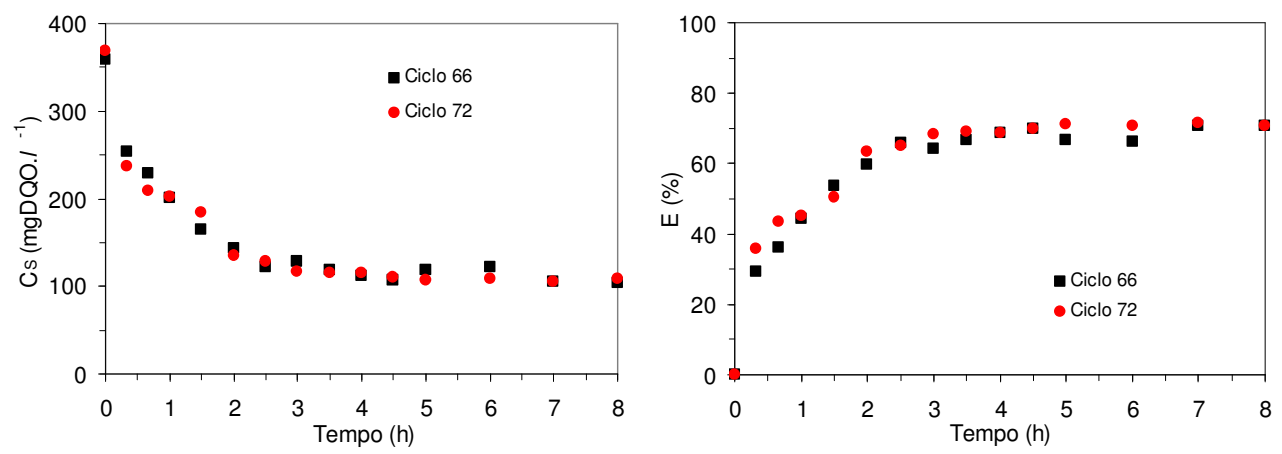

Figura 4.58. Perfis da concentração de matéria orgânica na forma de DQO e da eficiência de conversão ao longo de dois ciclos de operação na condição Pd120.
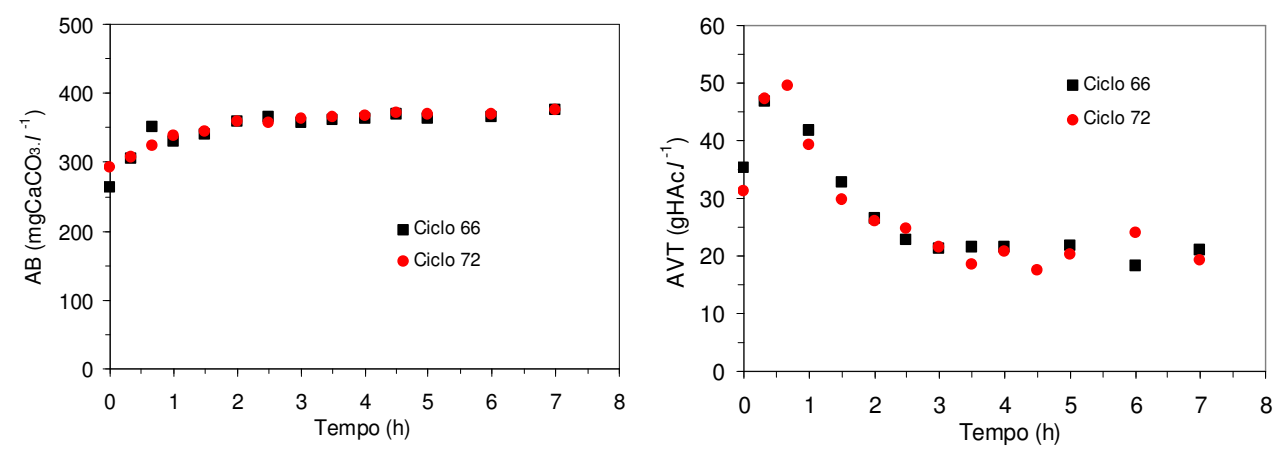

Figura 4.59. Perfis da alcalinidade na forma de bicarbonato de cálcio e da concentração de ácidos voláteis totais na forma de ácido acético ao longo de dois ciclos de operação na condição $\operatorname{Pd} 120$. 

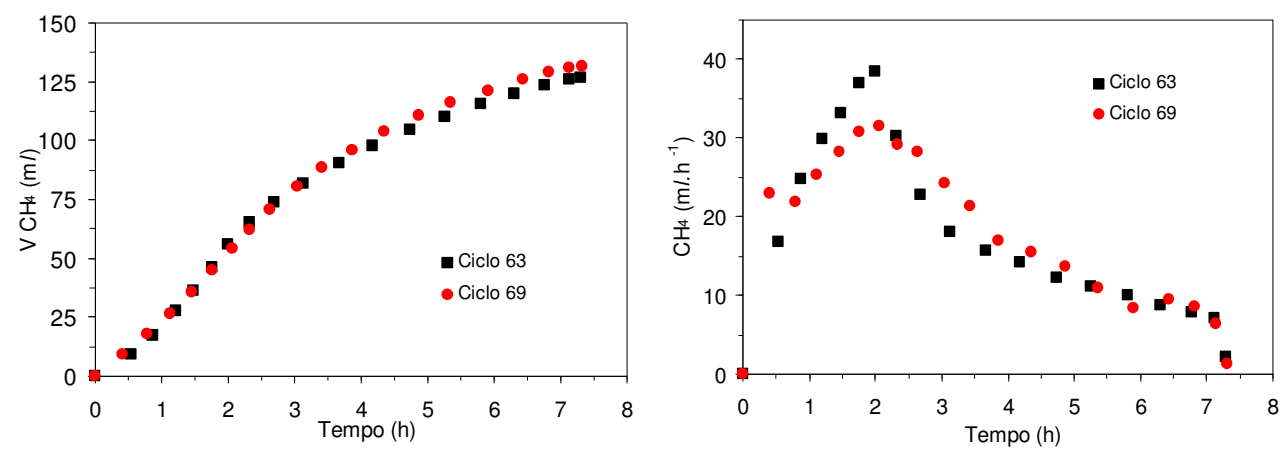

Figura 4.60. Perfis do volume acumulado e da produção de metano no reator ao longo de dois ciclos de operação na condição Pd120.
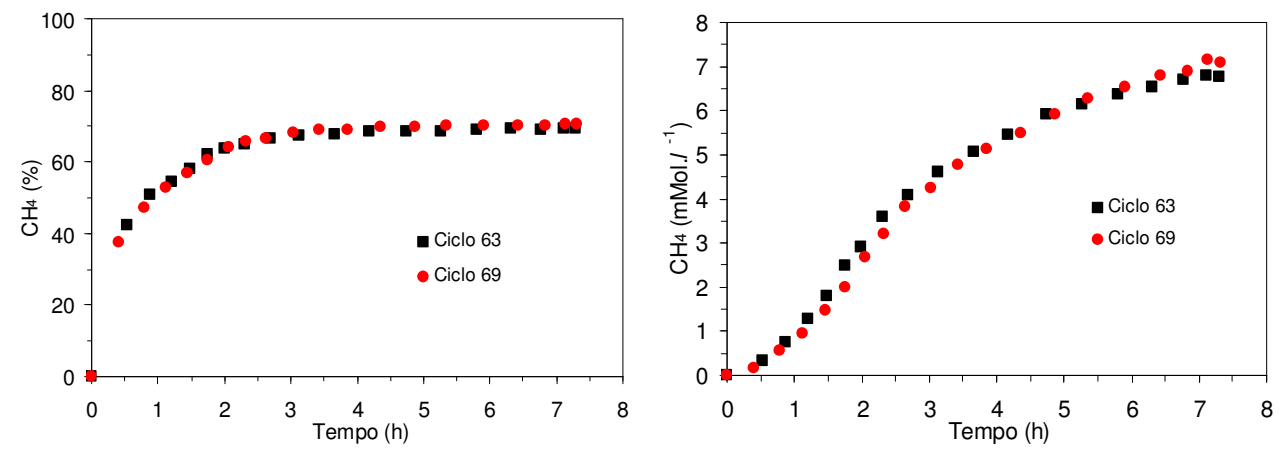

Figura 4.61. Perfis da fração molar e da concentração de metano no "head-space" ao longo de dois ciclos de operação na condição Pd120.

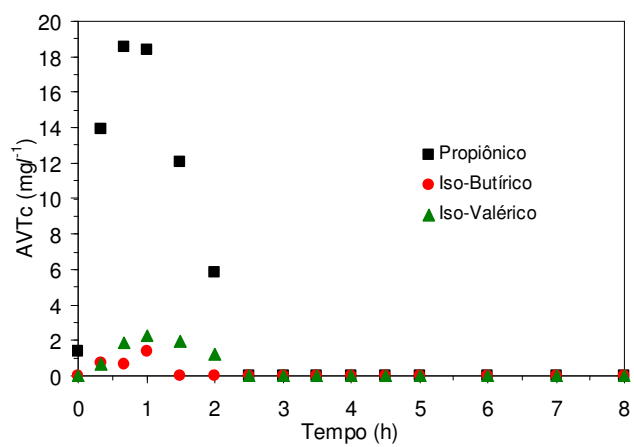

Figura 4.62. Perfis da concentração de ácidos voláteis por cromatografia durante dois ciclos de operação na condição Pd120.

O perfil de concentração de matéria orgânica mostra que a maior parte da remoção ocorre até $2,5 \mathrm{~h}$ atingido valor final próximo a $100 \mathrm{mgDQO} . l^{-1}$, enquanto que a conversão, similarmente à condição anterior, atingiu eficiência próxima a $70 \%$.

O perfil de ácidos voláteis totais estabilizou com três horas de ciclo tendo seu pico registrado com 40 minutos e concentração de aproximadamente 50 mgHAc. $l^{-1}$. Este pico aparentemente não provocou efeito nos valores de alcalinidade, visto que este 
apresentou somente valores crescentes até atingir a estabilidade, fato que ocorreu com 2,5 h de ciclo.

\subsubsection{Impelidor tipo hélice}

O ensaio com impelidor tipo hélice teve duração de 28 dias estudando-se duas condições de operação pela variação da intensidade de agitação com a alteração na velocidade rotacional da hélice. As velocidades estudadas foram de 70 e $100 \mathrm{rpm}$, sendo denominadas $\mathrm{He} 70$ e He100, respectivamente.

O esgoto sintético utilizado apresentou concentração de $800 \mathrm{mgDQO} . l^{-1}$ operando em ciclos de $8 \mathrm{~h}$ e volume alimentado de $2 l$. Os resultados experimentais deste ensaio estão apresentados na Tabela 4.6, da Figura 4.63 à Figura 4.65 e APÊNDICE G.

Tabela 4.6. Valores médios das variáveis monitoradas na operação com impelidor tipo hélice nas condições He70 e He100.

\begin{tabular}{cccc}
\hline Parâmetro & Afluente & He70 & He100 \\
\hline Duração ciclos (dias) & - & $1-42(14)$ & $43-84(14)$ \\
$\mathrm{C}_{\mathrm{ST}}\left(\mathrm{mgDQO} . l^{-1}\right)$ & $776 \pm 50(19)$ & $154 \pm 16(11)$ & $146 \pm 9(8)$ \\
$\mathrm{E}_{\mathrm{T}}(\%)$ & - & $80 \pm 2(11)$ & $81 \pm 1(8)$ \\
$\mathrm{C}_{\mathrm{SS}}\left(\mathrm{mgDQO} . l^{-1}\right)$ & - & $124 \pm 11(11)$ & $116 \pm 5(9)$ \\
$\mathrm{E}_{\mathrm{SS}}(\%)$ & - & $84 \pm 1(11)$ & $85 \pm 1(9)$ \\
V Descarregado $(l)$ & - & $2,00 \pm 0,04(7)$ & $2,01 \pm 0,01(8)$ \\
AVT (mgHAc. $\left.l^{-1}\right)$ & $44 \pm 5(17)$ & $24 \pm 4(8)$ & $19 \pm 2(8)$ \\
AB (mgCaCO.$\left.l^{-1}\right)$ & $212 \pm 16(17)$ & $380 \pm 26(8)$ & $366 \pm 18(8)$ \\
pH & $8,8 \pm 0,1(17)$ & $6,83 \pm 0,09(8)$ & $6,81 \pm 0,05(8)$ \\
ST (mg. $\left.l^{-1}\right)$ & $1458 \pm 71(7)$ & $999 \pm 22(4)$ & $1007 \pm 74(3)$ \\
SVT (mg. $\left.l^{-1}\right)$ & $763 \pm 54(7)$ & $299 \pm 37(4)$ & $325 \pm 104(3)$ \\
SST (mg. $\left.l^{-1}\right)$ & $74 \pm 31(7)$ & $22 \pm 8(4)$ & $35 \pm 13(3)$ \\
SSV (mg. $\left.l^{-1}\right)$ & $68 \pm 33(7)$ & $16 \pm 8(4)$ & $32 \pm 15(3)$ \\
ST biomassa $\left(\mathrm{g} . l^{-1}\right)$ & - & $39,9(1)$ & $42,3(1)$ \\
SFT biomassa $\left(\mathrm{g} . l^{-1}\right)$ & - & $5,3(1)$ & $5,4(1)$
\end{tabular}

(*) Os valores entre parênteses representam o número de amostras 
As velocidades escolhidas foram baseadas em análise visual da movimentação dos grânulos no interior do reator. Para a condição de rotação a 70 rpm tentou-se obter movimentação parecida com a obtida no ensaio com turbina de pás planas operando a 50 rpm, já para a condição He100 utilizou-se rotação em que era visível o aumento da movimentação dos grânulos. A possibilidade de utilização de rotações superiores existiu, porém em maiores rotações poderia ocorrer o rompimento dos grânulos o que prejudicaria a biomassa.

O sistema atingiu estabilidade com extrema rapidez, tendo sido utilizados todos os dados coletados para o cálculo dos valores médios.

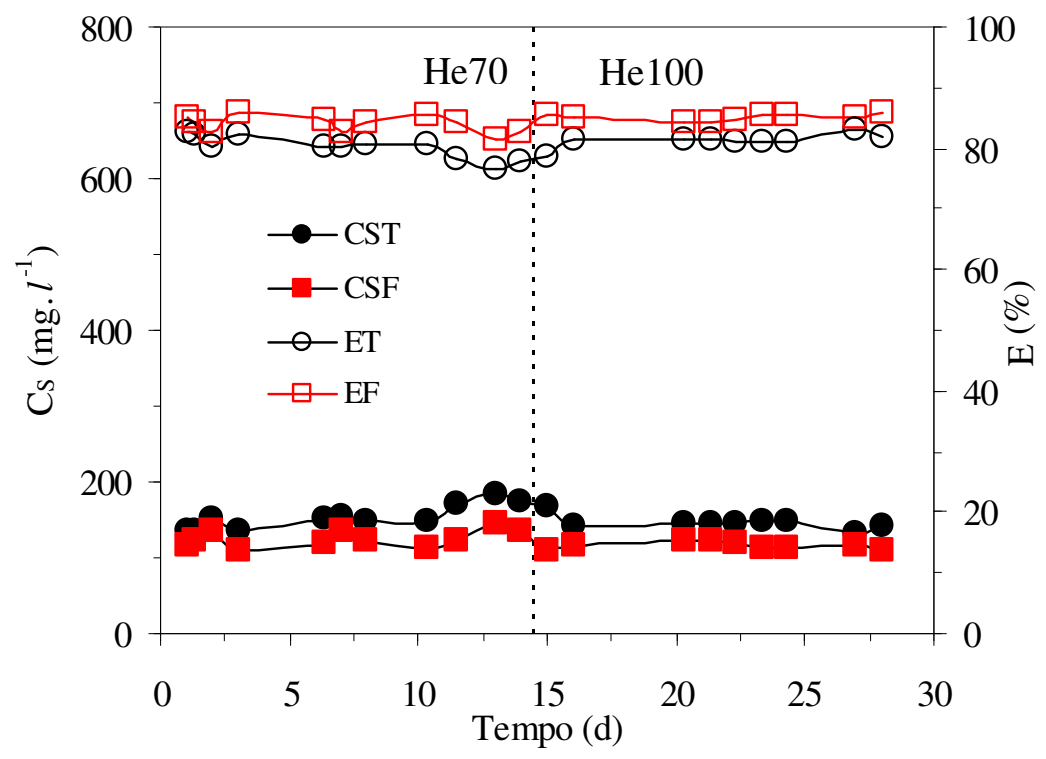

Figura 4.63. Concentração de matéria orgânica efluente e eficiência de remoção nas condições He70 e He100. 


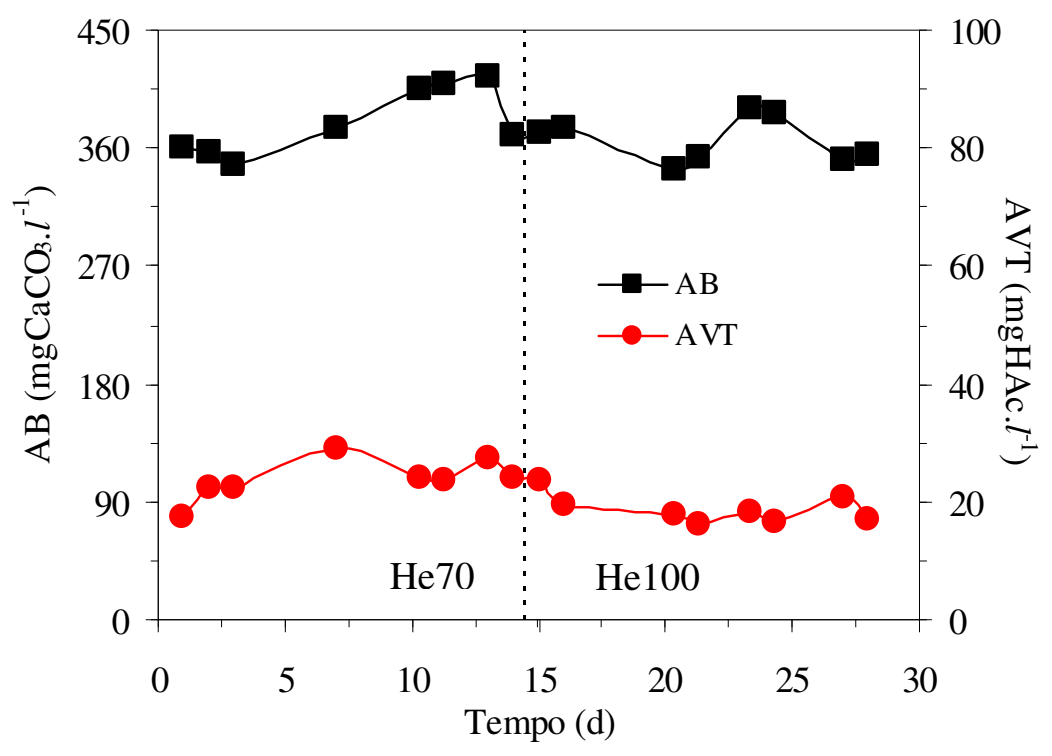

Figura 4.64. Alcalinidade a bicarbonato e Ácidos voláteis totais nas condições He70 e He100.

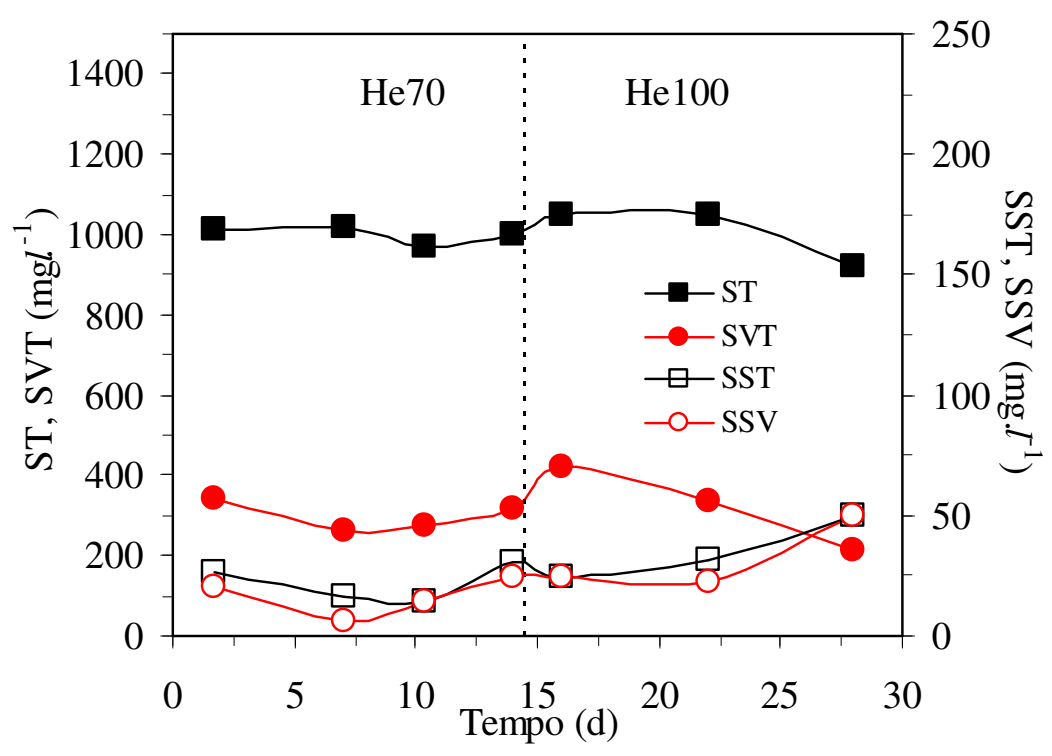

Figura 4.65. Sólidos totais (ST), sólidos voláteis totais (SVT), sólidos suspensos totais (SST) e sólidos suspensos voláteis (SSV) nas condições He70 e He100.

A concentração de matéria orgânica efluente na forma de DQO manteve-se sempre pouco superior a $100 \mathrm{mg} . l^{-1}$ tanto para amostras filtradas como para não filtradas nas duas condições de trabalho. Ao mesmo tempo a eficiência de remoção foi sempre superior a $80 \%$. Enquanto que os valores de alcalinidade a bicarbonato mostram que o 
sistema manteve-se estável, esta confirmada pelo acréscimo de alcalinidade efluente em relação a afluente.

A concentração de ácidos voláteis totais foi baixa durante todo o ensaio, não sendo encontrados valores superiores a $35 \mathrm{mgAc} . l^{-1}$ e valores médios iguais a $24 \pm 4$ mgHAc. $l^{-1}$ e $19 \pm 2$ mgHAc. $l^{-1}$ para as condições He70 e He100, respectivamente. Observou-se aqui uma diminuição no valor de ácidos voláteis com o aumento da rotação do impelidor podendo ser esta uma evidência da melhora na transferência de massa intra-partícula.

Foi observada remoção de sólidos totais de 31,5 e 30,9 \% para He70 e He100, respectivamente, tendo sido os piores valores de remoção de sólidos deste ensaio. Já que para sólidos voláteis totais as remoções foram de 60,8 e 57,4 \%, sólidos suspensos totais 70,3 e 52,7\% e sólidos suspensos voláteis 76,5 e 52,9\% para He70 e He100, respectivamente. Apesar dos melhores valores de remoção de sólidos na condição He70 cabe ressaltar a importância dos altos valores do desvio-padrão encontrados nestas análises.

Ao final das duas condições de operação observou-se o acumulo de material esbranquiçado gelatinoso aparentando ser polímeros extracelulares em toda a superfície do impelidor, este fato demonstrou que, possivelmente, não houve contato entre o impelidor e os grânulos. Esta observação pode ser entendida como uma vantagem do impelidor tipo hélice sobre o tipo turbina, pois em não ocorrer contato direto do impelidor sobre a biomassa, pressupõe-se que esta se mantém integra diminuindo a possibilidade de sua eliminação com o efluente do reator na forma de material particulado. 


\subsubsection{Condição de operação He70}

Os perfis das variáveis concentração de matéria orgânica de amostras filtradas, eficiência de remoção de matéria orgânica, alcalinidade na forma de bicarbonato, ácidos voláteis totais na forma ácido acético, volume acumulado, produção, fração molar no "head-space" e concentração de metano realizados na condição He70 são apresentados da Figura 4.66 à Figura 4.70 e APÊNDICE G.
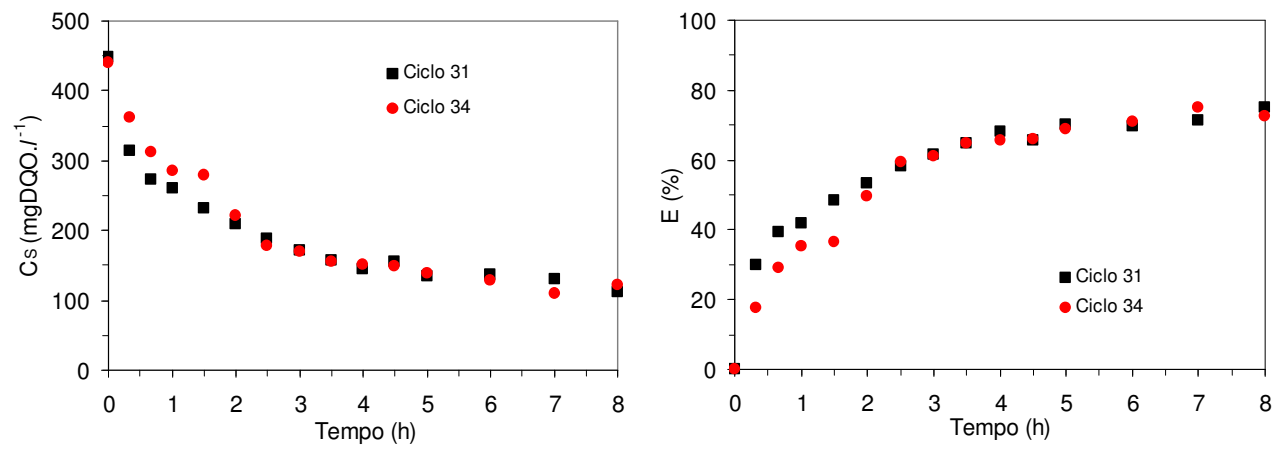

Figura 4.66. Perfis da concentração de matéria orgânica na forma de DQO e da eficiência de conversão ao longo de dois ciclos de operação na condição He70.
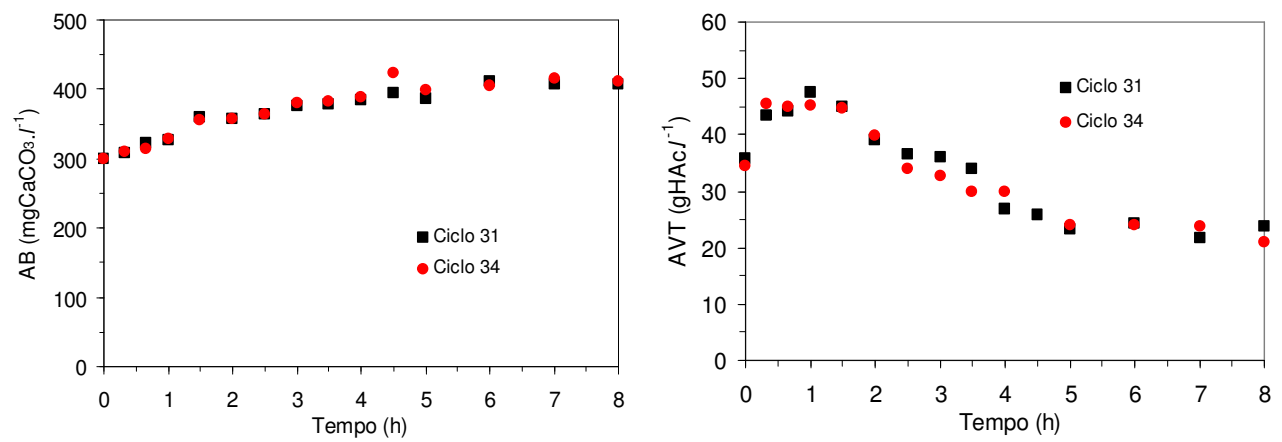

Figura 4.67. Perfis da alcalinidade na forma de carbonato de cálcio e da concentração de ácidos voláteis totais na forma de ácido acético ao longo de dois ciclos de operação na condição He70. 

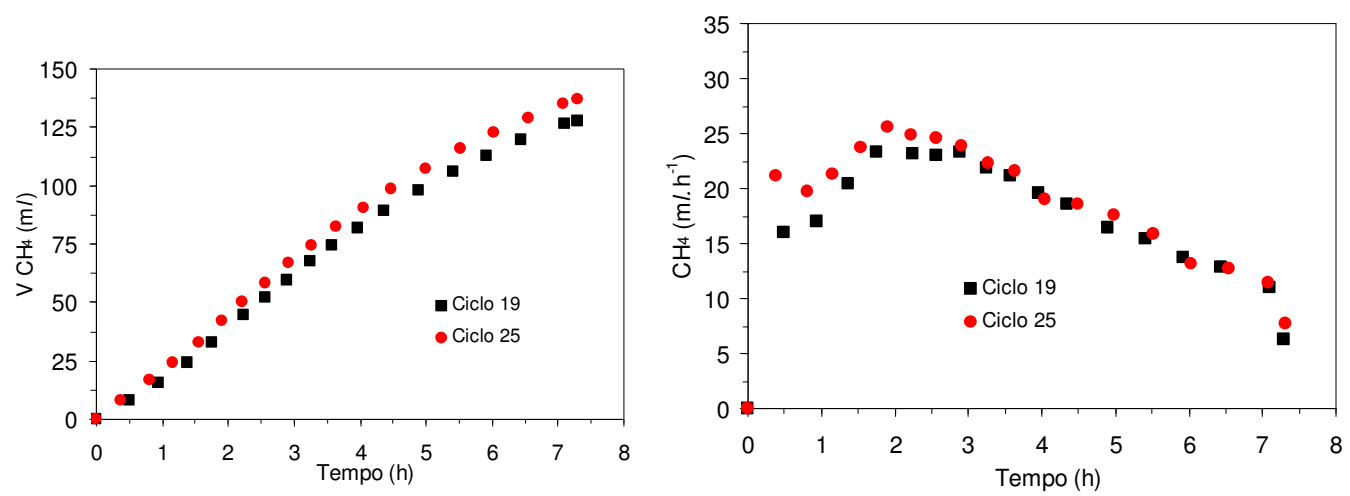

Figura 4.68. Perfis do volume acumulado e da produção de metano no reator ao longo de dois ciclos de operação na condição He70.
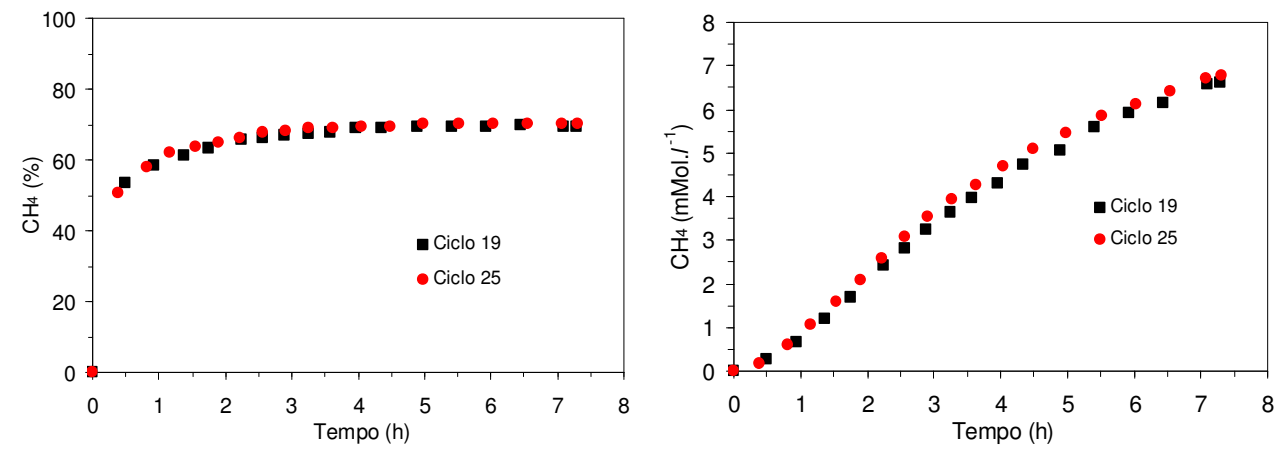

Figura 4.69. Perfis da fração molar e da concentração de metano no "head-space" ao longo de dois ciclos de operação na condição He70.

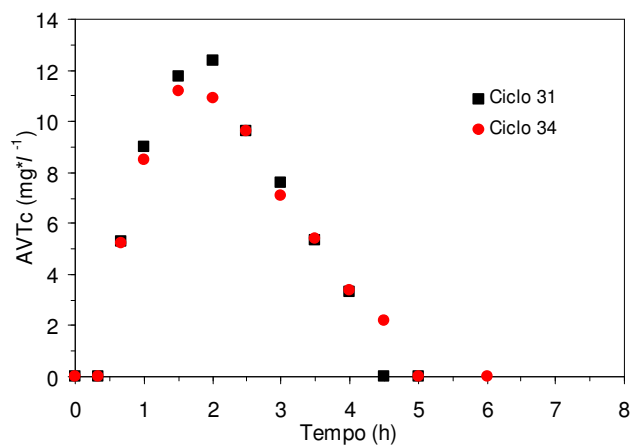

Figura 4.70. Perfis da concentração de ácidos voláteis por cromatografia durante dois ciclos de operação na condição He70.

A remoção de matéria orgânica atingiu seu valor de equilíbrio próximo a $5 \mathrm{~h}$ de ciclo com concentração deste na forma de DQO em torno de $120 \mathrm{mg} . \mathrm{l}^{-1}$ e alcançando eficiência de remoção superior a $70 \%$, valor abaixo do encontrado na Tabela 4.6 de monitoramento em função da diluição do matéria orgânica no reator. 
O pico de ácidos voláteis totais ocorreu dos $20 \mathrm{mim}$ até $1,5 \mathrm{~h}$ de ciclo e concentração inferior a $50 \mathrm{mgHAc} . l^{-1}$. A alcalinidade na forma bicarbonato apresentou somente tendência a subida não sendo afetada pela produção de ácidos. Em ambos os casos o sistema atingiu o equilíbrio somente após a quinta hora de ciclo, fato também ocorrido com ácidos voláteis intermediários, onde a partir da quinta hora não foi mais registrada a presença do ácido propiônico, cujo pico foi próximo a $12 \mathrm{mg} . l^{-1}$ por volta da segunda hora de ciclo e único ácido volátil intermediário identificado nesta condição de operação.

Os perfis de monitoramento de metano mostram que em menos de uma hora a porcentagem de metano no "head-space" já era superior a $60 \%$ e atingindo ao final dos perfis valores próximos a $70 \%$ enquanto que a concentração de metano nos finais dos perfis apresentou valores próximos a $7 \mathrm{mMol} . l^{-1}$. O volume acumulado foi superior a $125 \mathrm{~m} l$ tendo como pico de produção um valor entre 22,5 e $25 \mathrm{ml} \cdot \mathrm{h}^{-1}$ entre a segunda e a terceira horas de ciclo conforme Figura 4.69. 


\subsubsection{Condição de operação He100}

Os perfis das variáveis concentração de substrato de amostras filtradas, eficiência de remoção de matéria orgânica, alcalinidade na forma de bicarbonato, ácidos voláteis totais na forma ácido acético, volume acumulado, produção, fração molar no "head-space" e concentração de metano realizados na condição He100 são apresentados da Figura 4.71 a Figura 4.75 e APÊNDICE G.
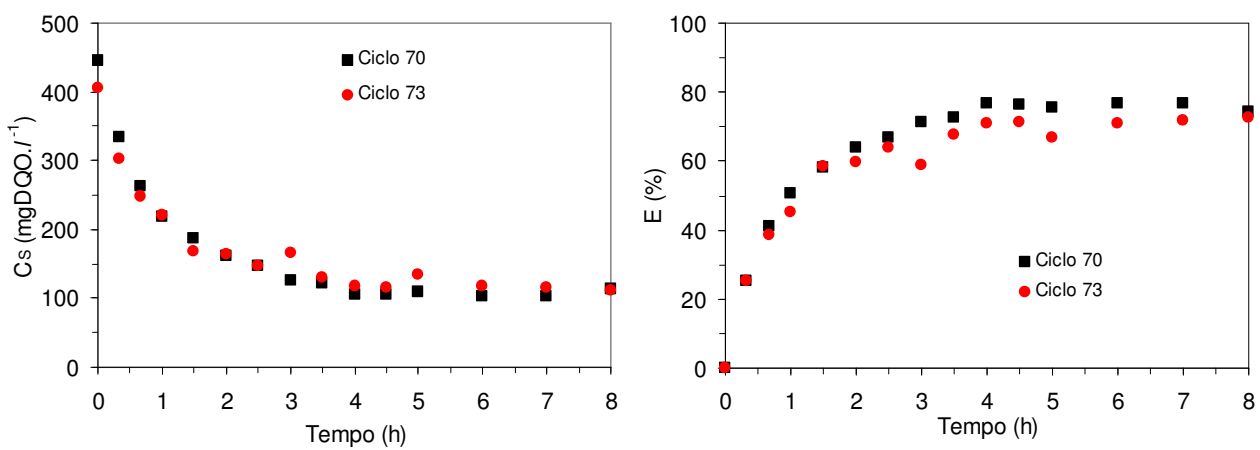

Figura 4.71. Perfis da concentração de matéria orgânica na forma de DQO e da eficiência de conversão ao longo de dois ciclos de operação na condição He100.
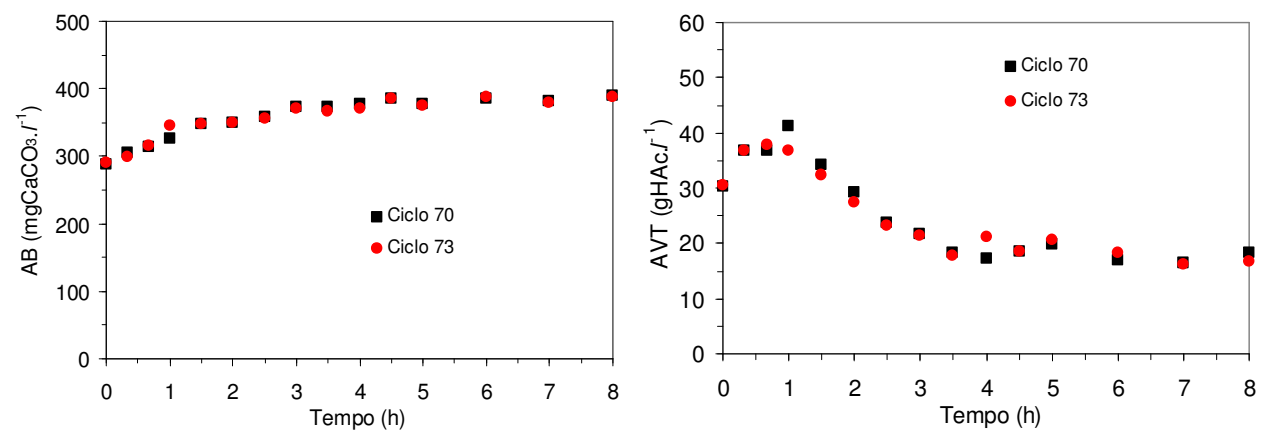

Figura 4.72. Perfis da alcalinidade na forma de bicarbonato de cálcio e da concentração de ácidos voláteis totais na forma de ácido acético ao longo de dois ciclos de operação na condição He100. 

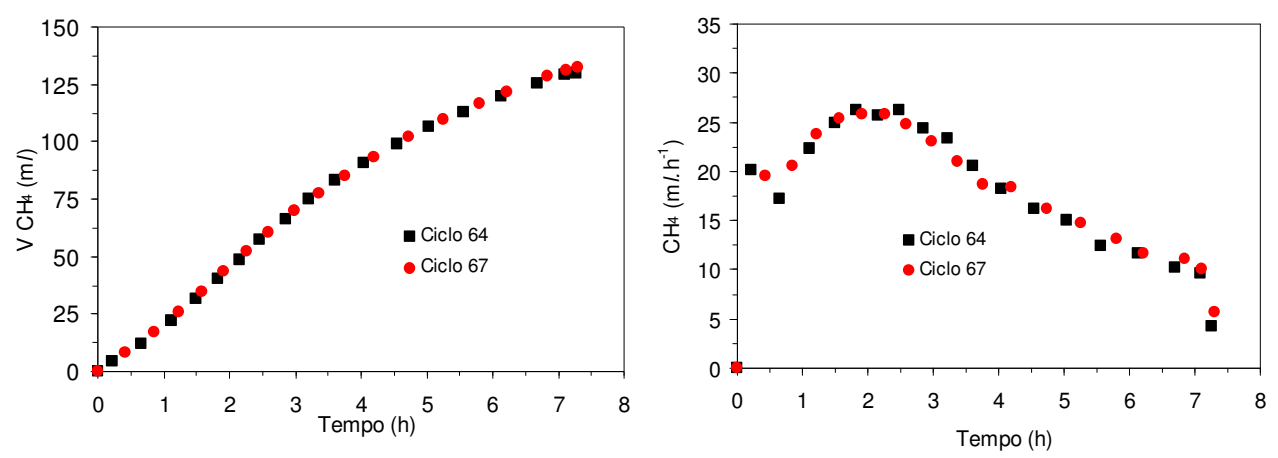

Figura 4.73. Perfis do volume acumulado e da produção de metano no reator ao longo de dois ciclos de operação na condição He100.
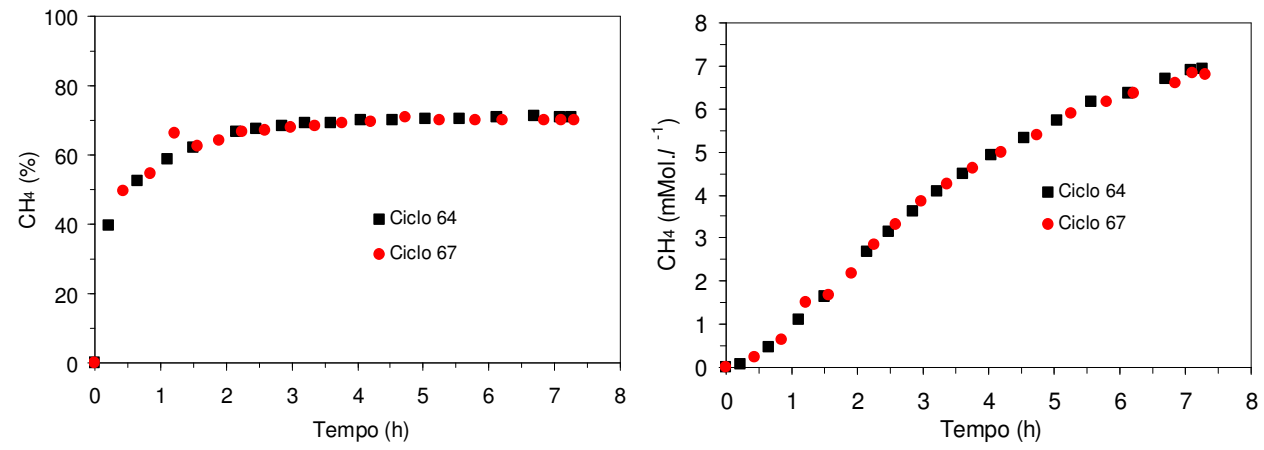

Figura 4.74. Perfis da fração molar e da concentração de metano no "head-space" ao longo de dois ciclos de operação na condição He100.

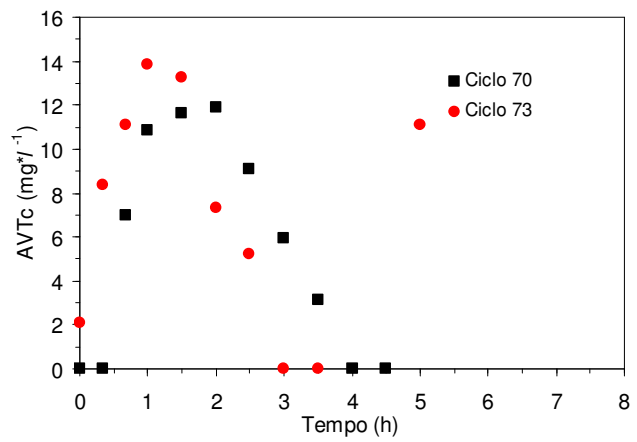

Figura 4.75. Perfis da concentração de ácidos voláteis por cromatografia durante dois ciclos de operação na condição He100.

Observa-se uma rápida degradação da matéria orgânica com valores de concentração residual em torno de $100 \mathrm{mg} . l^{-1}$ e eficiência de remoção de $70 \%$, ambos atingidos em um tempo de ciclo próximo a quatro horas.

A alcalinidade a bicarbonato não aparentou ser influenciada pela produção de ácidos, que apresentou pico de $40 \mathrm{mgAc} . l^{-1}$ entre $20 \mathrm{mim}$ e duas horas de ciclo. Um fato importante a ser observado é que o pico de ácidos voláteis totais na condição He100 foi 
inferior ao observado na condição He70. Também se nota que com $4 \mathrm{~h}$ de ciclo os parâmetros DQO e ácidos voláteis totais já se encontram estáveis. A análise de ácidos voláteis por cromatografia, assim como na condição He70, detectou somente a presença de ácido propiônico, com concentração máxima entre 1,5 e 2,5 h com pico de concentração de $12 \mathrm{mg} . l^{-1}$ a presença deste ácido foi detectada durante $60 \mathrm{mim}$ e $4,5 \mathrm{~h}$ de ciclo.

O volume de metano nos dois ciclos chegou a $130 \mathrm{~m} l$ sendo a velocidade máxima de produção de metano foi entre 1,5 e $3 \mathrm{~h}$ com produção de $25 \mathrm{~m} l \cdot \mathrm{h}^{-1}$ durante este intervalo de tempo. A porcentagem de metano no "head-space" estabilizou próximo a $70 \%$ com concentração de metano de $7 \mathrm{mMol} . l^{-1}$. 


\subsubsection{Impelidor tipo hélice e tubo de tiragem}

Neste ensaio, utilizando impelidor tipo hélice, foi testada a implementação de tubo de tiragem e concêntrico.O reator operou com concentração inicial de esgoto sintético de $800 \mathrm{mgDQO} . l^{-1}$, em ciclos de $8 \mathrm{~h}$ e volume alimentado de $2 l$. Os resultados experimentais deste ensaio são apresentados na Tabela 4.7, da Figura 4.76 à Figura 4.78 e APÊNDICE H.

Tabela 4.7. Valores médios das variáveis monitoradas na operação com impelidor tipo hélice com tubo de tiragem nas condições de operação Hd100 e Hd120.

\begin{tabular}{cccc}
\hline Parâmetro & Afluente & Hd100 & Hd120 \\
\hline Duração ciclos (dias) & - & $1-46(15)$ & $47-87(13)$ \\
$\mathrm{C}_{\mathrm{ST}}\left(\mathrm{mgDQO} . l^{-1}\right)$ & $776 \pm 32(19)$ & $123 \pm 9(10)$ & $124 \pm 7(9)$ \\
$\mathrm{E}_{\mathrm{T}}(\%)$ & - & $84 \pm 1(10)$ & $84 \pm 1(10)$ \\
$\mathrm{C}_{\mathrm{SS}}\left(\mathrm{mgDQO} . l^{-1}\right)$ & - & $106 \pm 6(10)$ & $115 \pm 10(9)$ \\
$\mathrm{E}_{\mathrm{SS}}(\%)$ & - & $86 \pm 1(10)$ & $85 \pm 1(9)$ \\
$\mathrm{V}(l)$ & - & $2,02 \pm 0,03(7)$ & $2,00 \pm 0,02(5)$ \\
$\mathrm{AVT}\left(\mathrm{mgHAc} . l^{-1}\right)$ & $39 \pm 4(17)$ & $18 \pm 4(7)$ & $16 \pm 1(9)$ \\
$\mathrm{AB}\left(\mathrm{mgCaCO} \cdot l^{-1}\right)$ & $228 \pm 14(17)$ & $396 \pm 3(7)$ & $396 \pm 8(9)$ \\
$\mathrm{pH}$ & $8,8 \pm 0,2(17)$ & $6,8 \pm 0,1(8)$ & $6,8 \pm 0,1(9)$ \\
$\mathrm{ST}\left(\mathrm{mg} . l^{-1}\right)$ & $1537 \pm 126(8)$ & $1099 \pm 128(4)$ & $1102 \pm 74(4)$ \\
$\mathrm{SVT}\left(\mathrm{mg} . l^{-1}\right)$ & $854 \pm 96(8)$ & $345 \pm 25(4)$ & $383 \pm 99(4)$ \\
$\mathrm{SST}\left(\mathrm{mg} . l^{-1}\right)$ & $31 \pm 11(8)$ & $69 \pm 15(4)$ & $52 \pm 12(4)$ \\
$\mathrm{SSV}\left(\mathrm{mg} . l^{-1}\right)$ & $26 \pm 10(8)$ & $54 \pm 2(4)$ & $51 \pm 11(4)$ \\
$\mathrm{ST}$ biomassa $\left(\mathrm{g} . l^{-1}\right)$ & - & - & $49,4(1)$ \\
$\mathrm{SFT}$ biomassa $\left(\mathrm{g} . l^{-1}\right)$ & - & - & $7,4(1)$ \\
\hline
\end{tabular}

* Os valores entre parênteses representam o número de amostras 


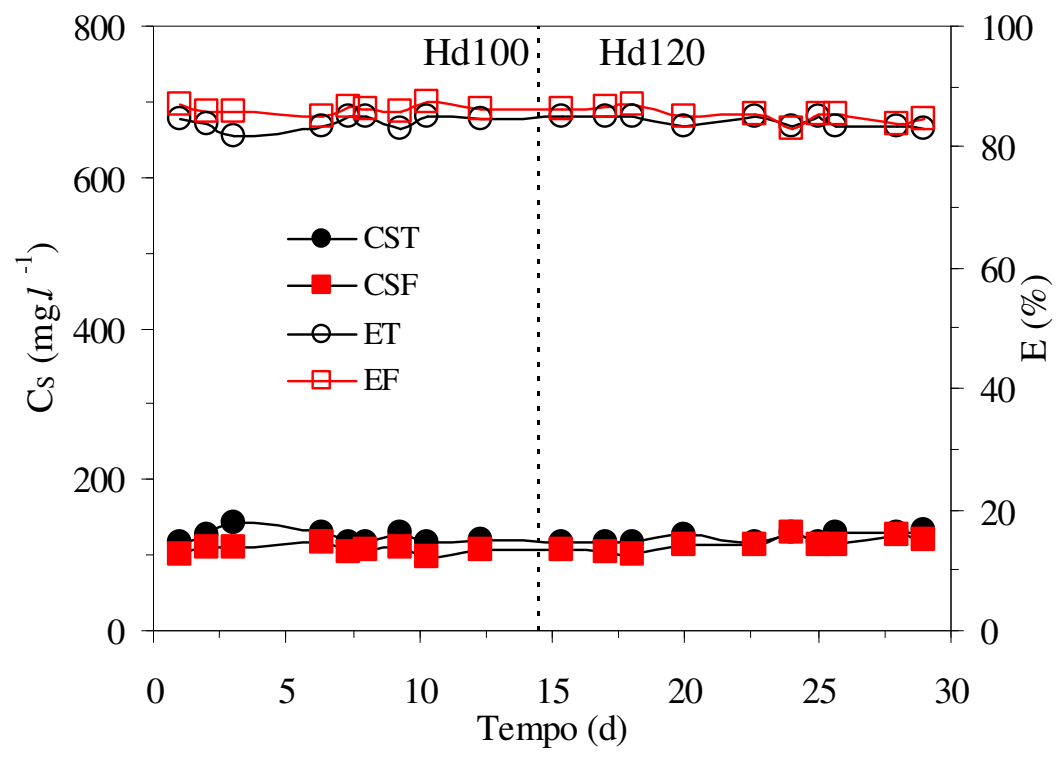

Figura 4.76. Concentração de matéria orgânica efluente e eficiência de remoção utilizando impelidor tipo hélice e reator com tubo de tiragem nas condições Hd100 e Hd120.

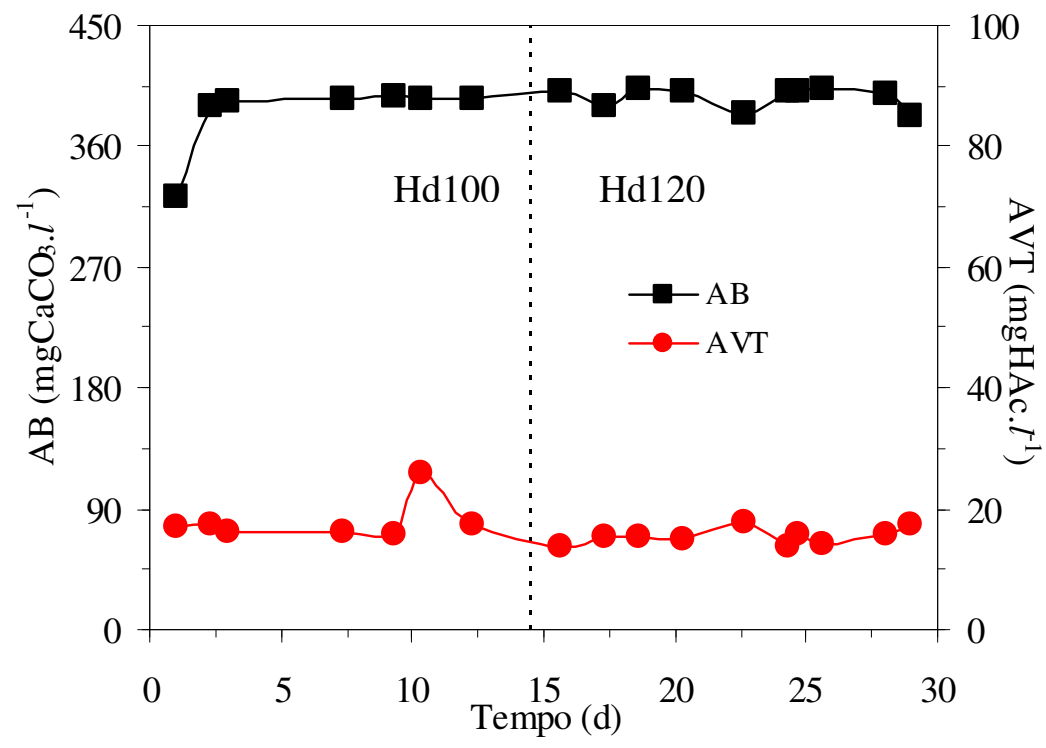

Figura 4.77. Alcalinidade a bicarbonato e Ácidos voláteis totais utilizando impelidor tipo hélice e reator com tubo de tiragem nas condições Hd100 e Hd120. 


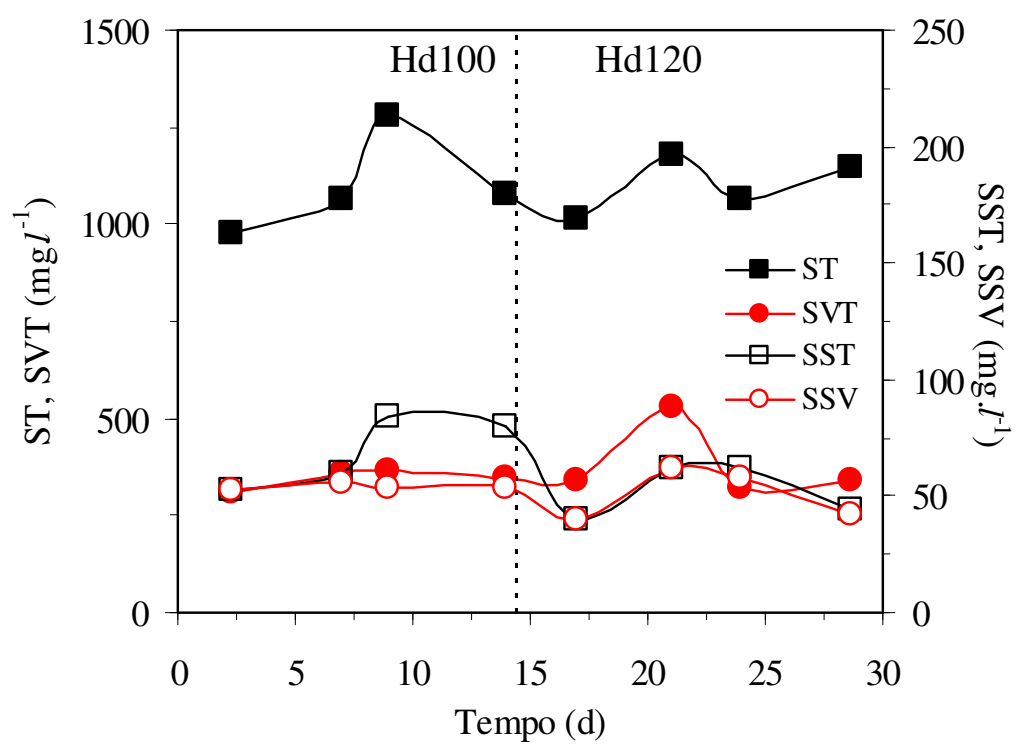

Figura 4.78. Sólidos totais (ST), sólidos voláteis totais (SVT), sólidos suspensos totais (SST) e sólidos suspensos voláteis (SSV) utilizando impelidor tipo hélice e reator com tubo de tiragem nas condições Hd100 e Hd120.

Este ensaio teve duração de 29 dias estudando-se duas condições operacionais, tendo como diferenciais a velocidade de rotação, sendo a primeira a $100 \mathrm{rpm}$ e a segunda a $120 \mathrm{rpm}$ e doravante denominadas condições Hd100 e Hd120, respectivamente. A escolha destas velocidades foi baseada em exigências operacionais, visto que para baixas rotações a movimentação do fluido, promovida pelo impelidor, não é suficiente para fazer com que o fluido suspenda a biomassa na região anular fato que faria com que ocorresse agitação somente dentro do tubo de tiragem e promoveria grande turbulência, podendo provocar a degradação da biomassa. Para rotações superiores a $120 \mathrm{rpm}$ o fluido promoveria suspensão completa o que também poderia romper os grânulos pelo contato intenso com o impelidor. Desta forma, as velocidades de rotação utilizadas encontram-se próximas aos limites impostos pelo sistema.

A concentração de matéria orgânica na forma de DQO para amostras filtradas e para amostras não filtradas apresentou valores muito próximos indicando que a quase totalidade da DQO foi proveniente de material dissolvido dando mais uma indicação da diminuição relativa da quantidade de material particulado no efluente do reator.

A alcalinidade na forma de bicarbonato manteve-se estável durante todo o ensaio e próximo ao valor de $400 \mathrm{mgCaCO}_{3} \cdot l^{-1}$. Os ácidos voláteis mantiveram-se em baixos níveis, não ultrapassando $20 \mathrm{mgAc} . l^{-1}$ na quase totalidade dos pontos. 
Ao final destas duas condições se verificou o acúmulo de material esbranquiçado gelatinoso em todas as superfícies do impelidor confirmando a provável não ocorrência de contato biomassa-impelidor, mesmo porque a utilização do tubo de tiragem tem este como um dos seus princípios de utilização. 


\subsubsection{Condição de operação Hd100}

São representados, da Figura 4.79 à Figura 4.83 e APÊNDICE H, os perfis das variáveis concentração de matéria orgânica de amostras filtradas, eficiência de remoção de matéria orgânica, alcalinidade na forma de bicarbonato, ácidos voláteis totais na forma ácido acético, volume acumulado, produção, fração molar no "head-space" e concentração de metano realizados na condição Hd100.
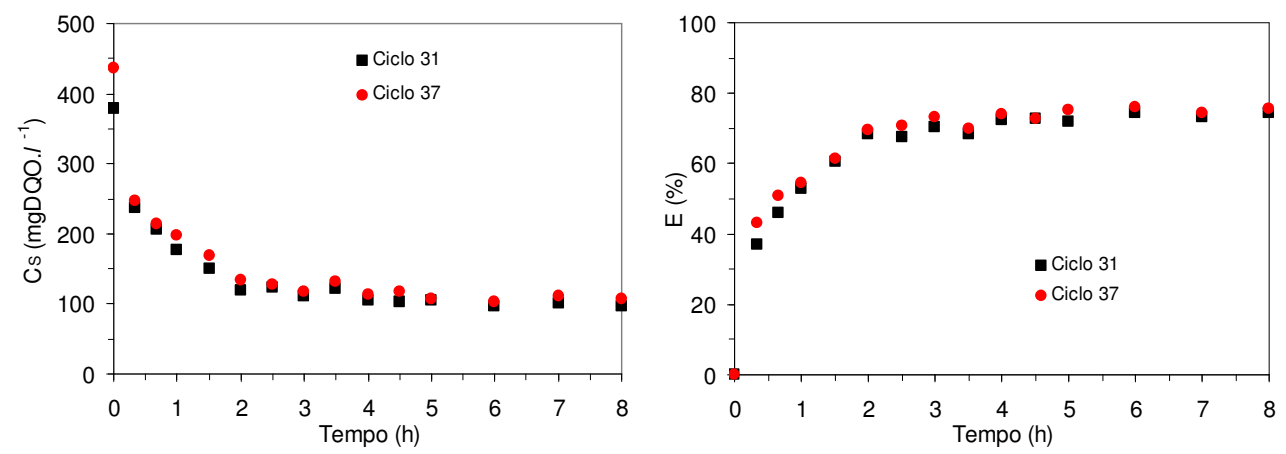

Figura 4.79. Perfis da concentração de matéria orgânica na forma de DQO e da eficiência de conversão ao longo de dois ciclos de operação na condição Hd100.
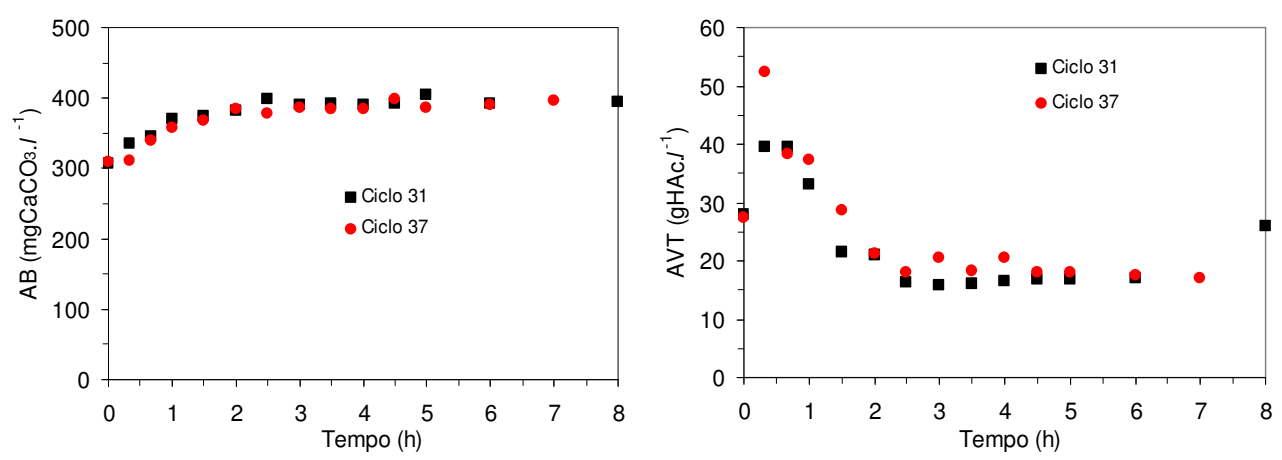

Figura 4.80. Perfis da alcalinidade na forma de bicarbonato de cálcio e da concentração de ácidos voláteis totais na forma de ácido acético ao longo de dois ciclos de operação na condição Hd100. 

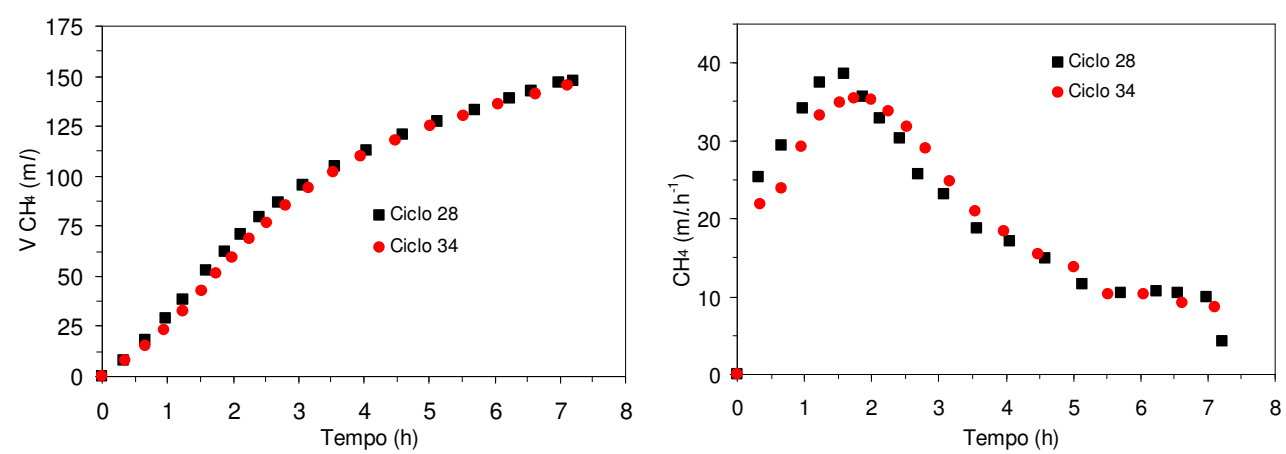

Figura 4.81. Perfis do volume acumulado e da produção de metano no reator ao longo de dois ciclos de operação na condição Hd100.
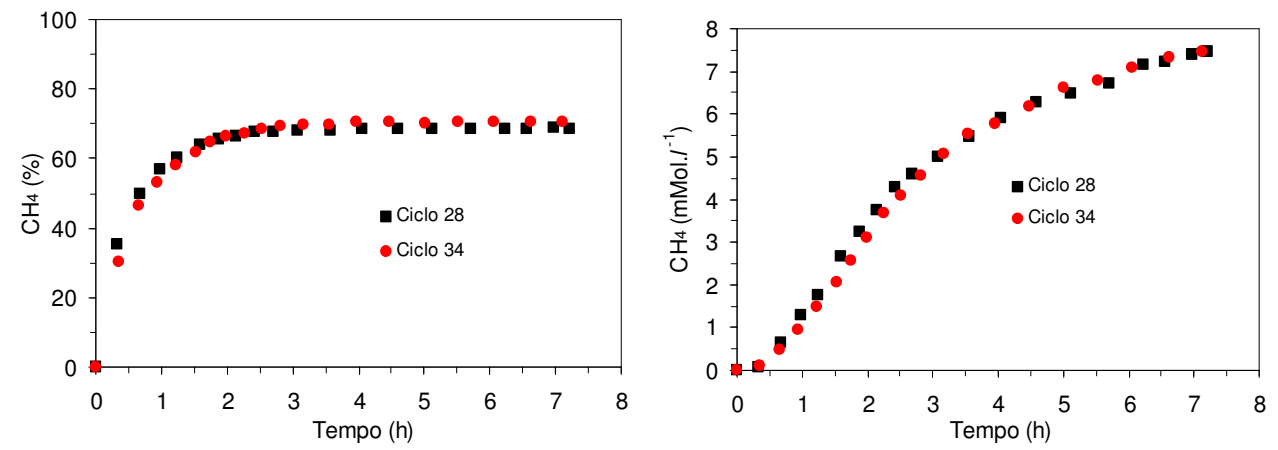

Figura 4.82. Perfis da fração molar e da concentração de metano no "head-space" ao longo de dois ciclos de operação na condição Hd100.

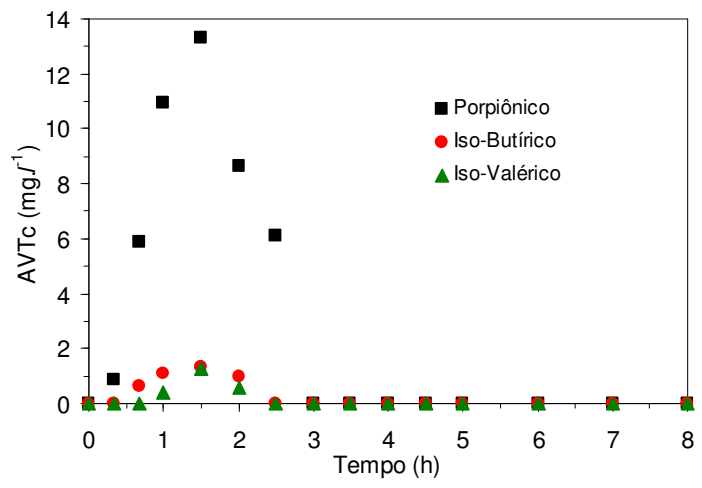

Figura 4.83. Média dos perfis da concentração de ácidos voláteis por cromatografia durante dois ciclos de operação na condição Hd100.

A concentração de matéria orgânica de $133 \mathrm{mgDQO} . l^{-1}$, que corresponde a aproximadamente $70 \%$, foi obtida com duas horas de ciclo. As concentrações finais de matéria orgânica foram de 97 e $106 \mathrm{mgDQO} . l^{-1}$ com respectivas conversões finais de 74,3 e $75,5 \%$ para os ciclos 31 e 37 , respectivamente. Desta forma a utilização de tubo 
de tiragem demonstrou incrementar significativamente a transferência de massa sólidolíquido, diminuindo assim o tempo necessário para degradação da matéria orgânica.

Os perfis de ácidos voláteis totais e alcalinidade na forma de bicarbonato atingiram seus valores de equilíbrio com tempos inferiores a três horas. Este também foi o período de ocorrência dos ácidos voláteis intermediários no qual foram detectados, além do ácido propiônico que atingiu concentração de $15 \mathrm{mg} \cdot l^{-1}$, também o ácido isobutírico e o ácido iso-valerico, estes em menor quantidade não ultrapassando $2 \mathrm{mg} . l^{-1}$.

O volume acumulado de metano atingiu $147 \mathrm{ml}$, com produção máxima obtida entre 1,5 e 2,5 h de ciclo, como observado na Figura 4.81. Outras regiões que podem ser observadas neste perfil são a queda na produção entre 2,5 e $5,5 \mathrm{~h}$ e uma região de produção constante a partir de 5,5 h. A etapa de produção constante pode ser entendida como indício de consumo total de matéria orgânica passível de degradação pela via acetoclástica e conseqüente produção de metano exclusivamente pela via hidrogenotrófica. Este metano produzido pela via hidrogenotrófica tem como substrato o bicarbonato, este se encontra em alta concentração no meio, o que pode caracterizar reação de ordem zero. 


\subsubsection{Condição de operação Hd120}

Os perfis das variáveis concentração de matéria orgânica de amostras filtradas, eficiência de remoção de matéria orgânica, alcalinidade na forma de bicarbonato, ácidos voláteis totais na forma ácido acético, volume acumulado, produção, fração molar no "head-space" e concentração de metano realizados na condição Hd120 são apresentados da Figura 4.84 à Figura 4.88 e APÊNDICE H.
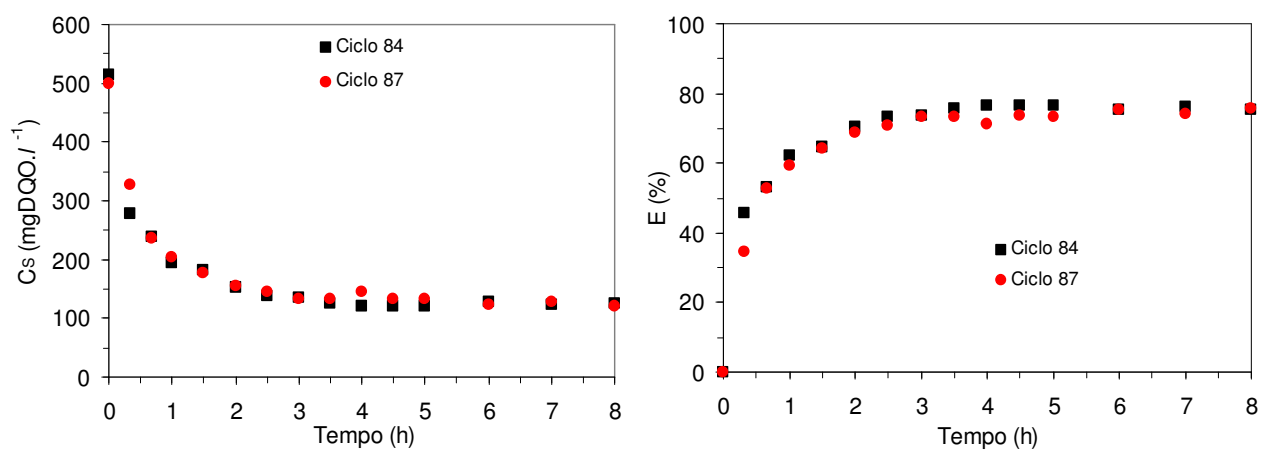

Figura 4.84. Perfis da concentração de matéria orgânica na forma de DQO e da eficiência de conversão ao longo de dois ciclos de operação na condição Hd120
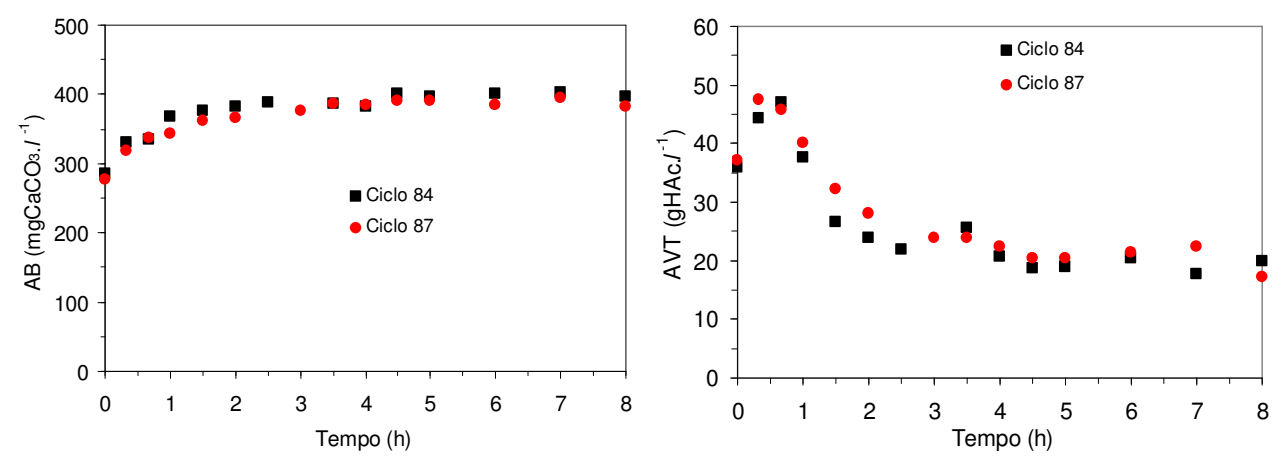

Figura 4.85. Perfis da alcalinidade na forma de bicarbonato de cálcio e da concentração de ácidos voláteis totais na forma de ácido acético ao longo de dois ciclos de operação na condição Hd120. 

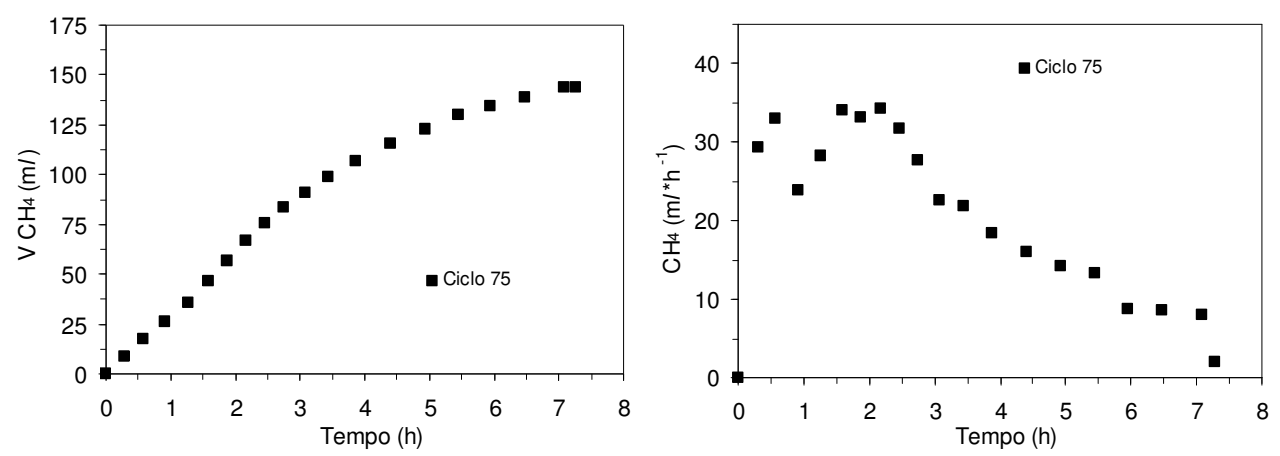

Figura 4.86. Perfis do volume acumulado e da produção de metano no reator ao longo de um ciclo de operação na condição hélice com tubo de tiragem a $120 \mathrm{rpm}$.
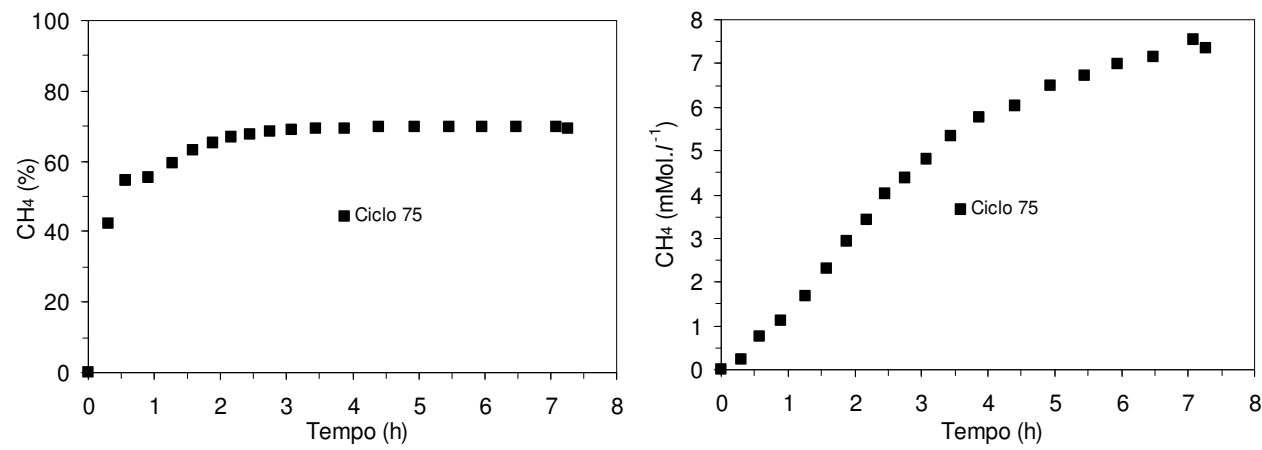

Figura 4.87. Perfis da fração molar e da concentração de metano no "head-space" ao longo de um ciclo de operação na condição Hd120.

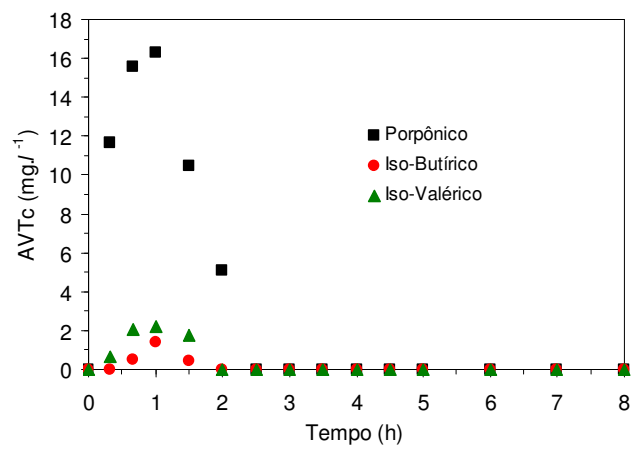

Figura 4.88. Média dos perfis da concentração de ácidos voláteis por cromatografia durante dois ciclos de operação na condição Hd120.

Desempenhos semelhantes são observados entre as condições Hd100 e Hd120. Como, por exemplo, a concentração de matéria orgânica se aproxima da concentração residual rapidamente, isto é, em tempo inferior a três horas de ciclo. O mesmo ocorre com a alcalinidade na forma de bicarbonato.

Os perfis de ácidos voláteis totais demonstram que o pico para este parâmetro teve curta duração (inferior a duas hora), fato confirmado pela análise de ácidos voláteis 
por cromatografia, onde também foi observada a presença de ácido iso-valérico e ácido iso-butírico além do ácido propiônico.

Os perfis de gases mostram que a maior produção de gases ocorre nas três primeiras horas de ensaio, tempo suficiente para a produção de $90 \mathrm{~m} l$ de gás metano nas CNTP. Já o aumento mais acentuado da concentração de metano no "head-space" ocorre até a quarta hora de ciclo onde se atinge concentração de 5,767 mMol. $l^{-1}$ para um tempo de 3,88 h sendo a concentração final de 7,09 mMol. $l^{-1}$.

\subsubsection{Análise microbiana}

Ao final dos experimentos foram coletadas amostras o lodo e do material gelatinoso para análises microbianas. As imagens obtidas foram provenientes de análise com luz visível, não tendo sido possível obter imagens em fluorescência em virtude do tempo de armazenamento anterior à análise.

\section{Inoculo}
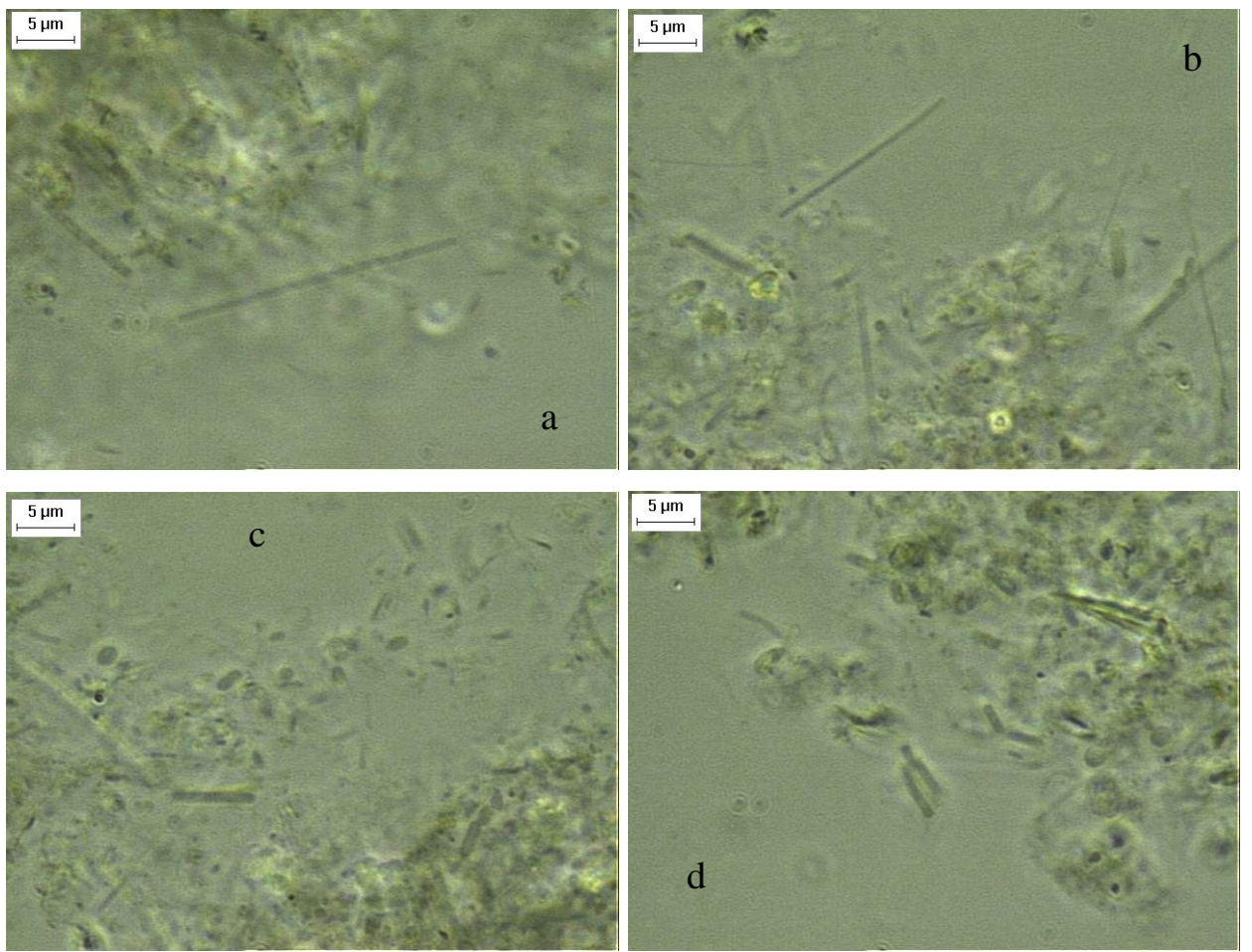

Figura 4.89. Imagens obtidas do inóculo utilizado no reator. 


\section{Lodo do reator}
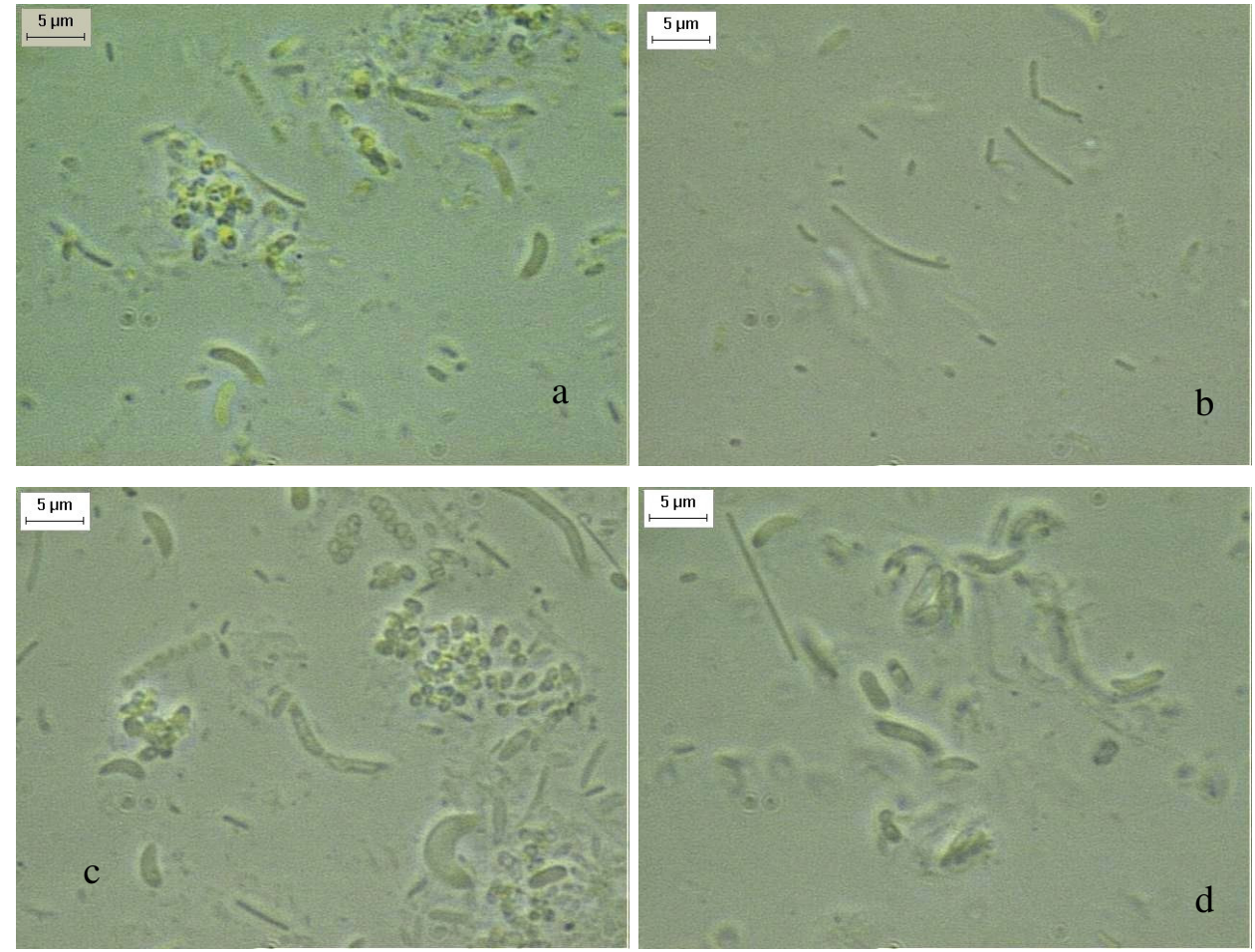

Figura 4.90. Imagens obtidas do lodo proveniente do reator ao final dos experimentos.

As imagens obtidas do inoculo utilizado neste trabalho apresentam grande quantidade de organismos filamentosos, poucos organismos parecidos com cocos ou bacilos. As imagens obtidas do lodo ao final dos experimentos demonstraram ter ocorrido alteração na comunidade microbiana tendo sido observada predominância de bacilos curvos e cocos.

Os filamentos encontrados no inóculo aparentam representar microrganismos semelhantes a Metanosaeta enquanto que os cocos presentes no lodo do reator aparentam-se com microrganismos do tipo Metanosarcina.

Desta forma as alterações mais sensíveis observadas entre o inoculo e a biomassa do reator foram a redução dos microrganismos filamentosos, o aumento dos microrganismos em forma de cocos e a predominância dos bacilos curvos no lodo do reator.Os fatores que influenciaram estas mudanças foram a alteração no substrato fornecido à biomassa antes dos ensaios (resíduos de abatedouro de aves) e durante os ensaios (esgoto sintético) e a mudança na configuração do reator sendo que o inóculo foi retirado de um reator UASB e durante os ensaios operou-se em regime de batelada seqüencial. 


\section{Material gelatinoso}
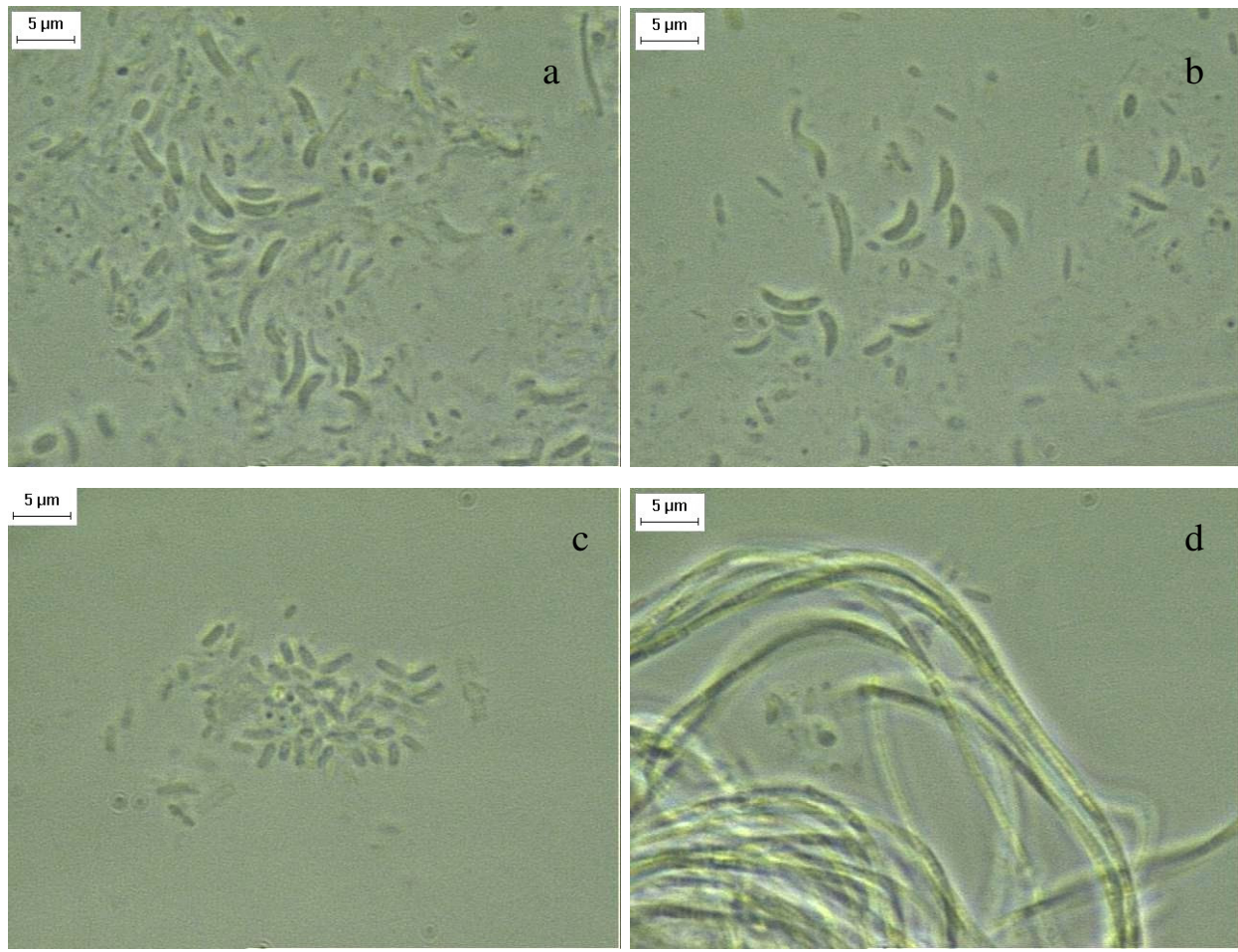

Figura 4.91. Imagens obtidas do material gelatinoso coletado ao final do experimento.

Os bacilos curvos encontrados no lodo do reator também foram encontrados no material gelatinoso formado no reator durante os ensaios estes apresentaram comprimentos próximos a $5 \mu \mathrm{m}$ conforme Figura 4.91 (a e b), também foram visualizados bacilos de menor tamanho Figura 4.91c e filamentos na Figura 4.91d.

Apesar de não haver sido realizada uma análise quantitativa sobre as amostras pôde-se observar que a presença de microrganismos na forma de bacilos curvos foi mais intensa no material gelatinoso quando comparados com a biomassa coletada após o término dos experimentos. 


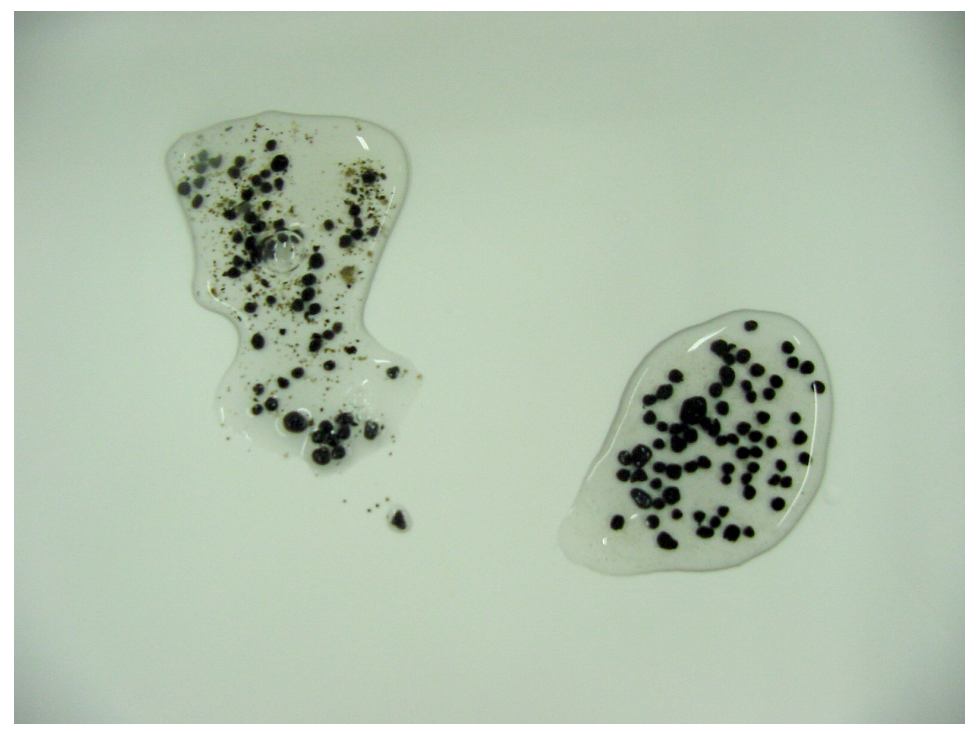

Figura 4.92. Comparação entre o lodo do inoculo (direita) e o lodo do reator após os ensaios (esquerda).

Durante a desmontagem do reator foi observado um tom acinzentado em grande parte dos grânulos da biomassa que dava ao lodo tonalidade parecida, e na Figura 4.92 este é comparado ao lodo do inóculo onde é visível a diferença entre o lodo após o período de realização dos ensaios com partes esbranquiçadas ao lado do inoculo, este totalmente negro e com grânulos mais uniformes.

Uma alíquota do material esbranquiçado é visualizável na Figura 4.93 onde se observa grânulos em meio a pequenas partículas deste material. A quantificação deste material foi inviável em função da dificuldade de separação total desta da biomassa.

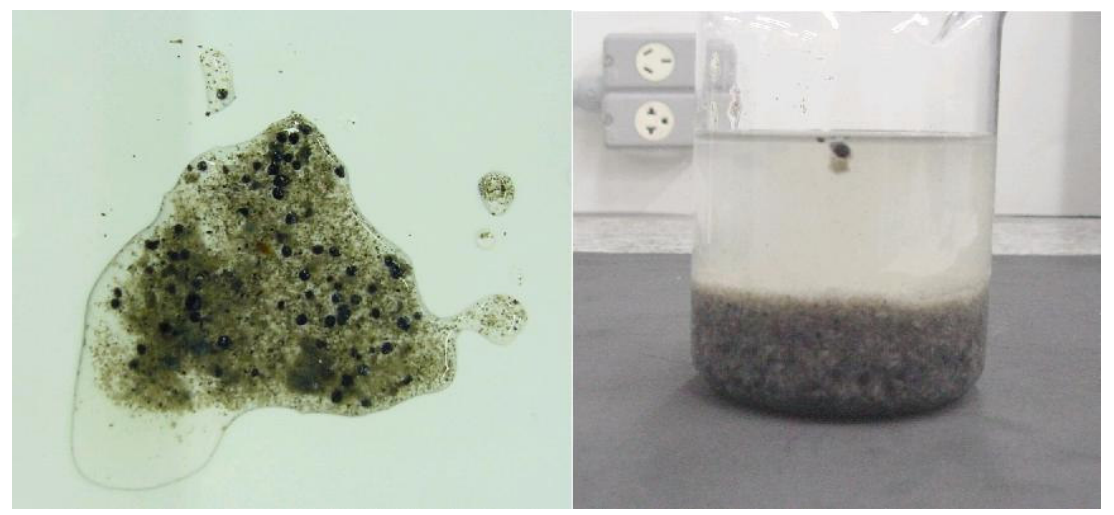

Figura 4.93. Material esbranquiçado gelatinoso coletado da biomassa do reator. 


\subsection{Viabilidade econômica}

As velocidades para cada ensaio estão contidas dentro do intervalo de 300 a 1700 rpm e os valores da relação entre número de potência e número de Reynolds são apresentados na Figura 4.94 e cujos valores numéricos estão no APÊNDICE I.

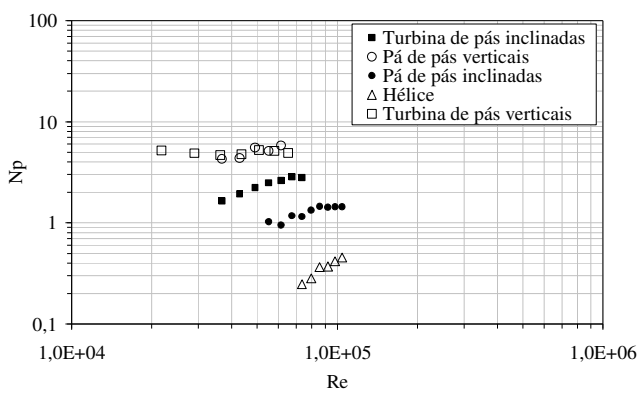

(a)

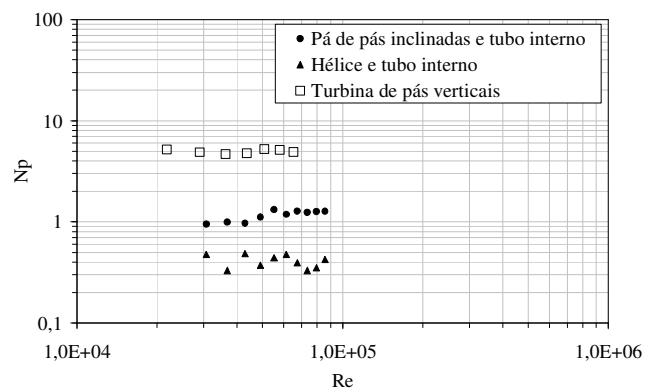

(b)

Figura 4.94. Variação de $\mathrm{N}_{P}$ em função de $\mathrm{N}_{\mathrm{Re}}$ para os ensaios realizados neste trabalho. (a) condições sem tubo de tiragem e (b) condições com tubo de tiragem.

O Número de potência tem a propriedade de tornar-se constante e distinto para cada configuração em altos valores de $\mathrm{N}_{\mathrm{Re}}$ e esta região foi atingida nestes ensaios, pois os valores do adimensional Número de Reynolds foram superiores a $10^{4}$ em todas as condições estudadas. Desta forma a média dos valores de $\mathrm{N}_{\mathrm{P}}$ pôde ser extrapolada como parâmetro da estimativa da potência consumida nos ensaios executados neste trabalho nas velocidades aplicadas durante os estudos de estabilidade e eficiência.

Na Tabela 4.8 são apresentados os valores do número de potência para cada impelidor na região de escoamento turbulento onde este valor é constante, juntamente com o valor da potência volumétrica, extrapolada para cada condição operacional. A potência volumétrica é um parâmetro bastante utilizado em cálculos de aumento de escala. 
Tabela 4.8. Valores médios do número de potência e da potência consumida nas treze condições operacionais deste trabalho.

\begin{tabular}{cccc}
\hline & & \multicolumn{2}{c}{ Potência $\left(\mathrm{kW} / 10^{3} \mathrm{~m}^{3}\right)$} \\
Impelidor & $\mathrm{N}_{\mathrm{P}}$ & $\begin{array}{c}\text { Velocidade } \\
\text { inferior }\end{array}$ & $\begin{array}{c}\text { Velocidade } \\
\text { superior }\end{array}$ \\
\hline Turbina de pás verticais & $5,0 \pm 0,2(7)$ & $5,3 \mathrm{E}-01$ & \\
Turbina de pás inclinadas & $2,6 \pm 0,4(7)$ & $1,8 \mathrm{E}-01$ & $6,1 \mathrm{E}-01$ \\
Pá de pás verticais & $5,0 \pm 0,7(5)$ & $3,5 \mathrm{E}-01$ & $1,2 \mathrm{E}+00$ \\
Pá de pás inclinadas & $1,3 \pm 0,2(9)$ & $8,8 \mathrm{E}-02$ & $3,0 \mathrm{E}-01$ \\
Pá de pás planas inclinadas e & $1,2 \pm 0,1(10)$ & $6,4 \mathrm{E}-01$ & $1,1 \mathrm{E}+00$ \\
tubo de tiragem & & & \\
Hélice & $0,36 \pm 0,08(6)$ & $6,8 \mathrm{E}-02$ & $2,0 \mathrm{E}-01$ \\
Hélice e tubo de tiragem & $0,41 \pm 0,06(10)$ & $2,3 \mathrm{E}-01$ & $3,9 \mathrm{E}-01$ \\
\hline
\end{tabular}

*os valores entre parênteses representam o número de pontos

** o fator conversão de $\mathrm{kW} \cdot 10^{-3} \mathrm{~m}^{-3}$ para HP. $10^{-3} \mathrm{~m}^{-3}$ é $1,3 \mathrm{HP} \cdot \mathrm{kW}^{-1}$

Como visto na literatura (RUSHTON et al, 1950) os impelidores tipo turbina e tipo pá, de pás planas verticais, são os maiores promotores de turbulência e com isto são os impelidores que geram maior transferência de energia para os meios líquidos. Esta característica é vantajosa para sistemas aeróbios em função destes necessitarem de alta turbulência para promoverem a dispersão de oxigênio no meio líquido, porém para sistemas anaeróbios a transferência de oxigênio não é o objetivo e sim a mistura do meio líquido, que pode ser atingida com um consumo de energia muito inferior.

A utilização de impelidores tipo turbina e tipo pá, ambos de pás planas inclinadas e com valores próximos a 2,6 e $1,3 \mathrm{~kW} \cdot 10^{-3} \mathrm{~m}^{-3}$, respectivamente, não promoveu a transferência de potência conseguida pelos de pás planas verticais. E o impelidor tipo hélice foi o responsável pela menor transferência de potência dentre os impelidores avaliados.

A utilização de tubo de tiragem em conjunto com os impelidores tipo pá de pás planas inclinadas e hélice não gerou alteração no número de potência destes impelidores quando comparados à operação destes sem tubo de tiragem. Esta constância pode ser entendida como vantajosa pois o caso do impelidor tipo hélice operando a $100 \mathrm{rpm}$ quando comparadas as condições sem e com tubo de tiragem consomem a mesma 
quantidade de potência, entretanto, para o caso do sistema com tubo de tiragem os problemas de transferência de massa externa aos grânulos são minimizados pela suspensão completa.

Os valores requeridos de potência volumétrica foram inferiores a $1 \mathrm{~kW} \cdot 10^{-3} \cdot \mathrm{m}^{-3}$ para todas as condições exceção da condição Pa75, que teve o maior valor de consumo de potência e igual a $1,2 \mathrm{~kW} \cdot 10^{-3} \cdot \mathrm{m}^{-3}$.

O livro da companhia Metcalf \& Eddy (2003) em sua quarta edição, página 448, sugere como valores típicos de requerimento de energia, em sistemas aeróbios, para manter regime de mistura completa com agitadores mecânicos de 20 a $40 \mathrm{~kW} \cdot 10^{-3} \cdot \mathrm{m}^{-3}$, dependendo do tipo e desenho do aerador. E o que se pode observar, através da Tabela 4.8 é que a potência necessária para promover mistura em sistemas anaeróbios equivale a menos que $5 \%$ do que é sugerido para sistemas aeróbios. Desta forma, o argumento de que a utilização de agitação em sistemas anaeróbios inviabilizaria o processo por causa do aumento da necessidade energética cai por terra.

\subsection{Visão holística sobre as condições estudadas}

\subsubsection{Monitoramento dos sistemas}

Neste tópico são apresentados comparativamente os valores de monitoramento dos ensaios realizados durante este projeto de mestrado. Em uma primeira etapa são analisados os ensaios realizados com os impelidores na busca pela melhor configuração, na segunda etapa é testada a utilização de tubo de tiragem em conjunto com o impelidor tipo pá de pás planas inclinadas e com o impelidor tipo hélice.

\subsubsection{Sistemas convencionais}

Na Tabela 4.9 são apresentados os parâmetros monitorados durante a realização dos ensaios com os seguintes impelidores sem o uso de tubo de tiragem:

- Tipo turbina de pás planas verticais na rotação de 50 rpm denominada Tu50;

- Tipo turbina de pás planas inclinadas nas rotações de 50 e 75 rpm, denominadas Ti50 e Ti75, respectivamente; 
- Tipo pá de pás planas verticais nas rotações de 50 e 75 rpm, denominadas Pa50 e Pa75, respectivamente;

- Tipo pá de pás planas inclinadas nas rotações de 50 e 75 rpm, denominadas Pi50 e Pi75, respectivamente e;

- Tipo hélice nas rotações de 70 e 100 rpm, denominadas He50 e He75, respectivamente.

Os maiores valores de eficiência de remoção de matéria orgânica em amostras filtradas foram obtidos nas condições Tu50, Ti50, Pi50 e Pi75 todos com valor de $87 \pm 1 \%$ de remoção e a diferença entre valores em condições dentro de um mesmo ensaio demonstra que não foi observado valor ótimo nos intervalos de rotação estudado.

As condições Pa50 e Pa75 apresentaram os piores desempenhos em termos de remoção de matéria orgânica na forma de DQO, apresentando $82 \pm 2$ e $83 \pm 1 \%$ para amostras filtradas e $79 \pm 2$ e $77 \pm 1 \%$ para amostras totais, respectivamente. Estranhamente os impelidores promotores de escoamento radial apresentaram o melhor e o pior desempenho dentre as condições estudadas, Tu50 e Pa50, respectivamente.

Ainda em termos de remoção de matéria orgânica na forma de DQO observa-se pouca diferença entre valores de concentração de matéria orgânica em amostras filtradas e não filtradas nas quais a diferença esteve entre $3 \%$ e $4 \%$ para a maior parte das condições e de $6 \%$ para as condições Pa75 e Pi50, levantando assim um indício da não degradação da biomassa presente no reator.

Os valores de concentração de ácidos voláteis totais e de alcalinidade na forma de bicarbonato apresentaram comportamentos semelhantes não produzindo variações significativas entre cada condição dentro de um mesmo ensaio, isto é, os valores de ácidos voláteis totais e de alcalinidade a bicarbonato mantiveram-se estáveis não produzindo valor ótimo de rotação para cada ensaio. Ao se comparar resultados de ácidos voláteis totais e alcalinidade a bicarbonato entre diferentes impelidores, novamente não foi observada variação marcante entre estes, indicando que o tipo de escoamento não altera significativamente estes parâmetro para o sistema que, ressaltando, foi operado em baixas cargas orgânicas.

Nas nove condições estudadas a remoção de sólidos totais foi próxima a 32 \% e a remoção de sólidos totais teve melhores resultados através da condição Tu50 e muita similaridade nas outras condições estudadas. Porém é necessário ressaltar que os valores de sólidos neste estudo têm relevância quando do estudo da perda de biomassa por 
rompimento dos grânulos do sistema, fato não ocorrido nos ensaios desenvolvidos, pois o efluente era sintético com baixa concentração de sólidos.

Os valores de sólidos obtidos da biomassa ao final de cada condição operacional fornecem um valor aproximado da concentração de sólidos totais e da concentração de sólidos fixos totais do lodo utilizado no experimento sem, contudo, fornecer valores conclusivos sobre mudança na densidade ou teor de sólidos fixos ao longo das condições operacionais estudadas.

De uma forma geral, através da Tabela 4.9, não há clara uma configuração que seja destacada pelo melhor desempenho na análise dos parâmetros de monitoramento dos sistemas, tornando necessária uma outra forma de avaliação, através da análise dos valores dos parâmetros do modelo cinético de primeira ordem. 
Tabela 4.9. Valores médios das variáveis monitoradas nas condições sem uso de tubo de tiragem.

\begin{tabular}{|c|c|c|c|c|c|c|c|c|c|c|}
\hline Parâmetro & Afluente & Tu50 $0^{(*)}$ & Ti50 & Ti75 & Pa50 & Pa75 & Pi50 & Pi75 & $\mathrm{He} 70$ & He100 \\
\hline $\mathrm{C}_{\mathrm{ST}}\left(\mathrm{mgDQO} \cdot l^{-1}\right)$ & $787 \pm 17$ & $125 \pm 11$ & $131 \pm 13$ & $143 \pm 13$ & $167 \pm 19$ & $185 \pm 8$ & $141 \pm 16$ & $129 \pm 13$ & $154 \pm 16$ & $146 \pm 9$ \\
\hline $\mathrm{C}_{\mathrm{SS}}\left(\mathrm{mgDQO} \cdot l^{-1}\right)$ & - & $102 \pm 9$ & $106 \pm 8$ & $113 \pm 7$ & $144 \pm 17$ & $139 \pm 11$ & $101 \pm 7$ & $100 \pm 11$ & $124 \pm 11$ & $116 \pm 5$ \\
\hline $\mathrm{E}_{\mathrm{T}}(\%)$ & - & $84 \pm 1$ & $84 \pm 2$ & $82 \pm 2$ & $79 \pm 2$ & $77 \pm 1$ & $81 \pm 2$ & $83 \pm 2$ & $80 \pm 2$ & $81 \pm 1$ \\
\hline $\mathrm{E}_{\mathrm{SS}}(\%)$ & - & $87 \pm 1$ & $87 \pm 1$ & $86 \pm 1$ & $82 \pm 2$ & $83 \pm 1$ & $87 \pm 1$ & $87 \pm 1$ & $84 \pm 1$ & $85 \pm 1$ \\
\hline $\operatorname{AVT}\left(\operatorname{mgHAc} . l^{-1}\right)$ & $40 \pm 3$ & $20 \pm 3$ & $19 \pm 1$ & $19 \pm 2$ & $22 \pm 5$ & $21 \pm 3$ & $17 \pm 2$ & $17 \pm 2$ & $24 \pm 4$ & $19 \pm 2$ \\
\hline $\mathrm{AB}\left(\mathrm{mgCaCO}_{3} \cdot l^{-1}\right)$ & $220 \pm 6$ & $389 \pm 24$ & $392 \pm 12$ & $385 \pm 14$ & $379 \pm 10$ & $375 \pm 18$ & $397 \pm 14$ & $395 \pm 6$ & $380 \pm 26$ & $366 \pm 18$ \\
\hline $\mathrm{pH}$ & $8,9 \pm 0,2$ & $6,72 \pm 0,09$ & $6,82 \pm 0,05$ & $6,75 \pm 0,06$ & $6,79 \pm 0,03$ & $6,79 \pm 0,05$ & $6,77 \pm 0,05$ & $6,77 \pm 0,04$ & $6,83 \pm 0,09$ & $6,81 \pm 0,05$ \\
\hline $\mathrm{ST}\left(\mathrm{mg} \cdot 1^{-1}\right)$ & $1545 \pm 76$ & $908 \pm 129$ & $1041 \pm 40$ & $1075 \pm 37$ & $1073 \pm 53$ & $1100 \pm 74$ & $1036 \pm 55$ & $1113 \pm 61$ & $999 \pm 22$ & $1007 \pm 74$ \\
\hline $\operatorname{SVT}\left(\mathrm{mg} . l^{-1}\right)$ & $841 \pm 49$ & $258 \pm 41$ & $336 \pm 50$ & $334 \pm 38$ & $340 \pm 34$ & $344 \pm 15$ & $327 \pm 27$ & $356 \pm 63$ & $299 \pm 37$ & $325 \pm 104$ \\
\hline $\operatorname{SST}\left(\mathrm{mg} \cdot l^{-1}\right)$ & $49 \pm 16$ & $62 \pm 26$ & $77 \pm 31$ & $69 \pm 9$ & $70 \pm 10$ & $67 \pm 17$ & $67 \pm 15$ & $81 \pm 24$ & $22 \pm 8$ & $35 \pm 13$ \\
\hline $\operatorname{SSV}\left(\mathrm{mg} . l^{-1}\right)$ & $42 \pm 17$ & $53 \pm 30$ & $61 \pm 12$ & $55 \pm 12$ & $60 \pm 3$ & $65 \pm 16$ & $66 \pm 15$ & $60 \pm 13$ & $16 \pm 8$ & $32 \pm 15$ \\
\hline STbiomassa $\left(\mathrm{g} . l^{-1}\right)$ & - & - & 66,5 & 46,0 & 46,5 & 59,4 & 57,5 & 61,6 & 39,9 & 42,3 \\
\hline SFTbiomassa $\left(\mathrm{g} \cdot l^{-1}\right)$ & - & - & 8,4 & 6,1 & 5,5 & 6,7 & 8,0 & 7,1 & 5,3 & 5,4 \\
\hline
\end{tabular}

(*) ensaio realizado em uma única condição por ser utilizado para fins de comparação 



\subsubsection{Sistemas com uso de tubo de tiragem}

A Tabela 4.10 apresenta os valores médios das variáveis de monitoramento nas condições operacionais em que foi utilizado o tubo de tiragem.

Tabela 4.10. Valores médios das variáveis monitoradas nas condições com uso de tubo

\begin{tabular}{|c|c|c|c|c|c|}
\hline Parâmetro & Afluente & $\operatorname{Pd} 100$ & Pd120 & Hd100 & Hd120 \\
\hline $\mathrm{C}_{\mathrm{ST}}\left(\mathrm{mgDQO} \cdot l^{-1}\right)$ & $787 \pm 17$ & $146 \pm 8$ & $127 \pm 9$ & $123 \pm 9$ & $124 \pm 7$ \\
\hline $\mathrm{C}_{\mathrm{SS}}\left(\mathrm{mgDQO} . l^{-1}\right)$ & - & $125 \pm 7$ & $113 \pm 8$ & $106 \pm 6$ & $115 \pm 10$ \\
\hline $\mathrm{E}_{\mathrm{T}}(\%)$ & - & $82 \pm 1$ & $84 \pm 1$ & $84 \pm 1$ & $84 \pm 1$ \\
\hline $\mathrm{E}_{\mathrm{SS}}(\%)$ & - & $84 \pm 1$ & $86 \pm 1$ & $86 \pm 1$ & $85 \pm 1$ \\
\hline $\operatorname{AVT}\left(\operatorname{mgHAc} . l^{-1}\right)$ & $40 \pm 3$ & $18 \pm 3$ & $14 \pm 2$ & $18 \pm 4$ & $16 \pm 1$ \\
\hline $\mathrm{AB}\left(\mathrm{mgCaCO}_{3} \cdot l^{-1}\right)$ & $220 \pm 6$ & $374 \pm 10$ & $376 \pm 5$ & $396 \pm 3$ & $396 \pm 8$ \\
\hline $\mathrm{pH}$ & $8,9 \pm 0,2$ & $6,86 \pm 0,03$ & $6,81 \pm 0,08$ & $6,8 \pm 0,1$ & $6,8 \pm 0,1$ \\
\hline $\mathrm{ST}\left(\mathrm{mg} \cdot \mathrm{l}^{-1}\right)$ & $1545 \pm 76$ & $1069 \pm 77$ & $1069 \pm 47$ & $1099 \pm 128$ & $1102 \pm 74$ \\
\hline $\operatorname{SVT}\left(\mathrm{mg} . l^{-1}\right)$ & $841 \pm 49$ & $357 \pm 62$ & $363 \pm 26$ & $345 \pm 25$ & $383 \pm 99$ \\
\hline $\operatorname{SST}\left(\mathrm{mg} . l^{-1}\right)$ & $49 \pm 16$ & $65 \pm 6$ & $70 \pm 13$ & $69 \pm 15$ & $52 \pm 12$ \\
\hline $\operatorname{SSV}\left(\mathrm{mg} . l^{-1}\right)$ & $42 \pm 17$ & $46 \pm 5$ & $66 \pm 11$ & $54 \pm 2$ & $51 \pm 11$ \\
\hline STbiomassa $\left(\mathrm{g} . l^{-1}\right)$ & - & 69,2 & 56,5 & - & 49,4 \\
\hline SFTbiomassa $\left(\mathrm{g} . l^{-1}\right)$ & - & 9,5 & 7,8 & - & 7,4 \\
\hline
\end{tabular}

As quatro condições apresentaram desempenhos muito semelhantes em termos de remoção de carga orgânica na forma total e filtrada para as condições Pd120, Hd100 e Hd120 e estas pouco superiores à condição Pd100 fazendo com que não se tenha um valor ótimo de velocidade rotacional nas rotações estudadas.

A diferença entre os valores de remoção total e remoção em amostras filtradas apresentou-se muito baixa fornecendo a informação de que a quase totalidade da matéria orgânica presente nos efluentes das condições estudadas era proveniente de matéria orgânica não degradada e não de degradação de material biológico do reator.

Os valores médios de ácidos voláteis totais mantiveram-se inferiores a 20 mgHAc. $l^{-1}$ em todas as condições, sendo muito pequena a diferença dos valores de 
ácidos voláteis totais entre as condições sem que se torne possível a obtenção de uma condição de operação ótima para a remoção de ácidos voláteis totais.

A alcalinidade a bicarbonato não demonstrou variação dentro de uma mesma condição, tanto quando entre as condições Pd100 e Pd120 quanto entre as condições Hd100 e Hd120. Ao se analisar os valores de alcalinidade a bicarbonato entre os dois impelidores observa-se que as condições Hd100 e Hd120 apresentaram valores mais elevados do que nas condições Pd100 e Pd120.

As análises de sólidos nestas quatro condições mostram muita similaridade com as condições sem utilização de tubo de tiragem, não apresentando diferenças significativas entre impelidores nem entre as condições de um mesmo impelidor. E como ocorrido nas condições de operação sem utilização de tubo de tiragem, as análises de sólidos demonstram não ter ocorrido perda de sólidos em suspensão na descarga do reator.

A análise dos parâmetros de monitoramento na Tabela 4.10 não foi suficiente para determinar uma condição ótima de operação dentre as condições estudadas. A comparação entre as condições em que o tubo de tiragem foi inserido com as condições onde este aparato não foi utilizado, isto é, comparação entre Tabela 4.9 e Tabela 4.10 mostram muita similaridade

\subsubsection{Perfis temporais}

A estabilidade e constância dos valores das variáveis de monitoramento dentre as condições avaliadas nesta pesquisa tornaram ainda mais relevante a importância dos resultados obtidos através da análise dos parâmetros cinéticos no intuito de se obter uma configuração ótima dentre as estudadas.

As equações de modelo utilizadas neste trabalho para representar a variação ao longo de um ciclo operacional da concentração de matéria orgânica (equação 3.17), de ácidos voláteis totais (equação 3.18) e de metano no "head-space" (equação 3.19) e desenvolvidas em materiais e métodos são aqui reescritas nas equações 4.1, 4.2 e 4.3.

$$
\begin{gathered}
\left(C_{S}-C_{S r}\right)=\left(C_{S 0}-C_{S r}\right) \exp \left(-k_{1 S} t\right) \\
\left(C_{A V T}-C_{A V T r}\right)=\left(C_{A V T 0}-C_{A V T r}\right) \exp \left(-k_{2 A V T} t\right)+\left(C_{S 0}-C_{S r}\right) k_{1 A V T}\left[\frac{\exp \left(-k_{1 A V T} t\right)}{\left(k_{2 A V T}-k_{1 A V T}\right)}+\frac{\exp \left(-k_{2 A V T} t\right)}{\left(k_{1 A V T}-k_{2 A V T}\right)}\right]
\end{gathered}
$$




$$
C_{M}=\left(C_{A V T 0}-C_{A V T r}\right)\left[1-\exp \left(-k_{2 M} t\right)\right]+\left(C_{S 0}-C_{S r}\right)\left[1+\frac{k_{2 M} \exp \left(-k_{1 M} t\right)}{\left(k_{1 M}-k_{2 M}\right)}+\frac{k_{1 M} \exp \left(-k_{2 M} t\right)}{\left(k_{2 M}-k_{1 M}\right)}\right]
$$

Os parâmetros foram obtidos por ajuste não linear usando o método LevenbergMarquardt com o software Microcal Origin 6.1®, onde os subscritos S, AVT e M indicam a equação usada para estimar o parâmetro, desta forma $\mathrm{k}_{1 \mathrm{~S}}$, $\mathrm{k}_{1 \mathrm{AVT}}$ e $\mathrm{k}_{1 \mathrm{M}}$ são os valores do parâmetro $\mathrm{k}_{1}$ estimado pelas equações 4.1, 4.2 e 4.3, respectivamente. $\mathrm{O}$ mesmo ocorre para o parâmetro $\mathrm{k}_{2}$.

A seguir, da Figura 4.95 à Figura 4.97 são apresentados os valores experimentais dos perfis temporais das variáveis concentração de matéria orgânica, concentração de ácidos voláteis totais e de metano em conjunto com os ajustes do modelo cinético proposto, representados pelas equações $4.1,4.2$ e 4.3, respectivamente para as treze condições experimentais.

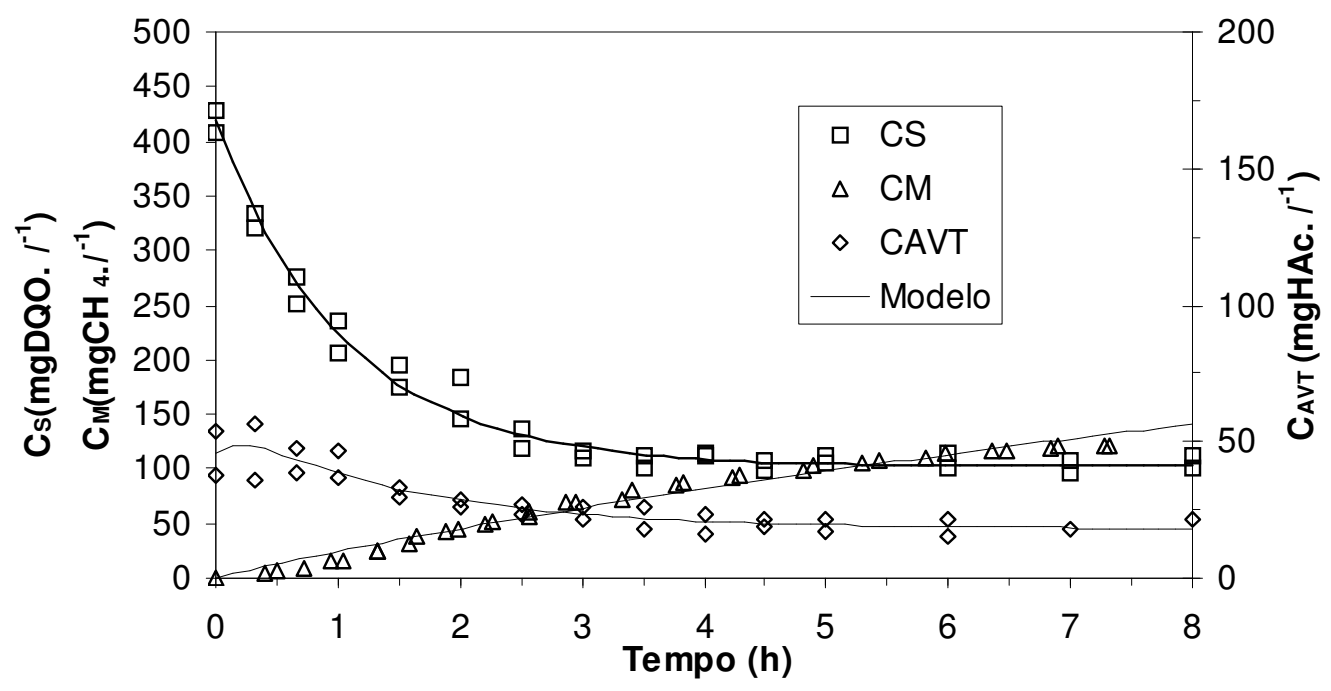

Figura 4.95. Valores experimentais e ajuste do modelo cinético na condição Tu50. 


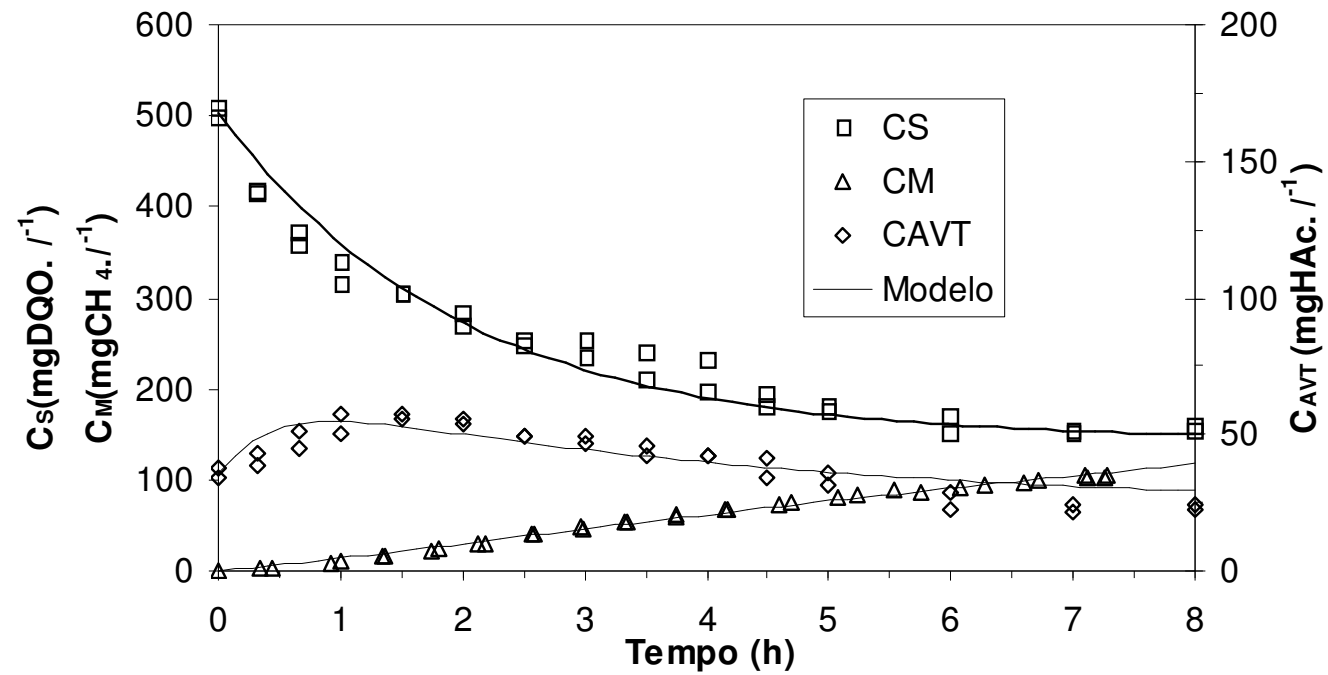

Figura 4.96. Valores experimentais e ajuste do modelo cinético na condição Pa50.

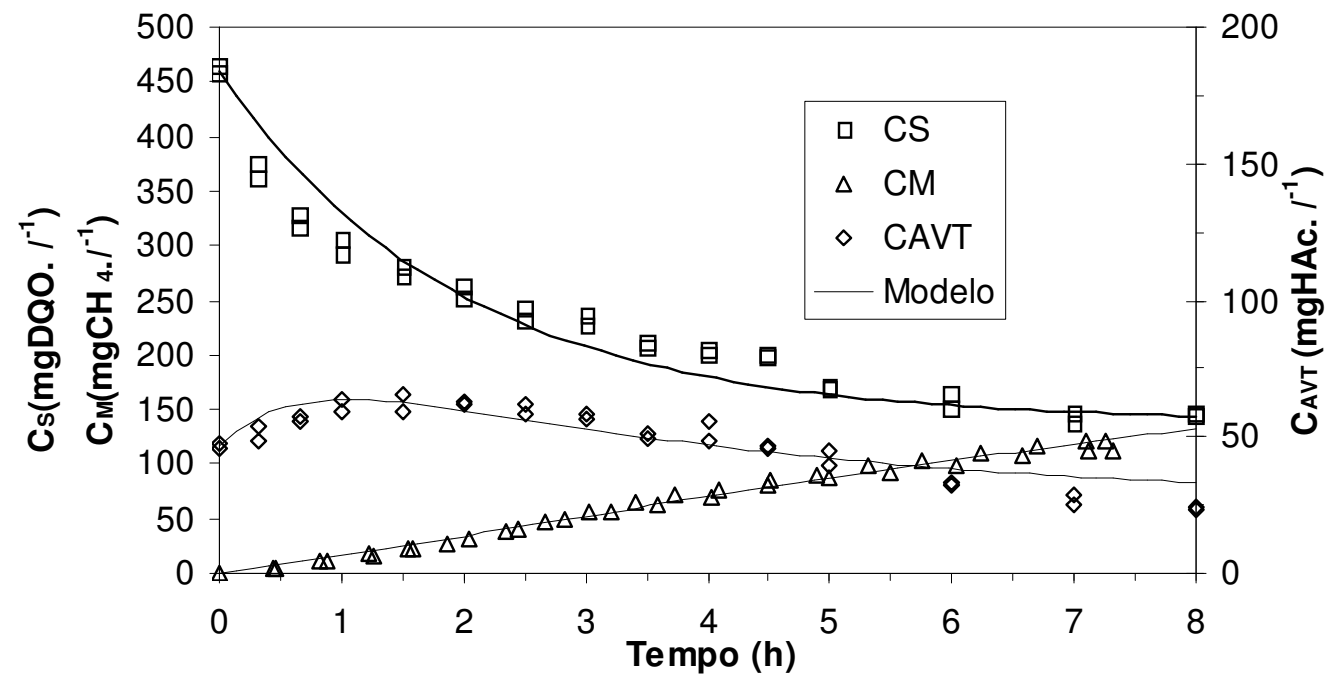

Figura 4.97. Valores experimentais e ajuste do modelo cinético na condição Pa75. 


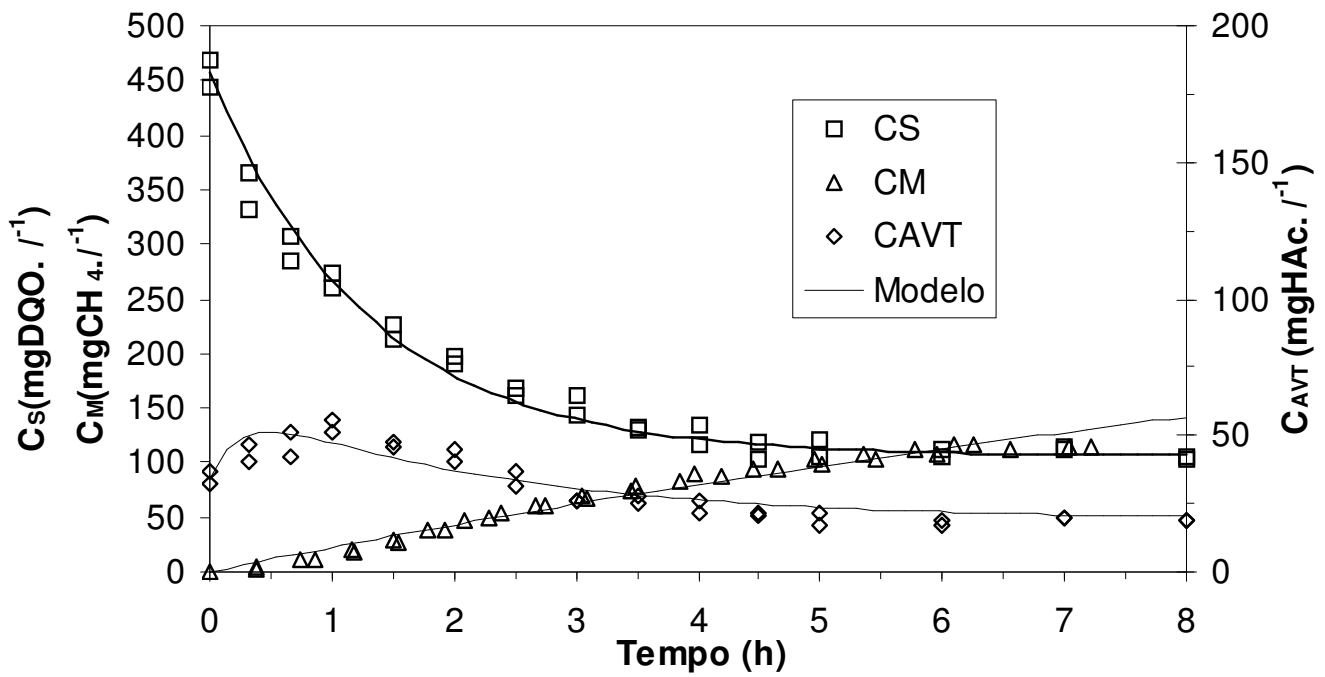

Figura 4.98. Valores experimentais e ajuste do modelo cinético na condição Ti50.

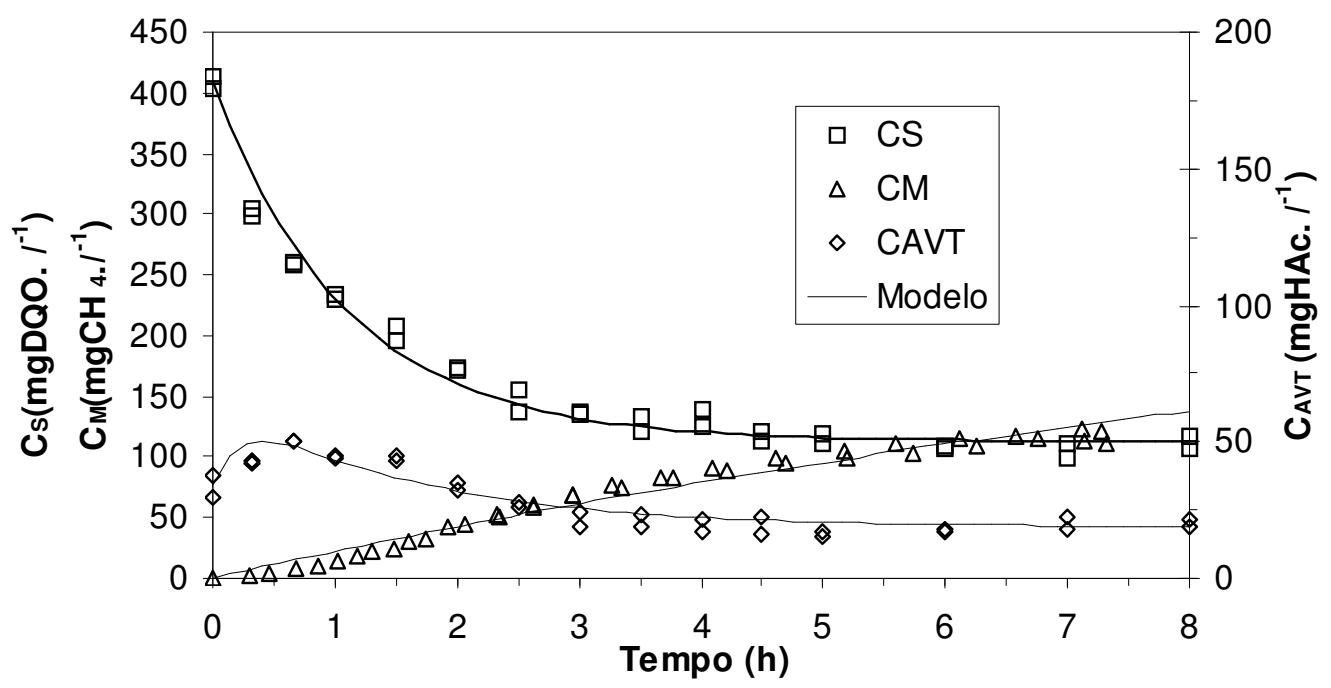

Figura 4.99. Valores experimentais e ajuste do modelo cinético na condição Ti75. 


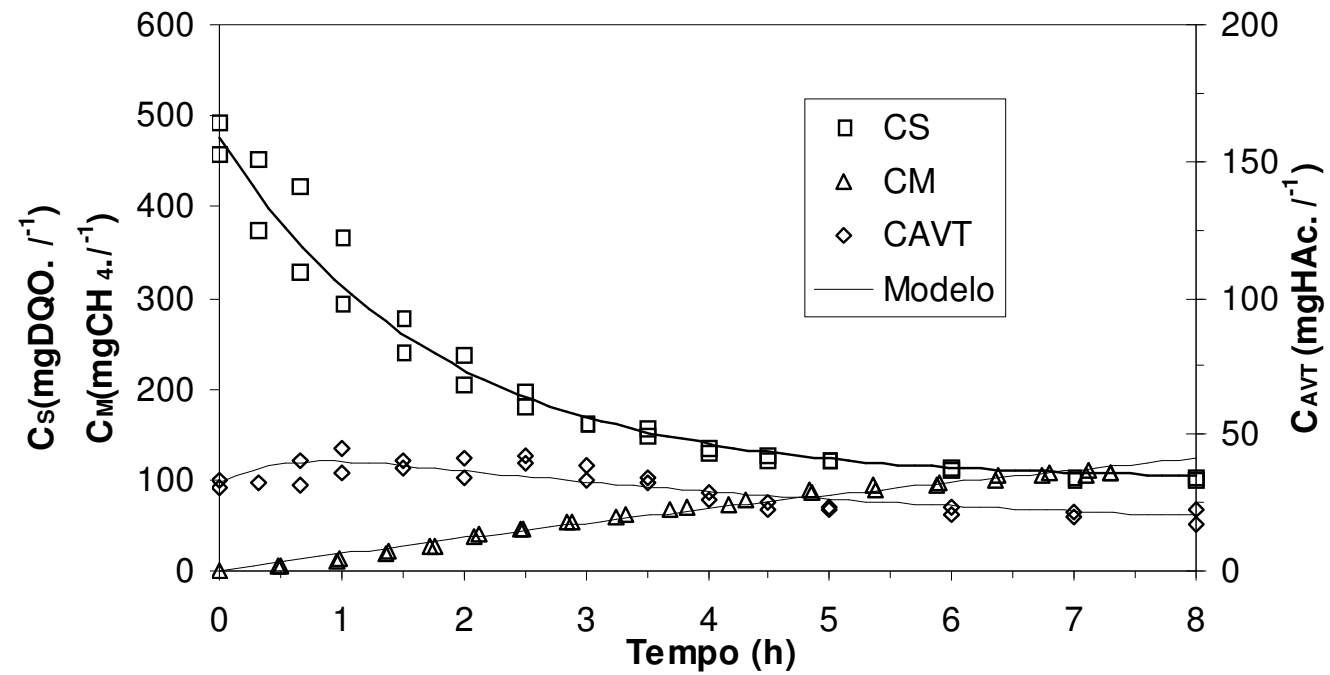

Figura 4.100. Valores experimentais e ajuste do modelo cinético na condição Pi50.

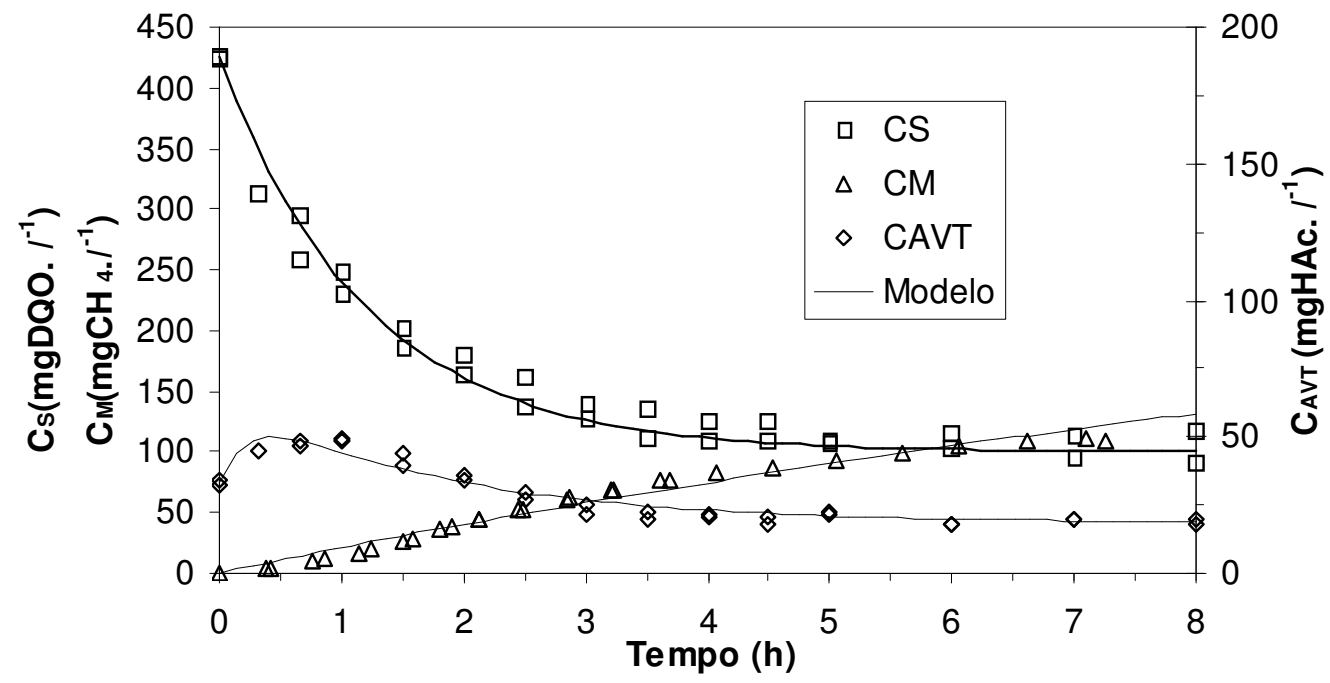

Figura 4.101. Valores experimentais e ajuste do modelo cinético na condição Pi75. 


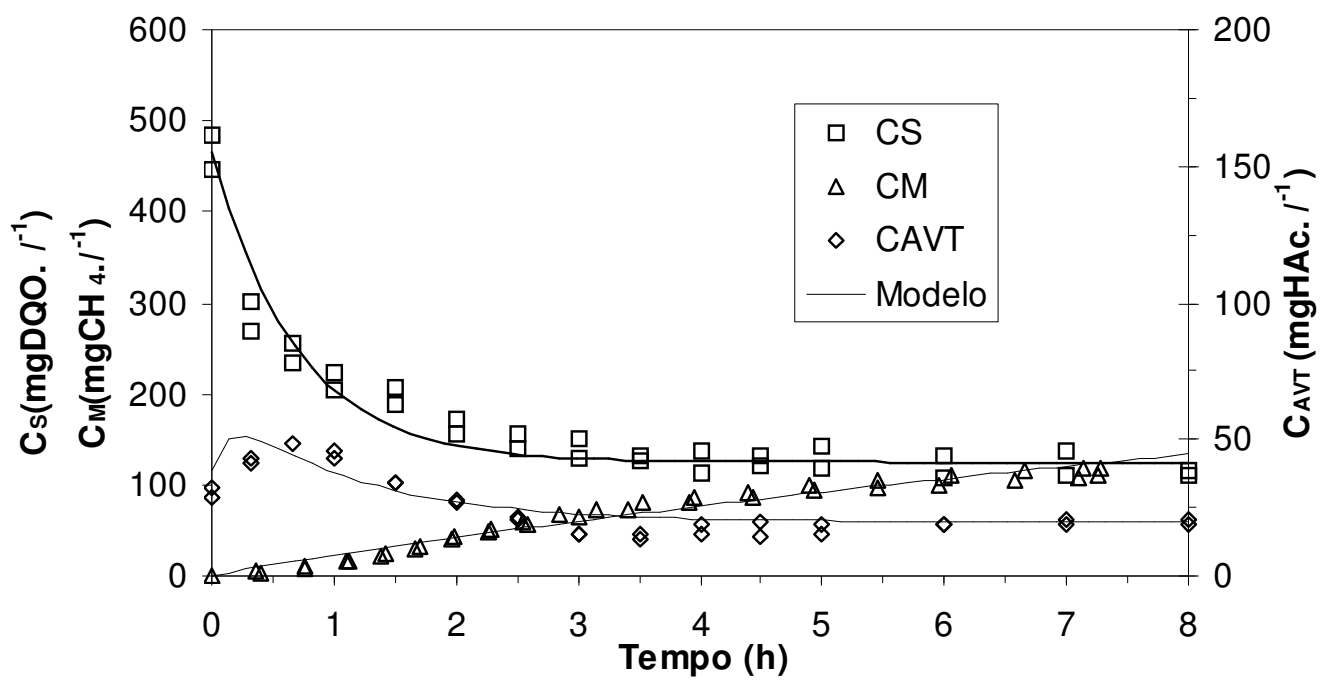

Figura 4.102. Valores experimentais e ajuste do modelo cinético na condição Pd100.

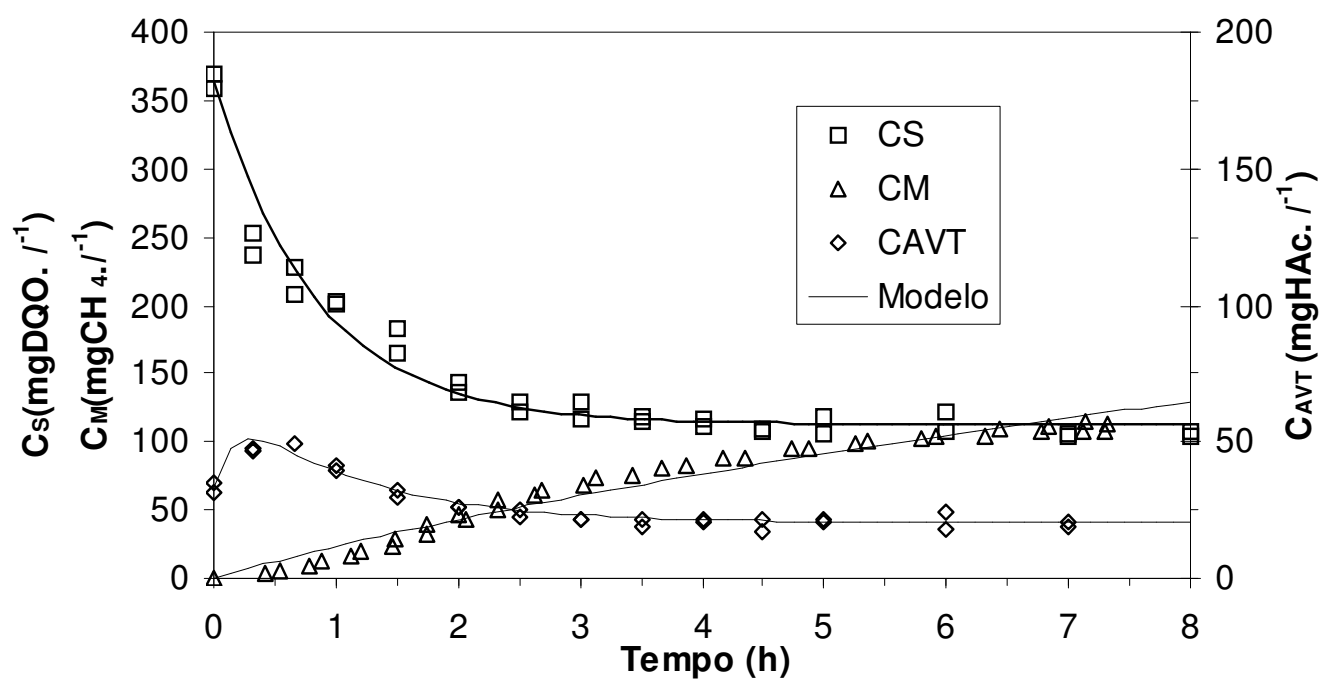

Figura 4.103. Valores experimentais e ajuste do modelo cinético na condição Pd120. 


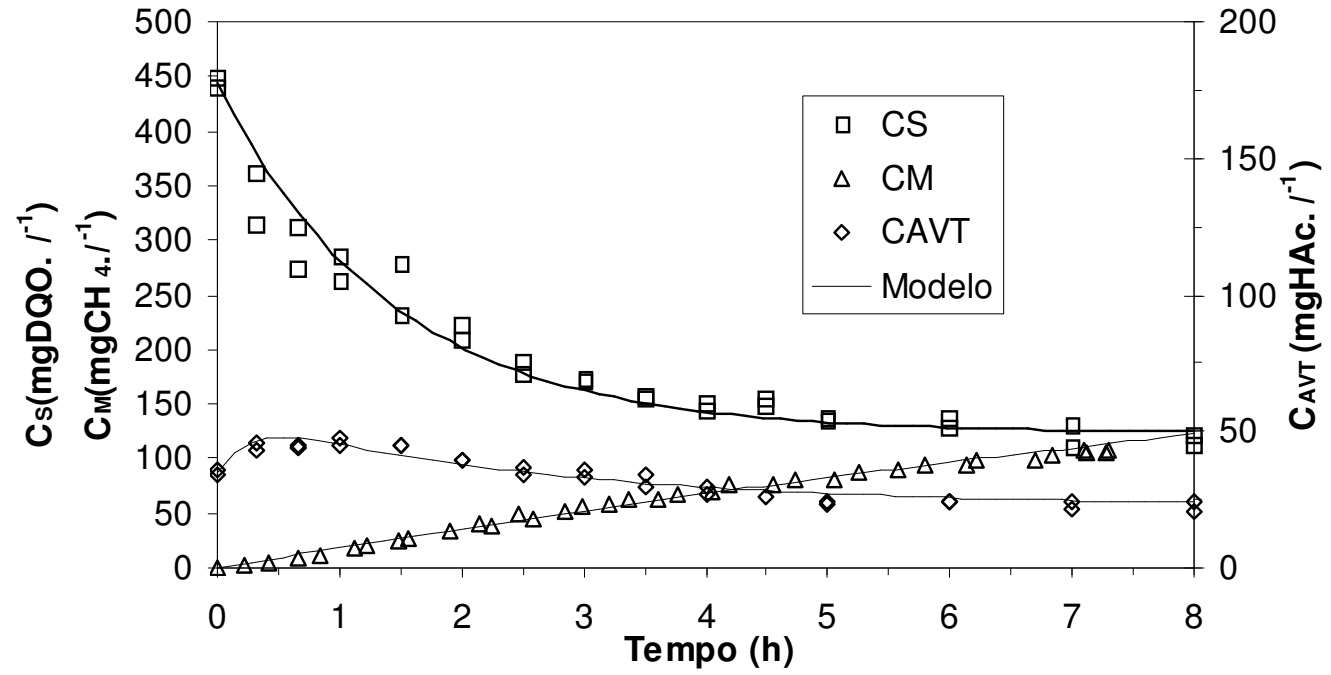

Figura 4.104. Valores experimentais e ajuste do modelo cinético na condição He70.

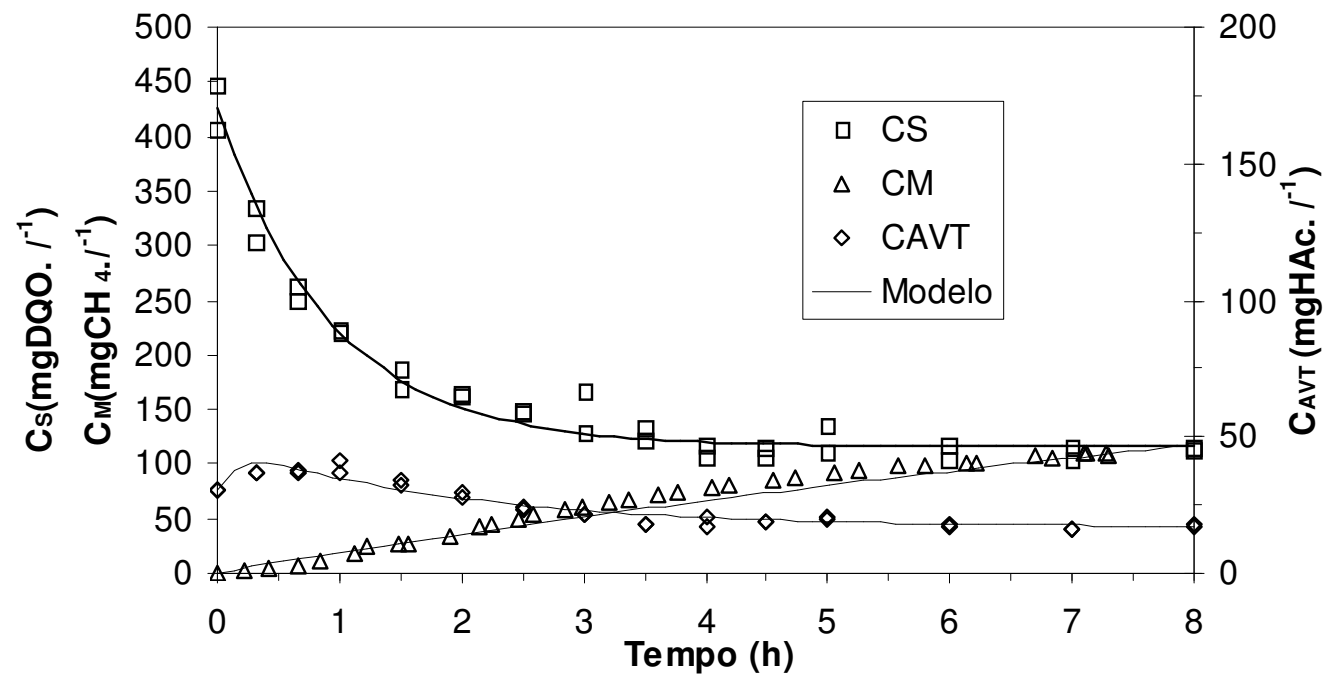

Figura 4.105. Valores experimentais e ajuste do modelo cinético na condição He100. 


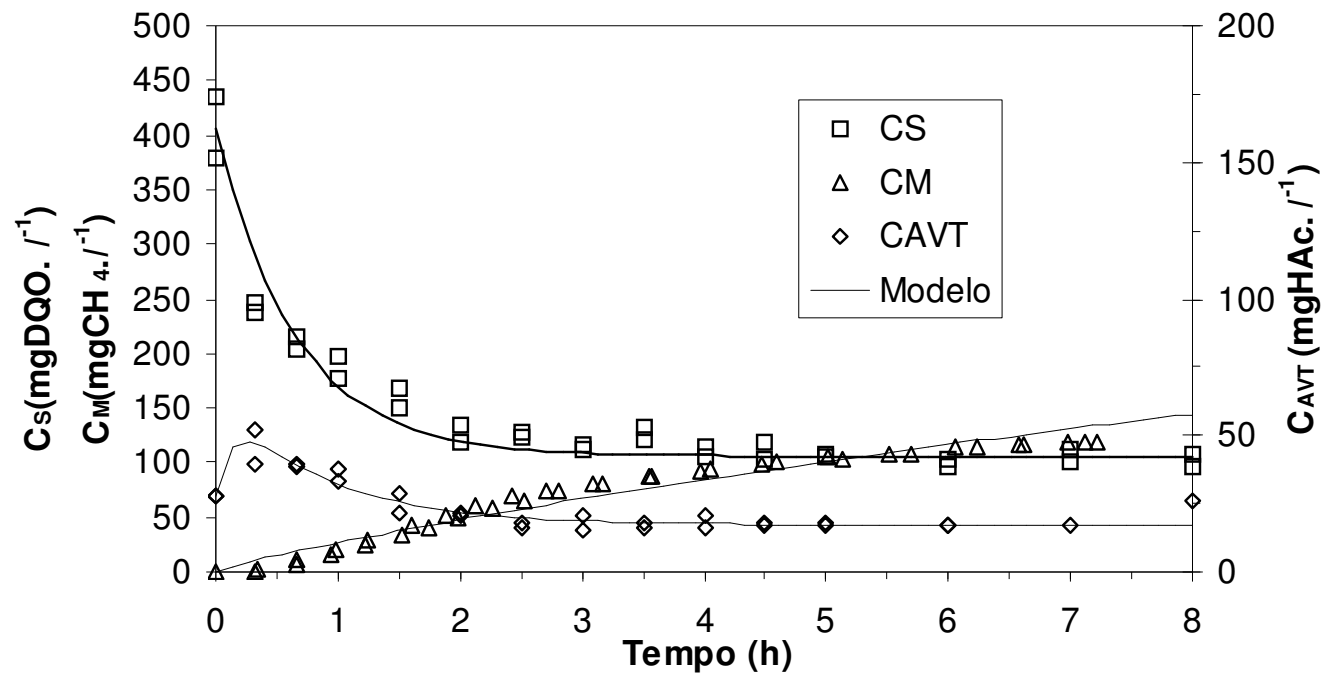

Figura 4.106. Valores experimentais e ajuste do modelo cinético na condição Hd100.

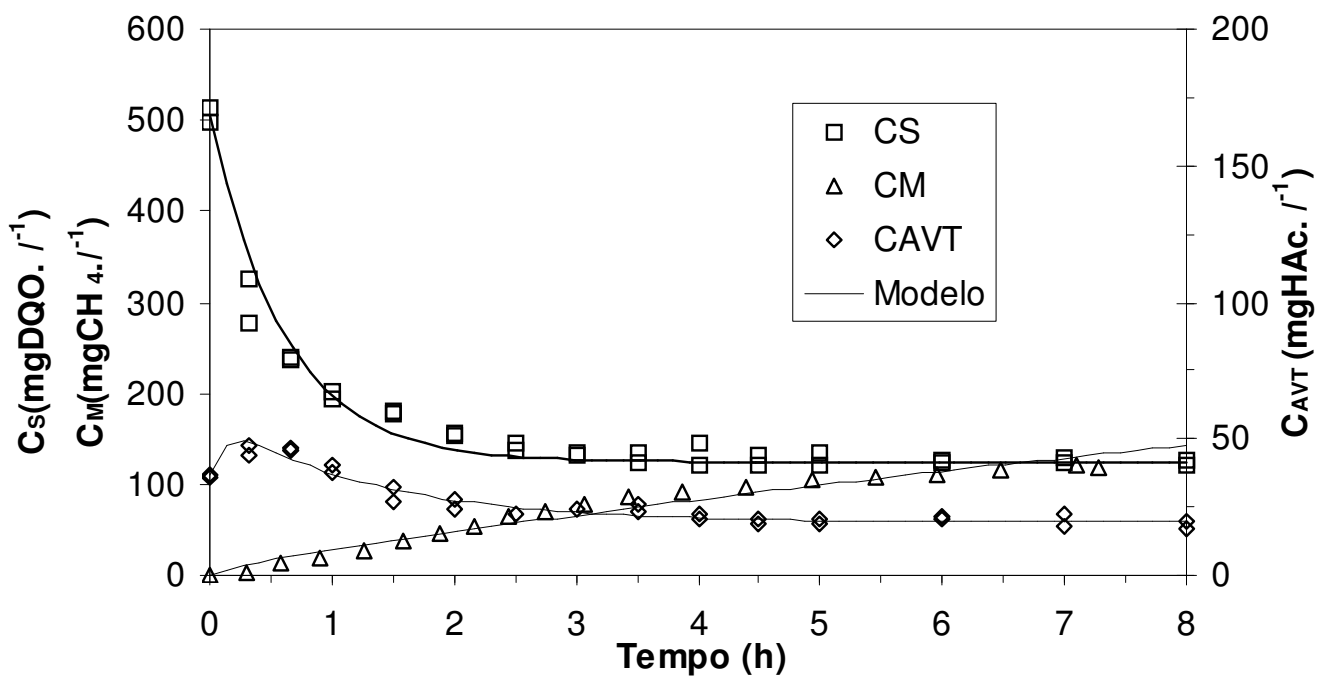

Figura 4.107. Valores experimentais e ajuste do modelo cinético na condição Hd120.

As equações 4.1, 4.2 foram ajustadas com base em 15 pontos experimentais, que são provenientes da média dos valores dos perfis em duplicata obtidos em cada condição operacional. Para o ajuste da equação 4.3 foram utilizados entre 35 e 39 pontos, esta variação se deve ao fato de o número de pontos não ser baseado em tempos pré-determinados mas sim no volume de biogás produzido.

Na Tabela 4.11 são apresentados os valores da constante cinética de primeira ordem $\left(\mathrm{k}_{1 \mathrm{~S}}\right)$ que representa o consumo de matéria orgânica na forma de DQO para cada uma das condições operacionais estudadas. 
Tabela 4.11. Parâmetro $\mathrm{k}_{1}$ estimado através ajustes da equação 4.1 aos perfis temporais coletados em cada condição operacional.

\begin{tabular}{|c|c|c|c|c|}
\hline \multicolumn{2}{|c|}{ Condição } & $\mathrm{k}_{1 \mathrm{~S}}\left(\mathrm{~h}^{-1}\right)$ & $\mathrm{r}^{2}$ & Chi-sqr \\
\hline \multirow{9}{*}{$\begin{array}{c}\text { Sem } \\
\text { tubo } \\
\text { interno }\end{array}$} & Tu50 & $0,96 \pm 0,02$ & 0,996 & 40,27 \\
\hline & Ti50 & $0,78 \pm 0,03$ & 0,989 & 120,13 \\
\hline & Ti75 & $0,92 \pm 0,04$ & 0,985 & 117,80 \\
\hline & $\mathrm{Pa} 50$ & $0,51 \pm 0,03$ & 0,967 & 350,04 \\
\hline & $\mathrm{Pa} 75$ & $0,52 \pm 0,04$ & 0,937 & 500,59 \\
\hline & Pi50 & $0,57 \pm 0,01$ & 0,996 & 53,98 \\
\hline & Pi75 & $0,84 \pm 0,03$ & 0,987 & 114,92 \\
\hline & He70 & $0,71 \pm 0,04$ & 0,971 & 263,3 \\
\hline & He100 & $1,08 \pm 0,04$ & 0,990 & 82,77 \\
\hline \multirow{4}{*}{$\begin{array}{l}\text { Com } \\
\text { tubo } \\
\text { interno }\end{array}$} & Pd100 & $1,4 \pm 0,1$ & 0,961 & 341,16 \\
\hline & $\operatorname{Pd} 120$ & $1,21 \pm 0,08$ & 0,971 & 151,73 \\
\hline & Hd100 & $1,5 \pm 0,1$ & 0,964 & 241,98 \\
\hline & Hd120 & $1,6 \pm 0,1$ & 0,967 & 352,81 \\
\hline
\end{tabular}


Na Tabela 4.12 são apresentados os parâmetros cinéticos utilizados na equação 4.2 para ajuste aos dados experimentais de variação de concentração de ácidos voláteis totais ao longo de ciclos operacionais.

Tabela 4.12. Parâmetros $k_{1}$ e $k_{2}$ estimados através ajustes da equação 4.2 aos perfis temporais coletados em cada condição operacional.

\begin{tabular}{cccccc}
\hline \multicolumn{2}{c}{ Condição } & $\mathrm{k}_{1 \mathrm{AVT}}\left(\mathrm{h}^{-1}\right)$ & $\mathrm{k}_{\text {2AVT }}\left(\mathrm{h}^{-1}\right)$ & $\mathrm{r}^{2}$ & Chi-sqr \\
\hline & Tu50 & $0,66 \pm 0,05$ & 0,981 & 3,2 & 0,981 \\
& Ti50 & $0,47 \pm 0,07$ & 0,886 & 17,99 & 0,886 \\
& Ti75 & $0,63 \pm 0,09$ & 0,905 & 14,05 & 0,905 \\
Sem & Pa50 & $0,25 \pm 0,07$ & 0,813 & 24,81 & 0,813 \\
tubo & Pa75 & $0,25 \pm 0,03$ & 0,845 & 26,53 & 0,845 \\
interno & Pi50 & $0,25 \pm 0,06$ & 0,707 & 18,11 & 0,707 \\
& Pi75 & $0,56 \pm 0,06$ & 0,943 & 7,87 & 0,943 \\
& He70 & $0,40 \pm 0,04$ & 0,943 & 4,73 & 0,943 \\
& He100 & $0,54 \pm 0,06$ & 0,935 & 4,67 & 0,935 \\
\hline \multirow{2}{*}{$\begin{array}{c}\text { Com } \\
\text { tubo }\end{array}$} & Pd100 & $0,9 \pm 0,2$ & 0,848 & 23,09 & 0,848 \\
& Hd100 & $0,97 \pm 0,09$ & 0,966 & 4,04 & 0,966 \\
& Hd120 & $0,79 \pm 0,08$ & 0,961 & 3,88 & 0,961 \\
\hline
\end{tabular}


A equação 4.3 descreve a variação da concentração de metano no decorrer de um ciclo experimental e os parâmetros $\mathrm{k}_{1 \mathrm{M}}$ e $\mathrm{k}_{2 \mathrm{M}}$, utilizados para ajuste desta equação, são apresentados na Tabela 4.13.

Tabela 4.13. Parâmetros $k_{1}$ e $k_{2}$ estimados através ajustes da equação 4.3 aos perfis temporais coletados em cada condição operacional.

\begin{tabular}{cccccc}
\hline \multicolumn{2}{c}{ Condição } & $\mathrm{k}_{1 \mathrm{AVT}}\left(\mathrm{h}^{-1}\right)$ & $\mathrm{k}_{2 \mathrm{AVT}}\left(\mathrm{h}^{-1}\right)$ & $\mathrm{r}^{2}$ & Chi-sqr \\
\hline & Tu50 & $0,065 \pm 0,002$ & $1,0 \pm 0,1$ & 0,979 & 36,33 \\
& Ti50 & $0,061 \pm 0,002$ & $1,6 \pm 0,3$ & 0,974 & 39,62 \\
& Ti75 & $0,073 \pm 0,003$ & $1,5 \pm 0,3$ & 0,968 & 52,25 \\
\multirow{4}{*}{$\begin{array}{c}\text { Sem } \\
\text { tubo }\end{array}$} & Pa50 & $0,050 \pm 0,001$ & $0,97 \pm 0,07$ & 0,994 & 6,67 \\
interno & Pa75 & $0,066 \pm 0,002$ & $0,68 \pm 0,05$ & 0,989 & 16,40 \\
& Pi50 & $0,049 \pm 0,001$ & $1,5 \pm 0,2$ & 0,985 & 20,05 \\
& Pi75 & $0,061 \pm 0,002$ & $1,6 \pm 0,3$ & 0,975 & 32,94 \\
& He70 & $0,057 \pm 0,002$ & $1,4 \pm 0,2$ & 0,985 & 17,85 \\
& He100 & $0,061 \pm 0,002$ & $1,8 \pm 0,3$ & 0,982 & 25,01 \\
\hline \multirow{2}{*}{$\begin{array}{c}\text { Com } \\
\text { tubo }\end{array}$} & Pd100 & $0,057 \pm 0,002$ & $1,4 \pm 0,3$ & 0,962 & 57,88 \\
& Hd100 & $0,076 \pm 0,003$ & $4 \pm 2$ & 0,953 & 74,77 \\
& Hd120 & $0,051 \pm 0,003$ & $3 \pm 1$ & 0,962 & 67,46 \\
\hline
\end{tabular}

A análise dos coeficientes de correlação indica um bom ajuste do modelo cinético de primeira ordem proposto neste trabalho, apesar das simplificações nos passos do metabolismo anaeróbio.

A constante $\mathrm{k}_{1}$ representa a etapa de hidrólise-acidogênse-acetogênese enquanto que a constante $\mathrm{k}_{2}$ representa a etapa de metanogênese acetoclástica. Este modelo é uma seqüência de reações irreversíveis em série e tem como etapa limitante a que apresenta $\mathrm{k}$ com menor valor. E a analise das Tabela 4.12 e Tabela 4.13 apresenta maiores valores para a constante $\mathrm{k}_{2}$ quando comparados à constante $\mathrm{k}_{1}$, desta forma, a etapa de conversão da matéria orgânica a ácidos voláteis totais, isto é, a etapa de hidróliseacidogênese-acetogênese é a etapa que limita o processo e não a segunda etapa, a de metanogênese acetoclástica. Como observado por Rodrigues et al (2004), isto pode ser consequiência do tipo de substrato, composto por carboidratos de degradação 
relativamente difícil como amido e celulose. Além disto, a hidrólise de proteínas e lipídeos pode representar uma etapa limitante da reação.

Os valores obtidos através dos parâmetros $k_{1}$ e $k_{2}$ a partir dos ajustes das equações 4.1 a 4.3 são provenientes dos coeficientes estequiométricos ( $a, b$ e c) dos compostos envolvidos nas reações consecutivas do modelo apresentado anteriormente. A constante cinética representa o consumo ou produção de determinado composto e a solução analítica desenvolvida neste trabalho pressupõe que a relação entre compostos seja 1:1:1, isto é, coeficientes estequimétricos iguais, caso este pressuposto fosse correto o a constante $\mathrm{k}_{1}$ teria o mesmo valor tanto para $\mathrm{k}_{1 \mathrm{~S}}, \mathrm{k}_{1 \mathrm{AVT}}$ e $\mathrm{k}_{1 \mathrm{M}}$, e este fato ocorreria também com as constantes $\mathrm{k}_{2}$. A diferença entre os valores das constantes cinéticas mostra que os coeficientes estequiométricos são diferentes porém constantes e isto pode ser confirmado pelo fato de que as relações $k_{1 A V T} / k_{1 S}$ e $k_{2 M} / k_{2 A V T}$ produziram valores muito próximos entre os ensaios, de $0,6 \pm 0,1$ e $0,35 \pm 0,09$, respectivamente, para todas as condições, indicando através dos baixos valores de desvio padrão, que os coeficientes estequimétricos mantiveram-se relativamente constantes ao longo dos ensaios. É relevante apontar o fato de que somente o parâmetro $\mathrm{k}_{1 \mathrm{M}}$ foi muito pequeno comparado aos outros e provavelmente este parâmetro não tem significado físico.

A mudança da condição Ti50 para a Ti75 foi acompanhada de um acréscimo próximo a 18 \% para o parâmetro $\mathrm{k}_{1 \mathrm{~S}}$. Aumentos dos valores numéricos também foram observados nos parâmetros $\mathrm{k}_{1 \mathrm{AVT}}$ e $\mathrm{k}_{1 \mathrm{M}}$ que aumentaram de 0,47 e $0,061 \mathrm{~h}^{-1}$ para 0,63 e $0,073 \mathrm{~h}^{-1}$, respectivamente, enquanto que os parâmetros $\mathrm{k}_{2 \mathrm{AVT}}$ e $\mathrm{k}_{2 \mathrm{M}}$ mantiveram-se constantes. Desta forma obtêm-se a condição Ti75 é preferível sobre a condição Ti50 por promover melhoras na etapa de hidrólise-acidogênese-acetogênese sem, contudo interferir na velocidade de conversão dos ácidos voláteis totais a metano. E como a primeira etapa é a limitante do processo de degradação da matéria orgânica conclui-se que a condição Ti75 é ótima em se tratando de impelidor tipo turbina de pás planas inclinadas para as velocidades rotacionais estudadas.

Ao se avaliar as condições Pa50 e Pa75 obtêm-se que o aumento da velocidade rotacional não promoveu alterações significativas nos parâmetros $\mathrm{k}_{1 \mathrm{~S}}$ e $\mathrm{k}_{1 \mathrm{AVT}}$ enquanto que a constante $\mathrm{k}_{1 \mathrm{M}}$ aumentou de $0,050 \pm 0,001$ a $0,066 \pm 0,002 \mathrm{~h}^{-1}$, para as mesmas condições, respectivamente. Fato que chamou a atenção neste ensaio foi a diminuição nos valores das constantes $\mathrm{k}_{2 \mathrm{AVT}}$ e $\mathrm{k}_{2 \mathrm{M}}$ com o aumento da velocidade rotacional. Coincidentemente a comparação entre as Figura 4.27 e Figura 4.32, no que diz respeito 
a ácidos voláteis totais, mostra que durante os ciclos na condição Pa75 os valores de ácidos voláteis totais foram superiores aos observados na condição Pa50.

O aumento na velocidade rotacional entre as condições Pi50 e Pi75 promoveu aumentos nos valores das constantes cinéticas $\mathrm{k}_{1 \mathrm{~S}}$, $\mathrm{k}_{1 \mathrm{AVT}}$ e $\mathrm{k}_{1 \mathrm{M}}$ superiores a $47 \%, 24 \%$ e $100 \%$, respectivamente. Os parâmetros $\mathrm{k}_{2 \mathrm{AvT}}$ e $\mathrm{k}_{2 \mathrm{M}}$ mantiveram-se constantes em função da variação da velocidade rotacional. A partir disto a rotação ótima dentre as condições estudadas para o impelidor tipo pá de pás planas inclinadas é operando a 75 rpm, isto é, condição Pi75.

O impelidor tipo hélice, nas condições He70 e He100 apresentou aumento mais expressivo para a constante $\mathrm{k}_{1 \mathrm{~s}}$ de $52 \%$ que aumentou de $0,71 \mathrm{~h}^{-1}$ a $1,08 \mathrm{~h}^{-1}$, respectivamente. Isto torna preferível a aplicação da rotação de $100 \mathrm{rpm}$ em detrimento da velocidade de rotação de $70 \mathrm{rpm}$ para o impelidor tipo hélice. A condição He100 foi a promotora do sistema ótimo dentre as condições utilizando impelidores promotores de escoamento axial, isto é, dentre as condições Pi50, Pi75, Ti50, Ti75, He70 e He100.

Ao se comparar entre o tipo de escoamento promovido pelos impelidores tipo turbina obteve-se que durante condição em que ocorreu escoamento radial (Tu50) o desempenho em termos de parâmetros cinéticos foi superior aos dois desenvolvidos em condições de escoamento axial (Ti50 e Ti75).

A comparação entre as condições Pa50 e Pi50 mostra que não ocorrem diferenças entre os valores das constantes $\mathrm{k}_{1 \mathrm{~S}}$, $\mathrm{k}_{1 \mathrm{AVT}}$ e $\mathrm{k}_{1 \mathrm{M}}$, mas os valores das constantes $k_{2 A V T}$ e $k_{2 M}$ são maiores na condição Pi50, apresentando vantagem para o sistema cujo impelidor promotor de escoamento axial. E ao comparar as condições Pa75 e Pi75 observa-se que a operação em escoamento axial foi promotora dos maiores valores das constantes cinéticas, principalmente para as constantes $\mathrm{k}_{2 \mathrm{AVT}}$ e $\mathrm{k}_{2 \mathrm{M}}$. Assim sendo, o impelidor tipo pá promotor de escoamento axial forneceu melhores resultados nas duas velocidades rotacionais estudadas, quando comparado com o impelidor tipo pá promotor de escoamento radial.

Até este ponto foram estudadas as influências da velocidade de rotação e do tipo de escoamento em sistemas desprovidas de tubo de tiragem e o que se concluiu foi que o aumento da velocidade rotacional promove melhoras na transferência de massa nos sistemas estudados. Impelidor tipo pá o de pás inclinadas é preferível em detrimento ao impelidor tipo pá de pás planas verticais e quando se analisou os impelidores tipo turbina a vantagem de desempenho foi obtida pela condição Tu50. E dentre as 
condições promotoras de escoamento axial a condição He100 foi a que apresentou melhores resultados.

Desta forma os ensaios com impelidores tipo hélice e tipo pá de pás planas inclinadas foram os que apresentaram maiores aumentos do valor da constante cinética $\mathrm{k}_{1 \mathrm{~S}}$ com o aumento da rotação dos impelidores, enquanto que as condições com impelidor tipo turbina de pás planas inclinadas apresentaram aumento pouco significativo. Já o ensaio com impelidor tipo pá de pás planas e o ensaio com impelidor tipo pá de pás planas inclinadas e tubo de tiragem mantiveram-se constantes.

Inicia-se agora a averiguação do desempenho, através da análise de parâmetros cinéticos, de sistemas utilizando tubo de tiragem em conjunto com impelidores característicos por promover escoamento axial, sendo estes o impelidor tipo pá de pás planas inclinadas e impelidor tipo hélice.

A utilização de tubo de tiragem em conjunto com impelidor tipo pá de pás planas inclinadas, nas condições Pd100 e Pd120 somente demonstrou influência positiva do aumento da velocidade rotacional para os parâmetros $k_{1 \mathrm{M}}$ e $\mathrm{k}_{2 \mathrm{M}}$, os quais apresentaram aumentos foram próximos a $50 \%$. Os parâmetros $\mathrm{k}_{1 \mathrm{~S}}$ e $\mathrm{k}_{1 \mathrm{AVT}}$ não apresentaram variação significativa enquanto que o parâmetro $\mathrm{k}_{2 \mathrm{AVT}}$ sofreu redução com o aumento da rotação do impelidor. Demonstrando que as alterações na velocidade rotacional não proporcionaram mudanças significativas no desempenho global entre as condições Pd100 e Pd120.

A alteração da velocidade rotacional entre as condições Hd100 e Hd120 mostram que os parâmetros $\mathrm{k}_{1 \mathrm{~S}}$, $\mathrm{k}_{1 \mathrm{AVT}}$ e $\mathrm{k}_{2 \mathrm{AVT}}$ não sofreram alterações superiores aos seus desvios padrões, já as constantes cinéticas $\mathrm{k}_{1 \mathrm{M}}$ e $\mathrm{k}_{2 \mathrm{M}}$ sofreram redução com $\mathrm{o}$ aumento da velocidade rotacional, apesar de os valores de concentração de metano ao final dos perfis estarem entre 6,5 e $7 \mathrm{mMol} . l^{-1}$ para as duas condições operacionais.

Os ensaios realizados em sistemas dotados de tubo de tiragem forneceram valores das constantes cinéticas superiores aos obtidos pelos mesmos impelidores quando o sistema foi operado sem o mesmo. Na qual este melhor desempenho não deve ser atribuído simplesmente a um aumento na rotação dos impelidores, quando comparados com as condições na qual o tubo de tiragem não foi utilizado, fato confirmado através da comparação entre as condições He100 e Hd100, na qual a condição com tubo de tiragem apresenta maiores valores nas constantes cinéticas das três equações utilizadas para ajustas o modelo proposto aos dados experimentais. 
A diferença entre o escoamento axial promovido unicamente pelos impelidores de pás planas inclinadas ou pelo impelidor tipo hélice dos sistemas com estes impelidores em conjunto com tubo de tiragem é que estas configurações garantem que o fluido desenvolva escoamento axial, enquanto que aquelas não podem garantir esta condição sob baixas condições rotacionais e a suspensão total sem tubo interno promoveria a quebra dos grânulos e que povocaria prejuízos à biomassa.

Esta obrigatoriedade de realização de escoamento axial no interior do reator facilita a promoção da suspensão completa da biomassa, minimizando assim o efeito de limitações por transferência de massa, visto que para Terron (1986) a suspensão completa é um estado satisfatório para a solução de problemas de transferência de massa. As condições Hd100 e Hd120 confirmam o observado nas condições Pd100 e Pd120 de que a garantia de suspensão completa minimiza problemas de transferência de massa e com isto as alterações na rotação dos impelidores não geram grandes diferenças no desempenho dos sistemas

Dentre as condições executadas com tubo de tiragem observa-se melhores resultados para a constante $\mathrm{k}_{1 \mathrm{~S}}$ dentre as condições com impelidor tipo hélice, isto é, condições Hd100 e Hd120, e dentre estas os valores das constantes $k_{1 \mathrm{AVT}}$ e $\mathrm{k}_{1 \mathrm{M}}$ mostram que a condição Hd100 apresenta resultados mais promissores quando comparadas à condição Hd120. Desta forma, a condição ótima de operação de sistema dotados de tubo de tiragem dentre as condições estudadas nesta pesquisa, com base nos parâmetros cinéticos é a condição Hd100.

Em função dos altos valores e da pequena discrepância entre as constantes cinéticas para as condições com tubo de tiragem pode-se concluir que nestas condições a influência da transferência de massa sólido-líquido externa à partícula foi minimizada, o que faz com que os parâmetros cinéticos sejam influenciados mais significativamente pela transferência de massa interna aos grânulos e pelas conseqüentes interações microbianas de simbiose. 


\section{CONCLUSÕES E SUGESTÕES}

\subsection{Considerações gerais}

Os estudos de monitoramento dos sistemas não ofereceram resultados conclusivos sobre uma configuração ótima em termos da estabilidade e eficiência dos sistemas em função da semelhança entre os resultados dos parâmetros de monitoramento entre todas as condições aplicadas. Esta semelhança tornou ainda mais significativa a importância do estudo cinético dos sistemas estudados, através da aplicação de um modelo que represente os mesmos.

Os impelidores promotores de escoamento axial apresentaram os melhores resultados nos valores das constantes cinéticas e dentre as condições em que este tipo de escoamento foi aplicado a condição ótima é foi He100.

Para os sistemas sem utilização de tubo de tiragem o aumento na velocidade rotacional foi muito significativo aumentando os valores das constantes cinéticas. Enquanto que para os sistemas providos de tubo de tiragem esta diferença não foi tão marcante.

A agitação mecânica em sistemas anaeróbios com biomassa granulada tratando efluente de baixa carga orgânica é viável por necessitar de baixos valores de fornecimento de energia quando comparada à energia necessária para promover mistura e aeração em sistemas de tratamento aeróbio. A utilização de tubo de tiragem em conjunto com impelidores promotores de escoamento axial demonstrou melhorar sobremaneira a transferência de massa nas condições estudadas nesta pesquisa, superando os resultados de todas as condições em que este dispositivo não foi aplicado e apresentando como condição de operação ótima a He100.

A potência consumida nestes sistemas é igual à potência consumida para os mesmos impelidores sem a utilização de tubo de tiragem desvinculando melhores resultados de um maior consumo de energia. 


\subsection{Considerações sobre tubo de tiragem}

Este tipo de acessório é utilizado para garantir fluxo axial no reator e é indicado para impelidores tipo hélice e tipo pá de pás planas inclinadas. Em contrapartida a utilização de tubo de tiragem não é recomendada para impelidores tipo turbina e pá ambos de pás planas verticais. A contra-indicação é decorrente do fato de que a proximidade do impelidor com a parede do tubo de tiragem pode propiciar o surgimento de uma região com alta tensão de cisalhamento. Esta tensão pode provocar o rompimento dos grânulos, prejudicando a biomassa. A altura Hi é mantida igual a D/3 quando os sistemas são operados sem tubo de tiragem, para os casos de utilização de tubo de tiragem e o impelidor foi posicionado no centro do tubo de tiragem.

O menor comprimento do eixo aumenta a durabilidade dos rolamentos em função de menor vibração além de requerer um eixo com menor diâmetro em relação ao impelidor colocado no centro do tubo de tiragem como foi o caso aqui estudado.

$\mathrm{Na}$ revisão bibliográfica foram abordados critérios na definição de condições operacionais em reatores operados com tubo de tiragem em sistemas sólido-líquido expostos por Shaw (1982) cujos critérios merecem novas considerações para o caso de ASBR de tubo de tiragem. O critério da velocidade do fluido na região anular não pode ser aplicado visto que o objetivo, em ASBR operado com biomassa granulada, é garantir que a biomassa permaneça suspensa na região anular, não entrando na região interna ao tubo de tiragem onde pode vir a sofrer rompimento em contato com o impelidor. E para o caso do critério da velocidade do fluido na base do tubo de tiragem, a atenção que deve ser dada é que a velocidade de rotação do impelidor no início de cada ciclo operacional não necessariamente é igual à velocidade durante o restante do período reacional de um ASBR em virtude de uma maior demanda de energia no momento de início de agitação para promover a suspensão da biomassa.

Desta forma o intervalo de velocidade rotacional do impelidor pode ser compreendido entre a velocidade mínima necessária para a suspensão adequada da biomassa no início de cada ciclo e a velocidade máxima na qual não ocorra o arraste dos grânulos para dentro do tubo de tiragem. Sendo este intervalo específico para cada sistema e aplicável nos casos onde o parâmetro velocidade rotacional não possa ser automatizado. Já para sistemas providos de inversores de freqüência deve-se buscar a utilização de duas velocidades rotacionais sendo a primeira alta para garantir a 
suspensão da biomassa e a segunda menor e suficiente para manter a suspensão completa dos sólidos.

\subsection{Propostas para trabalhos futuros}

Em virtude dos resultados promissores produzidos através dos ensaios realizados com tubo de tiragem torna-se interessante um aprofundamento no estudo de parâmetros construtivos e operacionais para reatores anaeróbios operados em batelada seqüencial com biomassa imobilizada e providos de tubo de tiragem.

Dentre os parâmetros construtivos, com vistas a reduzir o consumo energético e garantir a integridade da biomassa, pode-se destacar:

- A relação entre diâmetro do tubo e diâmetro do reator;

- Profundidade do tubo de tiragem em relação ao fundo do reator, e;

- A forma da base do reator.

Os ensaios, com tubo de tiragem, realizados neste trabalho tiveram os impelidores posicionados no centro do tubo de tiragem, entretanto, sabe-se que o melhor posicionamento para o impelidor é a parte superior do tubo. Desta forma sugere-se que em trabalhos futuros aplique-se esta recomendação.

O parâmetro operacional mais importante a ser investigado é a velocidade de rotação dos impelidores na busca pela rotação que consuma pouca energia e garanta a suspensão completa. E para sistemas providos de inversores de freqüência sugere-se a aplicação de duas velocidades onde inicialmente se promova a suspensão da biomassa e em seguida em menor velocidade o reator seja operado durante o período reacional. 


\section{REFERÊNCIAS BIBLIOGRÁFICAS}

Aiba, S.; Humphrey A. E.; Millis N.F., Biochemical Engineering. Academic Press, Inc., New York \& London.

Angenent, L.T.; Dague, R.R. (1995). A laboratory- scale comparison of the UASB and ASBR processes. In: 50. ${ }^{\text {th }}$ Purdue Industrial. Wastewater Conference Proceedings, Ann Arbor Press, Chelsea, p. 365-377.

Angenent, L.T.; Sung, S.; Raskin, L. (2002). Methanogenic population dynamics during startup of a full-scale anaerobic sequencing batch reactor treating swine waste. Water Research, 36, 4648-4654.

Angenent, L.T.; Sung.S.; Raskin, L. (2001). Mixing intensity I anaerobic sequencing batch reactors affects reactor perfornace and microbial community structure. In: $6^{\text {th }}$ World Congress of Anaerobic Digestion.

Bagley, D. M.; Brodkorb, T.S. (1999). Modeling Microbial Kinetics in an Anaerobic Sequencing Batch Reactor - Model Development and Experimental Validation. Water Environ. Res. 71, 1320-1332.

Baldi, G. (1980); Hydrodynamics of multiphase reactors, in multiphase chemical reactors, NATO Advanced Study Institution, Vimeiro, Portugal.

Brito, A.G.; Rodrigues, A.C.; Melo, F.L. (1997). Feasibility of a pulsed sequencing batch reactor with an anaerobic aggregated biomass for the treatment of low strength wastewaters. Water Science and Technology, 35, 193-198.

Camargo, E.F.M.; Ratusznei, S.M.; Rodrigues, J.A.D.; Zaiat, M.; Borzani, W. (2002). Treatment of low-strength wastewater using immobilized biomass in a sequencing batch external loop reactor: influence of the medium superficial velocity on the stability and performance. Brazilian Journal of Chemical Engineering, 19, 267-275. 
Cubas, S. A.; Pinho, S.C.; Foresti, E.; Rodrigues, J. A. D.; Ratusznei, S. M.; Zaiat, M. (2001). Effects of solid-phase mass transfer on na stirred anaerobic sequencing batch reactor containing immobilized biomass. In: VII Latin Americn Workshop and Symposium on Anaeribic Digestion.

Cubas, S.A.; Foresti, E.; Rodrigues, J.A.D.; Ratusznei, S.M.; Zaiat, M. (2004). Infuence of liquid-phase mass transfer on the preformance of a stirred anaerobic sequencing batch reactor containing immobilized biomass. Biochemical Engineering Journal, 17, 99-105.

Dague, R.R.; Habben, C.E.; Pidaparti, S.R. (1992). Initial studies on the anaerobic sequencing batch reactor. Water Science and Technology, 26, 2429-2432.

Deveci, H (2004). Effects of particle size and shape of solids on the viability of acidophilic bacteria during mixing in stirred tank reactors. Hydrometallurgy, 71, 385-396

Droste, R. L.; Massé, D. I (1995) Anaerobic treatment in sequencing batch reactors. In: Internacional Symposium on Technology Transfer, Pre-Prints, Salvador, Bahia, Brazil.

Fernandes, L.; Kennedy, K.J.; Ning, Z. (1993). Dynamic modeling of substrate degradation in sequencing batch anaerobic reactors (SBAR). Water Research, 27, 1619-1628.

Jivicková, E.; Rieger, F. (1995), Mixing in tall vessels with a drautht tube. The Cemical Engineering Journal, 59, 273-275.

Karim K.; Klasson, K. T.; Hoffmann, R.; Drescher S. R.; DePaoli, D. W.; Al-Dahhan, M. H., (2005). Anaerobic digestion of animal waste: Effect of mixing , Bioresourse Technology, no prelo

Karim K.; Hoffmann, R.; Klasson, K. T.; Al-Dahhan, M. H., (2005). Anaerobic digestion of animal waste: Waste strength versus impact of mixing, Bioresourse Technology, no prelo

Kennedy, K. J.; Sanchez, W. A.; Hamoda M. A.; Droste, R. L. (1991). Performance of anaerobic sludge blanket sequencing batch reactors. Res. J. Water. Pollut. Control Fed.,63, 75-83. 
Liu Y.; Tay, J. H., (2002). The essential role of hydrodynamic shear force in the formation of biofilm and granular sludge. Water Research,36, 1653-1665.

Massé, D.I.; Masse, L. (2000). Treatment of slaghterhouse wastewater in anaerobic sequencing batch reactors. Canadian Agricultural Engineering, 42, 131-137.

Monteith, H. D.; Stephenson, J. P (1981). Mixing efficiencies in ful-scale anaerobic digesters by tracer methods. Journal of Water Pollution Control Federation, 53, 7884.

Moreno,G.; Cruz, A. ;Buitrón, G. (1998), Influence of S0/X0 Ratio on anaerobic biodegradability test. In: Fifth Latin-american Workshop-Seminar Wastewater Anaerobic Treatment 27-30 october 1998, Viña del Mar, Chile.

Muroyama K.; Mochizuki, T.; Wakamura, T. (2001). Methane Fermentation of Bean Curd Refuse, Journal of Bioscience and Bioengineering, 91 (2), 208-212.

Ndon, U.J.; Dague, R.R. (1997). Effects of temperature and hydraulic retention time on anaerobic sequencing batch reactor treatment of low-strength wastewater. Water Research, 31, 2455-2466.

Ng, W.J. (1989). A sequencing batch anaerobic reactor for treating piggery wastewater. Biological Wastes. 28, 39-51.

Ramos, A.C.T.; Ratusznei, S.M.; Rodrigues, J.A.D.; Zaiat, M. (2003). Mass Transfer Improvement of a Fixed-Bed Anaerobic Sequencing Batch Reactor with Liquid Phase Circulation. Journal of Science and Technology of the Americas INTERCIENCIA, 28, 214-219.

Ratusznei, S.M.; Rodrigues, J.A.D.; Camargo, E.F.M.; Zaiat, M.; Borzani, W. (2001). Influence of agitation rate on the performance of a stirred anaerobic sequencing batch reactor containing immobilized biomass. Water Science and Technology, 44, 305-312.

Rodrigues, J.A.D.; Pinto, A.G.; Ratusznei, S.M.; Zaiat, M.; Gedraite, R. (2004). Enhancement of the performance of an anaerobic sequencing batch reactor treating low strength wastewater through implementation of a variable stirring rate program. Brazilian Journal of Chemical Engineering, 21,423-434. 
Rodrigues, J.A.D.; Ratusznei, S.M.; Camargo, E.F.M.; Zaiat, M. (2003). Influence of agitation rate on the performance of an anaerobic sequencing batch reactor containing granulated biomass treating low-strength wastewater. Advances in Environmental Research, 7, 405-410.

Schmit, G. C.; Dague, R. R. (1993). Anaerobic sequencing batch reactor treatment of swine waste at $20^{\circ} \mathrm{C}, 25^{\circ} \mathrm{C}$, and $35^{\circ} \mathrm{C}$. In: 48. ${ }^{\text {th }}$ Purdue Industrial. Wastewater Conference Proceedings, Lewis Publishers, Chelsea, 541-549.

Shaw, J., A.(1982); The Desing of Draft Tube Circulators. Proc. Australas. Inst. Metall. 283, September, p. 47-58.

Standard Methods for the Examination of Water and Wastewater (1995) APHA, AWWA, WPCF., $19^{\text {th }}$ edition, American Public Health Association, Washington.

Sung, S.; Dague, R.R. (1995); Laboratory studies on the anaerobic sequencing batch reactor, Water Environment Research, 67, 294.

Terron, L. R. (1986); Conceitos Fundamentais da Agitação de Líquidos. Revista Brasileira de Engenharia Química, 8 (4), 5-29.

TIMUR, H.; ÖZTURK, I. (1999). Anaerobic sequencing batch reactor treatment of landfill leachate. Water Research, v.33, p3225-3230.

Torres, P.; (1992). Desempenho de um Reator Anaeróbio de Manta de Lodo (UASB) de Bancada no Tratamento de Substrato Sintético Simulando Esgoto Sanitário. Dissertação (Mestrado), Escola de Engenharia de São Carlos, Universidade de São Paulo, São Carlos.

Wastewater engineering: treatment and reuse / Metcalf \& Eddy, Inc. $-4^{\text {th }}$ ed. Revised by George Tchobanoglous, Franklin L. Burton, H. David Stensel. McGraw-Hill, (2003).

Wirtz, R. A.; Dague, R. R. (1997). Laboratory studies on enhancement of granulation in the anaerobic sequencing batch reactor. Wat. Sci. Tech. v 36, p279-286.

Zaiat, M.; Rodrigues, J.A.D.; Ratusznei, S.M.; Camargo, E.F.M.; Borzani, W. (2001). Anaerobic sequencing batch reactors for wastewater treatment: a developing technology. Applied Microbiology and Biotechnology, 55, 29-35. 


\section{APÊNDICES}

\section{APÊNDICE A. Dedução do modelo cinético}

O modelo anaeróbio apresentado neste trabalho é baseado na aproximação apresentada por Bagley e Brodkorb (1999) e aplicado a um reator anaeróbio de batelada seqüencial por Rodrigues (2004), desta forma este modelo é uma adaptação do modelo desenvolvido para processos de tratamento aplicado em reatores de lodo ativado desenvolvido pela "International Water Association” (IWA).

Da equação 3.9 à equação 3.16 está representado o modelo proposto, onde a, b e c são coeficientes estequiométricos; $\mathrm{k}_{1}$ e $\mathrm{k}_{2}$ são parâmetros cinéticos aparentes de primeira ordem; $R_{S}$. $R_{A V T}, R_{A V T}$ e $R_{M}$ são as velocidades de reação de consumo de matéria orgânica em amostras filtradas, formação e consumo de ácidos voláteis totais e produção de metano, respectivamente; $\mu_{S}, \mu_{\mathrm{AVT}}, \mu^{\prime}{ }_{\mathrm{AVT}}$ e $\mu_{\mathrm{M}}$ são as velocidades reacionais específicas de consumo de matéria orgânica em amostras filtradas, formação e consumo de ácidos voláteis totais, e produção de metano, respectivamente; $\mathrm{C}_{\mathrm{X}}$ é a concentração de biomassa; $X_{1}, I_{1} X_{2}$, e $I_{2}$ são, respectivamente, a biomassa e outros compostos intermediários formados durante o processo de degradação anaeróbia, mas não considerados no modelo cinético; e o subscrito 0 denota os valores no tempo zero. Vale mencionar que existe consumo de matéria orgânica para manutenção celular e este não é considerado neste modelo cinético.

O modelo proposto seguiu as seguintes considerações:

- Reator operado em modo batelada;

- Volume constante;

- Reações exotérmicas;

- Reações em série;

- Modelo cinético de primeira ordem acrescido de residual, e;

- $t=0 \rightarrow C_{S}=C_{S 0}, C_{A V T}=C_{A V T 0}$ e $C_{M}=C_{M 0}$ 
Reação anaeróbia:

$$
a . S \stackrel{k_{1}}{\rightarrow} \text { b.AVT }+X_{1}+I_{1} \stackrel{k_{2}}{\rightarrow} c \cdot M+X_{2}+I_{2}
$$

Modelos cinéticos:

$$
\begin{gathered}
R_{S}=\mu_{S} C_{X}=k_{1 S}\left(C_{S}-C_{S r}\right) \\
R_{A V T}=\mu_{A V T} C_{X}=k_{1 A V T}\left(C_{S}-C_{S r}\right) \\
R_{A V T}^{\prime}=\mu_{A V T}^{\prime} C_{X}=k_{2 A V T}\left(C_{A V T}-C_{A V T r}\right) \\
R_{M}=\mu_{M} C_{X}=k_{2 M}\left(C_{A V T}-C_{A V T r}\right)
\end{gathered}
$$

Balanço material para o componente $\mathrm{S}$.

$$
\begin{gathered}
\frac{d C_{S}}{d t}=-R_{S}=-k_{1 S} \cdot\left(C_{S}-C_{S r}\right) \\
\frac{d C_{S}}{\left(C_{S}-C_{S r}\right)}=-k_{1 S} . d t
\end{gathered}
$$

aplicando a condição inicial $t=0 \rightarrow C_{S}=C_{S 0}$, e integrando a equação, temos:

$$
\left(C_{S}-C_{S r}\right)=\left(C_{S 0}-C_{S r}\right) \exp \left(-k_{1 S} t\right)
$$

Balanço material para o componente AVT.

$$
\begin{aligned}
& \frac{d C_{A V T}}{d t}=R_{A V T}-R_{A V T}^{\prime}=k_{1 A V T} \cdot\left(C_{S}-C_{S r}\right)-k_{2 A V T} \cdot\left(C_{A V T}-C_{A V T r}\right) \\
& \frac{d C_{A V T}}{d t}=k_{1 A V T} \cdot\left(C_{S}-C_{S 0}\right) \cdot \exp \left(-k_{1 A V T} \cdot t\right)-k_{2 A V T} \cdot\left(C_{A V T}-C_{A V T r}\right) \\
& \frac{d C_{A V T}}{d t}+k_{2 A V T} \cdot\left(C_{A V T}-C_{A V T r}\right)=k_{1 A V T} \cdot\left(C_{S 0}-C_{S r}\right) \cdot \exp \left(-k_{1 A V T} . t\right)
\end{aligned}
$$

temos aqui uma equação do tipo

$$
\frac{d x}{d y}=P(x) \cdot y=Q(x)
$$

cuja solução é

$$
\left.\left.y \cdot \exp \mid \int P(x) \cdot d x\right\rfloor=\int Q(x) \cdot \exp \mid \int P(x) \cdot d x\right\rfloor d x
$$

onde $y=C_{A V T}, x=t, P(x)=k_{2}$ e $Q(x)=k_{1 A V T}\left(C_{S}-C_{S r}\right) \cdot \exp \left(-k_{1 A V T} \cdot t\right)$

substituindo 
$\left.\left.C_{A V T} \cdot \exp \mid \int k_{2 A V T} \cdot d t\right]=\int k_{1 A V T} \cdot\left(C_{S 0}-C_{S r}\right) \cdot \exp \left(-k_{1 A V T} \cdot t\right) \cdot \exp \mid \int k_{2 A V T} \cdot d t\right] d t$

$\left(C_{A V T}-C_{A V T r}\right) \cdot \exp \left(k_{2 A V T} \cdot t\right)=k_{1 A V T} \cdot\left(C_{S 0}-C_{S r}\right) \cdot \int \exp \left[\left(-k_{1 A V T}=k_{2 A V T}\right) \cdot t\right] \cdot d t$

$$
=\frac{k_{1 A V T} \cdot\left(C_{S 0}-C_{S r}\right)}{k_{2 A V T}-k_{1 A V T}} \cdot\left\{\exp \left[\left(k_{2 A V T}-k_{1 A V T}\right) \cdot t\right]-1\right\}+C
$$

$$
\left(C_{A V T}-C_{A V T r}\right) \cdot \exp \left(k_{2 A V T} \cdot t\right)=\frac{k_{1 A V T} \cdot\left(C_{S 0}-C_{S r}\right)}{k_{2 A V T}-k_{1 A V T}} \cdot\left\{\exp \left[\left(k_{2 A V T}-k_{1 A V T}\right) \cdot t\right]-1\right\}+C
$$

aplicando a condição inicial $t=0 \rightarrow C_{A V T}=C_{A V T 0}(\neq 0) \therefore C=\left(C_{A V T 0}-C_{A V T r}\right)$

$$
\begin{gathered}
\left(C_{A V T}-C_{A V T r}\right) \cdot \exp \left(k_{2 A V T} \cdot t\right)=\frac{k_{1 A V T} \cdot\left(C_{S 0}-C_{S r}\right)}{k_{2 A V T}-k_{1 A V T}} \cdot\left\{\exp \left[\left(k_{2 A V T}-k_{1 A V T}\right) \cdot t\right]-1\right\}+\left(C_{A V T}-C_{A V T r}\right) \\
\left(C_{A V T}-C_{A V T 0}\right)=\left(C_{A V T 0}-C_{A V T r}\right) \cdot \exp \left(-k_{2 A V T} \cdot t\right)+ \\
+k_{1 A V T} \cdot\left(C_{S 0}-C_{S r}\right) \cdot\left[\frac{\exp \left(-k_{1 A V T} \cdot t\right)}{\left(k_{2 A V T}-k_{1 A V T}\right)}+\frac{\exp \left(-k_{2 A V T} . t\right)}{\left(k_{1 A V T}-k_{2 A V T}\right)}\right]
\end{gathered}
$$

Balanço material para o componente $\mathrm{M}$.

$$
\begin{aligned}
& \frac{d C_{M}}{d t}=k_{2 A V T} \cdot\left(C_{A V T}-C_{A V T r}\right) \\
& \frac{d C_{M}}{d t}=k_{2 M}\left(C_{A V T 0}-C_{A V T r}\right) \cdot \exp \left(-k_{2 M} \cdot t\right)+ \\
& +k_{1 M} \cdot k_{2 M} \cdot\left(C_{S 0}-C_{S r}\right) \cdot\left[\frac{\exp \left(-k_{1 M} \cdot t\right)}{\left(k_{2 M}-k_{1 M}\right)}+\frac{\exp \left(-k_{2 M} \cdot t\right)}{\left(k_{1 M}-k_{2 M}\right)}\right]
\end{aligned}
$$


integrando o lado esquerdo da equação

$$
\begin{gathered}
C_{M}=C+\frac{k_{2 M} \cdot\left(C_{A V T 0}-C_{A V T r}\right) \cdot \exp \left(-k_{2 M} \cdot t\right)}{-k_{2 M}}+ \\
+k_{1 M} \cdot k_{2 M} \cdot\left(C_{S 0}-C_{S r}\right) \cdot\left[\frac{\exp \left(-k_{1 M} \cdot t\right)}{\left(-k_{1 M}\right) \cdot\left(k_{2 M}-k_{1 M}\right)}+\frac{\exp \left(-k_{2 M} \cdot t\right)}{\left(-k_{2 M}\right) \cdot\left(k_{1 M}-k_{2 M}\right)}\right]
\end{gathered}
$$

simplificando

$$
\begin{gathered}
C_{M}=C+\left(C_{A V T 0}-C_{A V T r}\right) \cdot \exp \left(-k_{2 M} \cdot t\right)+ \\
+\left(C_{S 0}-C_{S r}\right) \cdot\left[\frac{k_{2 M} \cdot \exp \left(-k_{1 M} \cdot t\right)}{\left(k_{1 M}-k_{2 M}\right)}+\frac{k_{1 M} \exp \left(-k_{2 M} \cdot t\right)}{\left(k_{2 M}-k_{1 M}\right)}\right]
\end{gathered}
$$

aplicando a condição inicial $t=0 \rightarrow C_{M}=C_{M 0}$ e inicialmente $\mathrm{C}_{\mathrm{M} 0}=0$ portanto

$$
\begin{gathered}
C=-\left(C_{A V T}-C_{A V T r}\right)+\left(C_{S}-C_{S r}\right) \\
C_{M}=\left(C_{A V T}-C_{A V T r}\right) \cdot\left[1-\exp \left(-k_{2 M} \cdot t\right)\right]+ \\
+\left(C_{S}-C_{S r}\right) \cdot\left[1+\frac{k_{2 M} \cdot \exp \left(-k_{1 M} \cdot t\right)}{\left(k_{1 M}-k_{2 M}\right)}+\frac{k_{1 M} \cdot \exp \left(-k_{2 M} \cdot t\right)}{\left(k_{2 M}-k_{1 M}\right)}\right]
\end{gathered}
$$




\section{APÊNDICE B. Ensaio com impelidor tipo turbina de pás planas verticais - valores experimentais}

TABELA B.1: Resultados Experimentais da concentração de matéria orgânica em termos de DQO $\left(\mathrm{C}_{\mathrm{af}}\right), \mathrm{pH}$, Alcalinidade Parcial (AP), Alcalinidade Intermediária (AI), Alcalinidade Total (AT), Alcalinidade a Bicarbonato (AB) e Ácidos Voláteis Totais (AVT) em amostras do afluente do ensaio Tu50

\begin{tabular}{|c|c|c|c|c|c|c|c|}
\hline \multirow[t]{2}{*}{ Ciclo } & \multirow{2}{*}{$\begin{array}{c}\mathrm{C}_{\mathrm{AF}} \\
\left(\mathrm{mgDQO} .1^{-1}\right)\end{array}$} & \multirow[t]{2}{*}{$\mathrm{pH}$} & AP & AI & AT & $\mathrm{AB}$ & \multirow{2}{*}{$\begin{array}{c}\text { AVT } \\
\left(\text { mgHAc. }^{-1}\right)\end{array}$} \\
\hline & & & \multicolumn{4}{|c|}{$\left(\mathrm{mgCaCO}_{3} \cdot 1^{-1}\right)$} & \\
\hline 1 & 860,0 & 8,99 & 198,8 & 52,1 & 250,8 & 220,1 & 43,3 \\
\hline 3 & 699,0 & 8,96 & 183,4 & 60,3 & 243,7 & 213,5 & 42,6 \\
\hline 27 & 754,2 & 8,80 & 181,3 & 55,8 & 237,0 & 197,0 & 56,4 \\
\hline 31 & 831,2 & 8,78 & 175,5 & 56,9 & 232,4 & 196,2 & 51,0 \\
\hline 39 & 796,7 & 8,70 & 165,0 & 63,9 & 228,9 & 203,4 & 36,0 \\
\hline 43 & 876,4 & 9,13 & 197,7 & 51,2 & 248,8 & 216,0 & 46,2 \\
\hline 46 & 758,4 & 8,63 & 208,8 & 50,3 & 259,1 & 229,0 & 42,4 \\
\hline 49 & 748,5 & 9,04 & 198,2 & 57,3 & 255,5 & 225,2 & 42,8 \\
\hline 52 & 999,8 & 8,71 & 187,1 & 57,3 & 244,4 & 216,8 & 38,8 \\
\hline 63 & 736,8 & 8,97 & 190,9 & 47,7 & 238,6 & 210,6 & 39,4 \\
\hline
\end{tabular}


TABELA B.2: Resultados Experimentais da concentração de matéria orgânica em termos de DQO para amostras filtradas $\left(\mathrm{C}_{\mathrm{SF}}\right)$ e totais $\left(\mathrm{C}_{\mathrm{ST}}\right)$, eficiência de remoção de matéria orgânica em termos de DQO para amostras filtradas $\left(\mathrm{E}_{\mathrm{F}}\right)$ e totais $\left(\mathrm{E}_{\mathrm{T}}\right) \mathrm{pH}$, Alcalinidade Parcial (AP), Alcalinidade Intermediária (AI), Alcalinidade Total (AT), Alcalinidade a Bicarbonato (AB) e Ácidos Voláteis Totais (AVT) em amostras do efluente do ensaio Tu50

\begin{tabular}{|c|c|c|c|c|c|c|c|c|c|c|c|}
\hline \multirow{2}{*}{ Ensaio } & \multirow{2}{*}{ Ciclo } & $\mathrm{C}_{\mathrm{SF}}$ & $\mathrm{C}_{\mathrm{ST}}$ & $E_{F}$ & $\mathrm{E}_{\mathrm{T}}$ & \multirow{2}{*}{$\mathrm{pH}$} & AP & AI & AT & $\mathrm{AB}$ & \multirow{2}{*}{$\begin{array}{c}\text { AVT } \\
\left.\left(\mathrm{mgHAc}^{-1}\right)^{-1}\right)\end{array}$} \\
\hline & & \multicolumn{2}{|c|}{$\left(\mathrm{mgDQO} .1^{-1}\right)$} & \multicolumn{2}{|c|}{ (\%) } & & \multicolumn{4}{|c|}{$\left(\mathrm{mgCaCO}_{3} .1^{-1}\right)$} & \\
\hline \multirow{15}{*}{ Tu50 } & 1 & 105,4 & 118,5 & 86,8 & 85,2 & 6,89 & 274 & 95 & 369 & 355 & 20 \\
\hline & 3 & 98,9 & 120,8 & 87,6 & 84,9 & 6,75 & 308 & 121 & 428 & 414 & 20 \\
\hline & 6 & 99,2 & 119,1 & 87,6 & 85,1 & 6,65 & 296 & 137 & 433 & 420 & 18 \\
\hline & 24 & 83,4 & 119,6 & 89,6 & 85,1 & 6,74 & 288 & 98 & 386 & 370 & 22 \\
\hline & 27 & 105,2 & 128,7 & 86,9 & 83,9 & 6,70 & 291 & 102 & 393 & 375 & 25 \\
\hline & 30 & 110,4 & 131 & 86,2 & 83,6 & 6,72 & 267 & 121 & 388 & 372 & 23 \\
\hline & 33 & 90,1 & 104,1 & 88,7 & 87,0 & 6,61 & 261 & 128 & 389 & 375 & 20 \\
\hline & 39 & - & - & - & - & 6,55 & 243 & 138 & 381 & 368 & 18 \\
\hline & 42 & 116,1 & 147,6 & 85,5 & 81,6 & - & - & - & - & - & - \\
\hline & 43 & - & - & - & - & 6,81 & 319 & 106 & 425 & 410 & 21 \\
\hline & 46 & 100,1 & 132,4 & 87,5 & 83,5 & - & - & - & - & - & - \\
\hline & 49 & 111,1 & 140,4 & 86,1 & 82,5 & 6,77 & 308 & 120 & 428 & 414 & 19 \\
\hline & 52 & 104 & 272 & 87,0 & - & 6,73 & 302 & 115 & 416 & 406 & 14 \\
\hline & 55 & 106,1 & 124,2 & 86,7 & 84,5 & - & - & - & - & - & - \\
\hline & 63 & 96,9 & 116 & 87,9 & 85,5 & 6,75 & 311 & 105 & 416 & 398 & 25 \\
\hline
\end{tabular}


TABELA B.3: Resultados experimentais da concentração de sólidos totais (ST), sólidos voláteis totais (SVT), sólidos suspensos totais (SST) e sólidos suspensos voláteis (SSV) em amostras afluentes e efluentes coletadas durante o ensaio Tu50.

\begin{tabular}{|c|c|c|c|c|c|c|c|c|c|}
\hline \multirow{3}{*}{ Ensaio } & \multirow{3}{*}{$\begin{array}{l}\text { Tempo } \\
\text { (ciclo) }\end{array}$} & \multicolumn{4}{|c|}{ Afluente } & \multicolumn{4}{|c|}{ Efluente } \\
\hline & & ST & SVT & SST & SSV & ST & SVT & SST & SSV \\
\hline & & $\left(\mathrm{mg} . l^{-1}\right)$ & $\left(\mathrm{mg} . l^{-1}\right)$ & $\left(\mathrm{mg} . l^{-1}\right)$ & $\left(\mathrm{mg} . l^{-1}\right)$ & $\left(\mathrm{mg} . l^{-1}\right)$ & $\left(\mathrm{mg} . l^{-1}\right)$ & $\left(\mathrm{mg} \cdot l^{-1}\right)$ & $\left(\mathrm{mg} \cdot l^{-1}\right)$ \\
\hline \multirow{5}{*}{ Tu50 } & 4 & 1480 & 752 & 100 & 92 & 876 & 212 & 16 & 0 \\
\hline & 25 & 946 & 708 & 14 & 10 & 698 & 294 & 70 & 70 \\
\hline & 31 & 1566 & 750 & 34 & 28 & 994 & 248 & 72 & 60 \\
\hline & 43 & 1586 & 886 & 118 & 116 & 1018 & 306 & 74 & 60 \\
\hline & 49 & 1542 & 816 & 70 & 70 & 956 & 230 & 76 & 74 \\
\hline
\end{tabular}


TABELA B.4: Perfis Experimentais da concentração de matéria orgânica em termos de DQO para amostras filtradas $\left(\mathrm{C}_{\mathrm{SF}}\right)$, $\mathrm{pH}$, Alcalinidade Parcial (AP), Alcalinidade Intermediária (AI), Alcalinidade Total (AT), Alcalinidade a Bicarbonato (AB) e Ácidos Voláteis Totais (AVT) durante o ensaio Tu50

\begin{tabular}{|c|c|c|c|c|c|c|c|c|c|c|c|c|}
\hline \multirow[b]{2}{*}{$\begin{array}{c}\text { Tempo } \\
\text { (h) }\end{array}$} & \multicolumn{6}{|c|}{ Ciclo 46} & \multicolumn{6}{|c|}{ Ciclo 49} \\
\hline & $\begin{array}{c}\mathrm{C}_{\mathrm{AF}} \\
\left(\mathrm{mgDQO} .1^{-1}\right) \\
\end{array}$ & $\mathrm{pH}$ & $\mathrm{AP}$ & $\frac{\mathrm{AI}}{\mathrm{CaCO}_{3}}$ & $\mathrm{AB}$ & $\begin{array}{c}\text { AVT } \\
\left(\mathrm{mgHAc}^{\left.-l^{-1}\right)}\right.\end{array}$ & $\begin{array}{c}\mathrm{C}_{\mathrm{AF}} \\
\left(\mathrm{mgDQO} .1^{-1}\right) \\
\end{array}$ & $\mathrm{pH}$ & \multicolumn{3}{|c|}{$\left(\mathrm{mgCaCO}_{3} \cdot 1^{-1}\right)$} & $\begin{array}{c}\text { AVT } \\
\left.\left(\mathrm{mgHAc}^{-1}\right)^{-1}\right)\end{array}$ \\
\hline 0,00 & 408,4 & 6,9 & 219 & 89 & 271 & 54 & 429,1 & 6,9 & 207 & 89 & & \\
\hline 0,33 & 319,9 & 6,8 & 257 & 98 & 330 & 36 & 333,5 & 7,0 & 256 & 94 & 269 & 37 \\
\hline 0,67 & 250,8 & 6,7 & 258 & 99 & 324 & 47 & 275,0 & 6,8 & 256 & 97 & 311 & 56 \\
\hline 1,00 & 206,8 & 6,7 & 264 & 102 & 333 & 46 & 234,8 & 6,9 & 273 & 96 & 325 & 38 \\
\hline 1,50 & 174,8 & 6,7 & 268 & 108 & 356 & 29 & 194,0 & 6,9 & 272 & 95 & 344 & 36 \\
\hline 2,00 & 146,7 & 6,7 & 279 & 104 & 363 & 28 & 184,5 & 6,9 & 288 & 90 & 344 & 33 \\
\hline 2,50 & 118,6 & 6,6 & 291 & 110 & 385 & 23 & 137,2 & 6,9 & 307 & 94 & 360 & 25 \\
\hline 3,00 & 110,6 & 6,6 & 295 & 114 & 395 & 21 & 116,1 & 6,9 & 299 & 94 & 382 & 27 \\
\hline 3,50 & 101,9 & 6,8 & 276 & 120 & 385 & 17 & 112,1 & 6,9 & 294 & 97 & 375 & 26 \\
\hline 4,00 & 112,9 & 6,8 & 296 & 114 & 399 & 16 & 113,7 & 6,9 & 316 & 93 & 372 & 25 \\
\hline 4,50 & 108,3 & 6,7 & 297 & 108 & 392 & 18 & 99,7 & 6,9 & 324 & 89 & 393 & 23 \\
\hline 5,00 & 111,4 & 6,8 & 298 & 117 & 404 & 16 & 104,7 & 6,9 & 317 & 91 & 399 & 21 \\
\hline 6,00 & 101,1 & 6,9 & 294 & 115 & 399 & 15 & 113,5 & 6,9 & 317 & 94 & 393 & 21 \\
\hline 7,00 & 96,3 & 6,8 & 319 & 110 & - & & 106,7 & - & - & - & - & - \\
\hline 8,00 & 100,1 & 6,7 & 318 & 106 & 409 & 21 & 111,1 & - & - & - & - & - \\
\hline
\end{tabular}


TABELA B.5: Perfis Experimentais da concentração de metano $\left(\mathrm{C}_{\mathrm{CH} 4}\right)$, porcentagem de metano no "head-space" $\left(\%_{\mathrm{CH} 4}\right)$, volume de metano acumulado (V), velocidade de produção de metano (Vel) em dois ciclos do ensaio Tu50.

\begin{tabular}{cccccccccc}
\hline \multicolumn{1}{c}{ Ciclo 52 } & \multicolumn{5}{c}{ Ciclo 55 } \\
\hline $\begin{array}{c}\text { Tempo } \\
(\mathrm{h})\end{array}$ & $\begin{array}{c}\mathrm{C}_{\mathrm{CH} 4} \\
\left(\mathrm{mMol.} \mathrm{I}^{-1}\right)\end{array}$ & $\begin{array}{c}\%_{\mathrm{CH} 4} \\
(\%)\end{array}$ & $\begin{array}{c}\mathrm{V} \\
(\mathrm{m} l)\end{array}$ & $\begin{array}{c}\text { Vel } \\
\left(\mathrm{m} l . \mathrm{h}^{-1}\right)\end{array}$ & $\begin{array}{c}\text { Tempo } \\
(\mathrm{h})\end{array}$ & $\begin{array}{c}\mathrm{C}_{\mathrm{CH} 4} \\
\left(\mathrm{mMol} .1^{-1}\right)\end{array}$ & $\begin{array}{c}\%_{\mathrm{CH} 4} \\
(\%)\end{array}$ & $\begin{array}{c}\mathrm{V} \\
(\mathrm{m} l)\end{array}$ & $\begin{array}{c}\text { Vel } \\
\left(\mathrm{m} l . \mathrm{h}^{-1}\right)\end{array}$ \\
\hline 0,00 & 0,000 & 0,0 & 0 & 0,00 & 0,00 & 0,000 & 0,0 & 0,00 & 0,00 \\
0,40 & 0,222 & 47,3 & 7,06 & 17,86 & 0,50 & 0,375 & 52,1 & 6,35 & 12,70 \\
0,73 & 0,626 & 55,1 & 14,78 & 23,15 & 0,93 & 1,012 & 60,0 & 14,22 & 18,19 \\
1,04 & 1,016 & 57,8 & 23,82 & 29,36 & 1,32 & 1,524 & 62,2 & 22,45 & 21,42 \\
1,32 & 1,550 & 61,7 & 32,15 & 29,59 & 1,64 & 2,347 & 65,9 & 32,47 & 31,11 \\
1,59 & 1,986 & 63,6 & 39,94 & 28,64 & 1,98 & 2,747 & 66,4 & 40,95 & 24,87 \\
1,89 & 2,631 & 66,7 & 48,30 & 28,01 & 2,27 & 3,282 & 67,8 & 48,24 & 25,01 \\
2,21 & 3,015 & 66,6 & 56,86 & 26,63 & 2,57 & 3,773 & 68,5 & 55,17 & 23,24 \\
2,56 & 3,524 & 67,4 & 65,56 & 24,84 & 2,86 & 4,386 & 70,2 & 61,50 & 21,97 \\
2,96 & 4,352 & 69,9 & 74,73 & 23,18 & 3,41 & 5,085 & 70,8 & 71,09 & 17,44 \\
3,33 & 4,534 & 68,8 & 82,06 & 19,83 & 3,83 & 5,403 & 70,9 & 78,24 & 16,99 \\
3,78 & 5,289 & 70,3 & 90,86 & 19,50 & 4,30 & 5,904 & 71,0 & 85,45 & 15,30 \\
4,24 & 5,680 & 70,2 & 98,98 & 17,57 & 4,90 & 6,390 & 71,3 & 92,51 & 11,84 \\
4,81 & 6,155 & 70,8 & 107,75 & 15,32 & 5,44 & 6,775 & 71,3 & 98,77 & 11,44 \\
5,30 & 6,571 & 70,7 & 115,38 & 15,74 & 5,98 & 7,088 & 71,3 & 104,36 & 10,48 \\
5,81 & 6,915 & 70,9 & 122,69 & 14,22 & 6,48 & 7,257 & 71,2 & 109,71 & 10,72 \\
6,37 & 7,283 & 70,9 & 129,97 & 13,09 & 6,84 & 7,486 & 71,3 & 113,43 & 10,14 \\
6,89 & 7,554 & 70,9 & 136,06 & 11,58 & 7,31 & 7,577 & 71,3 & 115,94 & 5,37 \\
7,28 & 7,555 & 70,8 & 138,86 & 7,19 & & & & &
\end{tabular}




\section{APÊNDICE C. Ensaio com impelidor tipo turbina de pás planas inclinadas - valores experimentais}

TABELA C.1: Resultados Experimentais da concentração de matéria orgânica em termos de DQO $\left(\mathrm{C}_{\mathrm{af}}\right), \mathrm{pH}$, Alcalinidade Parcial (AP), Alcalinidade Intermediária (AI), Alcalinidade Total (AT), Alcalinidade a Bicarbonato (AB) e Ácidos Voláteis Totais (AVT) em amostras do afluente do ensaio com impelidor tipo turbina de pás planas verticais.

\begin{tabular}{cccccccc}
\hline Ciclo & $\begin{array}{c}\mathrm{C}_{\mathrm{AF}} \\
\left(\mathrm{mgDQO}^{-1}\right)\end{array}$ & $\mathrm{pH}$ & $\mathrm{AP}$ & $\mathrm{AI}$ & $\mathrm{AT}$ & $\mathrm{AB}$ & \multirow{2}{*}{\begin{tabular}{c}
$\mathrm{AVT}$ \\
\cline { 5 - 6 }$\left(\mathrm{mgHAc}^{-1}\right)$
\end{tabular}} \\
\hline 1 & 789,8 & 9,04 & 192 & 54 & 246 & 216 & 43 \\
6 & 776,2 & 8,99 & 188 & 52 & 241 & 212 & 41 \\
11 & 852,5 & 9,1 & 208 & 58 & 265 & 232 & 47 \\
15 & 799,8 & 9,14 & 194 & 51 & 244 & 213 & 43 \\
19 & 815,6 & 9,08 & 192 & 52 & 244 & 215 & 41 \\
22 & 899,8 & 9,08 & 188 & 54 & 243 & 215 & 38 \\
26 & 786,8 & 8,86 & 192 & 54 & 246 & 218 & 40 \\
28 & 815,4 & 9,02 & 194 & 56 & 250 & 220 & 41 \\
31 & 770,2 & 8,62 & 188 & 66 & 254 & 228 & 37 \\
34 & 627,5 & 9 & 195 & 52 & 248 & 222 & 37 \\
37 & 818,4 & 8,89 & 195 & 52 & 247 & 219 & 40 \\
41 & 790,5 & 8,93 & 190 & 56 & 246 & 222 & 34 \\
52 & 772,5 & 9,03 & 188 & 52 & 241 & 212 & 41 \\
56 & 811,6 & 9,16 & 188 & 58 & 246 & 218 & 39 \\
60 & 826,4 & 9,16 & 190 & 54 & 244 & 213 & 45 \\
65 & 778,3 & & & & & & \\
70 & 771,6 & 8,97 & 188 & 58 & 246 & 218 & 40 \\
72 & 774,0 & 8,59 & 194 & 54 & 247 & 224 & 33 \\
75 & 773,4 & 8,79 & 189 & 58 & 247 & 223 & 35 \\
80 & 861,2 & & & & & & \\
\hline
\end{tabular}


TABELA C.2: Resultados Experimentais da concentração de matéria orgânica em termos de DQO para amostras filtradas ( $\left.\mathrm{C}_{\mathrm{SF}}\right)$ e totais $\left(\mathrm{C}_{\mathrm{ST}}\right)$, eficiência de remoção de matéria orgânica em termos de DQO para amostras filtradas $\left(\mathrm{E}_{\mathrm{F}}\right)$ e totais $\left(\mathrm{E}_{\mathrm{T}}\right) \mathrm{pH}$, Alcalinidade Parcial $(\mathrm{AP})$, Alcalinidade Intermediária (AI), Alcalinidade Total (AT), Alcalinidade a Bicarbonato (AB) e Ácidos Voláteis Totais (AVT) em amostras do efluente do com impelidor tipo turbina de pás planas verticais.

\begin{tabular}{|c|c|c|c|c|c|c|c|c|c|c|c|}
\hline \multirow{2}{*}{ Ensaio } & \multirow{2}{*}{ Ciclo } & $\mathrm{C}_{\mathrm{SF}}$ & $\mathrm{C}_{\mathrm{ST}}$ & $E_{F}$ & $\mathrm{E}_{\mathrm{T}}$ & \multirow{2}{*}{$\mathrm{pH}$} & AP & $\mathrm{AI}$ & AT & $\mathrm{AB}$ & \multirow{2}{*}{$\begin{array}{c}\text { AVT } \\
\left(\text { mgHAc. } l^{-1}\right)\end{array}$} \\
\hline & & \multicolumn{2}{|c|}{$\left(\mathrm{mgDQO} .1^{-1}\right)$} & \multicolumn{2}{|c|}{$(\%)$} & & \multicolumn{4}{|c|}{$\left(\mathrm{mgCaCO}_{3} .1^{-1}\right)$} & \\
\hline \multirow{11}{*}{ Ti50 } & 7 & 99,1 & 144,0 & 87,5 & 81,9 & 6,85 & 289 & 102 & 390 & 378 & 17 \\
\hline & 10 & 95,8 & 119,1 & 88,0 & 85,0 & 6,78 & 307 & 85 & 392 & 380 & 17 \\
\hline & 13 & 106,5 & 126,6 & 86,6 & 84,1 & 6,78 & 321 & 104 & 425 & 413 & 17 \\
\hline & 22 & 108,5 & 150,2 & 86,4 & 81,1 & 6,78 & 289 & 115 & 404 & 392 & 18 \\
\hline & 27 & 107,5 & 122,8 & 86,5 & 84,6 & & & & & & \\
\hline & 28 & & & & & 6,81 & 298 & 109 & 408 & 394 & 19 \\
\hline & 31 & 102,5 & 116,9 & 87,1 & 85,3 & 6,78 & 287 & 116 & 403 & 390 & 19 \\
\hline & 33 & 109,0 & 139,7 & 86,3 & 82,4 & & & & & & \\
\hline & 34 & & & & & 6,93 & 300 & 102 & 403 & 388 & 20 \\
\hline & 37 & 106,3 & 120,1 & 86,6 & 84,9 & 6,86 & 317 & 102 , & 420 & 406 & 19 \\
\hline & 42 & 122,9 & 142,0 & 84,6 & 82,2 & 6,83 & 286 & 111 & 397 & 384 & 19 \\
\hline \multirow{10}{*}{ Ti75 } & 48 & 102,2 & 136,3 & 87,2 & 82,9 & 6,74 & 284 & 125 & 410 & 397 & 18 \\
\hline & 51 & 115,8 & 130,9 & 85,4 & 83,5 & 6,83 & 300 & 104 & 404 & 391 & 18 \\
\hline & 54 & 117,3 & 150,1 & 85,3 & 81,1 & 6,82 & 286 & 101 & 387 & 372 & 20 \\
\hline & 64 & 121,0 & 155,4 & 84,8 & 80,5 & 6,71 & 286 & 123 & 410 & 397 & 17 \\
\hline & 69 & 105,4 & 130,5 & 86,8 & 83,6 & & & & & & \\
\hline & 70 & & & & & 6,66 & 261 & 111 & 373 & 362 & 15 \\
\hline & 73 & 106,4 & 142,4 & 86,6 & 82,1 & 6,71 & 268 & 125 & 393 & 380 & 18 \\
\hline & 76 & 116,6 & 133,6 & 85,3 & 83,2 & 6,76 & 277 & 116 & 393 & 378 & 21 \\
\hline & 78 & 109,5 & 140,4 & 86,2 & 82,4 & & & & & & \\
\hline & 84 & 120,3 & 168,1 & 84,9 & 78,9 & 6,77 & 300 & 111 & 411 & 399 & 17,6 \\
\hline
\end{tabular}


TABELA C.3: Resultados experimentais da concentração de sólidos totais (ST), sólidos voláteis totais (SVT), sólidos suspensos totais (SST) e sólidos suspensos voláteis (SSV) em amostras afluentes e efluentes coletadas durante o ensaio com impelidor tipo turbina de pás planas verticais.

\begin{tabular}{lccccccccc}
\hline \multirow{2}{*}{ Ensaio } & Tempo & \multicolumn{9}{c}{ Afluente } \\
\cline { 3 - 9 } & & ST & SVT & SST & SSV & ST & SVT & SST & SSV \\
& $($ ciclo $)$ & $\left(\mathrm{mg} . l^{-1}\right)$ & $\left(\mathrm{mg} . l^{-1}\right)$ & $\left(\mathrm{mg} . l^{-1}\right)$ & $\left(\mathrm{mg} . l^{-1}\right)$ & $\left(\mathrm{mg} . l^{-1}\right)$ & $\left(\mathrm{mg} . l^{-1}\right)$ & $\left(\mathrm{mg} . l^{-1}\right)$ & $\left(\mathrm{mg} . l^{-1}\right)$ \\
\hline Ti50 & 3 & 1586 & 898 & 52 & 36 & 996 & 402 & 66 & 68 \\
& 9 & 1622 & 828 & 36 & 26 & 1028 & 286 & 40 & 48 \\
& 24 & 1552 & 876 & 64 & 42 & 1052 & 344 & 110 & 74 \\
& 30 & 1600 & 862 & 44 & 24 & 1090 & 314 & 94 & 54 \\
\hline Ti75 & 45 & 1652 & 844 & 58 & 58 & 1052 & 286 & 56 & 56 \\
& 52 & 1610 & 866 & 42 & 20 & 1062 & 326 & 68 & 52 \\
& 72 & 1658 & 934 & 28 & 18 & 1054 & 352 & 76 & 42 \\
& 84 & 1694 & 922 & 48 & 44 & 1130 & 374 & 76 & 72 \\
\hline
\end{tabular}


TABELA C.4: Perfis Experimentais da concentração de matéria orgânica em termos de DQO para amostras filtradas $\left(\mathrm{C}_{\mathrm{SF}}\right)$, $\mathrm{pH}$, Alcalinidade Parcial (AP), Alcalinidade Intermediária (AI), Alcalinidade Total (AT), Alcalinidade a Bicarbonato (AB) e Ácidos Voláteis Totais (AVT) durante a condição Ti50.

\begin{tabular}{|c|c|c|c|c|c|c|c|c|c|c|c|c|}
\hline & \multicolumn{6}{|c|}{ Ciclo 31} & \multicolumn{6}{|c|}{ Ciclo 37} \\
\hline \multirow{2}{*}{$\begin{array}{l}\text { Tempo } \\
\text { (h) }\end{array}$} & \multirow{2}{*}{$\begin{array}{c}\mathrm{C}_{\mathrm{AF}} \\
\left(\mathrm{mgDQO} . \mathrm{l}^{-1}\right)\end{array}$} & \multirow{2}{*}{$\mathrm{pH}$} & AP & AI & $\mathrm{AB}$ & \multirow{2}{*}{$\begin{array}{c}\text { AVT } \\
\left(\mathrm{mgHAc}^{\left.-1^{-1}\right)}\right.\end{array}$} & \multirow{2}{*}{$\begin{array}{c}\mathrm{C}_{\mathrm{AF}} \\
\left(\mathrm{mgDQO} .1^{-1}\right) \\
\end{array}$} & \multirow{2}{*}{$\mathrm{pH}$} & $\mathrm{AP}$ & $\mathrm{AI}$ & $\mathrm{AB}$ & \multirow{2}{*}{ 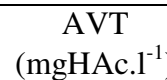 } \\
\hline & & & & $\mathrm{CaCO}$ & & & & & \multicolumn{3}{|c|}{$\left(\mathrm{mgCaCO}_{3} \cdot 1^{-1}\right)$} & \\
\hline 0 & 444,4 & 6,94 & 226 & 87 & 290 & 32 & 468,8 & 7,17 & 238 & 81 & 294 & 36 \\
\hline 0,33 & 331,3 & 6,79 & 225 & 108 & 304 & 40 & 365,9 & 6,98 & 239 & 96 & 302 & 47 \\
\hline 0,67 & 284,2 & 6,75 & 230 & 119 & 319 & 42 & 308,0 & 6,92 & 249 & 109 & & \\
\hline 1 & 259,1 & 6,73 & 239 & 118 & 320 & 51 & 272,6 & 6,89 & 256 & 109 & 326 & 55 \\
\hline 1,5 & 213,4 & 6,74 & 249 & 122 & 338 & 46 & 226,0 & 6,89 & 260 & 115 & 341 & 48 \\
\hline 2 & 189,5 & 6,75 & 254 & 130 & 355 & 41 & 198,3 & 6,87 & 273 & 108 & 349 & 45 \\
\hline 2,5 & 162,3 & 6,77 & 259 & 123 & 356 & 37 & 167,5 & 6,88 & 275 & 115 & 368 & 31 \\
\hline 3 & 142,6 & 6,77 & 270 & 118 & 370 & 26 & 161,0 & 6,88 & 294 & 103 & 379 & 26 \\
\hline 3,5 & 130,5 & 6,77 & 269 & 122 & 371 & 28 & 133,1 & 6,87 & 298 & 105 & 385 & 25 \\
\hline 4 & 117,3 & 6,78 & 290 & 109 & 384 & 22 & 133,6 & 6,88 & 296 & 108 & 386 & 26 \\
\hline 4,5 & 103,4 & 6,78 & 290 & 115 & 390 & 20 & 119,3 & 6,87 & 296 & 106 & 387 & 21 \\
\hline 5 & 105,5 & 6,79 & 291 & 109 & 385 & 22 & 120,8 & 6,88 & 294 & 106 & 387 & 17 \\
\hline 6 & 104,3 & 6,79 & 291 & 108 & 387 & 17 & 111,4 & 6,87 & 298 & 111 & 396 & 19 \\
\hline 7 & 112,4 & 6,78 & 291 & 113 & 391 & 20 & 113,7 & 6,86 & 309 & 107 & 402 & 20 \\
\hline 8 & 102,5 & 6,78 & 287 & 117 & 390 & 19 & 106,3 & 6,86 & 317 & 103 & 406 & 19 \\
\hline
\end{tabular}


TABELA C.5: Perfis Experimentais da concentração de metano $\left(\mathrm{C}_{\mathrm{CH} 4}\right)$, porcentagem de metano no "head-space" $\left(\%_{\mathrm{CH} 4}\right)$, volume de metano acumulado $(\mathrm{V})$, velocidade de produção de metano (Vel) em dois ciclos da condição Ti50.

\begin{tabular}{|c|c|c|c|c|c|c|c|c|c|}
\hline \multicolumn{5}{|c|}{ Ciclo 28} & \multicolumn{5}{|c|}{ Ciclo 34} \\
\hline $\begin{array}{l}\text { Tempo } \\
\text { (h) }\end{array}$ & $\begin{array}{c}\mathrm{C}_{\mathrm{CH} 4} \\
\left(\mathrm{mMol} \mathrm{l}^{-1}\right)\end{array}$ & $\begin{array}{l}\%_{\mathrm{CH} 4} \\
(\%)\end{array}$ & $\begin{array}{c}\mathrm{V} \\
(\mathrm{m} l)\end{array}$ & $\begin{array}{c}\mathrm{Vel} \\
\left(\mathrm{m} l \cdot \mathrm{h}^{-1}\right)\end{array}$ & $\begin{array}{l}\text { Tempo } \\
\text { (h) }\end{array}$ & $\begin{array}{c}\mathrm{C}_{\mathrm{CH} 4} \\
\left(\mathrm{mMol} \mathrm{l}^{-1}\right)\end{array}$ & $\begin{array}{l}\%_{\mathrm{CH} 4} \\
(\%)\end{array}$ & $\begin{array}{c}\mathrm{V} \\
(\mathrm{m} l)\end{array}$ & $\begin{array}{c}\mathrm{Vel} \\
\left(\mathrm{m} l \cdot \mathrm{h}^{-1}\right)\end{array}$ \\
\hline 0,00 & 0,000 & 0,0 & 0 & 0,00 & 0,00 & 0,000 & 0,0 & 0,00 & 0,00 \\
\hline 0,38 & 0,234 & 47,1 & 7,19 & 19,12 & 0,39 & 0,176 & 43,4 & 9,58 & 24,76 \\
\hline 0,75 & 0,635 & 51,8 & 15,36 & 22,02 & 0,86 & 0,720 & 55,1 & 20,43 & 23,09 \\
\hline 1,16 & 1,287 & 56,4 & 27,23 & 28,77 & 1,18 & 1,182 & 58,7 & 29,66 & 28,19 \\
\hline 1,50 & 1,848 & 59,3 & 37,68 & 30,90 & 1,54 & 1,681 & 62,1 & 39,65 & 27,77 \\
\hline 1,79 & 2,413 & 62,1 & 46,25 & 29,21 & 1,93 & 2,398 & 64,9 & 50,85 & 28,98 \\
\hline 2,09 & 2,930 & 63,8 & 54,59 & 27,83 & 2,29 & 3,140 & 67,6 & 61,73 & 30,24 \\
\hline 2,38 & 3,325 & 64,6 & 62,49 & 27,07 & 2,66 & 3,743 & 68,6 & 72,51 & 29,16 \\
\hline 2,74 & 3,809 & 65,7 & 71,75 & 26,05 & 3,04 & 4,376 & 69,5 & 82,88 & 27,28 \\
\hline 3,09 & 4,170 & 66,5 & 80,40 & 24,76 & 3,49 & 4,963 & 70,4 & 93,97 & 24,59 \\
\hline 3,45 & 4,623 & 67,2 & 88,77 & 23,23 & 3,97 & 5,566 & 71,1 & 104,45 & 22,02 \\
\hline 3,84 & 5,153 & 67,7 & 97,43 & 22,02 & 4,45 & 5,923 & 71,5 & 113,94 & 19,85 \\
\hline 4,20 & 5,499 & 68,3 & 104,59 & 20,04 & 4,96 & 6,483 & 71,7 & 122,92 & 17,45 \\
\hline 4,65 & 5,825 & 68,7 & 112,87 & 18,50 & 5,35 & 6,711 & 72,0 & 129,16 & 16,14 \\
\hline 5,02 & 6,151 & 69,0 & 119,59 & 18,07 & 5,78 & 7,015 & 72,0 & 135,28 & 13,97 \\
\hline 5,45 & 6,393 & 69,2 & 126,20 & 15,30 & 6,10 & 7,239 & 72,1 & 139,53 & 13,65 \\
\hline 5,96 & 6,771 & 69,3 & 133,54 & 14,36 & 6,27 & 7,330 & 72,2 & 141,84 & 13,62 \\
\hline 6,55 & 7,041 & 69,4 & 141,02 & 12,69 & & & & & \\
\hline 7,04 & 7,128 & 69,3 & 148,01 & 14,19 & & & & & \\
\hline 7,22 & 7,200 & 69,5 & 149,02 & 5,72 & & & & & \\
\hline
\end{tabular}


TABELA C.6: Perfis Experimentais da concentração de matéria orgânica em termos de DQO para amostras filtradas $\left(\mathrm{C}_{\mathrm{SF}}\right)$, $\mathrm{pH}$,

Alcalinidade Parcial (AP), Alcalinidade Intermediária (AI), Alcalinidade Total (AT), Alcalinidade a Bicarbonato (AB) e Ácidos Voláteis Totais (AVT) durante a condição Ti75.

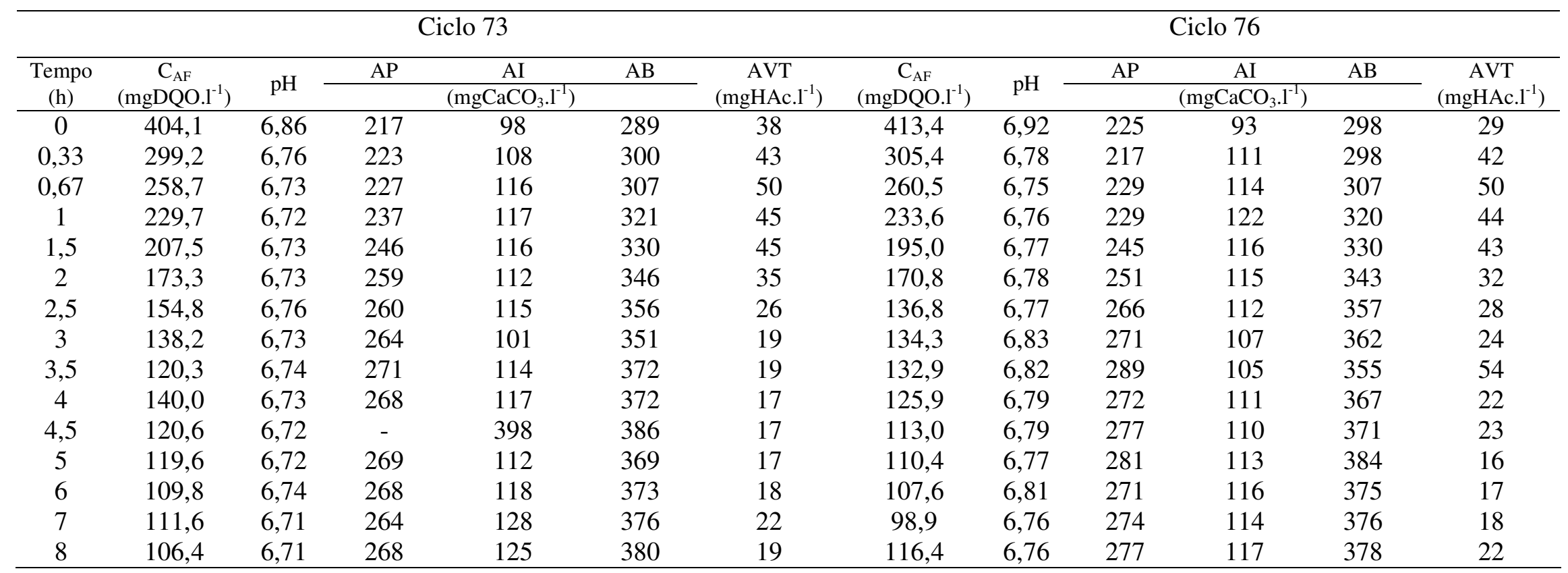


TABELA C.7: Perfis Experimentais da concentração de metano $\left(\mathrm{C}_{\mathrm{CH} 4}\right)$, porcentagem de metano no "head-space" $\left(\%_{\mathrm{CH} 4}\right)$, volume de metano acumulado (V), velocidade de produção de metano (Vel) em dois ciclos da condição Ti75.

\begin{tabular}{|c|c|c|c|c|c|c|c|c|c|}
\hline \multicolumn{5}{|c|}{ Ciclo 70} & \multicolumn{5}{|c|}{ Ciclo 79} \\
\hline $\begin{array}{l}\text { Tempo } \\
\text { (h) }\end{array}$ & $\begin{array}{c}\mathrm{C}_{\mathrm{CH} 4} \\
\left(\mathrm{mMol}^{-1} \mathrm{l}^{-1}\right)\end{array}$ & $\begin{array}{l}\%_{\mathrm{CH} 4} \\
(\%)\end{array}$ & $\begin{array}{c}\mathrm{V} \\
(\mathrm{m} l)\end{array}$ & $\begin{array}{c}\mathrm{Vel} \\
\left(\mathrm{m} l \cdot \mathrm{h}^{-1}\right)\end{array}$ & $\begin{array}{l}\text { Tempo } \\
\text { (h) }\end{array}$ & $\begin{array}{c}\mathrm{C}_{\mathrm{CH} 4} \\
\left(\mathrm{mMol} \mathrm{l}^{-1}\right)\end{array}$ & $\begin{array}{l}\%_{\mathrm{CH} 4} \\
(\%)\end{array}$ & $\begin{array}{c}\mathrm{V} \\
(\mathrm{m} l)\end{array}$ & $\begin{array}{c}\text { Vel } \\
\left(\mathrm{m} l \cdot \mathrm{h}^{-1}\right)\end{array}$ \\
\hline 0,00 & 0,000 & 0,0 & 0 & 0,00 & 0,00 & 0,000 & 0,0 & 0,00 & 0,00 \\
\hline 0,46 & 0,191 & 45,6 & 8,13 & 17,62 & 0,30 & 0,071 & 27,9 & 8,44 & 28,19 \\
\hline 0,85 & 0,608 & 55,3 & 17,27 & 23,26 & 0,68 & 0,446 & 46,5 & 17,00 & 22,35 \\
\hline 1,19 & 1,100 & 60,1 & 26,46 & 27,42 & 1,01 & 0,899 & 52,9 & 25,48 & 25,62 \\
\hline 1,47 & 1,575 & 63,0 & 35,36 & 31,29 & 1,31 & 1,378 & 56,9 & 33,63 & 27,70 \\
\hline 1,75 & 2,064 & 65,1 & 44,21 & 31,55 & 1,61 & 1,864 & 59,7 & 42,32 & 28,90 \\
\hline 2,06 & 2,794 & 68,1 & 53,84 & 31,49 & 1,93 & 2,603 & 63,7 & 51,50 & 28,33 \\
\hline 2,34 & 3,212 & 69,0 & 62,22 & 30,06 & 2,33 & 3,295 & 65,7 & 62,50 & 27,57 \\
\hline 2,62 & 3,710 & 70,0 & 70,61 & 29,73 & 2,63 & 3,760 & 66,8 & 70,78 & 27,70 \\
\hline 2,95 & 4,295 & 70,4 & 79,66 & 27,35 & 2,95 & 4,280 & 68,0 & 79,26 & 26,25 \\
\hline 3,35 & 4,617 & 71,2 & 88,83 & 23,24 & 3,27 & 4,747 & 68,8 & 86,98 & 24,10 \\
\hline 3,77 & 5,188 & 71,7 & 97,41 & 20,48 & 3,66 & 5,196 & 69,6 & 95,29 & 21,37 \\
\hline 4,21 & 5,510 & 71,8 & 105,43 & 18,03 & 4,08 & 5,638 & 70,4 & 103,06 & 18,44 \\
\hline 4,70 & 5,907 & 71,9 & 112,53 & 14,44 & 4,61 & 6,166 & 70,8 & 110,79 & 14,58 \\
\hline 5,20 & 6,148 & 72,0 & 119,12 & 13,16 & 5,16 & 6,525 & 71,2 & 117,53 & 12,27 \\
\hline 5,73 & 6,431 & 72,0 & 125,28 & 11,67 & 5,59 & 6,883 & 71,4 & 121,94 & 10,41 \\
\hline 6,25 & 6,866 & 72,0 & 130,48 & 10,07 & 6,12 & 7,139 & 71,6 & 126,79 & 9,13 \\
\hline 6,76 & 7,149 & 72,1 & 135,25 & 9,32 & 6,59 & 7,343 & 71,6 & 130,67 & 8,28 \\
\hline 7,13 & 7,069 & 72,0 & 138,54 & 8,89 & 7,11 & 7,663 & 71,7 & 134,80 & 7,91 \\
\hline 7,31 & 6,989 & 71,8 & 139,28 & 4,00 & 7,28 & 7,585 & 71,7 & 135,17 & 2,14 \\
\hline
\end{tabular}




\section{APÊNDICE D. Ensaio com impelidor tipo pá de pás planas verticais -}

\section{valores experimentais}

TABELA D.1: Resultados Experimentais da concentração de matéria orgânica em termos de DQO $\left(\mathrm{C}_{\mathrm{af}}\right), \mathrm{pH}$, Alcalinidade Parcial (AP), Alcalinidade Intermediária (AI), Alcalinidade Total (AT), Alcalinidade a Bicarbonato (AB) e Ácidos Voláteis Totais (AVT) em amostras do afluente do ensaio com impelidor tipo pá de pás planas verticais.

\begin{tabular}{cccccccc}
\hline Ciclo & \multirow{2}{*}{$\begin{array}{c}\mathrm{C}_{\mathrm{AF}} \\
\left(\mathrm{mgDQO} .1^{-1}\right)\end{array}$} & $\mathrm{pH}$ & $\mathrm{AP}$ & $\mathrm{AI}$ & $\mathrm{AT}$ & $\mathrm{AB}$ & \multirow{2}{*}{$\begin{array}{c}\text { AVT } \\
\left(\mathrm{mgHAc}^{-1}\right)\end{array}$} \\
\hline 1 & 861,0 & 9,1 & 197 & 54 & 251 & 221 & 42 \\
6 & 792,0 & 8,6 & 192 & 56 & 247 & 223 & 34 \\
11 & 757,5 & & & & & & \\
16 & 771,6 & 8,67 & 195 & 56 & 251 & 222 & 40 \\
20 & 788,3 & 8,72 & 192 & 57 & 249 & 219 & 42 \\
25 & 789,1 & 8,93 & 207 & 58 & 265 & 242 & 33 \\
28 & 810,7 & & & & & & \\
31 & 792,0 & 8,78 & 178 & 52 & 230 & 204 & 37 \\
34 & 822,8 & 8,77 & 194 & 60 & 253 & 227 & 37 \\
42 & 788,6 & 8,86 & 197 & 57 & 254 & 227 & 38 \\
45 & 782,5 & 8,88 & 192 & 57 & 249 & 223 & 37 \\
48 & & 8,97 & 195 & 54 & 249 & 220 & 41 \\
51 & 797,6 & 8,96 & 193 & 56 & 249 & 223 & 36 \\
54 & 839,7 & 8,9 & 192 & 56 & 247 & 219 & 40 \\
60 & 782,5 & 9,06 & 200 & 52 & 252 & 225 & 39 \\
64 & 842,1 & 9,02 & 197 & 52 & 249 & 219 & 42 \\
67 & 816,7 & 8,96 & 192 & 57 & 249 & 223 & 37 \\
70 & 794,5 & & & & & & \\
76 & 819,2 & 9 & 200 & 56 & 256 & 226 & 42 \\
79 & 818,9 & 8,96 & 198 & 50 & 249 & 220 & 41 \\
81 & 844,4 & & & & & & \\
85 & 833,1 & & & & & & \\
\hline
\end{tabular}


TABELA D.2: Resultados Experimentais da concentração de matéria orgânica em termos de DQO para amostras filtradas $\left(\mathrm{C}_{\mathrm{SF}}\right)$ e totais $\left(\mathrm{C}_{\mathrm{ST}}\right)$, eficiência de remoção de matéria orgânica em termos de DQO para amostras filtradas $\left(\mathrm{E}_{\mathrm{F}}\right)$ e totais $\left(\mathrm{E}_{\mathrm{T}}\right) \mathrm{pH}$, Alcalinidade Parcial $(\mathrm{AP})$, Alcalinidade Intermediária (AI), Alcalinidade Total (AT), Alcalinidade a Bicarbonato (AB) e Ácidos Voláteis Totais (AVT) em amostras do efluente do com impelidor tipo pá de pás planas verticais.

\begin{tabular}{|c|c|c|c|c|c|c|c|c|c|c|c|}
\hline \multirow{2}{*}{ Ensaio } & \multirow{2}{*}{ Ciclo } & $\mathrm{C}_{\mathrm{SF}}$ & $\mathrm{C}_{\mathrm{ST}}$ & $\mathrm{E}_{\mathrm{F}}$ & $\mathrm{E}_{\mathrm{T}}$ & \multirow{2}{*}{$\mathrm{pH}$} & AP & AI & $\mathrm{AT}$ & $\mathrm{AB}$ & \multirow{2}{*}{$\begin{array}{c}\text { AVT } \\
\left(\mathrm{mgHAc} .1^{-1}\right)\end{array}$} \\
\hline & & \multicolumn{2}{|c|}{$\left(\mathrm{mgDQO} .1^{-1}\right)$} & \multicolumn{2}{|c|}{$(\%)$} & & \multicolumn{4}{|c|}{$\left(\mathrm{mgCaCO}_{3} .1^{-1}\right)$} & \\
\hline \multirow{10}{*}{$\mathrm{Pa} 50$} & 3 & 134,0 & 151,9 & 83,4 & 81,2 & 6,78 & 272 & 103 & 374 & 362 & 17 \\
\hline & 9 & 123,0 & 147,0 & 84,8 & 81,8 & 6,77 & 284 & 108 & 392 & 382 & 13 \\
\hline & 12 & 123,8 & 139,0 & 84,7 & 82,8 & 6,76 & 298 & 103 & 400 & 386 & 20 \\
\hline & 24 & 177,7 & 202,2 & 78,0 & 75,0 & 6,81 & 280 & 115 & 395 & 376 & 27 \\
\hline & 25 & 146,4 & 171,5 & 81,9 & 78,8 & & & & & & \\
\hline & 28 & 153,5 & 175,5 & 81,0 & 78,3 & 6,77 & 279 & 118 & 397 & 378 & 26 \\
\hline & 30 & 139,0 & 166,1 & 82,8 & 79,5 & & & & & & \\
\hline & 31 & & & & & 6,82 & 292 & 122 & 413 & 397 & 23 \\
\hline & 34 & 158,4 & 176,6 & 80,4 & 78,2 & 6,76 & 286 & 111 & 397 & 376 & 29 \\
\hline & 42 & 139,5 & 172,4 & 82,8 & 78,7 & 6,82 & 247 & 108 & 355 & 343 & 18 \\
\hline \multirow{13}{*}{$\mathrm{Pa} 75$} & 45 & 113,4 & 183,2 & 86,0 & 77,4 & 6,73 & 289 & 104 & 393 & 380 & 19 \\
\hline & 48 & 135,7 & 184,1 & 83,2 & 77,3 & 6,80 & 279 & 118 & 397 & 382 & 21 \\
\hline & 51 & 131,8 & 182,5 & 83,7 & 77,5 & 6,74 & 286 & 115 & 400 & 388 & 18 \\
\hline & 54 & 149,9 & 188,7 & 81,5 & 76,7 & 6,79 & 299 & 104 & 404 & 388 & 23 \\
\hline & 63 & 129,3 & 184,8 & 84,0 & 77,2 & & & & & & \\
\hline & 64 & & & & & 6,79 & 301 & 108 & 408 & 391 & 24 \\
\hline & 67 & 144,2 & 180,9 & 82,2 & 77,6 & 6,82 & 296 & 104 & 401 & 384 & 24 \\
\hline & 70 & 144,8 & 185,1 & 82,1 & 77,1 & 6,88 & 259 & 106 & 366 & 351 & 21 \\
\hline & 73 & 142,4 & 189,8 & 82,4 & 76,5 & 6,87 & 303 & 104 & 407 & 397 & 15 \\
\hline & 75 & 131,3 & 171,3 & 83,8 & 78,8 & 6,82 & 273 & 117 & 390 & 373 & 24 \\
\hline & 84 & 137,7 & 177,9 & 83,0 & 78,0 & & & & & & \\
\hline & 87 & 146,4 & 187,9 & 81,9 & 76,8 & 6,76 & 273 & 117 & 390 & 373 & 24 \\
\hline & 90 & 156,5 & 206,0 & 80,7 & 74,5 & 6,72 & 265 & 106 & 371 & 354 & 24 \\
\hline
\end{tabular}


TABELA D.3: Resultados experimentais da concentração de sólidos totais (ST), sólidos voláteis totais (SVT), sólidos suspensos totais (SST) e sólidos suspensos voláteis (SSV) em amostras afluentes e efluentes coletadas durante o ensaio com impelidor tipo pá de pás planas verticais.

\begin{tabular}{|c|c|c|c|c|c|c|c|c|c|}
\hline \multirow{3}{*}{ Ensaio } & \multirow{3}{*}{$\begin{array}{l}\text { Tempo } \\
\text { (ciclo) }\end{array}$} & \multicolumn{4}{|c|}{ Afluente } & \multicolumn{4}{|c|}{ Efluente } \\
\hline & & $\mathrm{ST}$ & SVT & SST & SSV & ST & SVT & SST & SSV \\
\hline & & $\left(\mathrm{mg} . l^{-1}\right)$ & $\left(\mathrm{mg} . l^{-1}\right)$ & $\left(\mathrm{mg} \cdot l^{-1}\right)$ & $\left(\mathrm{mg} . l^{-1}\right)$ & $\left(\mathrm{mg} . l^{-1}\right)$ & $\left(\mathrm{mg} . l^{-1}\right)$ & $\left(\mathrm{mg} . l^{-1}\right)$ & $\left(\mathrm{mg} \cdot l^{-1}\right)$ \\
\hline \multirow{4}{*}{ Pa50 } & 9 & 1578 & 854 & 60 & 60 & 1012 & 334 & 60 & 58 \\
\hline & 24 & 1618 & 856 & 52 & 24 & 1134 & 384 & 82 & 60 \\
\hline & 30 & 1640 & 882 & 36 & 24 & 1100 & 338 & 74 & 58 \\
\hline & 42 & 1534 & 826 & 46 & 36 & 1054 & 302 & 64 & 64 \\
\hline \multirow{4}{*}{$\mathrm{Pa} 75$} & 51 & 1562 & 826 & 50 & 48 & 1032 & 330 & 74 & 68 \\
\hline & 66 & 1648 & 888 & 8 & 0 & 1192 & 364 & 48 & 48 \\
\hline & 72 & 1624 & 960 & 20 & 20 & 1128 & 338 & 60 & 58 \\
\hline & 87 & 1598 & 914 & 46 & 42 & 1048 & 344 & 88 & 86 \\
\hline
\end{tabular}


TABELA D.4: Perfis Experimentais da concentração de matéria orgânica em termos de DQO para amostras filtradas $\left(\mathrm{C}_{\mathrm{SF}}\right)$, $\mathrm{pH}$, Alcalinidade Parcial (AP), Alcalinidade Intermediária (AI), Alcalinidade Total (AT), Alcalinidade a Bicarbonato (AB) e Ácidos Voláteis Totais (AVT) durante a condição Pa50.

\begin{tabular}{|c|c|c|c|c|c|c|c|c|c|c|c|c|}
\hline \multirow[b]{2}{*}{$\begin{array}{l}\text { Tempo } \\
\text { (h) }\end{array}$} & \multicolumn{6}{|c|}{ Ciclo 28} & \multicolumn{6}{|c|}{ Ciclo 34} \\
\hline & $\begin{array}{c}\mathrm{C}_{\mathrm{AF}} \\
\left(\mathrm{mgDQO} \cdot \mathrm{l}^{-1}\right)\end{array}$ & $\mathrm{pH}$ & $\mathrm{AP}$ & $\begin{array}{c}\mathrm{AI} \\
\left(\mathrm{mgCaCO}_{3} . \mathrm{I}^{-1}\right)\end{array}$ & $\mathrm{AB}$ & $\begin{array}{c}\text { AVT } \\
\left(\text { mgHAc. }^{-1}\right)\end{array}$ & $\begin{array}{c}\mathrm{C}_{\mathrm{AF}} \\
\left(\mathrm{mgDQO} \cdot \mathrm{l}^{-1}\right)\end{array}$ & $\mathrm{pH}$ & $\mathrm{AP}$ & $\frac{\mathrm{AI}}{\left(\mathrm{mgCaCO}_{3} \mathrm{I}^{-1}\right)}$ & $\mathrm{AB}$ & $\begin{array}{c}\text { AVT } \\
\left(\mathrm{mgHAc}^{-1}\right)^{-1}\end{array}$ \\
\hline 0 & 508,0 & 7,06 & 214 & 89 & 280 & 34 & 499,1 & 6,96 & 212 & 94 & 279 & 37 \\
\hline 0,67 & 371,0 & 6,82 & 218 & 109 & 295 & 45 & 358,2 & 6,73 & 216 & 118 & 298 & 51 \\
\hline 1 & 338,6 & 6,77 & 219 & 113 & 296 & 50 & 313,8 & 6,71 & 225 & 128 & 313 & 57 \\
\hline 1,5 & 302,9 & 6,75 & 233 & 124 & 318 & 55 & 304,3 & 6,71 & 229 & 130 & 318 & 57 \\
\hline 3 & 252,1 & 6,78 & 246 & 123 & 336 & 47 & 233,6 & 6,73 & 246 & 135 & 345 & 50 \\
\hline 3,5 & 240,2 & 6,77 & 249 & 124 & 340 & 46 & 209,0 & 6,74 & 254 & 130 & 354 & 42 \\
\hline 4 & 231,3 & 6,75 & 258 & 121 & 349 & 42 & 195,4 & 6,73 & 258 & 133 & 362 & 42 \\
\hline 4,5 & 193,3 & 6,77 & 264 & 115 & 350 & 41 & 180,0 & 6,74 & 263 & 132 & 370 & 34 \\
\hline 5 & 179,7 & 6,77 & 261 & 121 & 357 & 36 & 174,5 & 6,76 & 218 & 171 & 367 & 31 \\
\hline 6 & 168,9 & 6,78 & 275 & 117 & 371 & 29 & 151,6 & 6,81 & 293 & 126 & 404 & 23 \\
\hline
\end{tabular}


TABELA D.5: Perfis Experimentais da concentração de metano $\left(\mathrm{C}_{\mathrm{CH} 4}\right)$, porcentagem de metano no "head-space" $\left(\%_{\mathrm{CH} 4}\right)$, volume de metano acumulado (V), velocidade de produção de metano (Vel) em dois ciclos da condição Pa50.

\begin{tabular}{|c|c|c|c|c|c|c|c|c|c|}
\hline \multicolumn{5}{|c|}{ Ciclo 25} & \multicolumn{5}{|c|}{ Ciclo 31} \\
\hline $\begin{array}{l}\text { Tempo } \\
\text { (h) }\end{array}$ & $\begin{array}{c}\mathrm{C}_{\mathrm{CH} 4} \\
\left(\mathrm{mMol} .1^{-1}\right)\end{array}$ & $\begin{array}{l}\%_{\mathrm{CH} 4} \\
(\%)\end{array}$ & $\begin{array}{c}\mathrm{V} \\
(\mathrm{m} l)\end{array}$ & $\begin{array}{c}\text { Vel } \\
\left(\mathrm{m} l \cdot \mathrm{h}^{-1}\right)\end{array}$ & $\begin{array}{c}\text { Tempo } \\
\text { (h) }\end{array}$ & $\begin{array}{c}\mathrm{C}_{\mathrm{CH} 4} \\
\left(\mathrm{mMol} \mathrm{l}^{-1}\right)\end{array}$ & $\begin{array}{c}\%_{\mathrm{CH} 4} \\
(\%)\end{array}$ & $\begin{array}{c}\mathrm{V} \\
(\mathrm{m} l)\end{array}$ & $\begin{array}{c}\mathrm{Vel} \\
\left(\mathrm{m} l \cdot \mathrm{h}^{-1}\right)\end{array}$ \\
\hline 0,00 & 0,000 & 0,0 & 0 & 0,00 & 0,00 & 0,000 & 0,0 & 0,00 & 0,00 \\
\hline 0,35 & 0,172 & 41,9 & 7,60 & 21,71 & 0,43 & 0,219 & 48,3 & 8,64 & 20,04 \\
\hline 0,99 & 0,675 & 46,9 & 18,20 & 16,45 & 0,93 & 0,583 & 49,3 & 17,32 & 17,43 \\
\hline 1,37 & 1,043 & 49,4 & 25,21 & 18,89 & 1,35 & 0,984 & 51,8 & 26,04 & 20,91 \\
\hline 1,80 & 1,455 & 51,7 & 33,91 & 20,10 & 1,75 & 1,422 & 54,7 & 34,83 & 21,72 \\
\hline 2,19 & 1,876 & 53,9 & 42,27 & 21,12 & 2,12 & 1,854 & 56,9 & 43,20 & 22,74 \\
\hline 2,57 & 2,518 & 57,6 & 50,38 & 21,51 & 2,59 & 2,557 & 60,7 & 53,81 & 22,64 \\
\hline 2,98 & 2,911 & 59,1 & 58,78 & 20,60 & 2,96 & 2,949 & 62,3 & 62,11 & 22,04 \\
\hline 3,36 & 3,344 & 60,4 & 66,43 & 20,36 & 3,34 & 3,327 & 63,6 & 70,04 & 21,37 \\
\hline 3,74 & 3,728 & 61,7 & 73,99 & 19,46 & 3,75 & 3,790 & 64,6 & 78,39 & 20,30 \\
\hline 4,18 & 4,171 & 62,9 & 81,61 & 17,51 & 4,16 & 4,180 & 65,7 & 86,45 & 19,72 \\
\hline 4,70 & 4,644 & 64,0 & 90,34 & 16,72 & 4,60 & 4,561 & 66,8 & 94,84 & 19,07 \\
\hline 5,23 & 5,131 & 65,0 & 98,45 & 15,23 & 5,06 & 4,969 & 67,6 & 103,23 & 17,88 \\
\hline 5,76 & 5,433 & 66,0 & 106,27 & 14,97 & 5,54 & 5,501 & 68,4 & 111,47 & 17,24 \\
\hline 6,28 & 5,842 & 66,8 & 113,55 & 13,81 & 6,07 & 5,740 & 69,4 & 120,11 & 16,49 \\
\hline 6,72 & 6,170 & 67,4 & 119,34 & 13,31 & 6,61 & 6,127 & 70,0 & 128,69 & 15,89 \\
\hline 07,12 & 6,453 & 67,8 & 124,18 & 12,05 & 7,10 & 6,624 & 70,4 & 136,84 & 16,47 \\
\hline 7,28 & 6,513 & 68,0 & 125,33 & 7,06 & 7,26 & 6,443 & 70,6 & 137,87 & 6,32 \\
\hline
\end{tabular}


TABELA D.6: Perfis Experimentais da concentração de matéria orgânica em termos de DQO para amostras filtradas $\left(\mathrm{C}_{\mathrm{SF}}\right), \mathrm{pH}$,

Alcalinidade Parcial (AP), Alcalinidade Intermediária (AI), Alcalinidade Total (AT), Alcalinidade a Bicarbonato (AB) e Ácidos Voláteis Totais (AVT) durante a condição Pa75.

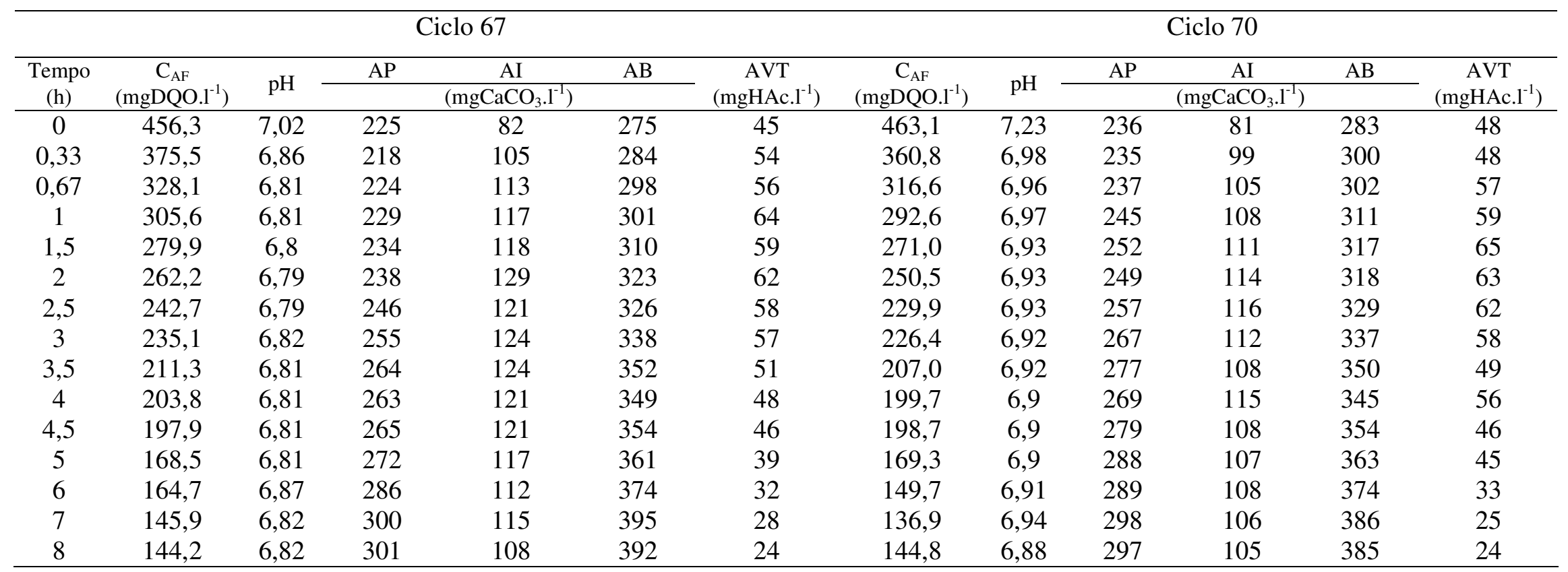


TABELA D.7: Perfis Experimentais da concentração de metano $\left(\mathrm{C}_{\mathrm{CH} 4}\right)$, porcentagem de metano no "head-space" $\left(\%_{\mathrm{CH} 4}\right)$, volume de metano acumulado (V), velocidade de produção de metano (Vel) em dois ciclos da condição Pa75.

\begin{tabular}{|c|c|c|c|c|c|c|c|c|c|}
\hline \multicolumn{5}{|c|}{ Ciclo 64} & \multicolumn{5}{|c|}{ Ciclo 87} \\
\hline $\begin{array}{l}\text { Tempo } \\
\text { (h) }\end{array}$ & $\begin{array}{c}\mathrm{C}_{\mathrm{CH} 4} \\
\left(\mathrm{mMol}^{-1} \mathrm{l}^{-1}\right)\end{array}$ & $\begin{array}{l}\%_{\mathrm{CH} 4} \\
(\%)\end{array}$ & $\begin{array}{c}\mathrm{V} \\
(\mathrm{m} l)\end{array}$ & $\begin{array}{c}\text { Vel } \\
\left(\mathrm{m} l \cdot \mathrm{h}^{-1}\right)\end{array}$ & $\begin{array}{c}\text { Tempo } \\
\text { (h) }\end{array}$ & $\begin{array}{c}\mathrm{C}_{\mathrm{CH} 4} \\
\left(\mathrm{mMol}^{-1} \mathrm{l}^{-1}\right)\end{array}$ & $\begin{array}{c}\%_{\mathrm{CH} 4} \\
(\%)\end{array}$ & $\begin{array}{c}\mathrm{V} \\
(\mathrm{m} l)\end{array}$ & $\begin{array}{c}\mathrm{Vel} \\
\left(\mathrm{m} l \cdot \mathrm{h}^{-1}\right)\end{array}$ \\
\hline 0,00 & 0,000 & 0,0 & 0 & 0,00 & 0,00 & 0,000 & 0,0 & 0,00 & 0,00 \\
\hline 0,47 & 0,262 & 39,7 & 7,85 & 16,81 & 0,45 & 0,303 & 39,3 & 7,88 & 17,47 \\
\hline 0,88 & 0,647 & 45,6 & 15,52 & 18,67 & 0,83 & 0,642 & 43,4 & 16,05 & 21,53 \\
\hline 1,26 & 1,031 & 47,4 & 23,41 & 20,88 & 1,23 & 1,082 & 47,7 & 25,43 & 23,52 \\
\hline 1,59 & 1,393 & 49,9 & 30,31 & 20,87 & 1,55 & 1,425 & 50,9 & 34,29 & 27,60 \\
\hline 2,05 & 1,976 & 53,6 & 39,95 & 20,63 & 1,86 & 1,720 & 53,0 & 41,88 & 24,46 \\
\hline 2,44 & 2,560 & 57,6 & 47,98 & 20,86 & 2,34 & 2,358 & 56,8 & 53,63 & 24,58 \\
\hline 2,83 & 3,048 & 59,4 & 55,86 & 20,23 & 2,66 & 2,997 & 59,2 & 61,70 & 24,77 \\
\hline 3,20 & 3,540 & 60,7 & 63,45 & 20,24 & 3,02 & 3,498 & 60,8 & 70,52 & 24,74 \\
\hline 3,59 & 3,978 & 62,1 & 70,76 & 18,85 & 3,40 & 3,999 & 62,0 & 79,99 & 24,89 \\
\hline 4,03 & 4,401 & 63,8 & 78,98 & 18,51 & 3,73 & 4,418 & 63,3 & 87,78 & 24,06 \\
\hline 4,49 & 5,029 & 64,6 & 86,79 & 17,32 & 4,09 & 4,794 & 64,2 & 96,25 & 23,13 \\
\hline 4,99 & 5,430 & 65,9 & 95,02 & 16,37 & 4,50 & 5,282 & 65,2 & 105,20 & 21,66 \\
\hline 5,50 & 5,774 & 67,1 & 103,08 & 15,74 & 4,89 & 5,674 & 66,1 & 113,44 & 21,58 \\
\hline 6,03 & 6,171 & 67,8 & 110,63 & 14,34 & 5,31 & 6,108 & 66,7 & 122,29 & 20,98 \\
\hline 6.58 & 6.684 & 68.5 & 117.86 & 13.03 & 5.75 & 6,465 & 67.7 & 130,75 & 19,12 \\
\hline 7,11 & 7,051 & 69,1 & 124,06 & 11,73 & 6,23 & 6,929 & 68,2 & 139,12 & 17,55 \\
\hline \multirow[t]{3}{*}{7,31} & 7,041 & 69,1 & 124,90 & 4,21 & 6,69 & 7,273 & 68,7 & 146,50 & 16,02 \\
\hline & & & & & 7,10 & 7,538 & 69,1 & 152,54 & 14,65 \\
\hline & & & & & 7,26 & 7,536 & 69,0 & 153,56 & 6,55 \\
\hline
\end{tabular}




\section{APÊNDICE E. Ensaio com impelidor tipo pá de pás planas inclinadas - valores experimentais}

Tabela E.1: Resultados Experimentais da concentração de matéria orgânica em termos de DQO $\left(\mathrm{C}_{\mathrm{af}}\right), \mathrm{pH}$, Alcalinidade Parcial (AP), Alcalinidade Intermediária (AI), Alcalinidade Total (AT), Alcalinidade a Bicarbonato (AB) e Ácidos Voláteis Totais (AVT) em amostras do afluente do ensaio com impelidor tipo pá de pás planas inclinadas.

\begin{tabular}{cccccccc}
\hline \multirow{2}{*}{ Ciclo } & \multirow{2}{*}{$\begin{array}{c}\mathrm{C}_{\mathrm{AF}} \\
\left(\mathrm{mgDQO}^{-1}\right)\end{array}$} & $\mathrm{pH}$ & $\mathrm{AP}$ & $\mathrm{AI}$ & $\mathrm{AT}$ & $\mathrm{AB}$ & \multirow{2}{*}{$\begin{array}{c}\mathrm{AVT} \\
\left(\mathrm{mgHAc}^{-1}\right)\end{array}$} \\
\hline 2 & 769,0 & 8,45 & 192 & 54 & 247 & 223 & 33 \\
7 & 753,4 & 8,73 & 192 & 56 & 248 & 224 & 33 \\
12 & 750,9 & 8,71 & 195 & 56 & 251 & 227 & 35 \\
17 & 735,2 & 8,84 & 195 & 56 & 251 & 224 & 38 \\
22 & 723,5 & 8,94 & 189 & 59 & 248 & 222 & 37 \\
25 & 768,3 & 9,12 & 195 & 53 & 248 & 221 & 38 \\
28 & 759,7 & 8,8 & 188 & 57 & 245 & 218 & 38 \\
31 & 774,6 & 8,75 & 186 & 59 & 245 & 219 & 37 \\
34 & 761,5 & 8,75 & 202 & 56 & 258 & 232 & 36 \\
42 & 727,8 & 8,74 & 191 & 56 & 247 & 219 & 38 \\
45 & 817,7 & 9,1 & 195 & 56 & 251 & 224 & 39 \\
48 & 784,1 & 8,72 & 195 & 59 & 254 & 228 & 37 \\
53 & 715,4 & 8,5 & 191 & 56 & 247 & 221 & 36 \\
58 & 783,9 & 8,56 & 192 & 54 & 247 & 221 & 36 \\
62 & 756,0 & 8,68 & 195 & 57 & 253 & 226 & 37 \\
67 & 731,7 & 8,81 & 192 & 65 & 257 & 229 & 40 \\
70 & 755,2 & 8,89 & 198 & 56 & 254 & 226 & 39 \\
73 & 775,4 & 8,68 & 201 & 61 & 262 & 233 & 41 \\
76 & 756,8 & 8,25 & 253 & 65 & 318 & 297 & 29 \\
\hline
\end{tabular}


Tabela E.2: Resultados Experimentais da concentração de matéria orgânica em termos de DQO para amostras filtradas $\left(\mathrm{C}_{\mathrm{SF}}\right)$ e totais $\left(\mathrm{C}_{\mathrm{ST}}\right)$, eficiência de remoção de matéria orgânica em termos de DQO para amostras filtradas $\left(\mathrm{E}_{\mathrm{F}}\right)$ e totais $\left(\mathrm{E}_{\mathrm{T}}\right) \mathrm{pH}$, Alcalinidade Parcial $(\mathrm{AP})$, Alcalinidade Intermediária (AI), Alcalinidade Total (AT), Alcalinidade a Bicarbonato (AB) e Ácidos Voláteis Totais (AVT) em amostras do efluente do com impelidor tipo pá de pás planas inclinadas.

\begin{tabular}{|c|c|c|c|c|c|c|c|c|c|c|c|}
\hline \multirow{2}{*}{ Ensaio } & \multirow{2}{*}{ Ciclo } & $\mathrm{C}_{\mathrm{SF}}$ & $\mathrm{C}_{\mathrm{ST}}$ & $E_{F}$ & $E_{T}$ & \multirow{2}{*}{$\mathrm{pH}$} & AP & AI & AT & $\mathrm{AB}$ & \multirow{2}{*}{$\begin{array}{c}\text { AVT } \\
\left.\left(\mathrm{mgHAc}^{-1}\right)^{-1}\right)\end{array}$} \\
\hline & & \multicolumn{2}{|c|}{$\left(\operatorname{mgDQO} .1^{-1}\right)$} & \multicolumn{2}{|c|}{$(\%)$} & & \multicolumn{4}{|c|}{$\left(\mathrm{mgCaCO}_{3} .1^{-1}\right)$} & \\
\hline \multirow{10}{*}{ Pi50 } & 3 & 106,1 & 141,8 & 86,0 & 81,3 & 6,80 & 295 & 102 & 397 & 386 & 15 \\
\hline & 6 & 110,8 & 122,8 & 85,4 & 83,8 & 6,80 & 295 & 112 & 406 & 396 & 15 \\
\hline & 9 & 91,1 & 116,7 & 88,0 & 84,6 & 6,78 & 315 & 101 & 416 & 404 & 16 \\
\hline & 12 & 92,9 & 123,8 & 87,7 & 83,7 & 6,73 & 295 & 124 & 419 & 407 & 17 \\
\hline & 21 & 104,7 & 166,8 & 86,2 & 78,0 & 6,64 & 301 & 130 & 431 & 418 & 19 \\
\hline & 24 & 111,9 & 146,0 & 85,2 & 80,7 & 6,77 & 304 & 101 & 405 & 392 & 18 \\
\hline & 28 & 98,8 & 134,0 & 87,0 & 82,3 & 6,75 & 285 & 110 & 394 & 379 & 22 \\
\hline & 30 & 98,3 & 150,3 & 87,0 & 80,2 & 6,83 & 293 & 101 & 394 & 381 & 18 \\
\hline & 34 & 102,6 & 153,3 & 86,5 & 79,8 & 6,78 & 309 & 120 & 430 & 417 & 17 \\
\hline & 42 & 97,0 & 156,7 & 87,2 & 79,3 & 6,81 & 295 & 112 & 406 & 396 & 15 \\
\hline \multirow{12}{*}{ Pi75 } & 45 & 117,6 & 153,8 & 84,5 & 79,7 & 6,82 & 298 & 105 & 403 & 391 & 17 \\
\hline & 48 & 107,3 & 146,3 & 85,8 & 80,7 & 6,75 & 292 & 110 & 402 & 390 & 16 \\
\hline & 51 & 89,5 & 109,6 & 88,2 & 85,5 & & & & & & \\
\hline & 54 & 95,9 & 134,7 & 87,3 & 82,2 & & & & & & \\
\hline & 55 & & & & & 6,72 & 282 & 116 & 399 & 387 & 17 \\
\hline & 63 & 102,6 & 119,5 & 86,5 & 84,2 & 6,73 & 292 & 115 & 406 & 396 & 15 \\
\hline & 66 & 95,4 & 125,5 & 87,4 & 83,4 & & & & & & \\
\hline & 67 & & & & & 6,83 & 292 & 116 & 408 & 398 & 14 \\
\hline & 70 & 116,4 & 124,8 & 84,6 & 83,5 & 6,77 & 295 & 119 & 414 & 401 & 18 \\
\hline & 73 & 89,8 & 129,4 & 88,2 & 82,9 & 6,77 & 298 & 120 & 418 & 404 & 20 \\
\hline & 78 & 96,6 & 131,1 & 87,3 & 82,7 & 6,78 & 295 & 108 & 403 & 390 & 18 \\
\hline & 84 & 89,5 & 118,6 & 88,2 & 84,4 & 6,78 & 304 & 108 & 412 & 400 & 16 \\
\hline
\end{tabular}


Tabela E.3: Resultados experimentais da concentração de sólidos totais (ST), sólidos voláteis totais (SVT), sólidos suspensos totais (SST) e sólidos suspensos voláteis (SSV) em amostras afluentes e efluentes coletadas durante o ensaio com impelidor tipo pá de pás planas inclinadas.

\begin{tabular}{|c|c|c|c|c|c|c|c|c|c|}
\hline \multirow{3}{*}{ Ensaio } & \multirow{3}{*}{$\begin{array}{l}\text { Tempo } \\
\text { (ciclo) }\end{array}$} & \multicolumn{4}{|c|}{ Afluente } & \multicolumn{4}{|c|}{ Efluente } \\
\hline & & ST & SVT & SST & SSV & ST & SVT & SST & SSV \\
\hline & & $\left(\mathrm{mg} . l^{-1}\right)$ & $\left(\mathrm{mg} . l^{-1}\right)$ & $\left(\mathrm{mg} \cdot l^{-1}\right)$ & $\left(\mathrm{mg} . l^{-1}\right)$ & $\left(\mathrm{mg} . l^{-1}\right)$ & $\left(\mathrm{mg} . l^{-1}\right)$ & $\left(\mathrm{mg} . l^{-1}\right)$ & $\left(\mathrm{mg} \cdot l^{-1}\right)$ \\
\hline \multirow{5}{*}{ Pi50 } & 3 & 1590 & 886 & 36 & 36 & 998 & 366 & 52 & 52 \\
\hline & 9 & 1652 & 858 & 46 & 34 & 1106 & 320 & 70 & 64 \\
\hline & 21 & 1502 & 822 & 54 & 54 & 986 & 316 & 86 & 86 \\
\hline & 33 & 1630 & 858 & 26 & 18 & 1054 & 304 & 60 & 60 \\
\hline & 45 & 1698 & 866 & 50 & 42 & 1126 & 320 & 86 & 60 \\
\hline \multirow{5}{*}{ Pi75 } & 51 & 1606 & 884 & 60 & 34 & 1100 & 364 & 110 & 76 \\
\hline & 66 & 1514 & 784 & 44 & 32 & 1188 & 440 & 76 & 60 \\
\hline & 72 & 1576 & 818 & 36 & 32 & 1040 & 298 & 52 & 44 \\
\hline & 3 & 1590 & 886 & 36 & 36 & 998 & 366 & 52 & 52 \\
\hline & 9 & 1652 & 858 & 46 & 34 & 1106 & 320 & 70 & 64 \\
\hline
\end{tabular}


Tabela E.4: Perfis Experimentais da concentração de matéria orgânica em termos de DQO para amostras filtradas $\left(\mathrm{C}_{\mathrm{SF}}\right)$, $\mathrm{pH}$, Alcalinidade Parcial (AP), Alcalinidade Intermediária (AI), Alcalinidade Total (AT), Alcalinidade a Bicarbonato (AB) e Ácidos Voláteis Totais (AVT) durante a condição Pi50.

\begin{tabular}{|c|c|c|c|c|c|c|c|c|c|c|c|c|}
\hline \multirow[b]{2}{*}{$\begin{array}{l}\text { Tempo } \\
\text { (h) }\end{array}$} & \multicolumn{6}{|c|}{ Ciclo 28} & \multicolumn{6}{|c|}{ Ciclo 34} \\
\hline & $\begin{array}{c}\mathrm{C}_{\mathrm{AF}} \\
\left(\mathrm{mgDQO} \cdot \mathrm{l}^{-1}\right)\end{array}$ & $\mathrm{pH}$ & $\mathrm{AP}$ & $\begin{array}{c}\mathrm{AI} \\
\left(\mathrm{mgCaCO}_{3} .1^{-1}\right)\end{array}$ & $\mathrm{AB}$ & 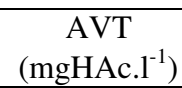 & $\begin{array}{c}\mathrm{C}_{\mathrm{AF}} \\
\left(\mathrm{mgDQO} \cdot \mathrm{I}^{-1}\right)\end{array}$ & $\mathrm{pH}$ & $\mathrm{AP}$ & $\frac{\mathrm{AI}}{\left(\mathrm{mgCaCO}_{3} .^{-1}\right)}$ & $\mathrm{AB}$ & $\begin{array}{c}\text { AVT } \\
\left(\text { mgHAc. }^{-1}\right)\end{array}$ \\
\hline 0 & 458,3 & 8,8 & 188 & 57 & 218 & 38 & 493,3 & 7,03 & 223 & 80 & 232 & 36 \\
\hline 0,67 & 328,4 & 6,86 & 225 & 94 & & & 422,5 & 6,84 & 229 & 86 & 284 & 33 \\
\hline 1 & 292,8 & 6,78 & 220 & 107 & 299 & 40 & 365,7 & 6,84 & 226 & 98 & 292 & 32 \\
\hline 1,5 & 240,2 & 6,75 & 229 & 107 & 304 & 45 & 278,1 & 6,75 & 230 & 111 & 299 & 36 \\
\hline 3 & 161,8 & 6,75 & 258 & 115 & 345 & 39 & 162,2 & 6,73 & 255 & 122 & 337 & 42 \\
\hline 3,5 & 155,6 & 6,73 & 271 & 115 & 362 & 33 & 148,9 & 6,73 & 261 & 117 & 350 & 38 \\
\hline 4 & 128,1 & 6,76 & 273 & 114 & 364 & 32 & 133,8 & 6,71 & 271 & 111 & 354 & 34 \\
\hline 4,5 & 126,5 & 6,73 & 269 & 114 & 364 & 26 & 122,0 & 6,74 & 272 & 116 & 361 & 28 \\
\hline 5 & 120,0 & 6,74 & 278 & 111 & 371 & 25 & 121,6 & 6,74 & 268 & 122 & 372 & 23 \\
\hline 6 & 112,4 & 6,76 & 275 & 114 & 372 & 23 & 111,2 & 6,76 & 283 & 114 & 374 & 23 \\
\hline
\end{tabular}


Tabela E.5: Perfis Experimentais da concentração de metano $\left(\mathrm{C}_{\mathrm{CH} 4}\right)$, porcentagem de metano no "head-space" $\left(\%_{\mathrm{CH} 4}\right)$, volume de metano acumulado (V), velocidade de produção de metano (Vel) em dois ciclos da condição Pi50.

\begin{tabular}{|c|c|c|c|c|c|c|c|c|c|}
\hline \multicolumn{5}{|c|}{ Ciclo 25} & \multicolumn{5}{|c|}{ Ciclo 31} \\
\hline $\begin{array}{l}\text { Tempo } \\
\text { (h) }\end{array}$ & $\begin{array}{c}\mathrm{C}_{\mathrm{CH} 4} \\
\left(\mathrm{mMol} .1^{-1}\right)\end{array}$ & $\begin{array}{l}\%_{\mathrm{CH} 4} \\
(\%)\end{array}$ & $\begin{array}{c}\mathrm{V} \\
(\mathrm{m} l)\end{array}$ & $\begin{array}{c}\mathrm{Vel} \\
\left(\mathrm{m} l \cdot \mathrm{h}^{-1}\right)\end{array}$ & $\begin{array}{l}\text { Tempo } \\
\text { (h) }\end{array}$ & $\begin{array}{c}\mathrm{C}_{\mathrm{CH} 4} \\
\left(\mathrm{mMol} .1^{-1}\right)\end{array}$ & $\begin{array}{l}\%_{\mathrm{CH} 4} \\
(\%)\end{array}$ & $\begin{array}{c}\mathrm{V} \\
(\mathrm{m} l)\end{array}$ & $\begin{array}{c}\mathrm{Vel} \\
\left(\mathrm{ml} \cdot \mathrm{h}^{-1}\right)\end{array}$ \\
\hline 0,00 & 0,000 & 0,0 & 0 & 0,00 & 0,00 & 0,000 & 0,0 & 0,00 & 0,00 \\
\hline 0,50 & 0,299 & 51,6 & 8,32 & 16,71 & 0,48 & 0,283 & 50,4 & 9,02 & 18,85 \\
\hline 0,99 & 0,762 & 55,0 & 16,77 & 17,25 & 0,97 & 0,733 & 55,9 & 17,17 & 16,70 \\
\hline 1,37 & 1,270 & 57,7 & 25,32 & 22,18 & 1,36 & 1,219 & 59,5 & 25,46 & 20,97 \\
\hline 1,77 & 1,763 & 60,2 & 34,21 & 22,29 & 1,73 & 1,709 & 61,6 & 33,67 & 22,60 \\
\hline 2,13 & 2,440 & 63,4 & 42,46 & 22,80 & 2,09 & 2,283 & 63,0 & 42,08 & 23,35 \\
\hline 2,49 & 2,926 & 64,1 & 51,37 & 24,81 & 2,46 & 2,865 & 64,7 & 50,60 & 22,56 \\
\hline 2,88 & 3,404 & 65,0 & 59,62 & 21,21 & 2,84 & 3,319 & 66,4 & 59,34 & 22,98 \\
\hline 3,32 & 3,919 & 65,8 & 68,64 & 20,52 & 3,25 & 3,713 & 66,9 & 67,96 & 20,96 \\
\hline 3,82 & 4,389 & 66,6 & 78,12 & 18,88 & 3,69 & 4,192 & 67,6 & 76,87 & 20,50 \\
\hline 4,31 & 4,881 & 67,3 & 86,65 & 17,41 & 4,17 & 4,623 & 68,1 & 85,92 & 18,94 \\
\hline 4,82 & 5,542 & 67,3 & 94,77 & 15,92 & 4,86 & 5,326 & 68,6 & 97,92 & 17,30 \\
\hline 5,35 & 5,862 & 67,8 & 101,85 & 13,57 & 5,37 & 5,612 & 69,1 & 105,03 & 13,84 \\
\hline 5,87 & 5,849 & 68,3 & 108,68 & 13,12 & 5,89 & 6,007 & 69,3 & 111,51 & 12,55 \\
\hline 6,38 & 6,640 & 68,3 & 114,26 & 10,80 & 6,36 & 6,295 & 69,6 & 117,29 & 12,35 \\
\hline 6,80 & 6,770 & 68,4 & 118,80 & 10,79 & 6,74 & 6,552 & 69,8 & 121,67 & 11,44 \\
\hline 7,13 & 6,940 & 68,5 & 121,93 & 9,73 & 7,11 & 6,603 & 69,9 & 125,39 & 10,22 \\
\hline 7,30 & 6,720 & 68,9 & 122,12 & 1,11 & 7,30 & 6,665 & 70,0 & 126,60 & 6,29 \\
\hline
\end{tabular}


Tabela E.6: Perfis Experimentais da concentração de matéria orgânica em termos de DQO para amostras filtradas $\left(\mathrm{C}_{\mathrm{SF}}\right), \mathrm{pH}, \mathrm{Alcalinidade}$ Parcial (AP), Alcalinidade Intermediária (AI), Alcalinidade Total (AT), Alcalinidade a Bicarbonato (AB) e Ácidos Voláteis Totais (AVT) durante a condição Pi75.

\begin{tabular}{|c|c|c|c|c|c|c|c|c|c|c|c|c|}
\hline \multirow[b]{2}{*}{$\begin{array}{l}\text { Tempo } \\
\text { (h) }\end{array}$} & \multicolumn{6}{|c|}{ Ciclo 70} & \multicolumn{6}{|c|}{ Ciclo 73} \\
\hline & $\begin{array}{c}\mathrm{C}_{\mathrm{AF}} \\
\left(\mathrm{mgDQO} \cdot \mathrm{l}^{-1}\right)\end{array}$ & $\mathrm{pH}$ & $\mathrm{AP}$ & $\frac{\mathrm{AI}}{\left(\mathrm{mgCaCO}_{3} \cdot \mathrm{I}^{-1}\right)}$ & $\mathrm{AB}$ & $\begin{array}{c}\text { AVT } \\
\left(\mathrm{mgHAc} . \mathrm{l}^{-1}\right)\end{array}$ & $\begin{array}{c}\mathrm{C}_{\mathrm{AF}} \\
\left(\mathrm{mgDQO} . \mathrm{l}^{-1}\right)\end{array}$ & $\mathrm{pH}$ & \multicolumn{3}{|c|}{$\begin{array}{c}\mathrm{AI} \\
\left(\mathrm{mgCaCO}_{3} \cdot \mathrm{l}^{-1}\right)\end{array}$} & $\begin{array}{c}\text { AVT } \\
\left(\mathrm{mgHAc} . \mathrm{l}^{-1}\right.\end{array}$ \\
\hline 0 & 426,6 & 6,98 & 241 & 93 & 311 & 32 & 423,3 & 6,97 & 234 & 90 & 300 & 34 \\
\hline 0,67 & 294,7 & 6,74 & 243 & 115 & 323 & 49 & 258,8 & 6,77 & 239 & 116 & 322 & 47 \\
\hline 1 & 247,8 & 6,75 & 251 & 117 & 333 & 48 & 229,7 & 6,76 & 250 & 122 & 338 & 50 \\
\hline 1,5 & 202,8 & 6,76 & 258 & 123 & 350 & 44 & 186,6 & 6,76 & 263 & 120 & 355 & 39 \\
\hline 3 & 138,5 & 6,8 & 286 & 112 & 384 & 21 & 126,9 & 6,82 & 284 & 114 & 381 & 25 \\
\hline 3,5 & 135,0 & 6,77 & 285 & 122 & 390 & 23 & 110,4 & 6,81 & 289 & 114 & 389 & 20 \\
\hline 4 & 125,9 & 6,77 & 288 & 120 & 393 & 21 & 108,3 & 6,85 & 295 & 115 & 394 & 21 \\
\hline 4,5 & 125,7 & 6,78 & 283 & 125 & 393 & 21 & 108,8 & 6,84 & 300 & 113 & 400 & 18 \\
\hline 5 & 109,7 & 6,76 & 294 & 117 & 395 & 23 & 107,6 & 6,8 & 296 & 114 & 395 & 21 \\
\hline 6 & 114,5 & 6,8 & 293 & 119 & 399 & 18 & 103,8 & 6,81 & 300 & 110 & 398 & 18 \\
\hline
\end{tabular}


Tabela E.7: Perfis Experimentais da concentração de metano $\left(\mathrm{C}_{\mathrm{CH} 4}\right)$, porcentagem de metano no "head-space" $\left(\%_{\mathrm{CH} 4}\right)$, volume de metano acumulado (V), velocidade de produção de metano (Vel) em dois ciclos da condição Pi75.

\begin{tabular}{|c|c|c|c|c|c|c|c|c|c|}
\hline \multicolumn{5}{|c|}{ Ciclo 67} & \multicolumn{5}{|c|}{ Ciclo 79} \\
\hline $\begin{array}{l}\text { Tempo } \\
\text { (h) }\end{array}$ & $\begin{array}{c}\mathrm{C}_{\mathrm{CH} 4} \\
\left(\mathrm{mMol} .1^{-1}\right)\end{array}$ & $\begin{array}{l}\%_{\mathrm{CH} 4} \\
(\%)\end{array}$ & $\begin{array}{c}\mathrm{V} \\
(\mathrm{m} l)\end{array}$ & $\begin{array}{c}\mathrm{Vel} \\
\left(\mathrm{m} l \cdot \mathrm{h}^{-1}\right)\end{array}$ & $\begin{array}{l}\text { Tempo } \\
\text { (h) }\end{array}$ & $\begin{array}{c}\mathrm{C}_{\mathrm{CH} 4} \\
\left(\mathrm{mMol} \mathrm{l}^{-1}\right)\end{array}$ & $\begin{array}{l}\%_{\mathrm{CH} 4} \\
(\%)\end{array}$ & $\begin{array}{c}\mathrm{V} \\
(\mathrm{m} l)\end{array}$ & $\begin{array}{c}\text { Vel } \\
\left(\mathrm{m} l \cdot \mathrm{h}^{-1}\right)\end{array}$ \\
\hline 0,00 & 0,000 & 0,0 & 0 & 0,00 & 0,00 & 0,000 & 0,0 & 0,00 & 0,00 \\
\hline 0,38 & 0,226 & 45,2 & 7,49 & 19,90 & 0,42 & 0,252 & 49,3 & 8,63 & 20,38 \\
\hline 0,77 & 0,635 & 51,3 & 15,43 & 20,31 & 0,87 & 0,756 & 55,6 & 18,17 & 21,48 \\
\hline 1,15 & 0,971 & 55,7 & 24,52 & 23,63 & 1,25 & 1,262 & 58,6 & 28,13 & 26,29 \\
\hline 1,51 & 1,682 & 58.6 & 34,19 & 27,29 & 1,59 & 1,799 & 61,2 & 37,74 & 27,67 \\
\hline 1,80 & 2,248 & 62,1 & 42,85 & 29,10 & 1,90 & 2,431 & 64,2 & 46,28 & 27,85 \\
\hline 2,12 & 2,747 & 63,2 & 51,62 & 28,03 & 2,13 & 2,765 & 65,4 & 52,38 & 27,16 \\
\hline 2,48 & 3,325 & 64,5 & 61,59 & 27,18 & 2,45 & 3,279 & 66,3 & 61,06 & 26,36 \\
\hline 2,84 & 3,778 & 65,6 & 70,74 & 25,77 & 2,87 & 3,857 & 67,3 & 71,38 & 24,62 \\
\hline 3,20 & 4,262 & 66,3 & 79,58 & 24,37 & 3,23 & 4,237 & 68,1 & 79,82 & 23,51 \\
\hline 3,61 & 4,749 & 67,0 & 88,95 & 22,79 & 3,69 & 4,761 & 68,7 & 89,57 & 21,35 \\
\hline 4,03 & & & 97,31 & 20,03 & 4,08 & 5,125 & 69,1 & 96,99 & 18,98 \\
\hline 4,52 & & & 105,87 & 17,48 & 4,53 & 5,469 & 69,4 & 104,89 & 17,40 \\
\hline 5,02 & & & 113,87 & 15,92 & 5,05 & 5,849 & 69,7 & 113,16 & 16,09 \\
\hline 5,53 & & & 121,08 & 14,30 & 5,59 & 6,176 & 69,7 & 120,60 & 13,86 \\
\hline 6,08 & & & 127,91 & 12,32 & 6,05 & 6,511 & 69,5 & 126,55 & 12,68 \\
\hline 6,60 & & & 133,94 & 11,57 & 6,61 & 6,750 & 69,8 & 132,83 & 11,28 \\
\hline 7,12 & & & 138,85 & 9,51 & 7,09 & 6,971 & 69,8 & 137,89 & 10,50 \\
\hline 7,29 & & & 139,57 & 4,30 & 7,26 & 6,860 & 69,8 & 138,72 & 4,85 \\
\hline
\end{tabular}




\section{APÊNDICE F. Ensaio com impelidor tipo pá de pás planas inclinadas e tubo de tiragem - valores experimentais}

TABELA F.1: Resultados Experimentais da concentração de matéria orgânica em termos de DQO $\left(\mathrm{C}_{\mathrm{af}}\right), \mathrm{pH}$, Alcalinidade Parcial (AP), Alcalinidade Intermediária (AI), Alcalinidade Total (AT), Alcalinidade a Bicarbonato (AB) e Ácidos Voláteis Totais (AVT) em amostras do afluente do ensaio com impelidor tipo pá inclinada com tubo de tiragem.

\begin{tabular}{|c|c|c|c|c|c|c|c|}
\hline \multirow[t]{2}{*}{ Ciclo } & \multirow{2}{*}{$\begin{array}{c}\mathrm{C}_{\mathrm{AF}} \\
\left(\mathrm{mgDQO} . \mathrm{l}^{-1}\right)\end{array}$} & \multirow[t]{2}{*}{$\mathrm{pH}$} & AP & $\mathrm{AI}$ & AT & $\mathrm{AB}$ & \multirow{2}{*}{$\begin{array}{c}\text { AVT } \\
\left.\left(\mathrm{mgHAc}^{-1}\right)^{-1}\right)\end{array}$} \\
\hline & & & \multicolumn{4}{|c|}{$\left(\mathrm{mgCaCO}_{3} 1^{-1}\right)$} & \\
\hline 2 & 834,8 & & & & & & \\
\hline 7 & 775,7 & 8,82 & 203 & 54 & 257 & 235 & 31 \\
\hline 10 & 811,1 & 8,98 & 203 & 57 & 260 & 235 & 35 \\
\hline 15 & 776,2 & 8,81 & 176 & 51 & 228 & 201 & 38 \\
\hline 20 & 777,8 & & & & & & \\
\hline 27 & 813,8 & 8,95 & 189 & 51 & 240 & 215 & 35 \\
\hline 30 & 795,3 & 8,97 & 196 & 45 & 241 & 214 & 38 \\
\hline 33 & 751,6 & 9 & 195 & 49 & 244 & 218 & 36 \\
\hline 38 & 823,2 & & & & & & \\
\hline 42 & 773,9 & 8,98 & 194 & 54 & 247 & 226 & 30 \\
\hline 47 & 814,5 & 9,08 & 184 & 52 & 237 & 214 & 31 \\
\hline 52 & 769,4 & 8,93 & 184 & 54 & 238 & 208 & 42 \\
\hline 59 & 782,6 & 9,07 & 196 & 52 & 248 & 224 & 34 \\
\hline 63 & 869,7 & 8,99 & 188 & 54 & 242 & 219 & 32 \\
\hline 66 & 739,2 & 8,87 & 186 & 56 & 242 & 215 & 39 \\
\hline 69 & 859,0 & 9,17 & 199 & 52 & 251 & 224 & 38 \\
\hline 72 & 775,1 & 8,75 & 203 & 49 & 252 & 226 & 36 \\
\hline 77 & 747,7 & 8,9 & 188 & 51 & 238 & 211 & 38 \\
\hline 82 & 801,7 & 8,93 & 192 & 49 & 242 & 214 & 38 \\
\hline
\end{tabular}


TABELA F.2: Resultados Experimentais da concentração de matéria orgânica em termos de DQO para amostras filtradas $\left(\mathrm{C}_{\mathrm{SF}}\right)$ e totais $\left(\mathrm{C}_{\mathrm{ST}}\right)$, eficiência de remoção de matéria orgânica em termos de DQO para amostras filtradas $\left(\mathrm{E}_{\mathrm{F}}\right)$ e totais $\left(\mathrm{E}_{\mathrm{T}}\right) \mathrm{pH}$, Alcalinidade Parcial (AP), Alcalinidade Intermediária (AI), Alcalinidade Total (AT), Alcalinidade a Bicarbonato (AB) e Ácidos Voláteis Totais (AVT) em amostras do efluente do com impelidor tipo pá de pás inclinadas e reator utilizando tubo de tiragem

\begin{tabular}{|c|c|c|c|c|c|c|c|c|c|c|c|}
\hline \multirow{2}{*}{ Ensaio } & \multirow{2}{*}{ Ciclo } & $\mathrm{C}_{\mathrm{SF}}$ & $\mathrm{C}_{\mathrm{ST}}$ & $\mathrm{E}_{\mathrm{F}}$ & $\mathrm{E}_{\mathrm{T}}$ & \multirow{2}{*}{$\mathrm{pH}$} & AP & AI & AT & $\mathrm{AB}$ & \multirow{2}{*}{$\begin{array}{c}\text { AVT } \\
\left(\mathrm{mgHAc} . l^{-1}\right)\end{array}$} \\
\hline & & \multicolumn{2}{|c|}{$\left(\mathrm{mgDQO} . l^{-1}\right)$} & \multicolumn{2}{|c|}{$(\%)$} & & \multicolumn{4}{|c|}{$\left(\mathrm{mgCaCO}_{3} . l^{-1}\right)$} & \\
\hline \multirow{12}{*}{ Pd100 } & 3 & 143,8 & 183,1 & 81,9 & 183,1 & 6,92 & 334 & 83 & 417 & 404 & 18 \\
\hline & 6 & 127,9 & 165,0 & 83,9 & 165,0 & 6,87 & 311 & 102 & 412 & 401 & 16 \\
\hline & 9 & 125,3 & 138,7 & 84,2 & 138,7 & 6,89 & 301 & 93 & 394 & 382 & 17 \\
\hline & 11 & 131,6 & 144,7 & 83,4 & 144,7 & 6,90 & 306 & 92 & 397 & 385 & 17 \\
\hline & 20 & 134,1 & 160,2 & 83,1 & 160,2 & 6,86 & 297 & 107 & 404 & 388 & 22 \\
\hline & 23 & 121,2 & 136,5 & 84,7 & 136,5 & & & & & & \\
\hline & 24 & & & & & 6,84 & 268 & 102 & 371 & 361 & 14 \\
\hline & 27 & & & & & 6,87 & 290 & 95 & 385 & 372 & 19 \\
\hline & 29 & 126,8 & 151,3 & 84,0 & 151,3 & & & & & & \\
\hline & 30 & & & & & 6,86 & 285 & 96 & 381 & 366 & 21 \\
\hline & 33 & 111,6 & 143,8 & 85,9 & 143,8 & 6,86 & 275 & 104 & 379 & 364 & 21 \\
\hline & 42 & 121,4 & 145,9 & 84,7 & 145,9 & 6,81 & 280 & 107 & 387 & 376 & 16 \\
\hline \multirow{13}{*}{$\operatorname{Pd} 120$} & 44 & 104,8 & 137,0 & 86,8 & 137,0 & 6,79 & 277 & 105 & 383 & 374 & 12 \\
\hline & 45 & & & & & 6,77 & 276 & 110 & 386 & 376 & 14 \\
\hline & 47 & 121,3 & 156,5 & 84,7 & 156,5 & 6,78 & 279 & 104 & 383 & 373 & 14 \\
\hline & 51 & 105,8 & 137,2 & 86,7 & 137,2 & 6,73 & 262 & 116 & 378 & 368 & 14 \\
\hline & 53 & 129,7 & 149,3 & 83,7 & 149,3 & 6,73 & 270 & 110 & 380 & 370 & 14 \\
\hline & 62 & 117,9 & 145,4 & 85,2 & 145,4 & & & & & & \\
\hline & 63 & & & & & 6,84 & 289 & 103 & 393 & 383 & 13 \\
\hline & 65 & 104,2 & 118,4 & 86,9 & 118,4 & & & & & & \\
\hline & 68 & 117,3 & 131,7 & 85,2 & 131,7 & & & & & & \\
\hline & 69 & & & & & 6,86 & 302 & 86 & 388 & 374 & 19 \\
\hline & 72 & 108,3 & 123,3 & 86,4 & 123,3 & & & & & & \\
\hline & 74 & 116,4 & 133,7 & 85,3 & 133,7 & 6,99 & 297 & 92 & 389 & 380 & 13 \\
\hline & 83 & 109,1 & 126,6 & 86,3 & 126,6 & 6,80 & 288 & 105 & 393 & 381 & 17 \\
\hline
\end{tabular}


TABELA F.3: Resultados experimentais da concentração de sólidos totais (ST), sólidos voláteis totais (SVT), sólidos suspensos totais (SST) e sólidos suspensos voláteis (SSV) em amostras afluentes e efluentes coletadas durante o ensaio utilizando impelidor tipo pá de pás planas inclinadas e reator utilizando tubo de tiragem.

\begin{tabular}{lrcccccccc}
\hline \multirow{2}{*}{ Ensaio } & \multirow{2}{*}{ Tempo } & \multicolumn{9}{c}{ Afluente } & \multicolumn{4}{c}{ Efluente } \\
\cline { 3 - 9 } & & ST & SVT & SST & SSV & ST & SVT & SST & SSV \\
$($ ciclo $)$ & $\left(\mathrm{mg} . l^{-1}\right)$ & $\left(\mathrm{mg} . l^{-1}\right)$ & $\left(\mathrm{mg} . l^{-1}\right)$ & $\left(\mathrm{mg} . l^{-1}\right)$ & $\left(\mathrm{mg} . l^{-1}\right)$ & $\left(\mathrm{mg} . l^{-1}\right)$ & $\left(\mathrm{mg} . l^{-1}\right)$ & $\left(\mathrm{mg} . l^{-1}\right)$ \\
\hline \multirow{4}{*}{ Pd100 } & 6 & 1604 & 826 & 64 & 62 & 1002 & 266 & 110 & 108 \\
& 10 & 1612 & 860 & 40 & 26 & 1124 & 404 & 72 & 50 \\
& 23 & 1590 & 878 & 34 & 22 & 1004 & 382 & 60 & 40 \\
& 29 & 1760 & 950 & 30 & 20 & 1146 & 376 & 62 & 48 \\
Pd120 & 44 & 1484 & 898 & 36 & 32 & 1112 & 368 & 78 & 64 \\
& 53 & 1370 & 908 & 22 & 22 & 1046 & 378 & 76 & 76 \\
& 65 & 1566 & 880 & 44 & 46 & 1012 & 326 & 50 & 50 \\
& 71 & 1622 & 890 & 50 & 40 & 1102 & 382 & 74 & 72 \\
& 6 & 1604 & 826 & 64 & 62 & 1002 & 266 & 110 & 108 \\
& 10 & 1612 & 860 & 40 & 26 & 1124 & 404 & 72 & 50 \\
\hline
\end{tabular}


TABELA F.4: Perfis Experimentais da concentração de matéria orgânica em termos de DQO para amostras filtradas $\left(\mathrm{C}_{\mathrm{SF}}\right)$, $\mathrm{pH}$, Alcalinidade Parcial (AP), Alcalinidade Intermediária (AI), Alcalinidade Total (AT), Alcalinidade a Bicarbonato (AB) e Ácidos Voláteis Totais (AVT) durante a condição Pd100.

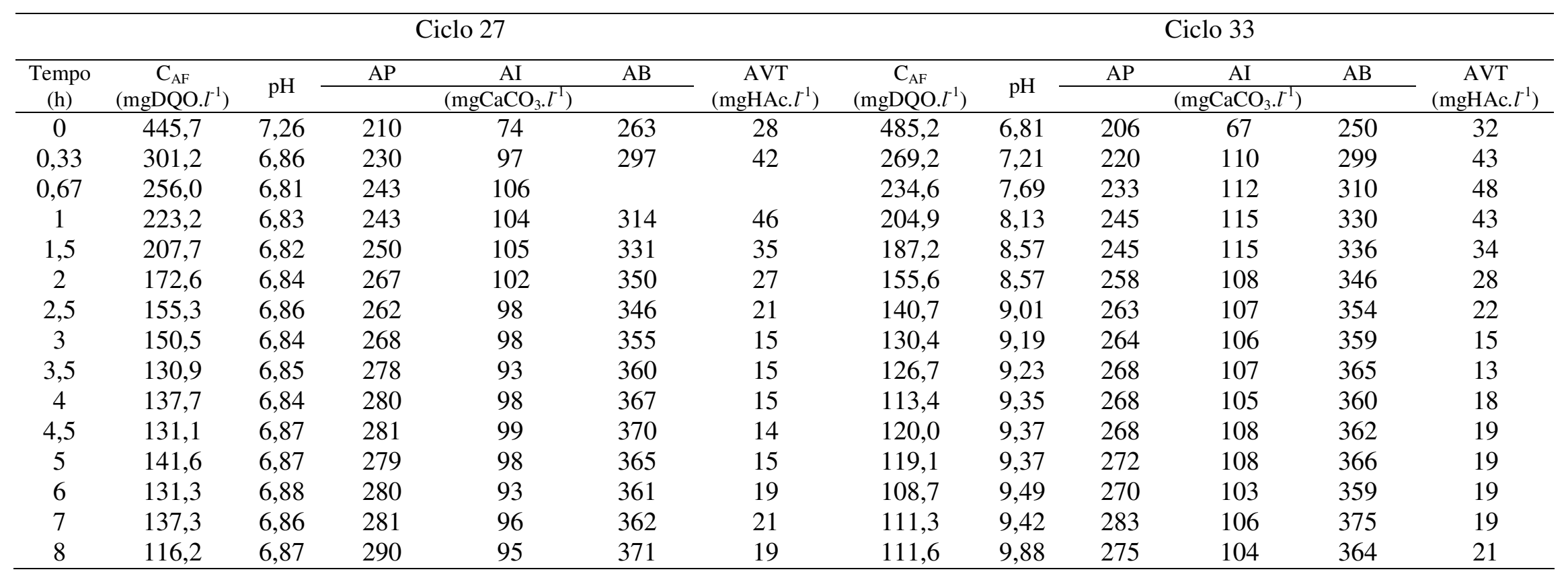


TABELA F.5: Perfis Experimentais da concentração de metano $\left(\mathrm{C}_{\mathrm{CH} 4}\right)$, porcentagem de metano no "head-space" $\left(\%_{\mathrm{CH} 4}\right)$, volume de metano acumulado (V), velocidade de produção de metano (Vel) em dois ciclos da condição Pd100.

\begin{tabular}{|c|c|c|c|c|c|c|c|c|c|}
\hline \multicolumn{5}{|c|}{ Ciclo 24} & \multicolumn{5}{|c|}{ Ciclo 30} \\
\hline $\begin{array}{l}\text { Tempo } \\
\text { (h) }\end{array}$ & $\begin{array}{c}\mathrm{C}_{\mathrm{CH} 4} \\
\left(\mathrm{mMol} . l^{-1}\right)\end{array}$ & $\begin{array}{c}\%_{\mathrm{CH} 4} \\
(\%)\end{array}$ & $\begin{array}{c}\mathrm{V} \\
(\mathrm{m} l)\end{array}$ & $\begin{array}{c}\text { Vel } \\
\left(\mathrm{m} l . \mathrm{h}^{-1}\right)\end{array}$ & $\begin{array}{l}\text { Tempo } \\
\text { (h) }\end{array}$ & $\begin{array}{c}\mathrm{C}_{\mathrm{CH} 4} \\
\left(\mathrm{mMol} . l^{-1}\right)\end{array}$ & $\begin{array}{c}\%_{\mathrm{CH} 4} \\
(\%)\end{array}$ & $\begin{array}{c}\mathrm{V} \\
(\mathrm{m} l)\end{array}$ & $\begin{array}{c}\text { Vel } \\
\left(\mathrm{ml} \cdot \mathrm{h}^{-1}\right)\end{array}$ \\
\hline 0,00 & 0,000 & 0,0 & 0,0 & 0,00 & 0,00 & 0,000 & 0,0 & 0,0 & 0,00 \\
\hline 0,40 & 0,184 & 37,2 & 7,1 & 17,56 & 0,36 & 0,273 & 51,0 & 8,6 & 24,22 \\
\hline 0,75 & 0,500 & 44,9 & 14,6 & 21,59 & 0,75 & 0,607 & 51,0 & 17,7 & 22,79 \\
\hline 1,11 & 0,946 & 50,7 & 23,5 & 25,25 & 1,12 & 1,075 & 55,4 & 27,4 & 27,00 \\
\hline 1,38 & 1,321 & 54,5 & 31,2 & 28,54 & 1,42 & 1,580 & 58,9 & 36,5 & 29,50 \\
\hline 1,67 & 1,844 & 58,0 & 39,7 & 28,81 & 1,70 & 2,065 & 61,5 & 45,1 & 30,78 \\
\hline 1,96 & 2,479 & 61,8 & 48,3 & 29,54 & 1,98 & 2,694 & 64,8 & 54,1 & 31,93 \\
\hline 2,26 & 2,991 & 63,8 & 57,0 & 28,82 & 2,29 & 3,248 & 66,4 & 63,6 & 31,60 \\
\hline 2,58 & 3,478 & 65,3 & 66,0 & 28,34 & 2,54 & 3,649 & 67,4 & 71,9 & 31,77 \\
\hline 3,01 & 4,106 & 66,9 & 76,7 & 24,51 & 2,84 & 4,175 & 68,4 & 80,6 & 28,95 \\
\hline 3,42 & 4,569 & 67,6 & 85,1 & 20,98 & 3,15 & 4,580 & 69,0 & 88,7 & 26,86 \\
\hline 3,91 & 5,124 & 68,2 & 93,4 & 16,91 & 3,52 & 5,042 & 69,6 & 97,3 & 22,75 \\
\hline 4,42 & 5,451 & 68,7 & 100,9 & 14,55 & 3,95 & 5,461 & 70,0 & 105,6 & 19,68 \\
\hline 4,94 & 5,825 & 69,0 & 107,3 & 12,30 & 4,38 & 5,723 & 70,2 & 113,3 & 17,71 \\
\hline 5,45 & 6,112 & 69,1 & 112,7 & 10,59 & 4,89 & 6,183 & 70,5 & 121,1 & 15,30 \\
\hline 5,96 & 6,223 & 69,3 & 117,5 & 9,50 & 5,44 & 6,573 & 70,5 & 128,3 & 13,04 \\
\hline 6,57 & 6,605 & 69,5 & 122,4 & 7,99 & 6,05 & 6,958 & 70,6 & 135,5 & 11,87 \\
\hline 7,09 & 6,788 & 69,6 & 126,8 & 8,51 & 6,65 & 7,240 & 70,7 & 141,8 & 10,50 \\
\hline \multirow[t]{2}{*}{7,26} & 6,834 & 69,6 & 126,9 & 0,56 & 7,14 & 7,386 & 70,8 & 146,6 & 9,67 \\
\hline & & & & & 7,28 & 7,356 & 70,8 & 146,6 & 0,00 \\
\hline
\end{tabular}


TABELA F.6: Perfis Experimentais da concentração de matéria orgânica em termos de DQO para amostras filtradas $\left(\mathrm{C}_{\mathrm{SF}}\right)$, $\mathrm{pH}$, Alcalinidade Parcial (AP), Alcalinidade Intermediária (AI), Alcalinidade Total (AT), Alcalinidade a Bicarbonato (AB) e Ácidos Voláteis Totais (AVT) durante a condição Pd120.

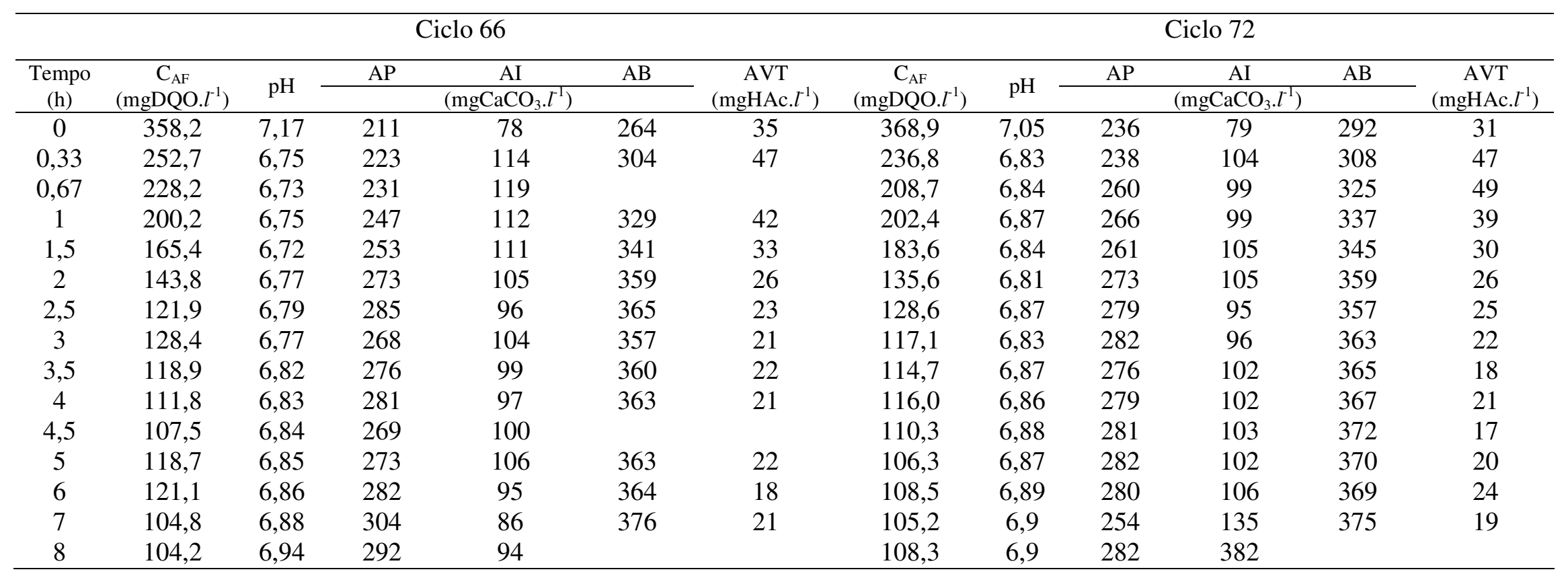


TABELA F.7: Perfis Experimentais da concentração de metano $\left(\mathrm{C}_{\mathrm{CH} 4}\right)$, porcentagem de metano no "head-space" $\left(\%_{\mathrm{CH} 4}\right)$, volume de metano acumulado (V), velocidade de produção de metano (Vel) em dois ciclos da condição Pd120.

\begin{tabular}{|c|c|c|c|c|c|c|c|c|c|}
\hline \multicolumn{5}{|c|}{ Ciclo } & \multicolumn{5}{|c|}{ Ciclo } \\
\hline $\begin{array}{c}\text { Tempo } \\
\text { (h) }\end{array}$ & $\begin{array}{c}\mathrm{C}_{\mathrm{CH} 4} \\
\left(\mathrm{mMol} . l^{-1}\right)\end{array}$ & $\begin{array}{c}\%_{\mathrm{CH} 4} \\
(\%)\end{array}$ & $\begin{array}{c}\mathrm{V} \\
(\mathrm{m} l)\end{array}$ & $\begin{array}{c}\text { Vel } \\
\left(\mathrm{m} l . \mathrm{h}^{-1}\right)\end{array}$ & $\begin{array}{l}\text { Tempo } \\
\text { (h) }\end{array}$ & $\begin{array}{c}\mathrm{C}_{\mathrm{CH} 4} \\
\left(\mathrm{mMol} . l^{-1}\right)\end{array}$ & $\begin{array}{c}\%_{\mathrm{CH} 4} \\
(\%)\end{array}$ & $\begin{array}{c}\mathrm{V} \\
(\mathrm{m} l)\end{array}$ & $\begin{array}{c}\text { Vel } \\
\left(\mathrm{m} l . \mathrm{h}^{-1}\right)\end{array}$ \\
\hline 0,00 & 0,000 & 0,0 & 0,0 & 0 & 0,00 & 0,000 & 0,0 & 0,0 & 0,00 \\
\hline 0,54 & 0,339 & 42,2 & 9,1 & 16,84 & 0,41 & 0,176 & 37,6 & 9,4 & 22,87 \\
\hline 0,87 & 0,766 & 50,8 & 17,4 & 24,79 & 0,79 & 0,546 & 47,2 & 17,7 & 21,90 \\
\hline 1,21 & 1,277 & 54,4 & 27,4 & 29,80 & 1,12 & 0,960 & 52,6 & 26,2 & 25,36 \\
\hline 1,48 & 1,789 & 58,1 & 36,3 & 33,18 & 1,45 & 1,453 & 57,0 & 35,5 & 28,21 \\
\hline 1,75 & 2,491 & 62,2 & 46,4 & 36,93 & 1,75 & 1,990 & 60,3 & 44,7 & 30,84 \\
\hline 2,00 & 2,922 & 63,8 & 55,8 & 38,43 & 2,06 & 2,687 & 64,1 & 54,4 & 31,51 \\
\hline 2,32 & 3,585 & 65,0 & 65,5 & 30,23 & 2,33 & 3,186 & 65,8 & 62,2 & 29,08 \\
\hline 2,69 & 4,089 & 66,7 & 73,9 & 22,76 & 2,64 & 3,818 & 66,7 & 70,9 & 28,18 \\
\hline 3,14 & 4,616 & 67,5 & 82,0 & 18,11 & 3,04 & 4,249 & 68,3 & 80,6 & 24,31 \\
\hline 3,67 & 5,073 & 67,8 & 90,3 & 15,69 & 3,42 & 4,754 & 68,9 & 88,8 & 21,24 \\
\hline 4,17 & 5,441 & 68,5 & 97,5 & 14,12 & 3,86 & 5,128 & 69,0 & 96,2 & 16,85 \\
\hline 4,74 & 5,899 & 68,6 & 104,4 & 12,26 & 4,35 & 5,499 & 69,8 & 103,7 & 15,43 \\
\hline 5,26 & 6,124 & 68,7 & 110,3 & 11,13 & 4,86 & 5,901 & 69,9 & 110,8 & 13,71 \\
\hline 5,80 & 6,367 & 68,8 & 115,7 & 10,03 & 5,36 & 6,262 & 70,1 & 116,2 & 10,99 \\
\hline 6,31 & 6,516 & 69,2 & 120,1 & 8,77 & 5,91 & 6,534 & 70,2 & 120,8 & 8,46 \\
\hline 6,77 & 6,701 & 69,1 & 123,8 & 7,89 & 6,43 & 6,801 & 70,3 & 125,8 & 9,43 \\
\hline 7,12 & 6,779 & 69,5 & 126,2 & 7,05 & 6,83 & 6,901 & 70,3 & 129,2 & 8,53 \\
\hline \multirow[t]{2}{*}{7,30} & 6,768 & 69,4 & 126,6 & 2,11 & 7,14 & 7,148 & 70,4 & 131,1 & 6,38 \\
\hline & & & & & 7,32 & 7,080 & 70,5 & 131,4 & 1,28 \\
\hline
\end{tabular}




\section{APÊNDICE G. Ensaio com impelidor tipo hélice - valores experimentais}

TABELA G.1: Resultados Experimentais da concentração de matéria orgânica em termos de DQO $\left(\mathrm{C}_{\mathrm{af}}\right), \mathrm{pH}$, Alcalinidade Parcial (AP), Alcalinidade Intermediária (AI), Alcalinidade Total (AT), Alcalinidade a Bicarbonato (AB) e Ácidos Voláteis

Totais (AVT) em amostras do afluente do ensaio com impelidor tipo hélice

\begin{tabular}{|c|c|c|c|c|c|c|c|}
\hline \multirow[t]{2}{*}{ Ciclo } & \multirow{2}{*}{$\begin{array}{c}\mathrm{C}_{\mathrm{AF}} \\
\left(\mathrm{mgDQ} . \mathrm{l}^{-1}\right)\end{array}$} & \multirow[t]{2}{*}{$\mathrm{pH}$} & AP & AI & AT & $\mathrm{AB}$ & \multirow{2}{*}{$\begin{array}{c}\text { AVT } \\
\left.\left(\mathrm{mgHAc}^{-1}\right)^{-1}\right)\end{array}$} \\
\hline & & & \multicolumn{4}{|c|}{$\left(\mathrm{mgCaCO} \cdot .^{-1}\right)$} & \\
\hline 3 & 896,3 & 8,9 & 195 & 55 & 250 & 224 & 37 \\
\hline 6 & 821,5 & 9,01 & 187 & 31 & 218 & 189 & 41 \\
\hline 9 & 691,3 & 8,8 & 187 & 44 & 231 & 201 & 42 \\
\hline 14 & 741,7 & 9,04 & 191 & 48 & 239 & 204 & 48 \\
\hline 19 & 722,7 & 8,99 & 198 & 44 & 242 & 206 & 51 \\
\hline 22 & 838,3 & 8,93 & 200 & 44 & 244 & 208 & 51 \\
\hline 31 & 819,4 & 8,71 & 200 & 61 & 261 & 232 & 40 \\
\hline 34 & 730,9 & 8,98 & 205 & 56 & 261 & 232 & 41 \\
\hline 39 & 758,3 & 8,77 & 213 & 49 & 262 & 229 & 46 \\
\hline 43 & 735,8 & 8,87 & 193 & 43 & 235 & 206 & 42 \\
\hline 48 & 791,5 & 8,8 & 194 & 46 & 241 & 208 & 45 \\
\hline 61 & 730,6 & 8,76 & 190 & 51 & 241 & 216 & 35 \\
\hline 64 & 770,2 & 8,77 & 196 & 49 & 245 & 221 & 34 \\
\hline 67 & 766,0 & 8,82 & 199 & 47 & 247 & 224 & 32 \\
\hline 70 & 834,7 & 8,56 & 189 & 52 & 242 & 215 & 37 \\
\hline 73 & 787,5 & 8,61 & 199 & 52 & 251 & 226 & 35 \\
\hline 82 & 795,9 & 8,91 & 196 & 47 & 243 & 217 & 37 \\
\hline
\end{tabular}


TABELA G.2: Resultados Experimentais da concentração de matéria orgânica em termos de DQO para amostras filtradas $\left(\mathrm{C}_{\mathrm{SF}}\right)$ e totais $\left(\mathrm{C}_{\mathrm{ST}}\right)$, eficiência de remoção de matéria orgânica em termos de DQO para amostras filtradas $\left(\mathrm{E}_{\mathrm{F}}\right)$ e totais $\left(\mathrm{E}_{\mathrm{T}}\right) \mathrm{pH}$, Alcalinidade Parcial $(\mathrm{AP})$, Alcalinidade Intermediária (AI), Alcalinidade Total (AT), Alcalinidade a Bicarbonato (AB) e Ácidos Voláteis Totais (AVT) em amostras do efluente do com impelidor tipo hélice.

\begin{tabular}{|c|c|c|c|c|c|c|c|c|c|c|c|}
\hline \multirow{2}{*}{ Condição } & \multirow{2}{*}{ Ciclo } & $\mathrm{C}_{\mathrm{SF}}$ & $\mathrm{C}_{\mathrm{ST}}$ & $E_{F}$ & $E_{T}$ & \multirow{2}{*}{$\mathrm{pH}$} & AP & AI & AT & $\mathrm{AB}$ & \multirow{2}{*}{$\begin{array}{c}\text { AVT } \\
\left(\text { mgHAc. }^{-1}\right)\end{array}$} \\
\hline & & \multicolumn{2}{|c|}{$\left(\mathrm{mgDQO} .1^{-1}\right)$} & \multicolumn{2}{|c|}{ (\%) } & & \multicolumn{4}{|c|}{$\left(\mathrm{mgCaCO}_{3} \cdot 1^{-1}\right)$} & \\
\hline \multirow{11}{*}{$\mathrm{He} 70$} & 3 & 116,1 & 135,6 & 85,0 & 82,5 & 6,73 & 279 & 94 & 372 & 360 & 17 \\
\hline & 4 & 121,1 & 136,5 & 84,4 & 82,4 & & & & & & \\
\hline & 6 & 134,2 & 152,0 & 82,7 & 80,4 & 6,88 & 292 & 80 & 372 & 356 & 22 \\
\hline & 9 & 108,6 & 136,6 & 86,0 & 82,4 & 6,88 & 284 & 78 & 363 & 347 & 23 \\
\hline & 19 & 118,9 & 152,1 & 84,7 & 80,4 & & & & & & \\
\hline & 21 & 134,2 & 154,0 & 82,7 & 80,2 & 7,01 & 333 & 63 & 396 & 375 & 29 \\
\hline & 24 & 122,1 & 148,7 & 84,3 & 80,8 & & & & & & \\
\hline & 31 & 111,5 & 149,0 & 85,6 & 80,8 & 6,76 & 299 & 124 & 423 & 406 & 24 \\
\hline & 34 & 121,4 & 169,7 & 84,4 & 78,1 & 6,82 & 315 & 111 & 425 & 408 & 24 \\
\hline & 39 & 145,2 & 182,6 & 81,3 & 76,5 & 6,78 & 322 & 112 & 433 & 414 & 27 \\
\hline & 42 & 134,3 & 172,9 & 82,7 & 77,7 & 6,77 & 298 & 89 & 387 & 370 & 24 \\
\hline \multirow{9}{*}{ He100 } & 45 & 111,2 & 166,5 & 85,7 & 78,5 & 6,85 & 296 & 93 & 389 & 372 & 24 \\
\hline & 48 & 115,5 & 142,8 & 85,1 & 81,6 & 6,75 & 289 & 100 & 389 & 375 & 20 \\
\hline & 61 & 123,6 & 143,8 & 84,1 & 81,5 & 6,79 & 267 & 90 & 357 & 344 & 18 \\
\hline & 64 & 121,1 & 144,8 & 84,4 & 81,3 & 6,84 & 274 & 90 & 364 & 352 & 16 \\
\hline & 67 & 118,9 & 145,8 & 84,7 & 81,2 & & & & & & \\
\hline & 70 & 114,1 & 146,8 & 85,3 & 81,1 & 6,79 & 291 & 113 & 404 & 391 & 18 \\
\hline & 73 & 111,3 & 147,8 & 85,7 & 81,0 & 6,72 & 283 & 116 & 399 & 387 & 17 \\
\hline & 81 & 115,0 & 131,8 & 85,2 & 83,0 & 6,85 & 288 & 78 & 365 & 351 & 21 \\
\hline & 84 & 110,9 & 141,0 & 85,7 & 81,8 & 6,85 & 291 & 76 & 367 & 355 & 17 \\
\hline
\end{tabular}


TABELA G.3: Resultados experimentais da concentração de sólidos totais (ST), sólidos voláteis totais (SVT), sólidos suspensos totais (SST) e sólidos suspensos voláteis (SSV) em amostras afluentes e efluentes coletadas durante o ensaio executado com impelidor tipo hélice.

\begin{tabular}{cccccccccc}
\hline \multirow{2}{*}{ Condição } & \multirow{2}{*}{ Tempo } & \multicolumn{6}{c}{ Afluente } & \multicolumn{4}{c}{ Efluente } \\
\cline { 3 - 10 } & & ST & SVT & SST & SSV & ST & SVT & SST & SSV \\
& $($ ciclo $)$ & $\left(\mathrm{mg} . l^{-1}\right)$ & $\left(\mathrm{mg} . l^{-1}\right)$ & $\left(\mathrm{mg} . l^{-1}\right)$ & $\left(\mathrm{mg} . l^{-1}\right)$ & $\left(\mathrm{mg} . l^{-1}\right)$ & $\left(\mathrm{mg} . l^{-1}\right)$ & $\left(\mathrm{mg} . l^{-1}\right)$ & $\left(\mathrm{mg} . l^{-1}\right)$ \\
\hline \multirow{3}{*}{ He100 } & 5 & 1344 & 708 & 126 & 122 & 1012 & 340 & 26 & 20 \\
& 21 & 1466 & 724 & 96 & 80 & 1018 & 264 & 16 & 6 \\
& 31 & 1430 & 744 & 50 & 48 & 968 & 272 & 14 & 14 \\
& 42 & 1478 & 764 & 72 & 66 & 998 & 318 & 30 & 24 \\
\hline \multirow{2}{*}{ He120 } & 48 & 1526 & 850 & 66 & 66 & 1050 & 422 & 24 & 24 \\
& 66 & 1552 & 824 & 76 & & 1050 & 338 & 32 & 22 \\
& 84 & 1410 & 724 & 30 & 24 & 922 & 216 & 50 & 50 \\
\hline
\end{tabular}


TABELA G.4: Perfis Experimentais da concentração de matéria orgânica em termos de DQO para amostras filtradas $\left(\mathrm{C}_{\mathrm{SF}}\right)$, pH, Alcalinidade Parcial (AP), Alcalinidade Intermediária (AI), Alcalinidade Total (AT), Alcalinidade a Bicarbonato (AB) e Ácidos Voláteis Totais (AVT) durante a condição He70.

\begin{tabular}{|c|c|c|c|c|c|c|c|c|c|c|c|c|}
\hline \multirow[b]{2}{*}{$\begin{array}{l}\text { Tempo } \\
\text { (h) }\end{array}$} & \multicolumn{6}{|c|}{ Ciclo 31} & \multicolumn{6}{|c|}{ Ciclo 34} \\
\hline & $\begin{array}{c}\mathrm{C}_{\mathrm{AF}} \\
\left(\mathrm{mgDQO} . \mathrm{I}^{-1}\right)\end{array}$ & $\mathrm{pH}$ & $\mathrm{AP}$ & $\begin{array}{c}\mathrm{AI} \\
\left(\mathrm{mgCaCO}_{3} .^{-1}\right)\end{array}$ & $\mathrm{AB}$ & $\begin{array}{c}\text { AVT } \\
\left({\left.\text { mgHAc. }{ }^{-1}\right)}^{-1}\right)\end{array}$ & $\begin{array}{c}\mathrm{C}_{\mathrm{AF}} \\
\left(\mathrm{mgDQO} \cdot \mathrm{l}^{-1}\right)\end{array}$ & $\mathrm{pH}$ & \multicolumn{3}{|c|}{$\left(\mathrm{mgCaCO}_{3} \cdot \mathrm{l}^{-1}\right)$} & $\begin{array}{c}\text { AVT } \\
\left(\mathrm{mgHAc} . \mathrm{l}^{-1}\right.\end{array}$ \\
\hline 0 & 449,1 & 6.97 & 237 & 89 & 300 & 36 & 439.6 & 6,98 & 237 & 87 & 300 & 34 \\
\hline 0,67 & 272,7 & 6,82 & 251 & 103 & 323 & 44 & 312,5 & 6,8 & 241 & 105 & 314 & 45 \\
\hline 1 & 261,3 & 6,78 & 257 & 104 & 327 & 47 & 284,7 & 6,8 & 251 & 110 & 329 & 45 \\
\hline 1,5 & 231,0 & 6,79 & 268 & 124 & 359 & 45 & 278,5 & 6,79 & 273 & 113 & 355 & 45 \\
\hline 3 & 172,5 & 6,83 & 295 & 107 & 376 & 36 & 170,4 & 6,85 & 296 & 108 & 381 & 33 \\
\hline 3,5 & 157,6 & 6,81 & 293 & 110 & 379 & 34 & 154,8 & 6,8 & 304 & 100 & 382 & 30 \\
\hline 4 & 144,2 & 6,77 & 285 & 118 & 384 & 27 & 150,6 & 6,87 & 308 & 101 & 388 & 30 \\
\hline 4,5 & 154,4 & 6,76 & 298 & 115 & 395 & 26 & 149,0 & 6,82 & 320 & 103 & - & - \\
\hline 5 & 133,8 & 6,75 & 280 & 123 & 386 & 23 & 137,5 & 6,79 & 310 & 105 & 398 & 24 \\
\hline 6 & 137,0 & 6,71 & 299 & 130 & 411 & 24 & 128,5 & 6,81 & 323 & 99 & 405 & 24 \\
\hline
\end{tabular}


TABELA G.5: Perfis Experimentais da concentração de metano $\left(\mathrm{C}_{\mathrm{CH} 4}\right)$, porcentagem de metano no "head-space" $\left(\%_{\mathrm{CH} 4}\right)$, volume de metano acumulado (V), velocidade de produção de metano (Vel) em dois ciclos da condição He70.

\begin{tabular}{cccccccccc}
\hline \multicolumn{3}{c}{ Ciclo 19 } & \multicolumn{7}{c}{ Ciclo 25 } \\
\hline $\begin{array}{c}\text { Tempo } \\
(\mathrm{h})\end{array}$ & $\begin{array}{c}\mathrm{C}_{\mathrm{CH} 4} \\
\left(\mathrm{mMol} . l^{-1}\right)\end{array}$ & $\begin{array}{c}\%_{\mathrm{CH} 4} \\
(\%)\end{array}$ & $\begin{array}{c}\mathrm{V} \\
(\mathrm{m} l)\end{array}$ & $\begin{array}{c}\text { Vel } \\
\left(\mathrm{m} l . \mathrm{h}^{-1}\right)\end{array}$ & $\begin{array}{c}\text { Tempo } \\
(\mathrm{h})\end{array}$ & $\begin{array}{c}\mathrm{C}_{\mathrm{CH} 4} \\
\left(\mathrm{mMol} . l^{-1}\right)\end{array}$ & $\begin{array}{c}\%_{\mathrm{CH} 4} \\
(\%)\end{array}$ & $\begin{array}{c}\mathrm{V} \\
(\mathrm{m} l)\end{array}$ & $\begin{array}{c}\text { Vel } \\
\left(\mathrm{m} l . \mathrm{h}^{-1}\right)\end{array}$ \\
\hline 0,00 & 0,000 & 0,0 & 0,0 & 0,0 & 0,00 & 0,000 & 0,0 & 0,0 & 0,0 \\
0,50 & 0,250 & 53,6 & 8,0 & 15,9 & 0,38 & 0,179 & 50,6 & 8,0 & 21,2 \\
0,94 & 0,663 & 58,5 & 15,4 & 17,0 & 0,81 & 0,604 & 58,0 & 16,5 & 19,7 \\
1,37 & 1,195 & 61,2 & 24,3 & 20,5 & 1,16 & 1,068 & 61,9 & 24,0 & 21,2 \\
1,75 & 1,697 & 63,1 & 33,0 & 23,4 & 1,55 & 1,592 & 63,6 & 33,1 & 23,7 \\
2,24 & 2,429 & 65,9 & 44,5 & 23,1 & 1,90 & 2,097 & 65,0 & 42,1 & 25,5 \\
2,57 & 2,806 & 66,2 & 52,0 & 22,9 & 2,22 & 2,580 & 66,2 & 50,1 & 24,9 \\
2,88 & 3,224 & 67,0 & 59,3 & 23,2 & 2,56 & 3,066 & 67,6 & 58,5 & 24,6 \\
3,25 & 3,652 & 67,5 & 67,4 & 21,9 & 2,91 & 3,545 & 68,3 & 66,8 & 23,9 \\
3,58 & 3,982 & 67,9 & 74,4 & 21,2 & 3,26 & 3,922 & 68,8 & 74,6 & 22,3 \\
3,96 & 4,304 & 69,0 & 81,8 & 19,5 & 3,63 & 4,273 & 69,0 & 82,6 & 21,6 \\
4,35 & 4,721 & 68,8 & 89,0 & 18,6 & 4,05 & 4,707 & 69,4 & 90,6 & 19,0 \\
4,89 & 5,045 & 69,3 & 98,0 & 16,4 & 4,48 & 5,083 & 69,5 & 98,6 & 18,6 \\
5,40 & 5,582 & 69,2 & 105,8 & 15,4 & 4,99 & 5,462 & 70,0 & 107,5 & 17,5 \\
5,93 & 5,929 & 69,3 & 112,9 & 13,7 & 5,51 & 5,849 & 70,1 & 115,8 & 15,8 \\
6,45 & 6,143 & 69,8 & 119,6 & 12,8 & 6,04 & 6,116 & 70,1 & 122,7 & 13,2 \\
7,10 & 6,573 & 69,5 & 126,7 & 11,0 & 6,55 & 6,423 & 70,1 & 129,2 & 12,7 \\
7,29 & 6,619 & 69,6 & 127,9 & 6,2 & 7,08 & 6,711 & 70,1 & 135,2 & 11,4 \\
& & & & & 7,31 & 6,791 & 70,2 & 137,0 & 7,7 \\
\hline
\end{tabular}


TABELA G.6: Perfis Experimentais da concentração de matéria orgânica em termos de DQO para amostras filtradas $\left(\mathrm{C}_{\mathrm{SF}}\right)$, $\mathrm{pH}$, Alcalinidade Parcial (AP), Alcalinidade Intermediária (AI), Alcalinidade Total (AT), Alcalinidade a Bicarbonato (AB) e Ácidos Voláteis Totais (AVT) durante a condição He100.

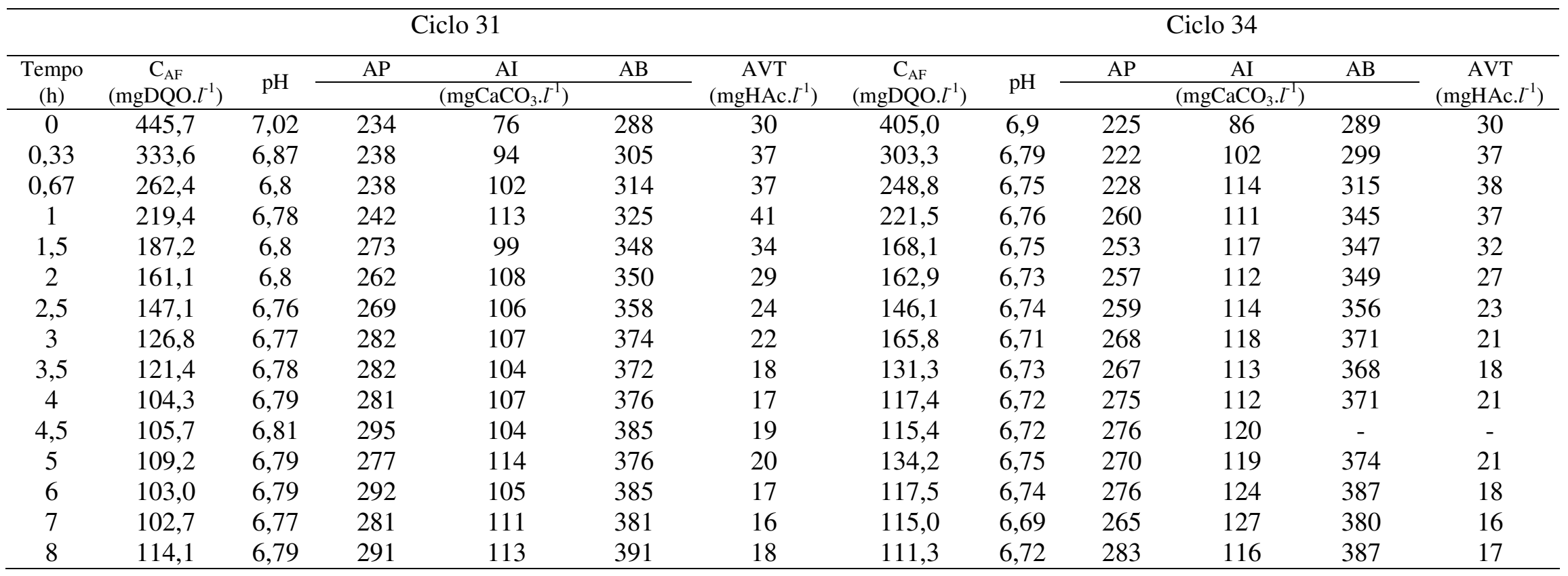


TABELA G.7: Perfis Experimentais da concentração de metano $\left(\mathrm{C}_{\mathrm{CH} 4}\right)$, porcentagem de metano no "head-space" $\left(\%_{\mathrm{CH} 4}\right)$, volume de metano acumulado (V), velocidade de produção de metano (Vel) em dois ciclos da condição He100.

\begin{tabular}{cccccccccc}
\hline & \multicolumn{3}{c}{ Ciclo 64 } & \multicolumn{5}{c}{ Ciclo 67 } \\
\hline $\begin{array}{c}\text { Tempo } \\
(\mathrm{h})\end{array}$ & $\begin{array}{c}\mathrm{C}_{\mathrm{CH} 4} \\
\left(\mathrm{mMol} . l^{-1}\right)\end{array}$ & $\begin{array}{c}\%_{\mathrm{CH} 4} \\
(\%)\end{array}$ & $\begin{array}{c}\mathrm{V} \\
(\mathrm{m} l)\end{array}$ & $\begin{array}{c}\mathrm{Vel} \\
\left(\mathrm{m} l . \mathrm{h}^{-1}\right)\end{array}$ & $\begin{array}{c}\text { Tempo } \\
(\mathrm{h})\end{array}$ & $\begin{array}{c}\mathrm{C}_{\mathrm{CH} 4} \\
\left(\mathrm{mMol} . l^{-1}\right)\end{array}$ & $\begin{array}{c}\%_{\mathrm{CH} 4} \\
(\%)\end{array}$ & $\begin{array}{c}\mathrm{V} \\
(\mathrm{m} l)\end{array}$ & $\begin{array}{c}\text { Vel } \\
\left(\mathrm{m} l \cdot \mathrm{h}^{-1}\right)\end{array}$ \\
\hline 0,00 & 0,000 & 0,0 & 0,0 & 0,0 & 0,00 & 0,000 & 0,0 & 0,0 & 0,0 \\
0,22 & 0,083 & 39,7 & 4,4 & 20,2 & 0,43 & 0,229 & 49,7 & 8,4 & 19,5 \\
0,66 & 0,480 & 52,4 & 12,0 & 17,3 & 0,85 & 0,644 & 54,6 & 17,0 & 20,6 \\
1,12 & 1,098 & 58,9 & 22,2 & 22,3 & 1,22 & 1,514 & 66,3 & 25,9 & 23,7 \\
1,49 & 1,635 & 62,1 & 31,6 & 25,0 & 1,57 & 1,676 & 62,3 & 34,8 & 25,4 \\
1,83 & 0,000 & 0,0 & 40,4 & 26,2 & 1,91 & 2,170 & 64,2 & 43,3 & 25,8 \\
2,15 & 2,663 & 66,6 & 48,7 & 25,7 & 2,25 & 2,858 & 66,6 & 52,3 & 25,8 \\
2,47 & 3,143 & 67,5 & 57,1 & 26,2 & 2,58 & 3,306 & 67,3 & 60,5 & 24,8 \\
2,86 & 3,627 & 68,4 & 66,4 & 24,4 & 2,98 & 3,837 & 67,8 & 69,8 & 23,1 \\
3,21 & 4,097 & 69,0 & 74,8 & 23,4 & 3,37 & 4,268 & 68,3 & 77,8 & 21,1 \\
3,61 & 4,502 & 69,1 & 82,9 & 20,6 & 3,77 & 4,613 & 69,0 & 85,2 & 18,6 \\
4,05 & 4,933 & 69,9 & 90,9 & 18,2 & 4,20 & 4,990 & 69,4 & 93,1 & 18,3 \\
4,54 & 5,322 & 70,2 & 98,9 & 16,2 & 4,73 & 5,401 & 70,8 & 101,8 & 16,2 \\
5,04 & 5,709 & 70,4 & 106,4 & 15,0 & 5,26 & 5,879 & 69,9 & 109,6 & 14,8 \\
5,57 & 6,170 & 70,4 & 112,9 & 12,4 & 5,80 & 6,144 & 69,8 & 116,7 & 13,1 \\
6,13 & 6,353 & 70,9 & 119,5 & 11,7 & 6,22 & 6,347 & 69,9 & 121,6 & 11,7 \\
6,69 & 6,682 & 71,1 & 125,2 & 10,2 & 6,84 & 6,578 & 70,1 & 128,4 & 11,0 \\
7,09 & 6,879 & 71,0 & 129,1 & 9,7 & 7,12 & 6,826 & 69,9 & 131,2 & 10,0 \\
7,27 & 6,923 & 70,8 & 129,9 & 4,2 & 7,29 & 6,779 & 70,1 & 132,2 & 5,6 \\
\hline
\end{tabular}




\section{APÊNDICE H. Ensaio com impelidor tipo hélice e tubo de tiragem - valores}

\section{experimentais.}

TABELA H.1: Resultados Experimentais da concentração de matéria orgânica em termos de DQO $\left(\mathrm{C}_{\mathrm{af}}\right), \mathrm{pH}$, Alcalinidade Parcial (AP), Alcalinidade Intermediária (AI), Alcalinidade Total (AT), Alcalinidade a Bicarbonato (AB) e Ácidos Voláteis

Totais (AVT) em amostras do afluente do ensaio com impelidor tipo hélice com tubo de tiragem.

\begin{tabular}{|c|c|c|c|c|c|c|c|}
\hline \multirow[t]{2}{*}{ Ciclo } & \multirow{2}{*}{$\begin{array}{c}\mathrm{C}_{\mathrm{AF}} \\
\left(\mathrm{mgDQO} \cdot l^{-1}\right)\end{array}$} & \multirow[t]{2}{*}{$\mathrm{pH}$} & AP & $\mathrm{AI}$ & AT & $\mathrm{AB}$ & \multirow{2}{*}{$\begin{array}{c}\text { AVT } \\
\left(\mathrm{mgHAc}^{-1}\right)^{-1}\end{array}$} \\
\hline & & & \multicolumn{4}{|c|}{$\left(\mathrm{mgCaCO}_{3} l^{-1}\right)$} & \\
\hline 6 & 759,7 & 8,7 & 201 & 47 & 248 & 221 & 38 \\
\hline 10 & 746,9 & 8,81 & 194 & 54 & 248 & 219 & 41 \\
\hline 18 & 808,8 & 8,94 & 201 & 49 & 250 & 223 & 38 \\
\hline 22 & 814,1 & 8,85 & 199 & 49 & 248 & 220 & 39 \\
\hline 25 & 770,7 & 8,77 & 196 & 54 & 250 & 220 & 41 \\
\hline 28 & 813,5 & 8,84 & 198 & 57 & 255 & 223 & 44 \\
\hline 31 & 776,6 & 8,82 & 213 & 50 & 262 & 239 & 32 \\
\hline 37 & 755,1 & 8,7 & 204 & 80 & 283 & 259 & 35 \\
\hline 42 & 787,6 & 8,85 & 200 & 55 & 255 & 228 & 38 \\
\hline 47 & 774,6 & 8,65 & 190 & 60 & 250 & 225 & 35 \\
\hline 52 & 754,9 & 8,3 & 195 & 60 & 255 & 228 & 39 \\
\hline 56 & 783,4 & 8,86 & 197 & 57 & 254 & 226 & 40 \\
\hline 61 & 796,4 & 8,81 & 193 & 60 & 254 & 231 & 31 \\
\hline 74 & 759,8 & 8,58 & 188 & 64 & 252 & 225 & 39 \\
\hline 79 & 817,8 & 8,8 & 190 & 62 & 252 & 226 & 36 \\
\hline 84 & 682,3 & 8,9 & 201 & 49 & 250 & 223 & 38 \\
\hline 87 & 810,0 & 8,85 & 199 & 55 & 254 & 227 & 39 \\
\hline
\end{tabular}


TABELA H.2: Resultados Experimentais da concentração de matéria orgânica em termos de DQO para amostras filtradas $\left(\mathrm{C}_{\mathrm{SF}}\right)$ e totais $\left(\mathrm{C}_{\mathrm{ST}}\right)$, eficiência de remoção de matéria orgânica em termos de DQO para amostras filtradas $\left(\mathrm{E}_{\mathrm{F}}\right)$ e totais $\left(\mathrm{E}_{\mathrm{T}}\right) \mathrm{pH}$, Alcalinidade Parcial $(\mathrm{AP})$, Alcalinidade Intermediária (AI), Alcalinidade Total (AT), Alcalinidade a Bicarbonato (AB) e Ácidos Voláteis Totais (AVT) em amostras do

\begin{tabular}{|c|c|c|c|c|c|c|c|c|c|c|c|}
\hline \multirow{2}{*}{ Ensaio } & \multirow{2}{*}{ Ciclo } & $\mathrm{C}_{\mathrm{SF}}$ & $\mathrm{C}_{\mathrm{ST}}$ & $\mathrm{E}_{\mathrm{F}}$ & $\mathrm{E}_{\mathrm{T}}$ & \multirow{2}{*}{$\mathrm{pH}$} & AP & $\mathrm{AI}$ & $\mathrm{AT}$ & $\mathrm{AB}$ & \multirow{2}{*}{ 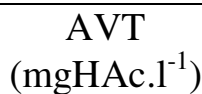 } \\
\hline & & \multicolumn{2}{|c|}{$\left(\mathrm{mgDQO} .1^{-1}\right)$} & \multicolumn{2}{|c|}{$(\%)$} & & \multicolumn{4}{|c|}{$\left(\mathrm{mgCaCO}_{3} .1^{-1}\right)$} & \\
\hline \multirow{12}{*}{ Hd100 } & 3 & 99,5 & 118,2 & 87,2 & 84,8 & 6,82 & 248 & 87 & 335 & 323 & 17 \\
\hline & 6 & 110,7 & 126,6 & 85,7 & 83,7 & 6,82 & 292 & 111 & 402 & 390 & 17 \\
\hline & 9 & 108,6 & 142,1 & 86,0 & 81,7 & 6,77 & 298 & 107 & 406 & 394 & 16 \\
\hline & 19 & 115,6 & 129,6 & 85,1 & 83,3 & & & & & & \\
\hline & 22 & 102,5 & 116,9 & 86,8 & 84,9 & 6,78 & 302 & 106 & 407 & 396 & 16 \\
\hline & 24 & 107,8 & 117,2 & 86,1 & 84,9 & & & & & & \\
\hline & 28 & 110,2 & 130,6 & 85,8 & 83,2 & 6,82 & 303 & 106 & 409 & 398 & 16 \\
\hline & 31 & 97,0 & 115,0 & 87,5 & 85,2 & 6,84 & 299 & 115 & 414 & 396 & 26 \\
\hline & 37 & 106,8 & 120,7 & 86,2 & 84,4 & 6,75 & 295 & 113 & 409 & 396 & 17 \\
\hline & 46 & 106,2 & 117,1 & 86,3 & 84,9 & 6,80 & 302 & 108 & 410 & 400 & 14 \\
\hline & 51 & 103,0 & 115,0 & 86,7 & 85,2 & & & & & & \\
\hline & 52 & & & & & 6,84 & 296 & 104 & 400 & 389 & 15 \\
\hline \multirow{11}{*}{$\operatorname{Hd} 120$} & 54 & 100,3 & 116,0 & 87,1 & 85,1 & & & & & & \\
\hline & 56 & & & & & 6,90 & 306 & 108 & 413 & 402 & 16 \\
\hline & 60 & 114,9 & 127,8 & 85,2 & 83,5 & & & & & & \\
\hline & 61 & & & & & 6,75 & 292 & 119 & 412 & 401 & 15 \\
\hline & 68 & 112,1 & 116,2 & 85,6 & 85,0 & 6,75 & 289 & 108 & 397 & 384 & 18 \\
\hline & 71 & 130,5 & 128,1 & 83,2 & 83,5 & & & & & & \\
\hline & 72 & & & & & 6,59 & 282 & 128 & 410 & 400 & 14 \\
\hline & 75 & 112,5 & 117,1 & 85,5 & 84,9 & 6,67 & 279 & 133 & 412 & 401 & 16 \\
\hline & 77 & 112,0 & 130,0 & 85,6 & 83,2 & 6,70 & 282 & 131 & 413 & 403 & 14 \\
\hline & 84 & 126,2 & 130,2 & 83,7 & 83,2 & 6,93 & 305 & 106 & 411 & 400 & 16 \\
\hline & 87 & 120,9 & 132,9 & 84,4 & 82,9 & 7,01 & 298 & 96 & 394 & 382 & 17 \\
\hline
\end{tabular}


TABELA H.3: Resultados experimentais da concentração de sólidos totais (ST), sólidos voláteis totais (SVT), sólidos suspensos totais (SST) e sólidos suspensos voláteis (SSV) em amostras afluentes e efluentes coletadas durante o ensaio com impelidor tipo hélice e tubo de tiragem.

\begin{tabular}{|c|c|c|c|c|c|c|c|c|c|}
\hline \multirow{3}{*}{ Condição } & \multirow{2}{*}{ Tempo } & \multicolumn{4}{|c|}{ Afluente } & \multicolumn{4}{|c|}{ Efluente } \\
\hline & & ST & SVT & SST & SSV & ST & SVT & SST & SSV \\
\hline & (ciclo) & $\left(\mathrm{mg} . l^{-1}\right)$ & $\left(\mathrm{mg} . l^{-1}\right)$ & $\left(\mathrm{mg} \cdot l^{-1}\right)$ & $\left(\mathrm{mg} \cdot l^{-1}\right)$ & $\left(\mathrm{mg} \cdot l^{-1}\right)$ & $\left(\mathrm{mg} \cdot l^{-1}\right)$ & $\left(\mathrm{mg} \cdot l^{-1}\right)$ & $\left(\mathrm{mg} \cdot l^{-1}\right)$ \\
\hline \multirow{4}{*}{ Hd100 } & 2 & 1392 & 690 & 22 & 18 & 976 & 310 & 52 & 52 \\
\hline & 7 & 1502 & 812 & 34 & 34 & 1064 & 358 & 60 & 56 \\
\hline & 9 & 1648 & 960 & 44 & 20 & 1278 & 368 & 84 & 54 \\
\hline & 14 & 1656 & 930 & 36 & 20 & 1078 & 346 & 80 & 54 \\
\hline \multirow{4}{*}{ Hd120 } & 17 & 1442 & 774 & 46 & 48 & 1016 & 340 & 40 & 40 \\
\hline & 21 & 1648 & 950 & 24 & 24 & 1178 & 532 & 62 & 62 \\
\hline & 24 & 1644 & 894 & 24 & 22 & 1068 & 324 & 62 & 58 \\
\hline & 29 & 1366 & 822 & 18 & 20 & 1146 & 338 & 44 & 42 \\
\hline
\end{tabular}


TABELA H.4: Perfis Experimentais da concentração de matéria orgânica em termos de DQO para amostras filtradas $\left(\mathrm{C}_{\mathrm{SF}}\right)$, $\mathrm{pH}$,

Alcalinidade Parcial (AP), Alcalinidade Intermediária (AI), Alcalinidade Total (AT), Alcalinidade a Bicarbonato (AB) e Ácidos Voláteis Totais (AVT) durante a condição Hd100.

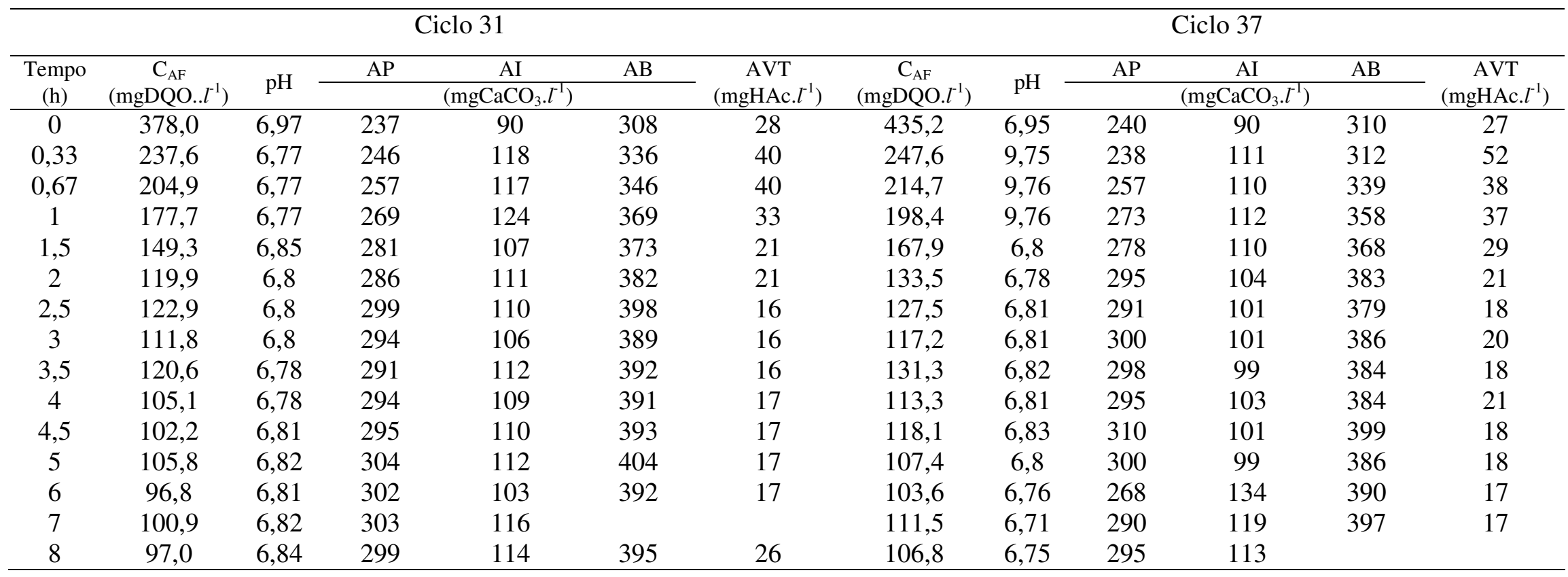


TABELA H.5: Perfis Experimentais da concentração de metano $\left(\mathrm{C}_{\mathrm{CH} 4}\right)$, porcentagem de metano no "head-space" $\left(\%_{\mathrm{CH} 4}\right)$, volume de metano acumulado (V), velocidade de produção de metano (Vel) em dois ciclos da condição Hd100.

\begin{tabular}{cccccccccc}
\hline \multicolumn{3}{c}{ Ciclo 28 } & \multicolumn{7}{c}{ Ciclo 34 } \\
\hline $\mathrm{h})$ & $\begin{array}{c}\mathrm{C}_{\mathrm{CH} 4} \\
\left(\mathrm{mMol} . l^{-1}\right)\end{array}$ & $\begin{array}{c}\%_{\mathrm{CH} 4} \\
(\%)\end{array}$ & $\begin{array}{c}\mathrm{V} \\
(\mathrm{m} l)\end{array}$ & $\begin{array}{c}\text { Vel } \\
\left(\mathrm{m} l . \mathrm{h}^{-1}\right)\end{array}$ & $\begin{array}{c}\text { Tempo } \\
(\mathrm{h})\end{array}$ & $\begin{array}{c}\mathrm{C}_{\mathrm{CH} 4} \\
\left(\mathrm{mMol} . l^{-1}\right)\end{array}$ & $\begin{array}{c}\%_{\mathrm{CH} 4} \\
(\%)\end{array}$ & $\begin{array}{c}\mathrm{V} \\
(\mathrm{m} l)\end{array}$ & $\begin{array}{c}\text { Vel } \\
\left(\mathrm{m} l . \mathrm{h}^{-1}\right)\end{array}$ \\
\hline 0,00 & 0,000 & 0,0 & 0,0 & 0,00 & 0,00 & 0,000 & 0,0 & 0,0 & 0,00 \\
0,33 & 0,061 & 35,1 & 8,2 & 25,27 & 0,35 & 0,110 & 30,1 & 7,6 & 21,86 \\
0,67 & 0,634 & 49,8 & 18,3 & 29,40 & 0,66 & 0,477 & 46,3 & 15,0 & 23,92 \\
0,98 & 1,266 & 56,6 & 29,0 & 34,22 & 0,95 & 0,940 & 53,0 & 23,5 & 29,17 \\
1,24 & 1,771 & 60,0 & 38,6 & 37,54 & 1,23 & 1,488 & 58,2 & 32,8 & 33,18 \\
1,60 & 2,677 & 63,8 & 52,7 & 38,66 & 1,52 & 2,059 & 61,6 & 43,0 & 34,81 \\
1,88 & 3,237 & 65,4 & 62,5 & 35,62 & 1,75 & 2,577 & 64,8 & 51,1 & 35,50 \\
2,13 & 3,730 & 66,5 & 70,9 & 32,92 & 1,99 & 3,117 & 66,2 & 59,6 & 35,26 \\
2,42 & 4,300 & 67,7 & 79,5 & 30,26 & 2,26 & 3,682 & 67,4 & 68,6 & 33,82 \\
2,70 & 4,583 & 67,7 & 86,7 & 25,64 & 2,52 & 4,068 & 68,5 & 76,9 & 31,69 \\
3,08 & 5,005 & 68,0 & 95,6 & 23,11 & 2,81 & 4,558 & 69,1 & 85,3 & 29,06 \\
3,57 & 5,480 & 68,2 & 104,7 & 18,74 & 3,17 & 5,051 & 69,6 & 94,3 & 24,74 \\
4,05 & 5,916 & 68,3 & 112,9 & 17,06 & 3,55 & 5,520 & 69,9 & 102,1 & 20,99 \\
4,59 & 6,272 & 68,4 & 121,0 & 14,89 & 3,97 & 5,770 & 70,4 & 109,9 & 18,35 \\
5,13 & 6,469 & 68,5 & 127,2 & 11,62 & 4,48 & 6,167 & 70,4 & 117,7 & 15,43 \\
5,70 & 6,733 & 68,6 & 133,3 & 10,50 & 5,02 & 6,601 & 70,3 & 125,1 & 13,71 \\
6,24 & 7,161 & 68,6 & 139,0 & 10,74 & 5,52 & 6,774 & 70,6 & 130,3 & 10,33 \\
6,57 & 7,225 & 68,6 & 142,5 & 10,51 & 6,05 & 7,079 & 70,6 & 135,9 & 10,31 \\
6,98 & 7,399 & 68,7 & 146,6 & 9,89 & 6,62 & 7,319 & 70,7 & 141,1 & 9,15 \\
7,21 & 7,462 & 68,7 & 147,5 & 4,25 & 7,12 & 7,460 & 70,7 & 145,3 & 8,59 \\
\hline
\end{tabular}


TABELA H.6: Perfis Experimentais da concentração de matéria orgânica em termos de DQO para amostras filtradas $\left(\mathrm{C}_{\mathrm{SF}}\right)$, $\mathrm{pH}$, Alcalinidade

Parcial (AP), Alcalinidade Intermediária (AI), Alcalinidade Total (AT), Alcalinidade a Bicarbonato (AB) e Ácidos Voláteis Totais (AVT) durante a condição Hd120.

\begin{tabular}{|c|c|c|c|c|c|c|c|c|c|c|c|c|}
\hline & \multicolumn{6}{|c|}{ Ciclo 84} & \multicolumn{6}{|c|}{ Ciclo 87} \\
\hline \multirow{2}{*}{$\begin{array}{l}\text { Tempo } \\
\text { (h) }\end{array}$} & \multirow{2}{*}{$\begin{array}{c}\mathrm{C}_{\mathrm{AF}} \\
\left(\mathrm{mgDQO} \cdot l^{-1}\right)\end{array}$} & \multirow{2}{*}{$\mathrm{pH}$} & AP & $\mathrm{AI}$ & $\mathrm{AB}$ & \multirow{2}{*}{$\begin{array}{c}\text { AVT } \\
\left(\mathrm{mgHAc} . l^{-1}\right)\end{array}$} & \multirow{2}{*}{$\begin{array}{c}\mathrm{C}_{\mathrm{AF}} \\
\left(\mathrm{mgDQO} . l^{-1}\right)\end{array}$} & \multirow{2}{*}{$\mathrm{pH}$} & $\mathrm{AP}$ & AI & $\mathrm{AB}$ & \multirow{2}{*}{$\begin{array}{c}\text { AVT } \\
\left(\mathrm{mgHAc} . l^{-1}\right.\end{array}$} \\
\hline & & & \multicolumn{3}{|c|}{$\left(\mathrm{mgCaCO}_{3} \cdot l^{-1}\right)$} & & & & \multicolumn{3}{|c|}{$\left(\mathrm{mgCaCO}_{3} \cdot l^{-1}\right)$} & \\
\hline 0 & 513,1 & 7,14 & 236 & 75 & 286 & 36 & 498,0 & 7,43 & 236 & 67 & 277 & 37 \\
\hline 0,33 & 277,8 & 6,82 & 258 & 104 & 330 & 44 & 326,8 & 7,01 & 254 & 97 & 318 & 47 \\
\hline 0,67 & 239,7 & 6,83 & 259 & 109 & 335 & 47 & 235,8 & 7,00 & 273 & 96 & 337 & 46 \\
\hline 1 & 194,6 & 6,8 & 284 & 111 & 368 & 38 & 203,0 & 6,98 & 273 & 99 & 343 & 40 \\
\hline 1,5 & 180,8 & 6,78 & 298 & 98 & 377 & 27 & 178,2 & 6,99 & 288 & 97 & 362 & 32 \\
\hline 2 & 152,9 & 6,82 & 292 & 107 & 382 & 24 & 156,1 & 6,98 & 293 & 92 & 365 & 28 \\
\hline 2,5 & 137,3 & 6,82 & 301 & 102 & 388 & 22 & 144,5 & 6,99 & 303 & 94 & - & - \\
\hline 3 & 134,3 & 6,88 & 310 & 101 & & & 133,0 & 6,98 & 303 & 90 & 376 & 24 \\
\hline 3,5 & 124,8 & 6,84 & 295 & 109 & 386 & 26 & 133,5 & 6,99 & 309 & 95 & 387 & 24 \\
\hline 4 & 121,0 & 6,88 & 295 & 101 & 382 & 21 & 144,2 & 7,01 & 301 & 99 & 384 & 22 \\
\hline 4,5 & 120,0 & 6,91 & 309 & 105 & 401 & 19 & 132,1 & 6,99 & 308 & 97 & 391 & 20 \\
\hline 5 & 120,6 & 6,9 & 311 & 99 & 396 & 19 & 134,0 & 7,00 & 310 & 94 & 389 & 21 \\
\hline 6 & 127,0 & 6,92 & 303 & 112 & 400 & 20 & 123,5 & 7,01 & 300 & 99 & 383 & 22 \\
\hline 7 & 122,5 & 6,96 & 311 & 103 & 402 & 18 & 128,5 & 7,01 & 308 & 102 & 394 & 22 \\
\hline 8 & 126,2 & 6,93 & 305 & 106 & 397 & 20 & 120,9 & 7,01 & 298 & 96 & 382 & 17 \\
\hline
\end{tabular}


TABELA H.7: Perfis Experimentais da concentração de metano $\left(\mathrm{C}_{\mathrm{CH} 4}\right)$, porcentagem de metano no "head-space" $\left(\%_{\mathrm{CH} 4}\right)$, volume de metano acumulado (V), velocidade de produção de metano (Vel) em um ciclo da condição Hd120.

\begin{tabular}{ccccc}
\hline \multicolumn{5}{c}{ Ciclo 75 } \\
\hline Tempo & $\begin{array}{c}\mathrm{C}_{\mathrm{CH} 4} \\
\left(\mathrm{mMl} l^{-}\right.\end{array} \%_{\mathrm{CH} 4}$ & $\mathrm{~V}$ & $\begin{array}{c}\text { Vel } \\
\left(\mathrm{m} l . \mathrm{h}^{-}\right.\end{array}$ \\
\hline 0,00 & 0,000 & 0,0 & 0 & 0,00 \\
0,30 & 0,229 & 42,1 & 8,6 & 29,27 \\
0,57 & 0,772 & 54,3 & 17,8 & 32,92 \\
0,91 & 1,116 & 55,5 & 25,8 & 23,83 \\
1,27 & 1,668 & 59,3 & 35,9 & 28,23 \\
1,58 & 2,316 & 63,3 & 46,6 & 33,99 \\
1,88 & 2,924 & 65,3 & 56,4 & 33,23 \\
2,17 & 3,437 & 66,7 & 66,5 & 34,29 \\
2,45 & 4,004 & 67,8 & 75,5 & 31,77 \\
2,75 & 4,369 & 68,6 & 83,7 & 27,60 \\
3,07 & 4,815 & 68,9 & 90,9 & 22,63 \\
3,44 & 5,321 & 69,1 & 99,0 & 21,93 \\
3,88 & 5,767 & 69,3 & 107,0 & 18,40 \\
4,40 & 6,040 & 69,5 & 115,4 & 16,07 \\
4,94 & 6,490 & 69,5 & 123,1 & 14,26 \\
5,45 & 6,706 & 69,5 & 130,0 & 13,32 \\
5,95 & 6,977 & 69,5 & 134,3 & 8,70 \\
6,48 & 7,160 & 69,5 & 138,8 & 8,53 \\
7,09 & 7,541 & 69,5 & 143,7 & 7,98 \\
7,27 & 7,338 & 69,3 & 144,0 & 2,02 \\
\hline
\end{tabular}




\section{APÊNDICE I. Ensaio de consumo de potência.}

Tabela I.1: Resultados Experimentais do Número de Potência e do Número de Reynolds para impelidor tipo turbina de pás planas verticais (Tu), Turbina de pás planas inclinadas (Ti), pá de pás planas verticais (Pa), pá de pás planas inclinadas (Pi), hélice (He), pá de pás planas inclinadas e tubo de tiragem (Pd) e hélice e tubo de tiragem (Hd).

\begin{tabular}{ccccccccc}
\hline \multirow{2}{*}{$\mathrm{Re}$} & $\mathrm{Np}$ & \multirow{2}{*}{$\mathrm{Re}$} & $\mathrm{Ti}$ & $\mathrm{Pa}$ & $\mathrm{Pi}$ & $\mathrm{He}$ & $\mathrm{Pd}$ & $\mathrm{Hd}$ \\
\hline & $\mathrm{Tu}$ & & & & & & \\
21775 & 5,20 & 18404 & & & & & & \\
29033 & 4,88 & 24539 & & & & & & \\
36292 & 4,68 & 30674 & & & & & 0,95 & 0,48 \\
43550 & 4,77 & 36809 & 1,65 & 4,29 & & & 0,99 & 0,33 \\
50809 & 5,25 & 42944 & 1,94 & 4,36 & & & 0,97 & 0,48 \\
58067 & 5,12 & 49079 & 2,23 & 5,57 & & & 1,11 & 0,37 \\
65326 & 4,91 & 55214 & 2,49 & 5,13 & 1,03 & & 1,32 & 0,44 \\
& & 61349 & 2,61 & 5,82 & 0,95 & & 1,19 & 0,48 \\
& & 67484 & 2,85 & & 1,18 & & 1,28 & 0,39 \\
& & 73619 & 2,80 & & 1,15 & 0,25 & 1,24 & 0,33 \\
& & 79754 & & & 1,34 & 0,28 & 1,27 & 0,35 \\
& & 85889 & & & 1,45 & 0,36 & 1,27 & 0,42 \\
& 92024 & & & 1,43 & 0,37 & & \\
& 98159 & & & 1,44 & 0,42 & & \\
\hline
\end{tabular}

